Classificação de séries temporais por similaridade e extração de atributos com aplicação na identificação automática de insetos

Diego Furtado Silva 



\section{Classificação de séries temporais por similaridade e extração de atributos com aplicação na identificação automática de insetos}

\section{Diego Furtado Silva}

Orientador: Prof. Dr. Gustavo Enrique de Almeida Prado Alves Batista

Dissertação apresentada ao Instituto de Ciências Matemáticas e de Computação - ICMC-USP, como parte dos requisitos para obtenção do título de Mestre em Ciências - Ciências de Computação e Matemática Computacional. VERSÃO REVISADA 
Ficha catalográfica elaborada pela Biblioteca Prof. Achille Bassi e Seção Técnica de Informática, ICMC/USP, com os dados fornecidos pelo(a) autor(a)

Furtado Silva, Diego

F992C Classificação de séries temporais por similaridade e extração de atributos com aplicação na identificação automática de insetos / Diego Furtado Silva; orientador Gustavo Enrique de Almeida Prado Alves Batista. -- São Carlos, 2014.

$142 \mathrm{p}$.

Dissertação (Mestrado - Programa de Pós-Graduação em Ciências de Computação e Matemática

Computacional) -- Instituto de Ciências Matemáticas e de Computação, Universidade de São Paulo, 2014.

1. Classificação. 2. Séries Temporais. 3.

Similaridade. 4. Extração de Atributos. 5. Insetos. I. de Almeida Prado Alves Batista, Gustavo Enrique, orient. II. Título. 


\section{Agradecimentos}

E é quando eu me deparo com a seção que, teoricamente, é a mais livre e sem compromisso da minha dissertação, que percebo que estou mais errado. Caso eu decidisse usar essa suposta liberdade e agradecer a todos que eu deveria - e o quanto merecem -, penso que precisaria de mais uma ou duas centenas de páginas. Mas, se é possível escrever meses de trabalho em seis páginas de um artigo, deve ser possível resumir meus agradecimentos.

Começo a agradecer as pessoas mais importantes na minha vida. Minha família. Em especial, gostaria de agradecer aos meus pais, Herminia e Eduardo, que se preocuparam com minha educação (entre milhões de outras coisas) desde de antes de eu me entender por gente. Eles são a maior prova de que, se eu estou finalizando este trabalho, é porque estou em um processo há mais de 26 anos.

Mas a família vai muito além disso. Aquele tio que te ajuda a resolver um problema num fim de semana, o primo que compra rifa para ajudar na formatura, quem aponta para um homem quando alguém diz que seu amigo secreto é uma mulher, os que jogam um truco só para esfriar a cabeça... Cada uma dessas pequenas atitudes fazem parte de um todo que é realmente muito grande.

Gostaria também de agradecer à minha noiva, Camila. Em breve ela deixará de ser minha noiva. Será minha esposa. Ainda não descobri como ela me aguenta e, ao mesmo tempo, consegue me ajudar tanto. Isso é ainda mais visível em tempos de escrita de dissertação. Seu carinho e dedicação foram de extrema importância nos últimos (muitos) anos da minha vida.

Agradeço, e muito, aos meus amigos de longa data. Especialmente, agradeço a Shimizu, Carol, Tiago, Bruno (Bigão), Marcus e outros que, se não moraram comigo em algum momento, ou viviam na minha casa ou eu vivia na casa deles. Sair da casa da mãe só não é tão difícil graças aos momentos em que estamos juntos a essas pessoas. Isso faz todos eles serem um pouco da minha família também. Além disso, é impossível falar de 
amizade e não lembrar de Larissa, Vitor, Bertoli, Nathalia e outros que, apesar de nos vermos poucas vezes ao ano, cada vez que nos encontramos parece que o último encontro foi há menos de uma semana.

Não menos importantes, agradeço aos meus colegas de laboratório. Em matéria de falar bobagens e de discutir ideias, duvido que haveria pessoas no mundo melhores que essas. Em especial, agradeço ao Vinícius, que foi o meu maior colaborador nos últimos anos. Tanto na hora de trabalhar, quanto na hora de inventar e divulgar piadas ruins.

Durante seis meses do desenvolvimento deste trabalho, estive na Columbia University, período completamente diferente da minha vida. Apesar de curto, esse período foi essencial para este trabalho. Há pessoas que conheci lá e gostaria de agradecer aqui. Em especial ao professor Dan Ellis, um homem que me surpreendeu com sua capacidade de ser tão ocupado e tão atencioso ao mesmo tempo. Entre as conversas às sextas-feiras e as análises de espectrogramas que não deram muito resultado, aprendi muito. Também agradeço à Hèléne, pessoa que melhor abraçou uma ideia que gerou um trabalho bastante interessante ao meu ver. Finalmente, agradeço ao Victor, pessoa com quem eu dividi um apartamento e algumas histórias que espero nunca esquecer. Infelizmente essas pessoas não poderão ler estes agradecimentos, pelo simples fato de não poderem ler em português. Mas farei questão de traduzí-los e enviá-los por email. Espero também poder fazê-los pessoalmente, um dia.

Gostaria ainda de agradecer a todos que fazem ou já fizeram parte do Grupo de Estudos para a Maratona de Programação. Um grupo que eu ajudei a tirar do papel, hoje é forte e reconhecido. Cada vez que eu me percebo um pouco longe dele, devido ao trabalho, sinto um aperto no coração. Em especial, agradeço a quem mais dividiu seu tempo comigo nessa empreitada: Quake e PH. Mas aqui não podem faltar agradecimentos a Shi, Denis, Bianca, Bruno e Filipe. Esse grupo sempre me foi motivador e, fazendo parte dele, hoje levo mais e mais coisas boas em minha bagagem.

Agradecimentos não podem faltar ao meu orientador, Gustavo Batista. Vejo nele uma pessoa que investiu em mim, quando eu ainda era um aluno de começo de graduação. Trabalhando com ele, consegui várias das maiores conquistas da minha vida. Do meu primeiro projeto de iniciação científica até este projeto em finalização, passando pela Maratona de Programação, pelos artigos e congressos e pela minha experiência internacional, todas minhas conquistas no âmbito acadêmico tiveram participação dele. Espero que eu esteja conseguindo retribuir o investimento à altura esperada.

Por fim, gostaria de agradecer à FAPESP por possibilitar o pleno desenvolvimento deste trabalho. Sem dúvida nenhuma, essa é uma agência de fomento que deve servir de exemplo a muitas outras instituições. 


\section{Resumo}

Um dos grandes desafios em mineração de dados é a integração de dados temporais ao seu processo. Existe um grande número de aplicações emergentes que envolvem dados temporais, incluindo a identificação de transações fraudulentas em cartões de crédito e ligações telefônicas, a detecção de intrusão em sistemas computacionais, a predição de estruturas secundárias de proteínas, a análise de dados provenientes de sensores, entre muitas outras. Neste trabalho, tem-se interesse na classificação de séries temporais que representam sinais de áudio. Como aplicação principal, tem-se interesse em classificar sinais de insetos coletados por um sensor óptico, que deve ser capaz de contar e classificar os insetos de maneira automática. Apesar de serem coletados opticamente, os sinais capturados se assemelham a sinais de áudio. O objetivo desta pesquisa é comparar métodos de classificação por similaridade e por extração de atributos que possam ser utilizados no contexto da classificação de insetos. Para isso, foram empregados os principais métodos de classificação de sinais de áudio, que têm sido propostos para problemas como reconhecimento de instrumentos musicais, fala e espécies animais. Neste trabalho, é mostrado que, de modo geral, a abordagem por extração de atributos é mais eficaz do que a classificação por similaridade. Mais especificamente, os melhores resultados são obtidos com a utilização de coeficientes mel-cepstrais. Este trabalho apresenta contribuições significativas em outras aplicações, também relacionadas à análise de séries temporais e sinais de áudio, por similaridade e por extração de atributos. 



\section{Abstract}

One of the major challenges in data mining is the integration of temporal data to its process. There are a number of emerging applications that involve temporal data, including fraud detection in credit card transactions and phone calls, intrusion detection in computer systems, the prediction of secondary structures of proteins, the analysis of data from sensors, and many others. In this work, our main interest is the classification of time series that represent audio signals. Our main interest is an application for classifying signals of insects collected from an optical sensor, which should count and classify insects automatically. Although these signals are optically collected, they resemble audio signals. The objective of this research is to compare classification methods based on similarity and feature extraction in the context of insects classification. For this purpose, we used the main classification methods for audio signals, which have been proposed for problems such as musical instrument, speech and animal species recognition. This work shows that, in general, the approach based on feature extraction is more accurate than the classification by similarity. More specifically, the best results are obtained with mel-frequency cepstrum coefficients. This work also presents significant contributions in other applications, also related to the analysis of time series and audio signals by similarity and feature extraction. 



\section{Sumário}

Agradecimentos .......................... . . i

Resumo ................................ iii

Abstract . . . . . . . . . . . . . . . . . .

Sumário . . . . . . . . . . . . . . . . . . . vii

Lista de Figuras . . . . . . . . . . . . . . . . . . . . . . xi

Lista de Tabelas . . . . . . . . . . . . . . . . . . . . xv

1 Introdução 1

1.1 Justificativa e Motivação . . . . . . . . . . . . . . . . . . . 2

1.2 Hipóteses e Objetivos . . . . . . . . . . . . . . . . . . 3

1.3 Principais Contribuições . . . . . . . . . . . . . . . . . . . . . 3

1.4 Organização do Trabalho . . . . . . . . . . . . . . . . 5

2 Classificação de Séries Temporais e Sinais de Áudio $\quad 7$

2.1 Classificação de Séries Temporais por Similaridade . . . . . . . . . . . 7

2.2 Classificação de Séries Temporais por Extração de Atributos . . . . . . . . 14

2.2.1 Representações do Sinal . . . . . . . . . . . . . . . . . . . . . 14

2.2.2 Extração de atributos . . . . . . . . . . . . . . . . . . 19

2.2.3 Classificação de Sinais de Áudio de Curta Duração . . . . . . . . . 28

3 Sensor para a Classificação Automática de Insetos 33

3.1 Motivação . . . . . . . . . . . . . . . . . . . . . . 33

3.2 Identificação Automática de Insetos . . . . . . . . . . . . . . . . . 35

3.2 .1 Descrição do Sensor . . . . . . . . . . . . . . . . . . . . 38

3.2 .2 Coleta e Pré-Processamento de Dados . . . . . . . . . . . . . . . 39

3.2 .3 Armadilha Inteligente . . . . . . . . . . . . . . . . 40 
4.1 Similaridade na Representação Temporal . . . . . . . . . . . . . . . . . 43

4.2 Similaridade em Diferentes Representações de Séries Temporais . . . . . . 46

4.2.1 Similaridade nas Representações Espectral e Cepstral . . . . . . . . 47

4.2.2 Diferentes Medidas de Distância Aplicadas na Representação Espectral . . . . . . . . . . . . . . . . . 5 50

4.2.3 Filtro de Suavização Sobre Diferentes Representações . . . . . . . . 51

4.2.4 Similaridade Espectral Aplicada na Classificação de Nove Espécies de Insetos . . . . . . . . . . . . . . . . . . . . . . . 52

4.3 Considerações Finais . . . . . . . . . . . . . . . . . . . 54

5 Classificação de Insetos por Extração de Atributos $\quad 57$

5.1 Estudo Comparativo Entre as Abordagens de Classificação por Similaridade e Extração de Atributos . . . . . . . . . . . . . . . . . . . . . 58

5.1.1 Baseline Baseado na Classificação por Similaridade no Domínio Espectral . . . . . . . . . . . . . . . . . 5 58

5.1 .2 Extração de Atributos - Coeficientes Mel-Cepstrais . . . . . . . . 58

5.1 .3 Avaliação Experimental . . . . . . . . . . . . . . . . . 60

5.1 .4 Análise dos Resultados . . . . . . . . . . . . . . . . . 61

5.2 Extração de Atributos em Diferentes Representações de Séries Temporais . 62

5.2 .1 Extração de Atributos . . . . . . . . . . . . . . . . . 62

5.2 .2 Avaliação Experimental . . . . . . . . . . . . . . . 63

5.2.3 Combinação de Atributos e de Algoritmos de Aprendizado . . . . . 65

5.2.4 Classificação por Extração de Atributos Considerando Classes Binárias . . . . . . . . . . . . . . . . . . . . . 69

5.2.5 Análise dos Resultados . . . . . . . . . . . . . . . . 70

5.3 Classificação de Insetos em Fluxo de Dados . . . . . . . . . . . . . . . . 71

5.3.1 Estratégias de Aprendizado em Fluxo de Dados . . . . . . . . . . . 71

5.3.2 Resultados e Discussões . . . . . . . . . . . . . . . . . . . . . . . 72

5.3.3 Análise dos Resultados . . . . . . . . . . . . . . . . . . 74

5.4 Considerações Finais . . . . . . . . . . . . . . . . . . . . 75

6 Conclusão $\quad 77$

6.1 Perspectivas Futuras . . . . . . . . . . . . . . . . 79

$\begin{array}{ll}\text { A Outras Contribuições } & 81\end{array}$

A.1 Reconhecimento de Dígitos Falados . . . . . . . . . . . . . . . . . 82

A.1.1 Reconhecimento de Dígitos Falados em Português Utilizando LSF . 83 
A.1.2 Estudo Comparativo Entre a Utilização de MFCC e LSF no Reconhecimento de Dígitos Falados em Português e Inglês . . . . . . . 89

A.2 Análise de Séries Temporais e Sinais Musicais por Distância Baseada em Compressão de Vídeos ． . . . . . . . . . . . . . . . . . . . . . . . . . . . . 95

A.2.1 Classificação de Séries Temporais pela Medida de Distância RPCD 96

A.2.2 Recuperação de Música por Conteúdo pela Medida de Distância

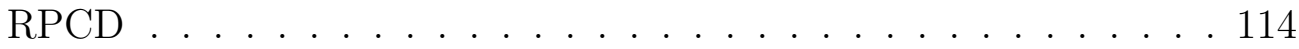





\section{Lista de Figuras}

2.1 Representação gráfica do alinhamento realizado pela distância de Minkowski entre duas séries temporais . . . . . . . . . . . . . . . . . . .

2.2 Representação gráfica do alinhamento não-linear ótimo obtido pelo algoritmo que calcula a medida de distância DTW . . . . . . . . . . . . . . . 11

2.3 Alinhamento não-linear ótimo e a matriz resultante, destacando o alinhamento ótimo . . . . . . . . . . . . . . . . . . . . . . . . . 12

2.4 Bandas de restrição, que limitam a distância do casamento no cálculo da DTW: banda de Sakoe-Chiba e paralelogramo de Itakura . . . . . . . . . . 12

2.5 Alinhamento não-linear ótimo entre duas séries temporais em dois casos: sem a utilização de banda de restrição e com o uso de banda de Sakoe-Chiba 13

2.6 Dois sinais, produzidos por um violino e por um piano, similares no domínio temporal. Porém, ao transformá-los para o domínio de frequências, as diferenças entre os sinais são claramente evidenciadas . . . . . . . . . . . . . 14

2.7 Exemplo de forma de onda senoide com amplitude $=1 \mathrm{~dB}$ e frequência $=$ $3 \mathrm{~Hz} \ldots \ldots \ldots \ldots \ldots \ldots \ldots \ldots \ldots$

2.8 Sinal de uma nota emitida por um baixo acústico . . . . . . . . . . . . 16

2.9 Função resultante da soma de quatro senoides . . . . . . . . . . . . . . . 17

2.10 Gráfico do espectro de uma função periódica composta por quatro componentes senoidais . . . . . . . . . . . . . . . . . . . 17

2.11 Espectro obtido a partir do sinal de uma nota emitida por um baixo acústico 18

2.12 Cepstro obtido a partir do sinal de uma nota emitida por um baixo acústico 19

2.13 Exemplo do procedimento de análise de harmônicas . . . . . . . . . . . . . 23

2.14 Exemplo do espectro e cesptro de um sinal, indicando o pico de maior amplitude no cepstro, representando o período relacionado à frequência fundamental . . . . . . . . . . . . . . . . . . . . 27 
3.1 Sistema de captura de informações de insetos proposto por Moore . . . . . 37

3.2 Projeto lógico do sensor em desenvolvimento . . . . . . . . . . . . . . . 38

3.3 Exemplo de sinal gravado pelo sensor, espécie Aedes aegypti . . . . . . . . 39

3.4 Esquema do detector de batidas de asas . . . . . . . . . . . . . . . 40

3.5 Armadilha comercial utilizada para capturar insetos em lavouras . . . . . . 41

3.6 Projeto lógico da armadilha inteligente . . . . . . . . . . . . . . . . . . . . 42

3.7 Sensor adaptado à armadilha comercial para capturar insetos em lavouras . 42

4.1 Histograma da frequência da batida de asas das espécies Bombus impatiens, Aedes aegypti e Culex quinquefasciatus . . . . . . . . . . . . . . . . . 47

4.2 Exemplo de um espectro de frequências antes e após a aplicação de filtro de suavização . . . . . . . . . . . . . . . . . . . . . . . . . . . 51

4.3 Exemplo de sinal segmentado relativo à passagem de um Aedes aegypti pelo sensor óptico . . . . . . . . . . . . . . . . . . . . . 5 53

5.1 Resultados obtidos pelos algoritmos 1-NN e SVM, dada a variação no número de coeficientes mel-cepstrais . . . . . . . . . . . . . . . . . 59

5.2 Desempenho do algoritmo 1-NN na classificação de insetos em fluxo de dados 73

5.3 Desempenho do algoritmo GMM na classificação de insetos em fluxo de dados 74

A.1 Esquema do janelamento dinâmico para extração de atributos . . . . . . . 85

A.2 Esquema de segmentação por amplitude utilizado na segmentação dos sinais de dígitos falados . . . . . . . . . . . . . . . . . . . . 86

A.3 Resultado do reconhecimento de dígitos falados em português e inglês, gravados com taxa de amostragem de $44100 \mathrm{~Hz}$. . . . . . . . . . . . . . . . 92

A.4 Acurácia obtida por diferentes classificadores conforme variação do número de atributos extraídos para a tarefa de reconhecimento de dígitos . . . . . 93

A.5 Resultado do reconhecimento de dígitos falados em português e inglês, reamostrados a uma taxa de $8820 \mathrm{~Hz}$. . . . . . . . . . . . . . . . . . . . 94

A.6 Alguns exemplos de gráficos de recorrência: ruído totalmente aleatório; caminhada aleatória; composição de senos e cossenos . . . . . . . . . . . . 98

A.7 Exemplo de gráficos de recorrência com e sem a utilização do limiar de proximidade, ambos gerados a partir de uma mesma série temporal . . . . 99

A.8 Gráficos de recorrência de três conjuntos de dados e, para cada conjuntos de dados, três diferentes classes . . . . . . . . . . . . . . . . . 103

A.9 Dendrogramas obtidos pelo agrupamento de seis séries temporais de três classes classes diferentes, utilizando-se distância euclidiana e distância baseada nos gráficos de recorrência . . . . . . . . . . . . . . . . . . . . . . 104 
A.10 Procedimento para calcular a medida de distância Recurrence Patterns Compression Distance . . . . . . . . . . . . . . . . . . . . . . . . 106

A.11 Representação gráfica dos resultados obtidos pela RPCD contra as distâncias euclidiana e DTW . . . . . . . . . . . . . . . . . . . 108

A.12 Exemplo do truque de representação que transforma objetos em séries temporais . . . . . . . . . . . . . . . . . . . 109

A.13 Representação gráfica do pós-teste de Bonferroni-Dunn. O intervalo marcado representa o intervalo de rankings sem diferença estatística em relação à RPCD, utilizada como controle . . . . . . . . . . . . . . . . . . . . . . . 109

A.14 Gráfico Texas sharpshooter da RPCD versus a distância euclidiana e a DTW112

A.15 Representação gráfica dos resultados obtidos por CK-1, distância euclidiana e NCD sobre gráficos de recorrência . . . . . . . . . . . . . . . . . . . . . . 114

A.16 Representação gráfica do pós-teste de Bonferroni-Dunn. O intervalo marcado representa o intervalo de rankings sem diferença estatística em relação ao RPCD, utilizado como controle . . . . . . . . . . . . . . . . . . . . . . . 114

A.17 Quatro diferentes representações da mesma gravação de uma peça de Chopin 123

A.18 Matrizes de auto-similaridade de uma mesma peça musical, extraídas com diferentes taxas amostragem . . . . . . . . . . . . . . . . 125 



\section{Lista de Tabelas}

2.1 Medidas de distância entre séries temporais . . . . . . . . . . . . . . . 10

2.2 Vogais presentes na base de vogais da Universidade do Texas em Dallas . . 30

4.1 Descrição resumida do conjunto de dados com três espécies de insetos . . . 44

4.2 Descrição resumida dos resultados da classificação utilizando apenas as observações no domínio temporal, no conjunto de dados com três espécies de insetos . . . . . . . . . . . . . . . . . . . . . 45

4.3 Distribuição da frequência da batida de asas de três espécies de insetos . 47

4.4 Descrição resumida do conjunto de dados com cinco espécies de insetos . . 48

4.5 Resultado da classificação por similaridade no domínio temporal utilizando o conjunto de dados com cinco espécies de insetos e as distâncias euclidiana, Manhattan, Chebyshev, cosseno e correlação . . . . . . . . . . . . . . . . . 48

4.6 Resultado da classificação por similaridade no domínio de frequências utilizando o conjunto de dados com cinco espécies de insetos e as distâncias euclidiana, Manhattan, Chebyshev, cosseno e correlação . . . . . . . . . . . 49

4.7 Resultado da classificação por similaridade no domínio cepstral utilizando o conjunto de dados com cinco espécies de insetos e as distâncias euclidiana, Manhattan, Chebyshev, cosseno e correlação . . . . . . . . . . . . . . . . 49

4.8 Resultado da classificação por similaridade no domínio de frequências utilizando o conjunto de dados com cinco espécies de insetos e as distâncias de Canberra, Jaccard, Topsoe, Clark, média $L_{1} L_{\infty}, \chi^{2}$ quadrático, e $\chi^{2}$ aditivo simétrico . . . . . . . . . . . . . . . . . . 50 50

4.9 Resultado da classificação por similaridade nos domínios espectral e cepstral após a aplicação de um filtro de suavização no conjunto de dados de cinco espécies de insetos . . . . . . . . . . . . . . . . . . . . 
4.10 Descrição resumida do conjunto de dados com nove espécies de insetos

4.11 Resultado da classificação por similaridade no domínio de frequências utilizando o conjunto de dados com nove espécies de insetos . . . . . . . . . . 54

4.12 Resultado da classificação por similaridade no domínio espectral após a aplicação de um filtro de suavização no conjunto de dados de nove espécies de insetos . . . . . . . . . . . . . . . . . . . . . . . 54

5.1 Algoritmos de classificação utilizados nos experimentos e parâmetros considerados para variação pelo método de busca em grade . . . . . . . . . . . 61

5.2 Resultados da classificação utilizando os parâmetros previamente encontrados 61

5.3 Lista dos atributos que compõem os vetores de atributos temporais e es-

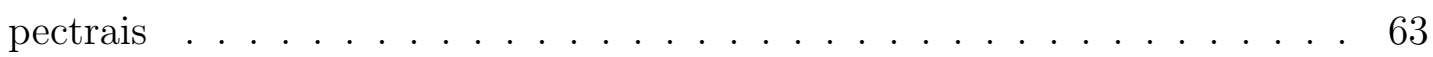

5.4 Algoritmos de aprendizado com seus respectivos intervalos de valores de parâmetros . . . . . . . . . . . . . . . . . . . . 64

5.5 Resultados por classificador e conjunto de atributos, e os valores dos parâmetros ideais. O melhor resultado em cada conjunto de atributos está destacado em negrito . . . . . . . . . . . . . . . . . . . 64

5.6 Resultados obtidos pela combinação da saída de diferentes classificadores treinados com o mesmo conjunto de atributos . . . . . . . . . . . . . . 66

5.7 Resultados obtidos pela combinação da saída de classificadores treinados com diferentes conjuntos de atributos . . . . . . . . . . . . . . . 67

5.8 Atributos selecionados pelos algoritmos CFS e relief . . . . . . . . . . . 68

5.9 Resultado da classificação com todos os conjuntos de atributos e técnicas de seleção de atributos . . . . . . . . . . . . . . . . . . . . . 69

A.1 Descrição dos cenários de classificação - dígitos falados em português . . . 87

A.2 Acurácia e desvio padrão médios para os três métodos de extração de atributos analisados nos 12 cenários . . . . . . . . . . . . . . . . . . . 88

A.3 Matriz de confusão de uma execução do algoritmo SVM no conjunto de dados de dígitos falados, utilizando LSF . . . . . . . . . . . . . 88

A.4 Descrição dos cenários de classificação - dígitos falados em português e inglês 91

A.5 Resultados obtidos pelos melhores classificadores para os diferentes tipos de atributos e taxas de amostragem no reconhecimento de dígitos em português e inglês . . . . . . . . . . . . . . . . . . . . . . . . . . . . . 94

A.6 Comparação dos resultados (acurácia) da medida RPCD contra distância euclidiana e DTW . . . . . . . . . . . . . . . . . . . 107

A.7 Ganhos esperados e reais entre RPCD e outras distâncias . . . . . . . . . . 111 
A.8 Taxas de acurácia do classificador do vizinho mais próximo com distância euclidiana, NCD e CK-1 (RPCD) entre gráficos de recorrência . . . . . . . 113

A.9 Resultados (MAP) obtidos com atributos cromáticos no conjunto 123tracks 120

A.10 Resultados (MAP) obtidos com atributos CENS no conjunto 123tracks . . 120

A.11 Resultados (MAP) obtidos com atributos CRP no conjunto 123tracks . . . 121

A.12 Resultados obtidos pela aplicação da NCD e da distância euclidiana sobre matrizes de auto-similaridade em algumas configurações de parâmetros da extração de atributos . . . . . . . . . . . . . . . . . . . . . . . . . . . . 122

A.13 Resultados obtidos após a aplicação da binarização e do filtro de desfoque nos gráficos de recorrência . . . . . . . . . . . . . . . . . . . . . . . 124 



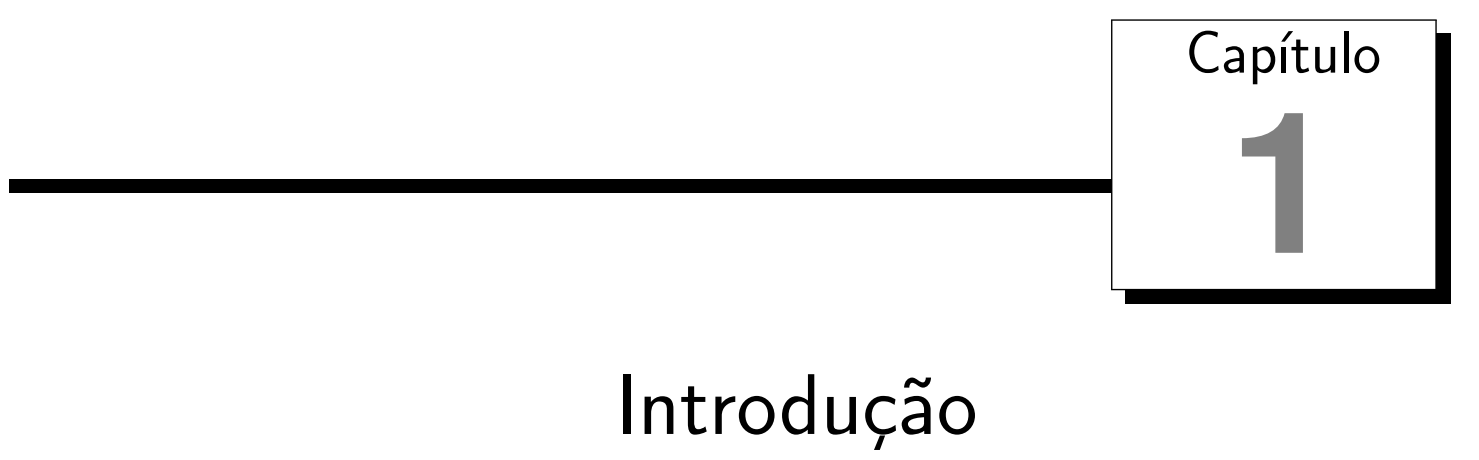

Um dos grandes desafios em mineração de dados é a integração de dados temporais ao seu processo (Yang e Wu, 2006). Existe um grande número de aplicações emergentes que envolvem o aprendizado de um mapeamento $f: X \rightarrow Y$, no qual $X$ representa o espaço de objetos complexos, como dados sequenciais ou séries temporais (Last et al., 2001). Algumas dessas aplicações incluem a identificação de transações fraudulentas em cartões de crédito e ligações telefônicas, a detecção de intrusão em sistemas computacionais, a predição de estruturas secundárias de proteínas, a análise de dados provenientes de sensores, entre muitas outras.

Neste trabalho, tem-se interesse na classificação de séries temporais que representam sinais de áudio. Para essa classe de problemas, $Y$ representa o espaço das possíveis categorias ou classes para as quais cada série temporal pode ser associada.

Existem duas abordagens frequentemente utilizadas para a classificação de séries temporais: por similaridade e por extração de atributos (Ratanamahatana et al., 2010). A classificação por similaridade utiliza uma função de distância para identificar as séries mais similares à uma série de consulta, cuja classe é definida pela classe dominante entre as séries similares; a classificação por extração de atributos busca por atributos locais que permitam caracterizar a série e, então, um sistema de aprendizado de máquina é utilizado para induzir um classificador sobre os atributos extraídos.

Como aplicação principal, tem-se interesse em classificar sinais de insetos coletados por um sensor óptico. Tal sensor utiliza um feixe de luz laser para capturar dados de insetos à distância. Quando um inseto atravessa esse feixe de luz, um fotosensor captura a variação 
da luz, resultante da oclusão parcial do feixe causada pelo inseto. Essa variação possui informações que podem ser utilizadas para identificar a espécie que gerou a perturbação no sinal. O sensor deve ser capaz de contar e classificar os insetos de maneira automática.

O objetivo deste trabalho é avaliar métodos de classificação por similaridade e por extração de atributos que possam ser utilizados no contexto da classificação de insetos por sensores ópticos. Apesar de serem coletados opticamente, os sinais se assemelham a sinais de áudio. Assim, foi realizado um levantamento dos principais métodos de identificação de atributos utilizados na classificação de sinais de áudio, que têm sido propostos para problemas como reconhecimento de instrumentos musicais, fala e espécies animais. Tais métodos foram aplicados a dados coletados de diversas espécies de insetos.

\subsection{Justificativa e Motivação}

Insetos possuem uma forte relação com o bem-estar do ser humano. Por exemplo, doenças transmitidas por mosquitos, como malária e dengue, matam mais de um milhão de pessoas por ano. Além disso, insetos são causadores de enormes perdas na produção de alimentos. Por outro lado, são responsáveis pela polinização de grande parte do alimento consumido no mundo. Insetos também são comumente utilizados como bioindicadores de qualidade ambiental.

Desenvolver um sistema capaz de automaticamente identificar e estimar a densidade de insetos de uma determinada espécie em uma região é um problema central no controle de pragas e vetores de doenças. Somente com o conhecimento em tempo real da distribuição espaço-temporal dos insetos é possível fazer uso eficaz de técnicas de controle.

Neste trabalho, o principal interesse é a classificação de sinais de áudio. A aplicação de principal interesse é a classificação de sinais de insetos, coletados por sensores ópticos. Esses sinais possuem curta duração e uma estrutura simples, uma vez que não possuem variações estruturais importantes entre segmentos de interesse. Sinais com estruturas simples podem ser encontrados em outras tarefas da análise de sinais, como o reconhecimento de vogais, de instrumentos musicais e de espécies animais por gravações de áudio. Por exemplo, o reconhecimento de fala pode ser uma importante ferramenta para que pessoas com dificuldades motoras possam controlar aparelhos eletrônicos e até mesmo navegar na internet. O reconhecimento de vogais, por sua vez, pode ser considerado um sub-problema do reconhecimento de fala, uma vez que fonemas vocálicos são importantes componentes de formação das palavras (dos Santos, 2006).

Dada a estrutura simples do problema, acreditamos que uma abordagem igualmente simples, que identifica atributos presentes sobretudo no tempo, espectro e cepstro do 
sinal, pode ser efetiva. Assim, foram consideradas diferentes representações do sinal e estratégias de extração de atributos, propostas em áreas correlatas de processamento de sinais.

\subsection{Hipóteses e Objetivos}

Como mencionado anteriormente, uma característica comum aos dados da aplicação de maior interesse deste trabalho é o fato dos dados apresentarem uma estrutura simples e uma curta duração. Dessa maneira, a principal hipótese deste trabalho é:

Atributos simples, que podem ser obtidos de forma automática e não supervisionada a partir de representações do sinal no tempo, espectro e cepstro são relevantes para a criação de classificadores com alto grau de acurácia na classificação de sinais de estrutura simples e curta duração.

Entretanto, entendemos que um único atributo não seja capaz de caracterizar os sinais completamente e que composições desses atributos são essenciais para a indução de classificadores precisos. A avaliação de quais atributos são relevantes para a classificação, a sua seleção e composição são passos importantes para a criação de classificadores precisos.

Dada essa hipótese, os objetivos deste trabalho são:

- Pesquisar métodos de extração automática de atributos intrínsecos aos sinais de interesse. Encontrar o melhor subconjunto de atributos para ser utilizado na classificação de insetos, criando modelos de classificação com os atributos selecionados. Avaliar e comparar esses modelos com a classificação por similaridade para a identificação de espécies de insetos;

- Desenvolver um ambiente computacional capaz de integrar os métodos pesquisados para servir como base para a realização de avaliações e para a disponibilização para a comunidade científica. Publicar na internet de todos os resultados detalhados e códigos-fonte desenvolvidos para facilitar a replicação dos resultados obtidos;

- Colaborar com o desenvolvimento de novas tecnologias de monitoramento ambiental que contribuam para a saúde pública e a agricultura e que tenham significativo impacto social.

\subsection{Principais Contribuições}

Este trabalho foi iniciado com a análise dos sinais coletados pelo sensor utilizando apenas informações contidas na representação temporal. Os resultados obtidos pela clas- 
sificação por similaridade nessa representação foram muito abaixo do desejado. Ao avaliar a classificação utilizando um simples atributo relacionado à frequência de batida de asas dos insetos o resultado pode ser muito superior ao alcançado pela similaridade no domínio temporal do sinal. Isso remete à primeira conclusão importante deste trabalho: as informações contidas na representação de frequências do sinal possuem informações muito mais relevantes para a classificação do que os valores das observações no domínio temporal. Esses resultados, publicados no VIII Encontro Nacional de Inteligência Artificial (Silva et al., 2011), são apresentados no Capítulo 4.

A partir dessa conclusão, foi aplicada a estratégia de classificação por similaridade em diferentes representações do sinal. Nessa etapa, foi demonstrado que essa abordagem é mais eficaz na representação de frequências do sinal. Os resultados nesse domínio foram superiores aos obtidos pela similaridade nas outras representações analisadas. Esses resultados são apresentados no Capítulo 4, mais especificamente na Seção 4.2, e fazem parte de um trabalho submetido ao Journal of Intelligent and Robotic Systems (Silva et al., 2014).

Além da classificação por similaridade, as diferentes representações do sinal foram utilizadas na classificação por extração de atributos. Foi demonstrado que essa abordagem é ainda mais eficaz que a classificação por similaridade em diversos dos cenários analisados. Em um primeiro momento, foi demonstrado que a utilização dos bem conhecidos - e comumente utilizados - coeficientes mel-cepstrais pode ser significativamente mais eficaz do que a classificação por similaridade. Esses resultados, apresentados no Capítulo 5, Seção 5.1, são a base de um trabalho apresentado no X Encontro Nacional de Inteligência Artificial e Computacional (de Souza et al., 2013b).

Em outro trabalho, apresentado na $12^{\text {a }}$ International Conference on Machine Learning and Applications (Silva et al., 2013b), foi realizado um amplo experimento com diferentes estratégias de extração de atributos, comprovando a eficácia dos coeficientes mel-cepstrais na classificação de insetos por sensores ópticos. Além disso, foi realizado um experimento com diferentes combinações de atributos e classificadores. Ao combinar diferentes classificadores, não houve ganho de desempenho na classificação. Entretanto, a combinação de diferentes atributos obteve resultados superiores à utilização de classificadores com apenas um vetor de atributos. Esses resultados são apresentados no Capítulo 5, Seção 5.2.

A análise de sinais de áudio foi extrapolada em relação à classificação de insetos. Foram realizadas contribuições na análise de sinais de fala e de música, bem como séries temporais de variados domínios. Essas contribuições são detalhadas no Apêndice A.

Primeiramente, foi proposta a utilização dos atributos Line Spectral Frequencies (LSF) na tarefa de reconhecimento de dígitos em português, em um trabalho apresentado na $13^{\mathrm{a}}$ Ibero-American Conference on Artificial Intelligence (Silva et al., 2012). Foi demonstrado que esses atributos podem superar os comumente utilizados coeficientes mel- 
cepstrais. Esse trabalho foi estendido para publicação no periódico Acta Scientiarum Technology (Silva et al., 2013d). Nesse trabalho, foi evidenciada a importância da variação do número de coeficientes mel-cepstrais e LSF a serem utilizados, sendo as LSF mais robustas a uma má escolha desse parâmetro. Além disso, foi mostrado que a mesma abordagem de classificação pode ser utilizada em diferentes idiomas e taxas de amostragem do sinal analisado, sem diferença significativa nos resultados. Esses trabalhos são descritos na Seção A.1.

Por fim, foi proposta uma medida de distância entre séries temporais, baseada em duas etapas principais: a transformação da série temporal para uma representação visual de seu padrão de repetição e uma medida de distância entre elas. Nesse trabalho, apresentado na IEEE International Conference on Data Mining, foram utilizados gráficos de recorrência, comparados por uma distância baseada em compressão de vídeos, na classificação de séries temporais em diversos domínios de aplicação, como medicina, biologia e movimentos humanos (Silva et al., 2013a). A utilização dessa medida de distância se mostrou competitiva com medidas de distância consideradas estado-da-arte na classificação de séries temporais por similaridade. Finalmente, essa medida de distância foi adaptada para ser aplicada na tarefa de recuperação de informação de música por conteúdo. Nesse trabalho, apresentado na $14^{\mathrm{a}}$ International Society for Music Information Retrieval Conference (Silva et al., 2013c), foi constatado que a medida de distância proposta supera os resultados obtidos por trabalhos relacionados. A medida de distância proposta, bem como os resultados obtidos por sua utilização são apresentados na Seção A.2.

Ainda, durante o desenvolvimento deste trabalho, houve a colaboração na elaboração de um design experimental para a avaliação tratamento de classes desbalanceadas na tarefa de classificação, apresentado na $11^{\mathrm{a}}$ International Conference on Machine Learning and Applications (Batista et al., 2012). Esse trabalho foi estendido, propondo um procedimento estatístico para avaliar a recuperação do desempenho da classificação ao utilizar métodos de tratamento de classes desbalanceadas (Prati et al., 2014). Esse procedimento, baseado em intervalos de confiança, serve como visualização dos resultados, bem como base para se tirar conclusões estatísticas.

Em resumo, foram publicados oito artigos em conferências científicas e um artigo em periódico, além de dois artigos submetidos a periódicos.

\subsection{Organização do Trabalho}

O restante deste trabalho está organizado do seguinte modo: o Capítulo 2 é destinado a descrever conceitos básicos da análise de séries temporais e sinais de áudio, considerando 
as abordagens por similaridade e por extração de atributos; no Capítulo 3 é descrito o sensor laser para a identificação automática de insetos utilizado neste trabalho, bem como é apresentada uma revisão bibliográfica sobre esse assunto; nos Capítulos 4 e 5 são apresentados os experimentos e resultados da classificação dos sinais obtidos pelo sensor, utilizando estratégias de similaridade e extração de atributos, respectivamente; este trabalho é concluído no Capítulo 6; no Apêndice A são exibidos os resultados da utilização de técnicas de similaridade e extração de atributos em diferentes aplicações: análise de fala, música e séries temporais geradas em variados domínios; por fim, são apresentadas referências bibliográficas utilizadas no decorrer do trabalho. 


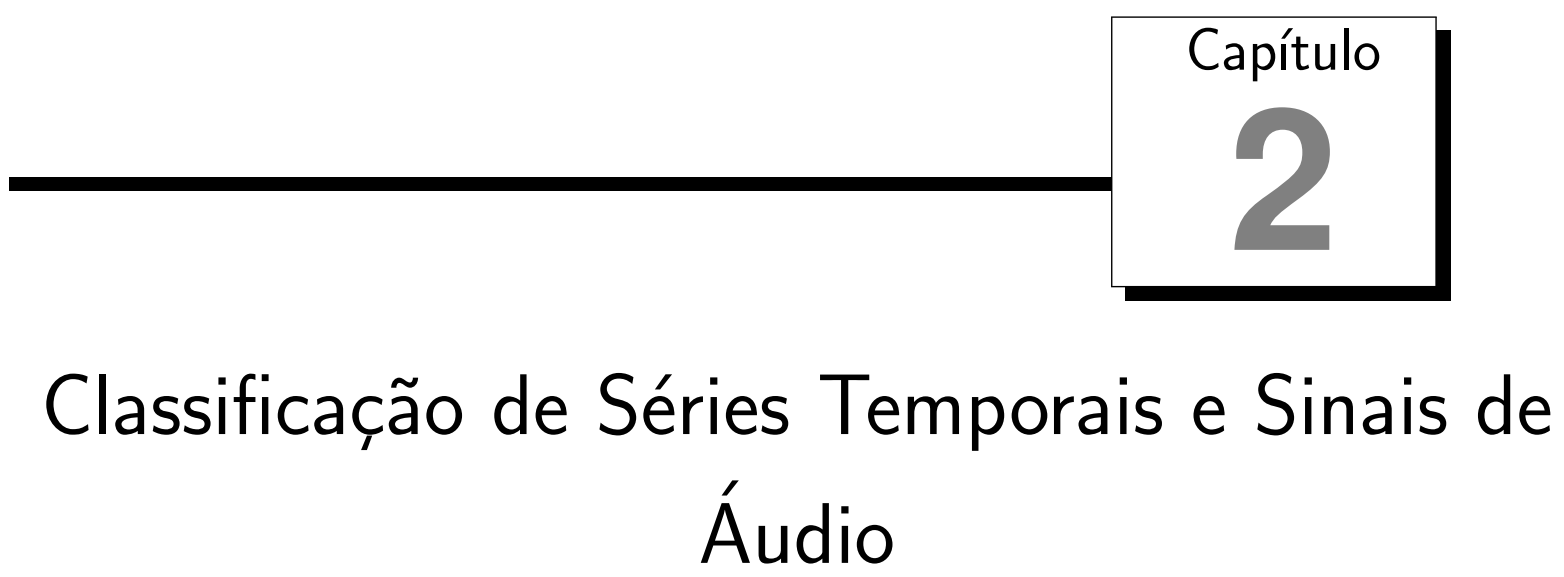

A análise de séries temporais tem atraído muitos pesquisadores em mineração de dados ao redor do mundo. Isso deve-se principalmente aos inúmeros domínios de aplicação a que esse tipo de dados está associado, como medicina, economia e processamento de sinais. Dentre as possíveis tarefas de mineração de dados, a de maior interesse deste trabalho é a classificação. Nessa tarefa, séries temporais desconhecidas devem ser associadas a um rótulo que as descreva. Esse rótulo deve ser fornecido a partir de um conjunto de treinamento constituído por séries temporais previamente rotuladas.

Neste capítulo, são abordadas estratégias para a classificação de séries temporais. Na Seção 2.1, são apresentados os conceitos básicos da classificação de séries temporais por similaridade, estratégia comumente utilizada com sucesso no cumprimento da tarefa. Na Seção 2.2, é abordada a estratégia de classificação de séries temporais por extração de atributos, com maior foco na classificação de sinais de áudio, caso especial de séries temporais.

\subsection{Classificação de Séries Temporais por Similaridade}

Séries temporais são onipresentes no dia-a-dia dos seres humanos. Dados dispostos no tempo são gerados em aplicações de diversos domínios, como medicina, biologia, econo- 
mia, processamento de sinais, entre muitas outras. Consequentemente, a área de análise de séries temporais tem atraído a atenção e o esforço de muitos pesquisadores ao redor do mundo. Tal esforço pode ser dividido em diversas tarefas, como classificação, agrupamento, descoberta de motifs e detecção de anomalias.

Informalmente, uma série temporal pode ser descrita como uma coleção de informações de um fenômeno observado ao longo de um determinado período, organizadas em ordem cronológica (Kirchgässner e Wolters, 2007).

Devido ao grande interesse em séries temporais, inúmeros métodos de análise foram propostos nas últimas décadas. Diversos desses métodos possuem uma característica em comum: em seus cernes existe uma função de similaridade como principal maneira de comparar as séries temporais. Por exemplo, a classificação de séries temporais pode ser realizada com o uso do algoritmo do vizinho mais próximo com grande sucesso (Ding et al., 2008). Outro exemplo são os algoritmos de agrupamento de dados baseados em similaridade entre objetos. Há diversos desses métodos que, sem nenhuma adaptação, podem ser utilizados para agrupar séries temporais. Em outras tarefas, o conceito de similaridade é utilizado diretamente na definição do problema, como no caso de detecção de motifs. Um motif é o par de subsequências mais similar em uma série temporal (Mueen, 2013). Na tarefa de detecção de anomalias, um time series discord é o par de subsequências que possui maior distância entre si (Keogh et al., 2007a).

A análise de séries temporais pode ser descrita como o aprendizado de um mapeamento $f: X \rightarrow Y$, no qual $X$ representa as séries temporais. Em um problema de classificação, principal interesse deste trabalho, $Y$ representa o espaço das possíveis categorias ou classes para as quais cada série temporal pode ser associada (Last et al., 2001).

Mais especificamente, há trabalhos que evidenciam que o simples algoritmo do vizinho mais próximo, frequentemente utilizado na classificação de séries temporais, é muito difícil de ser batido (Ding et al., 2008; Wang et al., 2013).

Essa abordagem de classificação de séries temporais assume que séries mais semelhantes têm maior probabilidade de pertencerem à mesma classe. Dessa maneira, uma série temporal pode ser classificada utilizando-se uma medida de distância entre uma série temporal de consulta e séries temporais previamente rotuladas, atribuindo à consulta o rótulo previamente dado à série mais similar. Apesar de parecer uma abordagem simples, a classificação por similaridade tem se mostrado competitiva com métodos de classificação mais complexos, inclusive em problemas de classificação de séries temporais.

Um dos problemas inerentes à essa abordagem é a escolha da medida de distância. Comumente, é utilizada uma medida que pode ser obtida por meio da distância de Minkowski, definida na Equação 2.1. Nessa equação, $x=\left(x_{1}, x_{2}, \ldots, x_{n}\right)$ e $y=\left(y_{1}, y_{2}, \ldots, y_{n}\right)$ são séries temporais de comprimento $n$. $d$ pode assumir qualquer valor, sendo a distância 
de Manhattan, $\operatorname{com} d=1$, e a distância euclidiana, $\operatorname{com} d=2$, casos especiais da distância de Minkowski.

$$
\operatorname{dist}(x, y)=\left(\sum_{k=1}^{n}\left|x_{k}-y_{k}\right|^{d}\right)^{1 / d}
$$

Dessa maneira, a utilização dessa medida faz com que a dissimilaridade de duas séries temporais seja representada por uma função das distâncias das observações nos mesmos valores no eixo do tempo entre as duas séries, como é mostrado na Figura 2.1.

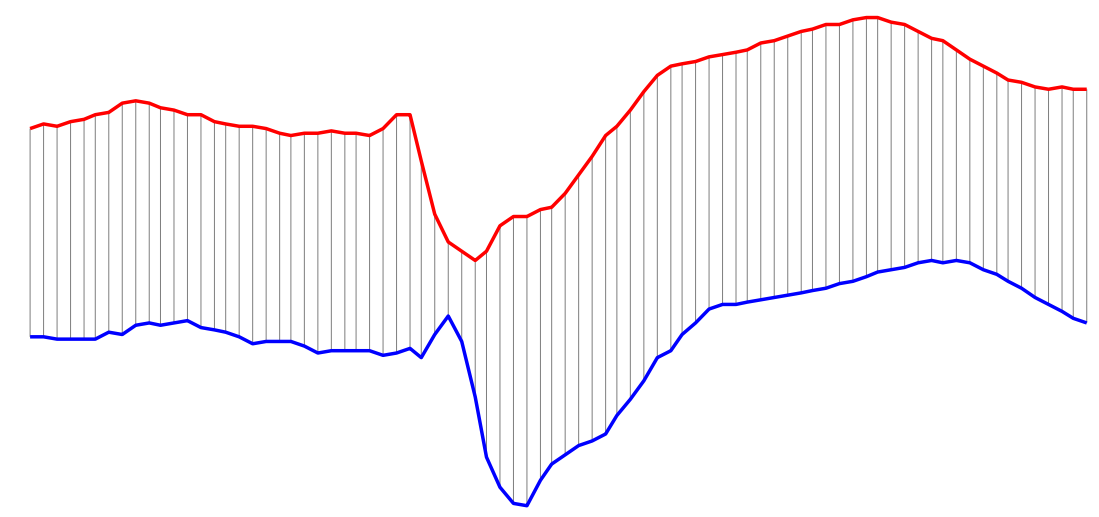

Figura 2.1: Representação gráfica do alinhamento realizado pela distância de Minkowski entre duas séries temporais

Existe na literatura uma infinidade de medidas de distâncias que pode ser facilmente adaptada, ou até mesmo utilizada diretamente, para ser aplicada à comparação de séries temporais. No geral, cada medida leva alguma característica diferente em consideração, mas obedecem o alinhamento linear, como feito no cálculo da distância de Minkowski. Na Tabela 2.1 são apresentadas as equações que definem várias das medidas de distância que podem ser aplicadas a este contexto. Essas e diversas outras medidas de distância são melhor descritas em um trabalho de Cha (2007), em que são apresentadas maneiras de comparar densidades de probabilidades. Essas distâncias, porém, são facilmente adaptáveis à comparação de séries temporais (Giusti e Batista, 2013).

As distâncias apresentadas até aqui medem a dissimilaridade entre séries temporais considerando-se apenas observações no mesmo exato momento. No entanto, essas distâncias são muito sensíveis a algumas distorções no eixo do tempo (Keogh e Ratanamahatana, 2005). Por isso, muitas aplicações necessitam de um casamento mais flexível de observações, no qual uma observação de $x$ no tempo $t_{x}$ pode ser combinada com uma observação de $y$ em um tempo $t_{y} \neq t_{x}$. A medida Dynamic Time Warping (DTW) proporciona a menor distância obtida pelo casamento não-linear das observações de acordo com as seguintes restrições (Ratanamahatana e Keogh, 2004): 
Tabela 2.1: Medidas de distância entre séries temporais

\begin{tabular}{|c|c|}
\hline Distância Euclidiana & $D_{e u c}(x, y)=\sum_{k=1}^{n} \sqrt{\left(x_{k}-y_{k}\right)^{2}}$ \\
\hline Distância de Manhattan & $D_{\text {man }}(x, y)=\sum_{k=1}^{n}\left|x_{k}-y_{k}\right|$ \\
\hline Distância de Chebyshev & $D_{\text {che }}(x, y)=\max _{k}\left|x_{k}-y_{k}\right|$ \\
\hline Distância do Cosseno & $D_{\cos }(x, y)=1-\frac{\sum_{k=1}^{n} x_{k} y_{k}}{\sqrt{\sum_{k=1}^{n}\left(x_{k}\right)^{2}} \sqrt{\sum_{k=1}^{n}\left(y_{k}\right)^{2}}}$ \\
\hline Distância de Correlação & $D_{c o r}(x, y)=1-\frac{n \sum_{k=1}^{n} x_{i} y_{i}-\sum_{k=1}^{n} x_{i} \sum_{k=1}^{n} y_{i}}{\sqrt{n \sum_{k=1}^{n} x_{i}^{2}-\left(\sum_{k=1}^{n} x_{i}\right)^{2}} \sqrt{n \sum_{k=1}^{n} y_{i}^{2}-\left(\sum_{k=1}^{n} y_{i}\right)^{2}}}$ \\
\hline Distância de Canberra & $D_{c a n}(x, y)=\sum_{k=1}^{n} \frac{\left|x_{k}-y_{k}\right|}{x_{k}+y_{k}}$ \\
\hline Distância de Jaccard & $D_{j a c}(x, y)=\frac{\sum_{k=1}^{n}\left(x_{k}-y_{k}\right)^{2}}{\sum_{k=1}^{n} x_{k}^{2}+\sum_{k=1}^{n} y_{k}^{2}+\sum_{k=1}^{n} x_{k} y_{k}}$ \\
\hline Distância de Topsoe & $D_{\text {top }}(x, y)=\sum_{k=1}^{n}\left(x_{k} \ln \left(\frac{2 x_{k}}{x_{k}+y_{k}}\right)+y_{k} \ln \left(\frac{2 y_{k}}{x_{k}+y_{k}}\right)\right)$ \\
\hline Distância de Clark & $D_{c l k}(x, y)=\sqrt{\sum_{k=1}^{n}\left(\frac{\left|x_{k}-y_{k}\right|}{x_{k}+y_{k}}\right)^{2}}$ \\
\hline Distância Média $L_{1} L_{\infty}$ & $D_{\text {avg }}(x, y)=\frac{\sum_{k=1}^{n}\left|x_{k}-y_{k}\right|+\max _{k}\left|x_{k}-y_{k}\right|}{2}$ \\
\hline Distância $\chi^{2}$ quadrático & $D_{S q \chi^{2}}(x, y)=\sum_{k=1}^{n} \frac{\left(x_{k}-y_{k}\right)^{2}}{x_{k}+y_{k}}$ \\
\hline Distância $\chi^{2}$ Aditivo Simétrico & $D_{\chi^{2} A d}(x, y)=\sum_{k=1}^{n} \frac{\left(x_{k}-y_{k}\right)^{2}\left(x_{k}+y_{k}\right)}{x_{k} y_{k}}$ \\
\hline
\end{tabular}

- Restrição de fronteira: O casamento é realizado entre toda a série $x$ e toda a série $y$, portanto começa nas observações $(1,1)$ e termina em $(n, m)$, sendo $n$ e $m$ os comprimentos das séries temporais comparadas;

- Restrição de continuidade: Os casamentos são feitos em etapas de uma unidade. Isso significa que o casamento nunca salta uma ou mais observações;

- Restrição de monotonicidade: A ordem relativa das observações deve ser preservada.

Na Figura 2.2, é exibido um exemplo do alinhamento não-linear ótimo encontrado pelo algoritmo que calcula a medida DTW.

A DTW geralmente é calculada utilizando-se um algoritmo de programação dinâmica, cujo estado inicial é descrito na Equação 2.2. 


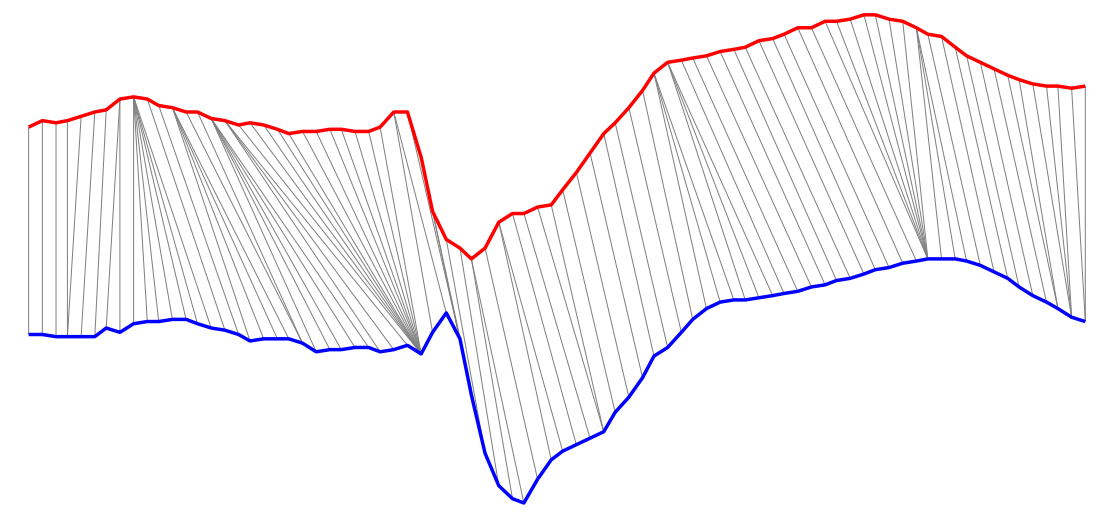

Figura 2.2: Representação gráfica do alinhamento não-linear ótimo obtido pelo algoritmo que calcula a medida de distância DTW

$$
\operatorname{DTW}(i, j)=\left\{\begin{array}{l}
0, \text { se } i, j=0 \\
\infty, \text { nos demais casos }
\end{array}\right.
$$

A relação de recorrência do algoritmo para calcular a DTW é apresentada na Equação 2.3 , em que $i=1 \ldots n$ e $j=1 \ldots m$ e $n$ e $m$ são os comprimentos das séries temporais $x$ e $y$, respectivamente. $C(x(i), y(j))$ é o custo para realizar o casamento entre $x(i)$ e $y(j)$, comumente calculado pela distância euclidiana entre os valores observados. O valor resultante em $D T W(n, m)$ é a distância entre $x$ e $y$.

$$
D T W(i, j)=C(x(i), y(j))+\min \left\{\begin{array}{l}
\operatorname{DTW}(i-1, j) \\
\operatorname{DTW}(i, j-1) \\
D T W(i-1, j-1)
\end{array}\right.
$$

Dessa maneira, o algoritmo preenche uma matriz com os menores custos acumulados para cada trajetória parcial possível, de modo que a distância ótima é dada pela trajetória com menor custo acumulado. Um exemplo do alinhamento não-linear ótimo encontrado pelo algoritmo e como ele é representado na matriz de cálculo da DTW é exibido na Figura 2.3.

Há diversos trabalhos que evidenciam a qualidade da medida DTW na classificação de séries temporais (Ding et al., 2008; Wang et al., 2013; Giusti e Batista, 2013). Especificamente, Giusti e Batista (2013) analisaram a utilização de 48 medidas diferentes na tarefa de classificação de séries temporais, incluindo a DTW, variações da distância de Minkowski e todas as medidas descritas na Tabela 2.1. Esse estudo evidenciou ainda mais a qualidade da DTW como uma medida de distância adequada para a tarefa de classi- 

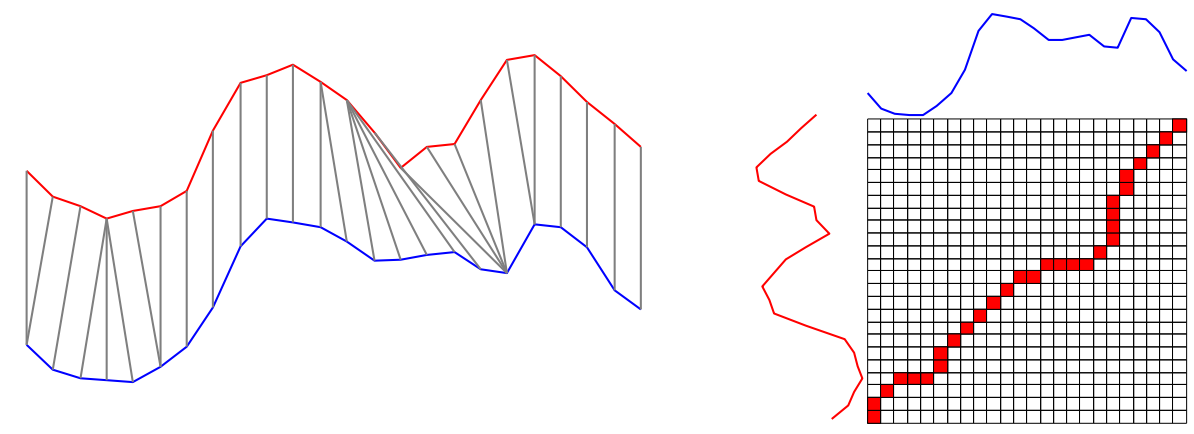

Figura 2.3: Alinhamento não-linear ótimo (esquerda) e a matriz resultante, destacando o alinhamento ótimo (direita)

ficação de séries temporais por similaridade, visto que nenhuma das medidas superou a DTW com diferença estatisticamente significativa.

Apesar das muitas evidências de que a análise de séries temporais por meio da medida DTW como dissimilaridade gera excelentes resultados em muitas aplicações, sua utilização em tarefas que envolvem grande quantidade de dados ainda é um desafio. O mesmo acontece em casos do seu uso em ambientes com limitações de processamento. Por isso, diversas técnicas foram propostas a fim de reduzir o tempo do cálculo da distância.

Provavelmente, a mais conhecida e utilizada é o uso de bandas de restrição, que delimitam valores máximos da distância entre observações em que um casamento pode ser feito. Em termos do algoritmo que calcula o alinhamento ótimo, tais bandas restringem uma área em torno da diagonal principal da matriz. Na Figura 2.4, são mostrados exemplos das duas bandas de restrição mais conhecidas na literatura: de Sakoe-Chiba (Sakoe e Chiba, 1978) e paralelogramo de Itakura (Itakura, 1975b).
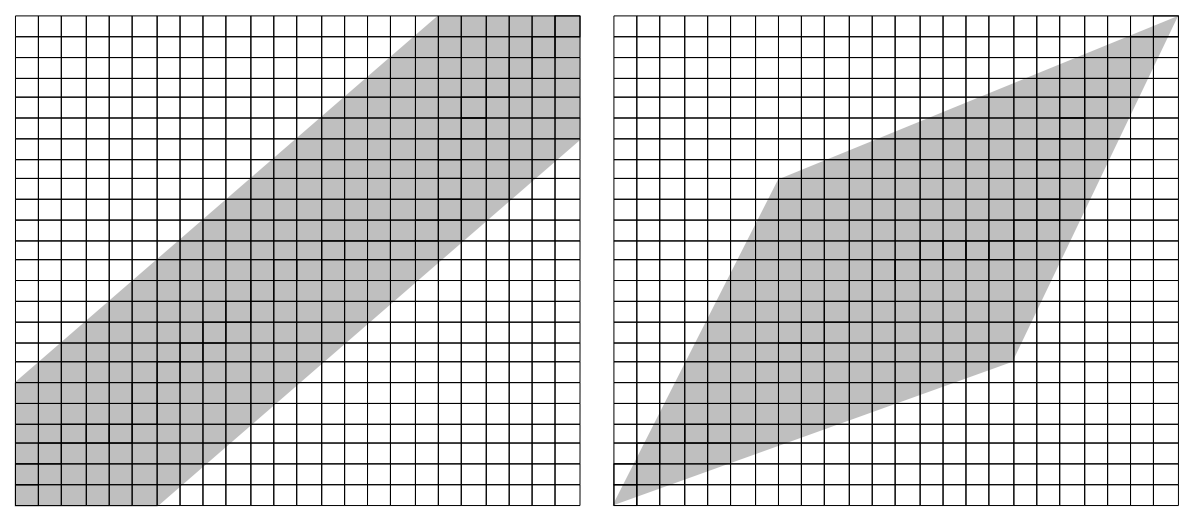

Figura 2.4: Bandas de restrição, que limitam a distância do casamento no cálculo da DTW: banda de Sakoe-Chiba (esquerda) e paralelogramo de Itakura (direita). A área demarcada em cinza compreende todas as células da matriz que serão calculadas 
Além de fornecer um valor de distância em menor tempo de execução - uma vez que não há a necessidade de se calcular toda a matriz DTW -, em alguns casos o uso de bandas de restrição pode melhorar o desempenho do algoritmo utilizado. Isso acontece pois essa estratégia evita casamentos espúrios. Por exemplo, se duas séries são bastante "comportadas", exceto pelo aparecimento de um único pico em sua trajetória, a medida DTW tradicional vai retornar um valor baixo, indicando que as séries temporais são bastante similares. Caso seja utilizada banda de restrição, esse valor só será baixo caso os picos apareçam em tempos próximos. Caso contrário, como por exemplo uma série possuir esse pico próximo ao seu início e outra próximo ao seu término, não serão consideradas séries temporais similares. Na Figura 2.5, é exibido um exemplo do alinhamento de séries temporais com e sem a utilização de banda de restrição.
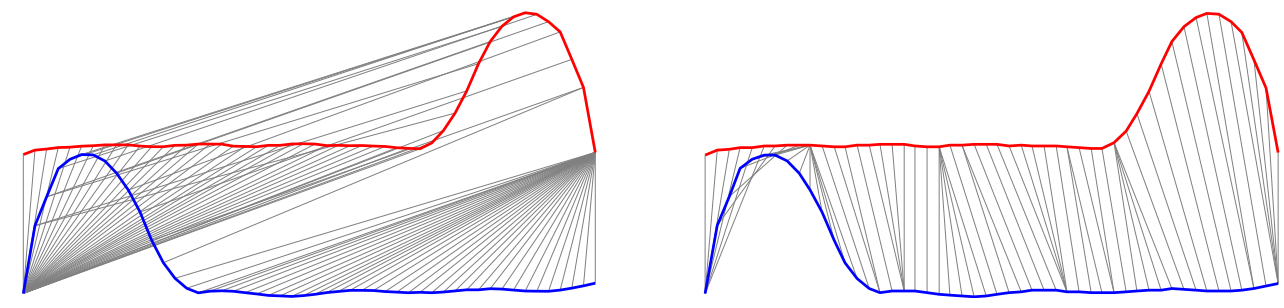

Figura 2.5: Alinhamento não-linear ótimo entre duas séries temporais em dois casos: sem a utilização de banda de restrição (esquerda) e com o uso de banda de Sakoe-Chiba (direita). A distância calculada no primeiro caso é 2, 76 e, no segundo, é 18,50

Apesar das evidências que a busca por similaridade é bastante efetiva para a classificação de séries temporais - e o crescente interesse em melhorar a eficiência de medidas de distância - essa estratégia pode não ser adequada em alguns domínios. Há domínios em que as principais características das séries temporais não são evidentes no domínio temporal. Isso acontece, principalmente, em casos em que as séries temporais analisadas são extensas e complexas, como sinais de áudio. Um exemplo disso é mostrado na Figura 2.6, em que dois sinais no domínio temporal parecem similares, mas suas diferenças são facilmente verificadas no domínio de frequências. De fato, esses sinais foram produzidos por instrumentos musicais diferentes emitindo notas musicais também diferentes.

Nesses casos, uma estratégia adequada para realizar a tarefa de classificação é a extração de atributos. Na próxima seção, serão apresentadas diferentes representações de séries temporais, assim como técnicas de extração de atributos utilizadas em cada uma delas. 

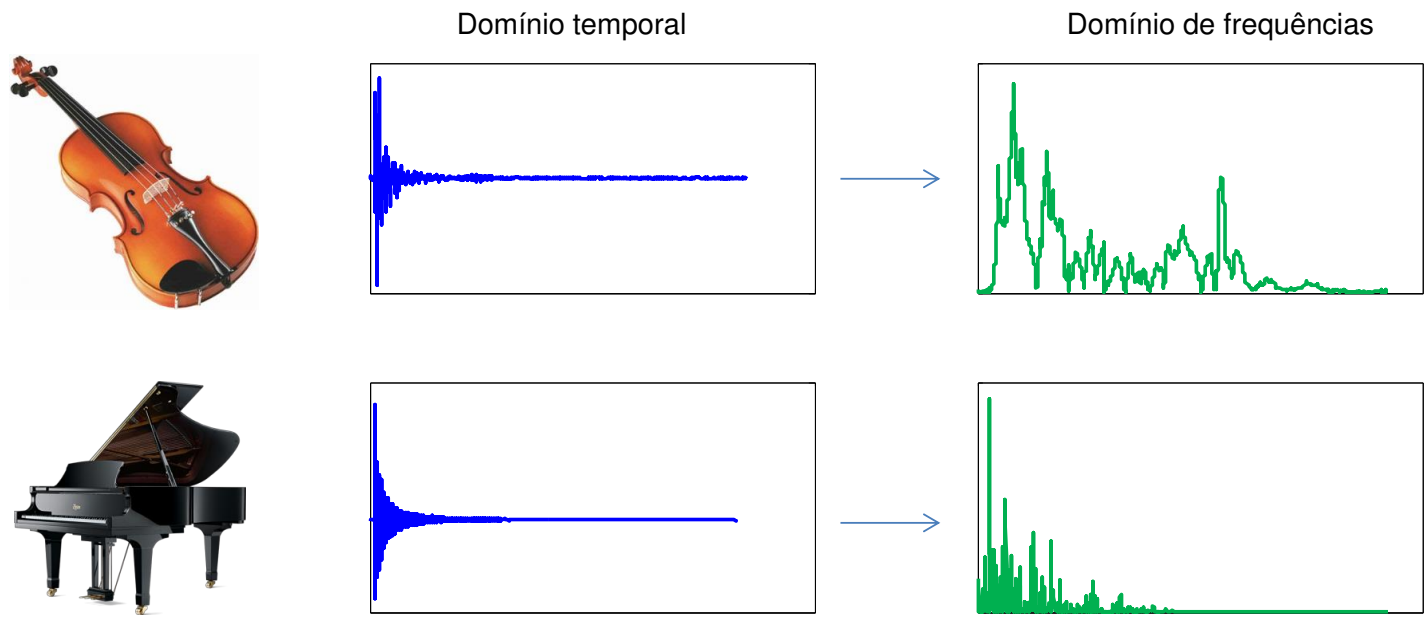

Figura 2.6: Dois sinais, produzidos por um violino e por um piano, similares no domínio temporal. Porém, ao transformá-los para o domínio de frequências, as diferenças entre os sinais são claramente evidenciadas

\subsection{Classificação de Séries Temporais por Extração de Atributos}

A análise de sinais de áudio é uma importante ferramenta em diversas áreas do conhecimento, como reconhecimento de fala e de locutor (Zhen et al., 2000), de gêneros musicais (Costa et al., 2012), de sons subaquáticos (Singer et al., 2009) e diversas aplicações em monitoramento, como do funcionamento de sistema hidráulico (Borges, 2011) e de populações de insetos da classe Orthoptera (Riede, 1998).

Nas tarefas de classificação de áudio geralmente busca-se por atributos com alto poder de predição, que caracterizem bem o sinal analisado. Esses atributos são extraídos em diferentes representações do sinal. Nesta seção, são apresentadas as principais representações utilizadas na literatura, bem como diversos atributos que podem ser extraídos de diferentes representações.

\subsubsection{Representações do Sinal}

Nas últimas décadas, as comunidades de processamento de sinais têm proposto um grande número de atributos para classificação de áudio (Park, 2004; Shirazi e Ghaemmaghami, 2008; Song et al., 2009; Ghoraani e Krishnan, 2011). Esses atributos podem ser utilizados em diversos contextos, como classificação de notas e instrumentos musicais e reconhecimento de fala e de locutor, e podem ser classificados de acordo com a representação do sinal utilizada para extraí-los.

Para identificar características nessas representações, é necessário compreender o que cada uma representa. A seguir, são apresentados os principais conceitos das representações 
que serão utilizadas neste trabalho e descritas algumas das principais características que podem ser utilizadas.

\section{Representação Temporal}

Todo sinal de áudio pode ser representado de diversas maneiras. Sua representação primitiva descreve a amplitude de sua forma de onda em cada momento de tempo. Essa representação é chamada temporal. Na Figura 2.7 são ilustrados os conceitos de amplitude e período em uma senoide. A amplitude é a distância de sua crista ao seu nível médio, no caso o eixo horizontal. Uma senoide é uma onda periódica, pois os valores da amplitude se repetem a cada intervalo fixo de tempo, que define um ciclo. O tempo entre esses ciclos é chamado período. A frequência é uma medida com valor inverso ao período e representa o número de ciclos por unidade de tempo, no caso, segundo. No exemplo apresentado, ocorrem três ciclos em um segundo, caracterizando uma frequência de 3 Hertz (Hz).

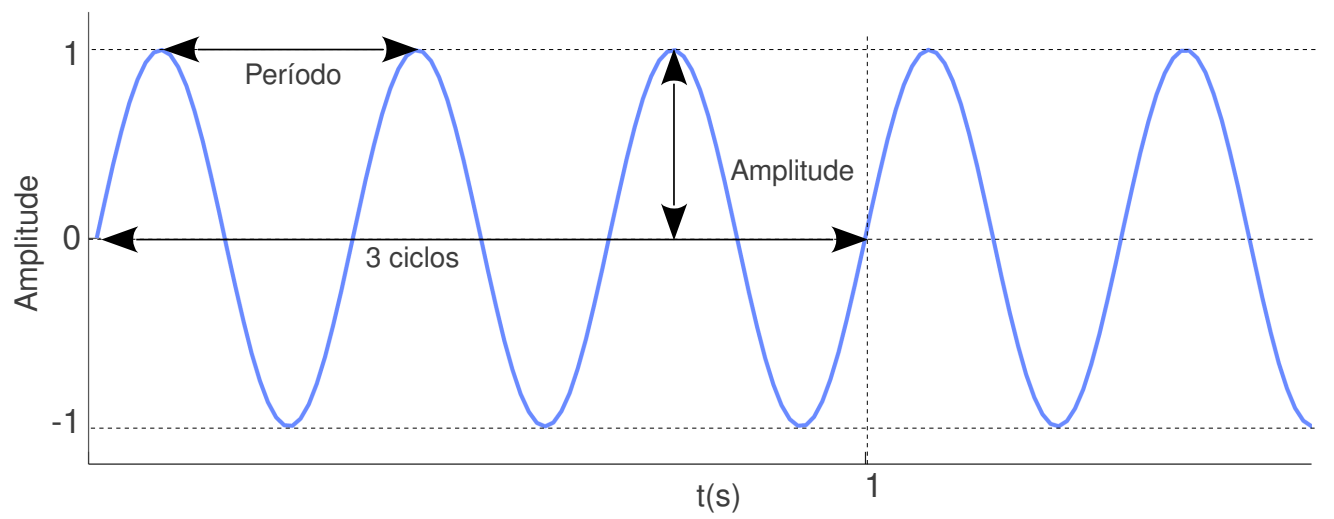

Figura 2.7: Exemplo de forma de onda senoide com amplitude $=1 \mathrm{~dB}$ e frequência $=3 \mathrm{~Hz}$

Uma senoide, assim como qualquer onda periódica, não é comum em sinais obtidos em aplicações práticas, que apresentam sinais mais complexos. Dessa maneira, as caraterísticas presentes no sinal não são tão simples quanto a amplitude e o período definidos como anteriormente. Um exemplo disso é o sinal exibido na Figura 2.8, obtido pela gravação de três segundos de uma única nota emitida por um baixo acústico.

Outra maneira de caracterizar o sinal de áudio é calcular seu envoltório, que estima uma forma para o sinal analisado. O modo mais básico de compor o envoltório é utilizando três características (Park, 2004): ataque, uma medida que representa a maneira com que o som se inicia, ou seja, se o som se inicia rápida ou lentamente; sustentação, que estima o tempo em que o som se sustenta entre ser atingido um pico e ocorrer perda significativa de intensidade; decaimento, que é a última etapa, ocorre entre o fim da sustentação e o fim do sinal. Um problema associado a essas características é que elas definem a forma de poucos 


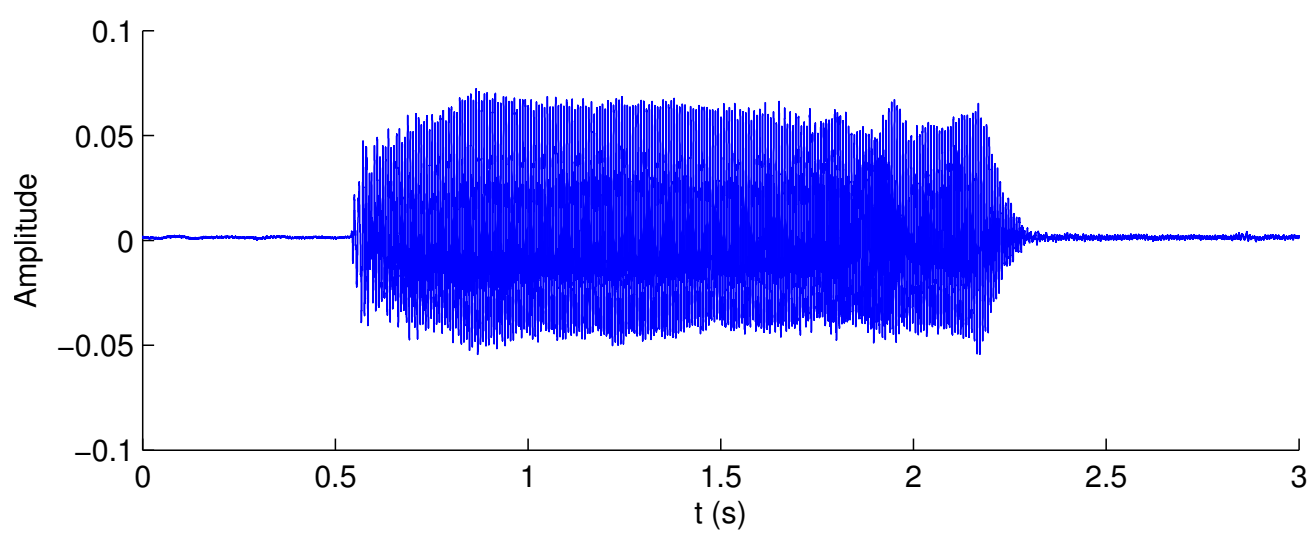

Figura 2.8: Sinal de uma nota emitida por um baixo acústico

tipos de geração de som (Altaf e Juang, 2011; Caetano e Rodet, 2011). Assim, o envoltório pode ser estimado de outras maneiras. Por exemplo, pode-se utilizar janelas deslizantes e atribuir, para cada segmento do sinal, uma medida como a amplitude máxima dentro da janela. Ainda, há trabalhos que buscam estimar o envoltório sonoro com métodos mais robustos. Por exemplo, Caetano e Rodet (2011) calculam o envoltório estimando uma função que coincida aproximadamente com os picos da forma de onda.

\section{Representação Espectral}

Muitas características do sinal podem ser difíceis de estimar na representação temporal. Por isso, é comum na análise de sinais transformar um sinal de modo que possa ser analisado em outra representação. Muitas dessas características envolvem a análise no domínio de frequências.

Para analisar as frequências de um sinal complexo, é necessário decompô-lo em uma soma de formas de onda simples, especificamente da família dos senos e cossenos, e trabalhar com essas componentes. Quando um sinal é periódico, essa decomposição se torna uma série de sinais senoidais e cossenoidais de diferentes amplitudes e frequências, chamada série de Fourier. Formalmente, uma série de Fourier com período $T$ é definida pela Equação 2.4, em que $a_{i}$ e $b_{j}$ são os pesos atribuídos à contribuição de cada componente cossenoidal e senoidal, respectivamente, e $c$ é constante.

$$
f(t)=\sum_{i=0}^{\infty} a_{i} \cos \left(\frac{2 \pi i t}{T}\right)+\sum_{j=0}^{\infty} b_{j} \operatorname{sen}\left(\frac{2 \pi j t}{T}\right)+c
$$

Para exemplificar esses conceitos, é mostrado na Figura 2.9 um gráfico com quatro ondas senoidais e a função resultante da soma delas, em linha pontilhada. O sinal representado por uma linha pontilhada é uma função de quatro diferentes componentes 
senoidais. A componente $2 \operatorname{sen}(2 x)$ tem a mesma frequência do sinal original e, por isso, é denominada oscilação fundamental. As demais componentes possuem frequência múltipla da fundamental e são chamadas componentes harmônicas do sinal.

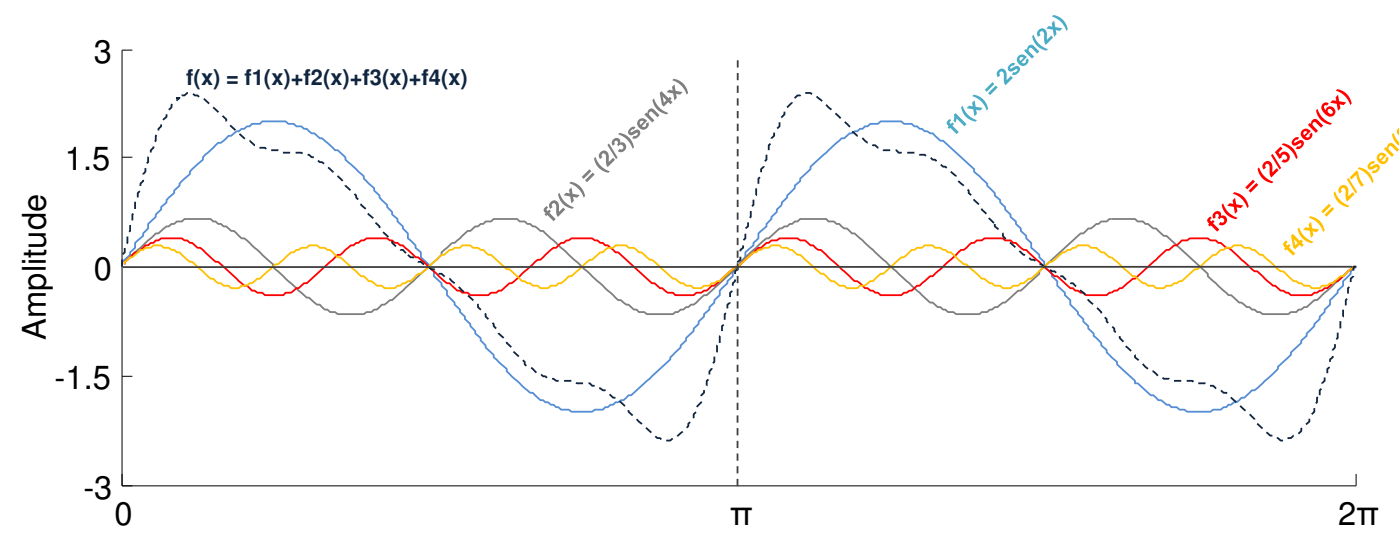

Figura 2.9: Função $f(x)$ resultante da soma de quatro senoides

A representação gráfica que expressa a variação da amplitude dessas componentes com a frequência, ou seja, o gráfico do espectro dessa função, é apresentada na Figura 2.10, em que é possível observar o pico de amplitude na frequência de valor 2, que representa a frequência fundamental. Também é possível observar as amplitudes em frequências múltiplas da fundamental.

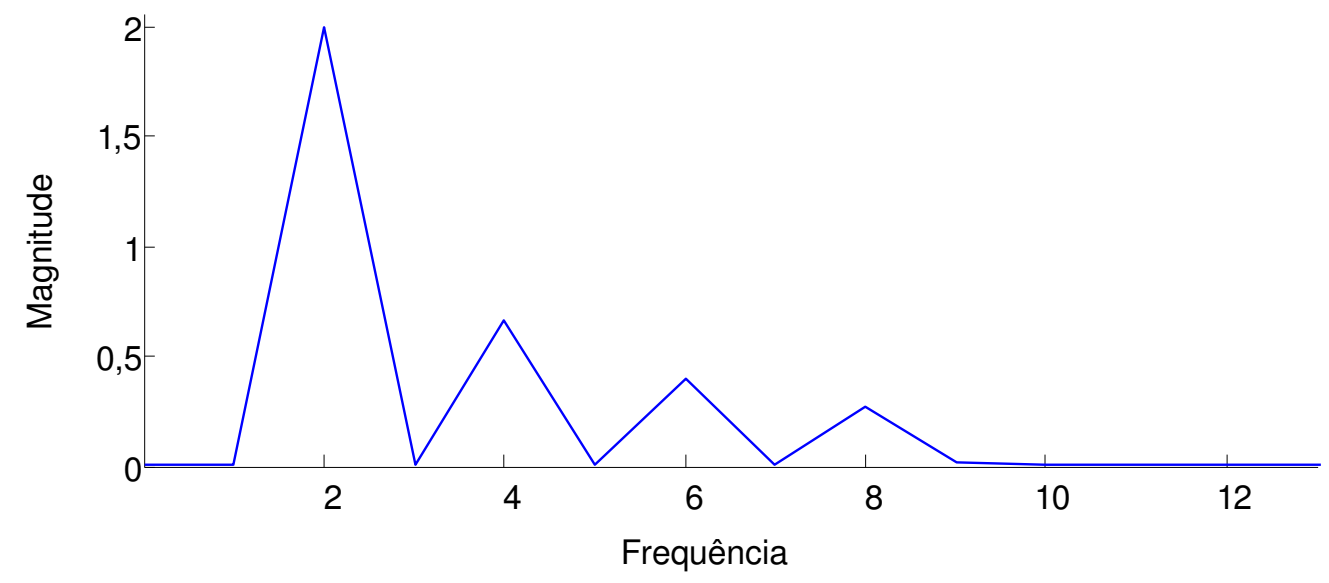

Figura 2.10: Espectro da função periódica composta por quatro componentes senoidais exibida na Figura 2.9

A série de Fourier pode ser estendida para sinais não periódicos. Essa operação é chamada transformada de Fourier, cujo resultado descreve um mapeamento das componentes de frequência que formam um sinal, envolvendo frequência e amplitude de cada harmônica. 
O cálculo da transformada de um sinal em tempo contínuo exige que esse sinal seja gerado por uma equação determinada. Como isso não é possível em diversos contextos, pode-se estimar o espectro utilizando a Transformada Discreta de Fourier (TDF). O método mais amplamente utilizado para se calcular a TDF é a Transformada Rápida de Fourier (Cooley e Tukey, 1965). A aplicação desse algoritmo sobre o sinal da Figura 2.8 gera o gráfico do espectro exibido na Figura 2.11.

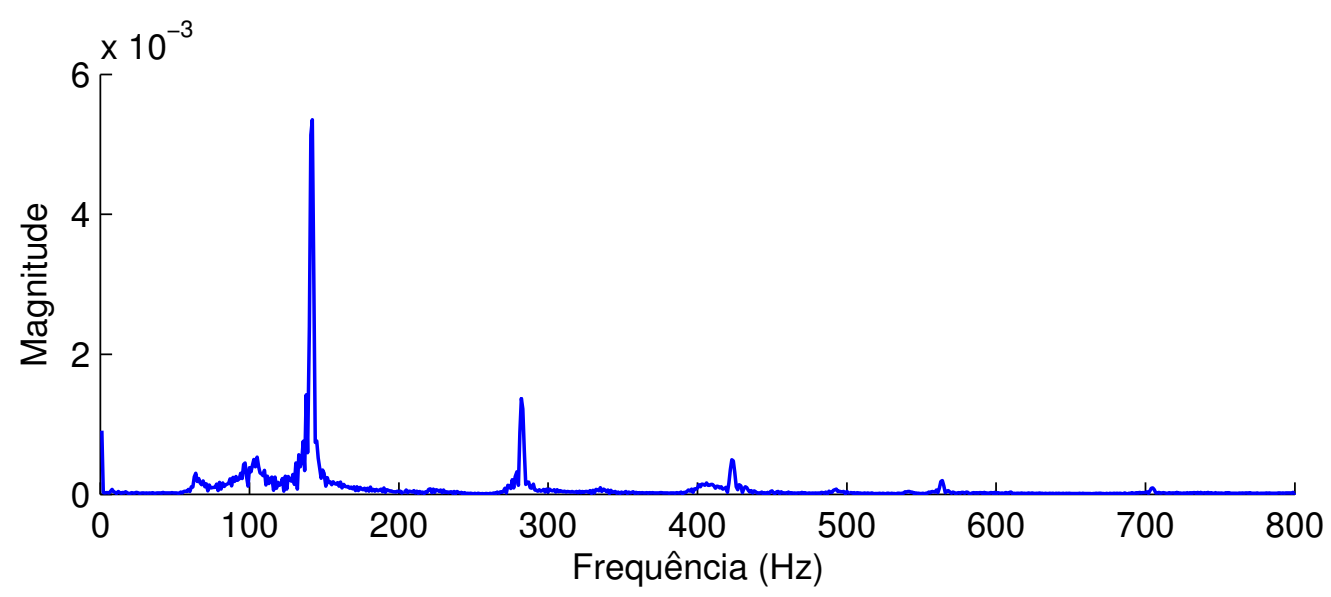

Figura 2.11: Espectro obtido a partir do sinal de uma nota emitida por um baixo acústico, exibido na Figura 2.8

\section{Representação Cepstral}

O cepstro é o resultado da aplicação da transformada de Fourier sobre um espectro na forma logarítmica. Sua variável independente é conhecida como quefrência e, apesar de ser uma medida de tempo, não possui relação direta com a representação temporal do sinal, mas sim ao período, inverso da frequência. Originalmente, o cepstro foi proposto para analisar ecos sísmicos de terremotos e bombas (Bogert et al., 1963). Atualmente, as características cepstrais também são utilizadas no domínio de análise de áudio, alcançando excelentes resultados em domínios como análise de fala e música. Na Figura 2.12, é exibido o cepstro obtido a partir do sinal de baixo acústico exibido na Figura 2.8.

Comumente são utilizadas variações do cepstro como características para a descrição do sinal. Além disso, devido à sua relação direta com as componentes de frequência, o cepstro pode auxiliar a estimar características do domínio de frequência, como a frequência fundamental do sinal. Por exemplo, a frequência fundamental do sinal exibido na Figura 2.8 é de $142 \mathrm{~Hz}$. Esse valor é obtido pelo inverso do valor de quefrência com maior amplitude no cepstro apresentado na Figura 2.12, que é de 0,007s.

Algumas das principais características extraídas em cada representação apresentada serão descritas na próxima seção. 


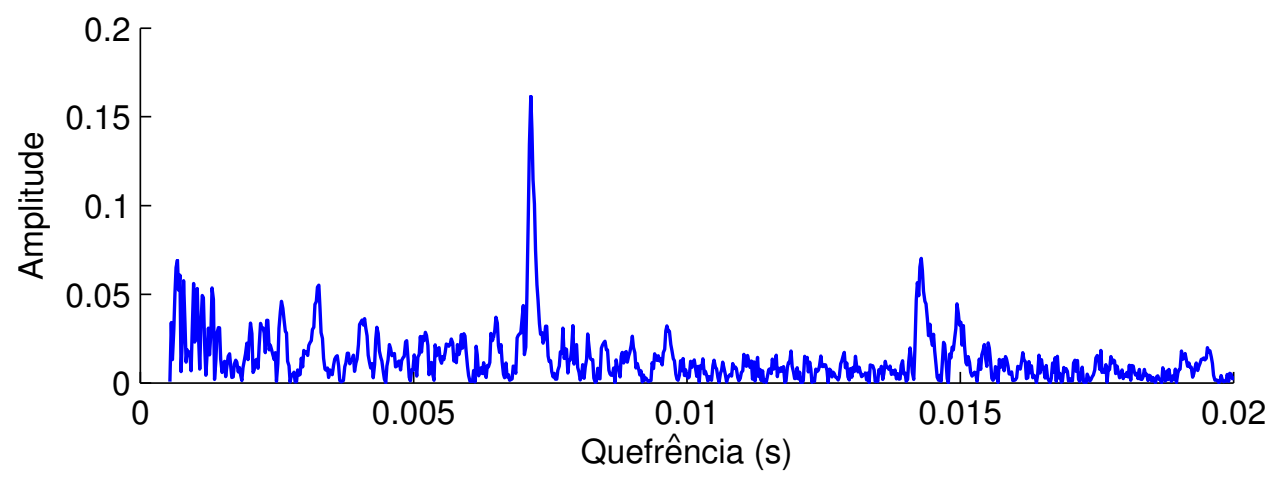

Figura 2.12: Cepstro obtido a partir do sinal de uma nota emitida por um baixo acústico, exibido na Figura 2.8, cujo espectro é exibido na Figura 2.11

\subsubsection{Extração de atributos}

Uma abordagem comumente utilizada na tarefa de classificação de séries temporais é a busca de características intrínsecas às séries que permitam diferenciar umas das outras. Essa abordagem é reconhecidamente efetiva nos casos de classificação de séries temporais extensas e complexas, como sinais de áudio (Geurts, 2001). Essas características podem ser utilizadas como atributos de entrada em sistemas tradicionais de aprendizado de máquina, como árvores de decisão ou modelos probabilísticos. Tais atributos podem ser extraídos em diferentes representações dos sinais.

No restante desta seção, serão descritos atributos que podem ser extraídos das representações temporal, espectral e cepstral, além de atributos baseados em coeficientes de predição linear.

Para realizar a leitura, considere a seguinte notação:

- Uma série temporal é representada por um vetor $x$, de comprimento $n$;

- Cada observação da série temporal é representada por $x_{i}$, sendo que $1 \leq i \leq n$;

- O espectro de frequências do sinal é representado por um vetor $Y$;

- O comprimento do vetor $Y$ é o número de diferentes frequências analisadas, $N$.

\section{Atributos Extraídos da Representação Temporal}

Atributos contidos na representação temporal dos sinais podem ser muito importantes para compreender melhor o comportamento da série no tempo. Quando analisamos séries temporais com muitas observações, podemos enfrentar diversos problemas, tais como a maldição da dimensionalidade (Beyer et al., 1999). Outro problema encontrado tem 
relação com o alinhamento da série. Em arquivos de áudio, por exemplo, pequenos deslocamentos no início do sinal podem prejudicar gravemente a consulta por similaridade.

A fim de contornar esses problemas, é possível utilizar atributos estimados na representação temporal. Por exemplo, em sinais simples e periódicos podem ser utilizadas as características que descrevem a onda fisicamente, como exibido na Seção 2.2.1. Porém, essas características não são evidentes em sinais complexos. Para diferenciar sinais nessa representação, são utilizadas estratégias para estimar características desse tipo de sinal.

Provavelmente, o atributo mais simples que pode ser extraído da representação temporal é a duração do sinal. Essa informação pode ser importante em diversos tipos de sinais de áudio. Por exemplo, a duração de uma nota emitida por um saxofone provavelmente é mais longa do que a emitida por um violino utilizando a técnica pizzicato, ou seja, pinçando as cordas com os dedos. A duração do sinal, em segundos, é calculada pela Equação 2.5 .

$$
\text { Duração }=\frac{n}{\text { taxa amostragem }}
$$

Diversos atributos temporais provêm da tentativa de aproximar as características primitivas para descrever uma onda, como amplitude e período. Por exemplo, a amplitude pode ser estimada pela magnitude média do sinal, descrita pela Equação 2.6.

$$
\operatorname{Mag}_{\mu}=\frac{1}{n} \sum_{i=1}^{n}\left|x_{i}\right|
$$

O valor quadrático médio, em inglês root mean square (RMS), também é muito utilizado como medida de magnitude do sinal. O RMS é definido pela Equação 2.7.

$$
R M S=\sqrt{\frac{1}{n} \sum_{i=1}^{n} x_{i}^{2}}
$$

Uma medida alternativa, ainda relacionada à amplitude, é obtida pelo cálculo do RMS, sem a raiz quadrada. Essa medida, conhecida como short-time energy (STE), é descrita pela Equação 2.8 .

$$
S T E=\frac{1}{n} \sum_{i=1}^{n} x_{i}^{2}
$$

Outra maneira de estimar a amplitude do sinal é dada pelo intervalo, a diferença entre os valores máximo e mínimo da amplitude do sinal, descrito na Equação 2.9. 


$$
I t v=\max _{1 \leq i \leq n}\left(x_{i}\right)-\min _{1 \leq i \leq n}\left(x_{i}\right)
$$

A concentração da energia do sinal no tempo também pode fornecer importantes informações sobre ele. O centroide, definido pela Equação 2.10, define o centro de massa do sinal, fornecendo um valor que estima a distribuição da energia no tempo.

$$
C T=\frac{\sum_{i=1}^{n} i x_{i}}{\sum_{i=1}^{n} x_{i}}
$$

O período (ou o comprimento de onda, distância entre dois vales ou cristas da onda) pode ser associado à taxa de cruzamento em zero, em inglês zero-crossing rate (ZCR). Essa medida, definida pela Equação 2.11, também pode dar estimativas do nível de ruído do sinal. Quanto maior a ZCR, maior o nível de ruído.

$$
\begin{gathered}
Z C R=\frac{1}{n-1} \sum_{i=2}^{n}\left|S\left(x_{i}\right)-S\left(x_{i-1}\right)\right| \\
S\left(x_{i}\right)=\left\{\begin{array}{l}
1 \text { se } x_{i} \geq 0 \\
0, \text { caso contrário }
\end{array}\right.
\end{gathered}
$$

A medida ZCR, por vezes, é interpretada como uma estimativa da complexidade do sinal. Uma maneira alternativa para calcular a complexidade do sinal, é medindo seu nível de variação no tempo. Intuitivamente, a complexidade estimada deve possuir maior valor quando há muitos picos e vales no sinal e baixo valor quando o sinal é mais "comportado". Na Equação 2.12, é definida uma medida de complexidade estimada.

$$
C E=\sqrt{\sum_{i=1}^{n-1}\left(x_{i}-x_{i+1}\right)^{2}}
$$

Medidas estatísticas também podem ser utilizadas sobre o sinal em sua forma temporal. Dois exemplos disso são a variância e o desvio padrão, definidos pelas Equações 2.13 e 2.14, respectivamente. O valor $M a g_{\mu}$ é dado pela magnitude média, definida na Equação 2.6.

$$
\begin{gathered}
\text { Var }=\frac{1}{n} \sum_{i=1}^{n-1}\left(x_{i}-M a g_{\mu}\right)^{2} \\
D P=\sqrt{\frac{1}{n} \sum_{i=1}^{n-1}\left(x_{i}-M a g_{\mu}\right)^{2}}=\sqrt{V a r}
\end{gathered}
$$


Por fim, as medidas de obliquidade, Equação 2.15, e curtose, Equação 2.16, podem ser úteis para estimar o formato do sinal analisado. Mais especificamente, a obliquidade é uma medida de simetria, sendo que valores próximos a 0 indicam simetria, valores negativos indicam maior concentração no lado direito e valores positivos indicam maior concentração no lado esquerdo do sinal. A curtose, por sua vez, mede o achatamento da distribuição em relação ao pico de uma distribuição normal. Valores pequenos de curtose indicam uma distribuição mais achatada. Ambas as medidas são comumente utilizadas como descritores de histogramas, mas podem ser utilizadas como atributos de séries temporais.

$$
\begin{aligned}
O b l & =\frac{\sum_{i=1}^{n-1}\left(\left|x_{i}\right|-M a g_{\mu}\right)^{3}}{(n-1) D P^{3}} \\
C u r t & =\frac{\sum_{i=1}^{n-1}\left(\left|x_{i}\right|-M a g_{\mu}\right)^{4}}{(n-1) D P^{4}}
\end{aligned}
$$

\section{Atributos Extraídos da Representação Espectral}

O espectro do sinal possui informações importantes para definir o som. No domínio de música, a altura (ou pitch), representada pela frequência fundamental, representa a nota musical proferida. Na classificação de insetos alados, tanto por sensores ópticos quanto gravações acústicas, essa característica representa a frequência das batidas da asas do inseto.

A frequência fundamental $\left(F_{0}\right)$ do sinal pode ser obtida de maneira simples, apenas encontrando-se a frequência de magnitude máxima no espectro. Essa abordagem é definida de modo formal na Equação 2.17.

$$
F_{0}=\arg \max _{\mathrm{i}}\left(Y_{i}\right)
$$

Essa abordagem, entretanto, não é muito eficaz. Algumas perturbações periódicas podem resultar em picos no espectro de frequência que não possuem significado interessante ao sinal. Por exemplo, no contexto de sinais captados opticamente, a presença de uma lâmpada fluorescente no ambiente pode causar um grande pico na frequência em que a lâmpada pisca. É comum que lâmpadas desse tipo tenham uma frequência de $60 \mathrm{~Hz}$, causando variações nas amplitudes nessa frequência e múltiplas dela. Outras abordagens para se extrair essa característica será apresentada na próxima seção.

Como descrito anteriormente, o espectro de um sinal possui uma componente principal, na frequência fundamental. Além disso, possui componentes harmônicas de menores magnitudes com frequências múltiplas à fundamental. Em um sinal periódico, composto por ondas senoidais, essa afirmação é facilmente verificada. Em sinais complexos, essa 
análise pode passar por certas dificuldades. A primeira delas é o fato de que a frequência fundamental exata é muito difícil de ser calculada. Outra dificuldade está relacionada ao fato de que pequenas perturbações podem causar um leve deslocamento das componentes harmônicas. Isso pode ser levado em consideração na extração de atributos. Para isso, é necessário realizar uma etapa a fim de se encontrar as verdadeiras posições das componentes harmônicas no espectro de frequência.

Na Figura 2.13, é exibida uma abordagem simplificada desta operação, proposta por Park (2004). Essa tarefa, chamada análise de harmônicas, busca os picos de magnitude em frequências próximas às harmônicas teóricas. Em outras palavras, o método busca a frequência de maior magnitude em uma área ao redor das frequências múltiplas à fundamental. Os valores encontrados são chamados de harmônicas estimadas.

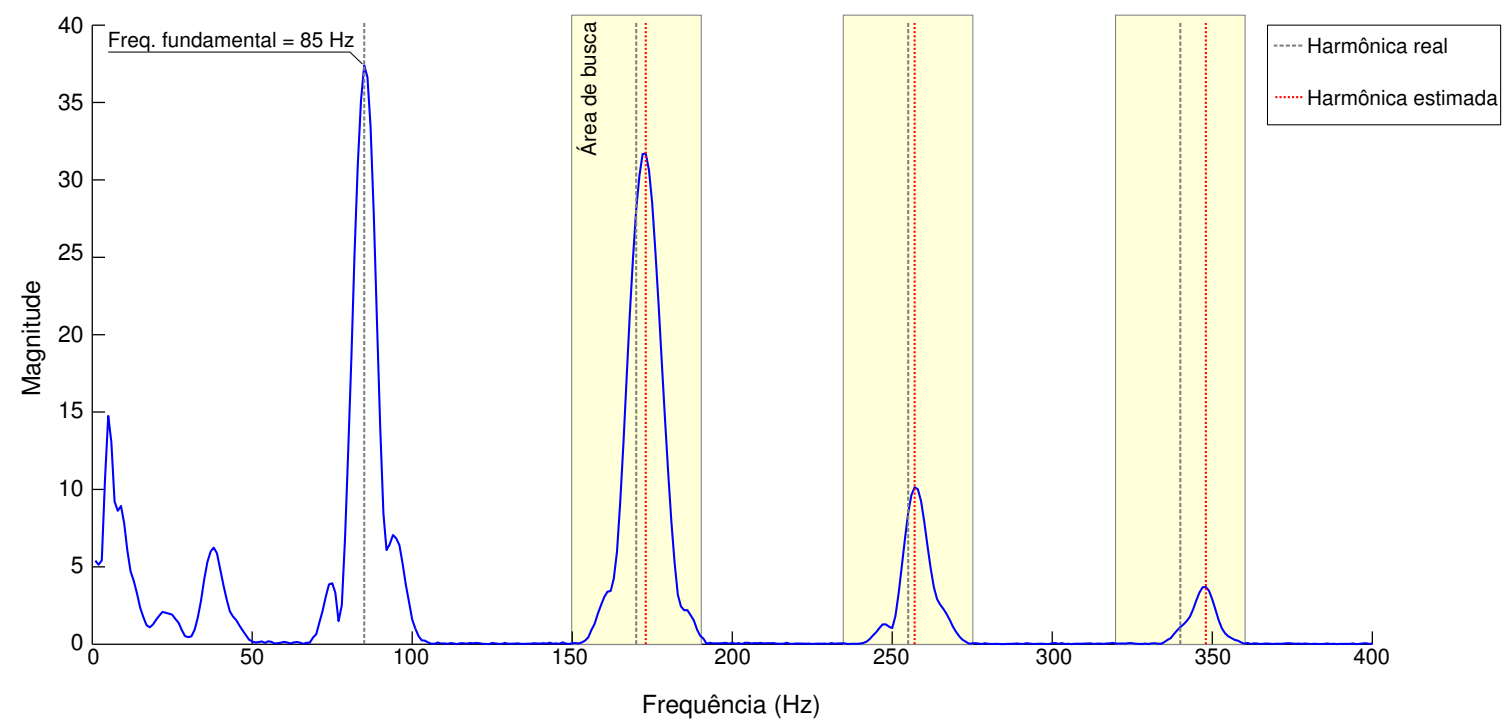

Figura 2.13: Exemplo do procedimento de análise de harmônicas. Nesse exemplo, as frequências relativas às harmônicas teóricas são $170 \mathrm{~Hz}, 255 \mathrm{~Hz}$ e $340 \mathrm{~Hz}$, enquanto as frequências referentes às harmônicas estimadas são $173 \mathrm{~Hz}, 257 \mathrm{~Hz}$ e $348 \mathrm{~Hz}$

A partir da análise de harmônicas, é possível extrair alguns atributos que poderão ser utilizados na classificação dos sinais. Na Equação 2.18, é definida a característica inarmonia, que mede a diferença média das distâncias entre as harmônicas teóricas e as estimadas. Na equação, $F_{i}$ é a posição estimada para a $i$-ésima harmônica e $N_{\text {harm }}$ é o número de componentes analisadas.

$$
\text { Inarm }=\sum_{i=1}^{N_{\text {harm }}} \frac{\left|F_{i}-i F_{0}\right|}{i F_{0}}
$$

Outros atributos provindos da análise de harmônicas são os tristimulus. Esses atributos são equivalentes aos atributos de cores utilizados pela visão humana (Pollard e Jansson, 
1982). A ideia básica de tristimulus na visão humana é que qualquer cor pode ser obtida pela combinação das cores primárias. Em relação à audição humana, qualquer som pode ser distinguido por características relacionadas à frequência fundamental e componentes harmônicas. Essas características são definidas pelas Equações 2.19, 2.20 e 2.21, em que $H_{k}$ se refere à magnitude da $k$-ésima harmônica, sendo a de número 0 a frequência fundamental.

$$
\begin{gathered}
t s 1=\frac{H_{0}}{\sum_{k=0}^{N_{\text {harm }}} H_{k}} \\
t s 2=\frac{\sum_{k=1}^{3} H_{k}-1}{\sum_{k=0}^{N_{\text {harm }}} H_{k}} \\
t s 3=\frac{\sum_{k=4}^{N_{\text {harm }}} H_{k}}{\sum_{k=0}^{N_{\text {harm }}} H_{k}}
\end{gathered}
$$

Além da análise de harmônicas, explorar a variação do espectro ao longo das frequências também pode proporcionar informações úteis para a análise de sinais de áudio. Por exemplo, a irregularidade espectral (Krimphoff et al., 1994) (ou suavidade espectral (McAdams et al., 1999)) revela a variabilidade das frequências vizinhas no espectro, analisando a diferença entre as magnitudes das frequências corrente, anterior e próxima à que se está analisando. Formalmente, a irregularidade espectral é definida pela Equação 2.22.

$$
I E=\sum_{i=2}^{N-1}\left(20 \log _{10}\left(Y_{i}\right) \frac{20 \log _{10}\left(Y_{i-1}\right)+20 \log _{10}\left(Y_{i}\right)+20 \log _{10}\left(Y_{i+1}\right)}{3}\right)
$$

Uma modificação da Equação 2.22 também pode ser utilizada como estimativa da variabilidade entre frequências vizinhas. Essa medida, aqui chamada de irregularidade espectral modificada, é descrita na Equação 2.23 (Park, 2004).

$$
I E_{\text {modif }}=\frac{\sum_{i=2}^{N}\left(Y_{i}-Y_{i-1}\right)^{2}}{\sum_{i=2}^{N}\left(Y_{i}\right)^{2}}
$$

Outra medida para estimar a variação do espectro é conhecida como fluxo espectral. Nela, é estimado quão rápido o valor de magnitude das componentes de frequência varia. O fluxo espectral é definido pela Equação 2.24. O valor de $q$ pode ser qualquer valor inteiro. Comumente é utilizado o valor 2 (Wang et al., 2012).

$$
\text { Fluxo }=\left[\sum_{i=1}^{N-1}\left(\left|Y_{i}-Y_{i+1}\right|\right)^{q}\right]^{1 / q}
$$


Outras características espectrais do sinal podem ser obtidas por equações semelhantes às utilizadas para se extrair atributos da representação temporal. Por exemplo, o centroide também é uma medida comumente utilizada no domínio espectral. Essa medida representa o centro de massa em relação à concentração de energia das componentes de frequência do sinal. Intuitivamente, se há componentes com grandes magnitudes em frequências de baixo valor, o centroide deverá possuir um valor pequeno. Caso a energia do sinal não se concentre em valores de baixa frequência, o valor do centroide será alto. Alguns exemplos disso são os casos do sinal possuir a frequência fundamental em um valor alto ou as amplitudes serem igualmente distribuídas na faixa de frequências analisada. O centroide espectral é definido pela Equação 2.25.

$$
C E=\frac{\sum_{i=1}^{N} i Y_{i}}{\sum_{i=1}^{N} Y_{i}}
$$

A equação apresentada é muito semelhante à equação que define o centroide temporal. De fato, isso acontece com diversos atributos. Todas as medidas estatísticas e relacionadas à forma utilizadas na representação temporal, podem ser facilmente adaptadas para serem utilizadas na representação de frequências. A variância (Equação 2.13), o desvio padrão (Equação 2.14), a curtose (Equação 2.16) e a obliquidade (Equação 2.15) são extraídas dessa representação com as mesmas equações apresentadas anteriormente, trocando-se a série temporal $x$ pelo espectro de frequência $Y$. O mesmo acontece com outras medidas, como a magnitude média (Equação 2.6) e a energia (Equação 2.8).

Assim como o centroide, há outra medida relacionada à concentração das magnitudes nas faixas de frequência. Essa característica, intitulada roll-off, é definida pela Equação 2.26. O valor dessa medida determina a frequência em que a energia do espectro alcança $85 \%$ do seu total. Assim, quanto mais a energia se concentra nas baixas frequências, menor o valor do roll-off.

$$
\text { RollOff }=R, \text { tal que } \sum_{i=1}^{R} Y_{i}=0,85 \sum_{i=1}^{N} Y_{i}
$$

A forma do espectro também pode ser estimada por uma medida de achatamento, conforme descrito na Equação 2.27. Essa medida é definida pela razão da média geométrica $(\mathrm{Mg})$ pela média aritmética $(\mathrm{Ma})$ dos valores de magnitude do espectro. Valores próximos de 0 indicam sinais aproximadamente periódicos, senoidais.

$$
A c h=10 \log _{10}\left(\frac{M g}{M a}\right)=10 \log _{10}\left(\frac{\left(\prod_{i=1}^{N} Y_{i}\right)^{\frac{1}{N}}}{\frac{1}{N} \sum_{i=1}^{N} Y_{i}}\right)
$$




\section{Atributos Extraídos da Representação Cepstral}

Basicamente, os atributos utilizados nesta representação são os coeficientes cepstrais. Para melhor aproveitamento desses coeficientes, é comum a utilização de uma escala acusticamente definida, criada a partir de um estudo realizado por Stevens et al. (1937), que relacionou as frequências físicas com as frequências percebidas pelo ouvido humano. Essa escala, intitulada mel, é utilizada para se extrair os chamados coeficientes mel-cepstrais (em inglês mel-frequency cepstral coefficients - MFCC), utilizados em diversos domínios de aplicação, como reconhecimento de fala e de locutor (Zhen et al., 2000) e classificação de instrumentos musicais (Terasawa et al., 2005). Basicamente, para calcular tais coeficientes, tomam-se as magnitudes das componentes de frequência utilizando a escala mel e aplica-se a Transformada Discreta do Cosseno - transformada que utiliza apenas ondas cossenoidais como componentes, muito utilizada para compressão de dados - sobre o logaritmo desses valores. Os MFCC são as amplitudes do cepstro resultante dessa operação. A Equação 2.28 define a escala para a conversão de frequência $(f)$ em mel $(m)$.

$$
m=2595 \log _{10}\left(1+\frac{f}{700}\right)
$$

Em algumas aplicações, a suposição de que uma escala baseada no sistema auditório humano é, de fato, a mais adequada pode ser errônea. Por isso, outras escalas podem ser utilizadas. Um exemplo é a escala logarítmica. Também é possível realizar a mesma operação sem utilizar qualquer transformação de escala.

Além dos coeficientes cepstrais, a representação cepstral pode ser utilizada para se estimar a frequência fundamental (Noll, 1967). Isso ocorre pelo fato de que, informalmente, o cepstro pode representar todas as componentes harmônicas do sinal em um único valor. Assim, o ponto com maior amplitude no cepstro representa o período relacionado à frequência fundamental do sinal. Na Figura 2.14, é apresentado um exemplo de como extrair tal característica no domínio cepstral. Nesse caso, o período encontrado foi de 0,001563s. Portanto, a frequência é de $1 / 0,001563=639,79 \mathrm{~Hz}$.

\section{Atributos de Predição Linear}

Predição linear é uma importante ferramenta em diversas áreas e é amplamente utilizada em aplicações de fala, como reconhecimento, compressão e modelagem. A ideia por trás da predição linear é, basicamente, representar um sinal por uma combinação linear de valores anteriormente observados. 

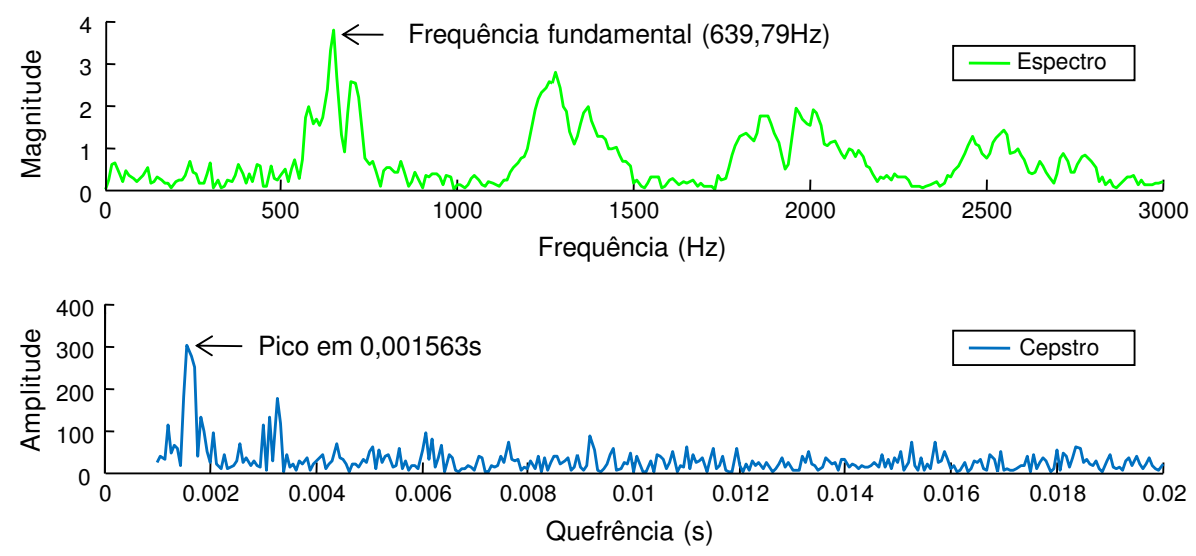

Figura 2.14: Exemplo do espectro (acima) e cesptro (abaixo) de um sinal, indicando o pico de maior amplitude no cepstro, representando o período relacionado à frequência fundamental

Um sinal pode ser descrito segundo a Equação 2.29, em que $k$ é o índice temporal e $L$ é o número de coeficientes de predição linear (em inglês, linear predictive coding coefficients - LPC) a ser utilizado. Os coeficientes $a_{l}$ são computados de modo a minimizar o erro de predição $E_{k}=\hat{x}_{k}-x_{k}$, por meio de um método de covariância ou de auto-correlação.

$$
\hat{x}_{k}=\sum_{l=1}^{L} a_{l} x_{k-l}
$$

Em uma transmissão de dados, é necessário apenas enviar os coeficientes $a_{l}$ e o erro de predição $E_{k}$, de forma que o volume de dados enviado é menor do que se fosse enviado o sinal completo. Para isso, o sinal é comprimido por meio de um filtro de análise, utilizandose uma função de transmissão que tenta suprimir frequências de maior magnitude. Para receber esse sinal, um filtro de recepção utiliza a função inversa da função de transmissão, voltando a amplificar as frequências suprimidas (Benesty et al., 2008).

A Equação 2.29 pode ser reescrita no domínio de frequência por meio de uma transformada- $z$ (Oppenheim et al., 1989). Desse modo, um curto segmento de sinal se presume ser gerado como a saída de um filtro $H(z)=1 / A(z)$, em que $A(z)$ é o inverso do filtro, conforme exibido na Equação 2.30.

$$
H(z)=\frac{1}{A(z)}=\frac{1}{1-\sum_{i=1}^{p} a_{i} z^{-i}}
$$

As Line Spectral Frequencies (LSF), introduzidas por Itakura (1975a), são um modo alternativo de representar os LPC. Para calcular esses coeficientes, o filtro polinomial inverso é decomposto em dois polinômios $P(z)$ e $Q(z)$. Esses polinômios são descritos 
na Equação 2.31, em que $P(z)$ é um polinômio simétrico e $Q(z)$ é um polinômio antisimétrico. As raízes de $P(z)$ e $Q(z)$ determinam os coeficientes LSF.

$$
P(z)=A(z)+z^{p+1} A\left(z^{-1}\right) \text { e } Q(z)=A(z)-z^{p+1} A\left(z^{-1}\right)
$$

As LSF formam um conjunto de características adequadas para as tarefas de quantização e interpolação (Paliwal e Kleijn, 1995). Assim, podem representar o sinal analisado mapeando-o em um pequeno número de coeficientes, melhor do que as outras representações de predição linear, como os LPC.

\subsubsection{Classificação de Sinais de Áudio de Curta Duração}

O principal interesse deste trabalho é a classificação de insetos utilizando os sinais coletados por sensores ópticos. Esses sinais são curtos, geralmente com duração de poucos décimos de segundo, e simples, não contendo transições importantes durante a passagem de um inseto pelo sensor. Por esse motivo, foi realizada uma revisão bibliográfica sobre a classificação de sinais com características semelhantes.

Os trabalhos encontrados utilizam diferentes tipos de produção de áudio. Assim, nesta seção serão abordados trabalhos em três domínios: música, com foco na classificação de instrumentos musicais; fala, especificamente na tarefa de reconhecimento de vogais; e reconhecimento de espécies animais por gravação de áudio. Em todos eles, é comum a utilização de atributos extraídos nas representações descritas neste capítulo.

\section{Classificação de Notas e Instrumentos Musicais}

O reconhecimento de notas e instrumentos musicais é uma ferramenta importante em diversas aplicações, tais como a classificação de gêneros musicais e a recuperação de informação em vídeos, além de servir de base para aulas de música (Deng et al., 2008).

A classificação de notas musicais é um problema bem fundamentado, uma vez que é sabido que uma nota musical é representada por uma única grandeza física, o pitch, ou altura do som. Dessa maneira, a identificação de notas depende apenas da estimação dessa característica, relacionada à frequência fundamental do sinal.

$\mathrm{Na}$ classificação de instrumentos musicais, entretanto, diferentes instrumentos podem gerar uma mesma nota, mas com características distintas que fazem com que o ouvido humano facilmente diferencie, por exemplo, uma nota gerada por um instrumento de corda de uma mesma nota gerada por um instrumento de sopro. Uma importante característica do som, que pode ser utilizada para diferenciar tipos de produção distintos, é chamada timbre. Entretanto, essa característica não pode ser definida por uma única grandeza 
física (Plomp, 1970). Por isso, há décadas são produzidos trabalhos que procuram estimar o timbre por meio da associação de diferentes grandezas físicas, comumente com objetivo de classificar instrumentos musicais.

Em um dos primeiros e mais relevantes trabalhos que buscam estimar o timbre por meio de características encontradas no sinal, Grey (1975) realizou um mapeamento do timbre de dezesseis instrumentos musicais de acordo com sua similaridade. Posteriormente, Grey (1977) sugeriu que a multidimensionalidade do timbre se deve à possibilidade de descrevêlo por atributos dos domínios temporal e espectral.

Agostini et al. (2003) propuseram a utilização de características do espectro de frequência como atributos para a classificação do timbre. Os autores relatam que os atributos mais relevantes de seu estudo foram a inarmonia, o centroide espectral e a frequência fundamental do sinal. Na mesma linha, Park (2004) apresentou, em sua tese de Doutorado, dezenas de atributos para caracterizar o timbre, também presentes nos domínios temporal e espectral ou baseados em coeficientes de predição linear.

Existem, também, trabalhos que buscam classificar instrumentos musicais utilizando atributos extraídos do domínio cepstral. Por exemplo, Poli e Prandoni (1997) associam os coeficientes mel-cepstrais à estimação do timbre. Suas aplicações incluem reconhecimento de instrumentos musicais e timbres vocais. Em um trabalho mais recente, Terasawa et al. (2005) demonstram experimentalmente que o timbre pode ser bem representado por esses coeficientes. Além disso, há trabalhos que utilizam coeficientes cepstrais na classificação de instrumentos musicais, mas sem associá-los explicitamente ao timbre (Eronen e Klapuri, 2000; Wicaksana et al., 2006; Nielsen et al., 2007).

\section{Classificação de Vogais}

O reconhecimento de fala e o reconhecimento de locutor são assuntos recorrentes na pesquisa científica, principalmente pelo número de aplicações em que essas tarefas podem ser utilizadas. Uma importante etapa para o reconhecimento da fala é o reconhecimento de vogais, uma vez que elas são o núcleo de formação de uma sílaba. As vogais são sons produzidos pela abertura total do trato vocal, gerando os sons com maior intensidade entre todos os fonemas (Callou e Leite, 2003).

Uma maneira de estudar a classificação de vogais é utilizando conjuntos de gravações de áudio de diferentes sílabas, de forma que possuam uma estrutura semelhante, mas sejam formadas por sons vocálicos distintos. Por exemplo, a base de vogais da Universidade do Texas em Dallas (Assmann et al., 2008) é um conjunto de arquivos de áudio distribuídos entre doze sílabas distintas da língua inglesa, exibidas na Tabela 2.2. É possível notar 
que todas as sílabas são iniciadas e terminadas por sons consonantais semelhantes, sendo diferenciadas apenas pelo som vocálico.

Tabela 2.2: Vogais presentes na base de vogais da Universidade do Texas em Dallas

\begin{tabular}{|c|c|}
\hline Som vocálico & Palavra utilizada \\
\hline $\mathrm{i}$ & heed \\
\hline $\mathrm{I}$ & hid \\
\hline $\mathrm{e}$ & hayed \\
\hline$\varepsilon$ & head \\
\hline$x$ & had \\
\hline$\Lambda$ & hud \\
\hline$\partial$ & hawed \\
\hline $\mathrm{a}$ & hod \\
\hline$\partial$ & herd \\
\hline $\mathrm{o}$ & hoed \\
\hline$\mho$ & hood \\
\hline $\mathrm{u}$ & who'd \\
\hline
\end{tabular}

Na descrição desse conjunto de dados, cada arquivo de áudio é associado à duração do sinal e a uma estimativa das principais frequências que o compõem, conhecidas como formantes. Alguns trabalhos que utilizam essa base, simplesmente baseiam seu estudo nesses atributos. Por exemplo, Papa et al. (2010) demonstraram que, utilizando esses atributos, alguns classificadores, como máquinas de vetores de suporte e floresta de caminhos ótimos, podem alcançar resultados acima de $90 \%$ de acurácia. De fato, os formantes são atributos comumente utilizados com sucesso nessa tarefa (Lindblom e Studdert-Kennedy, 1967; Hillenbrand et al., 1995; Swanepoel et al., 2012).

Além de características no domínio de frequências, também há trabalhos que realizam o reconhecimento de vogais utilizando outras representações. Yazama et al. (2004) utilizaram características de formato da onda no domínio temporal. Os LPC também foram utilizados com sucesso por Thasleema et al. (2007), bem como as LSF, por Paliwal (1989). Por fim, Liu e Fu (2007) realizaram a tarefa utilizando coeficientes mel-cepstrais.

\section{Classificação de Espécies Animais}

Outro domínio que envolve análise de dados acústicos é o estudo de espécies animais por meio dos sons produzidos por elas, área de pesquisa conhecida como bioacústica. Esse tipo de pesquisa pode auxiliar em tarefas como o estudo da biodiversidade de certas regiões e do comportamento espaço-temporal de espécies, além da detecção de pestes (Chesmore, 2004).

As espécies mais estudadas na área de bioacústica provavelmente são os pássaros. Por exemplo, Lopes et al. (2011) utilizaram atributos temporais, espectrais e coeficientes mel-cepstrais para identificar espécies de pássaros brasileiros. Nesse trabalho, os autores 
afirmam que o monitoramento de pássaros é importante pois, além de avaliar a diversidade da fauna e a qualidade de vida dos animais, pode auxiliar na prevenção de colisões entre pássaros e aviões, acidente que causa danos à fauna local e um prejuízo de mais de US\$ 3 milhões só no espaço aéreo brasileiro. O conjunto de dados utilizado nesse trabalho, assim como em muitos trabalhos recentes de análise acústica de pássaros, é um sub-conjunto dos arquivos de áudio disponíveis no website colaborativo Xeno-Canto ${ }^{1}$, no qual pesquisadores de pássaros de diversos países compartilham gravações de espécies realizadas ao redor do mundo.

No caso da classificação de pássaros, muitas vezes os sinais possuem uma duração de vários segundos, com importantes transições entre diferentes segmentos do sinal. Esse fato também é comum em outros domínios da bioacústica. Nesse caso, utilizar técnicas semelhantes às utilizadas em reconhecimento de fala e de locutor, que consideram as variações existentes entre os fonemas pronunciados, pode ser uma estratégia promissora. Por exemplo, Clemins et al. (2005) utilizaram coeficientes mel-cepstrais e Modelos Ocultos de Markov para classificar vocalizações de 6 elefantes africanos, atingindo uma acurácia de $94,3 \%$ para tipo de vocalização (5 classes) e 82,5\% para qual elefante vocalizou cada som, com gravações realizadas em ambiente natural. Posteriormente, Soltis et al. (2009) utilizaram estratégia semelhante para estudar o comportamento afetivo dessa espécie de elefantes, também atingindo bons resultados.

Outras espécies bastante estudadas acusticamente, nas quais os sinais emitidos são bastante curtos, estão nas famílias de morcegos. Parsons e Jones (2000) classificaram 14 espécies de morcegos por meio da análise das frequências e das durações de seus chamados, com médias de cada espécie variando entre 2,12ms e 51,50ms. Utilizando uma rede neural do tipo perceptron multi-camada, o melhor resultado alcançado foi de $87 \%$ de acurácia para todas as espécies. Nesse estudo, foi demonstrado que esse tipo de análise pode separar totalmente algumas espécies dentre as estudadas. Posteriormente, Corcoran (2007) desenvolveu um trabalho de Mestrado em Biologia em que coletou chamados de nove espécies de morcegos e os analisou acusticamente, conseguindo os melhores resultados quando utilizou a estratégia de classificação hierárquica.

\footnotetext{
${ }^{1}$ http://www . xeno-canto.org/
} 



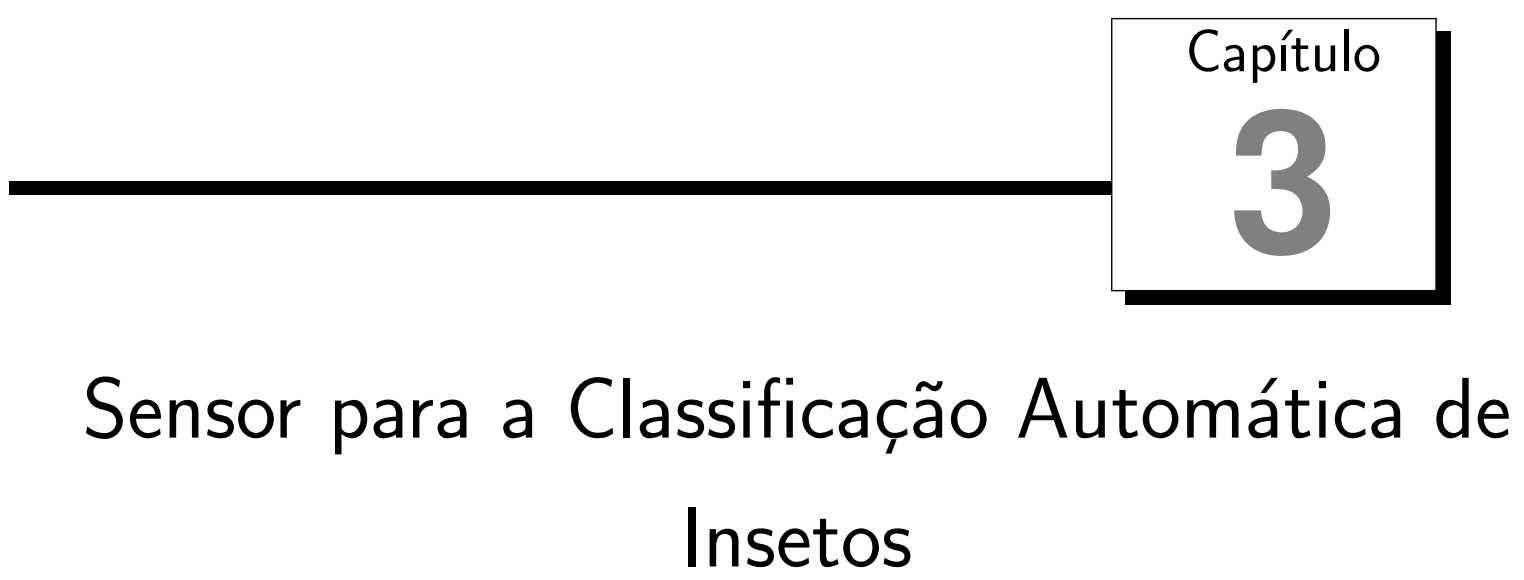

Este trabalho de Mestrado está inserido em um projeto de cooperação internacional que tem como objetivo o desenvolvimento de um sensor óptico para a classificação de insetos. Quando um inseto passa pelo sensor, é gerada uma saída semelhante a um sinal de áudio de curta duração, de tipicamente entre um e três décimos de segundo.

Esse projeto foi iniciado na Universidade da Califórnia, Riverside, com apoio da empresa de controle de pragas ISCA Technologies. O Instituto de Ciências Matemáticas e de Computação é parceiro do projeto desde o início de seu desenvolvimento.

Este capítulo é iniciado com uma motivação para a criação de sensores para a identificação automática de insetos, na Seção 3.1, seguida da apresentação de trabalhos relacionados que buscam maneiras de realizar essa tarefa, na Seção 3.2. Ainda na Seção 3.2, é descrito o funcionamento do sensor em desenvolvimento, bem como os métodos de coleta e pré-processamento dos sinais.

\subsection{Motivação}

Por toda a história da humanidade, os insetos possuem uma íntima relação com o nosso bem-estar, tanto de maneira positiva quanto negativa. Por exemplo, os danos causados por insetos na agricultura e pecuária frequentemente estão na raiz do problema 
chamado insegurança alimentar, referente ao risco de perdas significativas na produção de alimentos (Vreysen e Robinson, 2011). No Brasil, pragas agrícolas são responsáveis pela perda de $7,7 \%$ de toda a produção, totalizando aproximadamente US $\$ 17,7$ bilhões por ano (Oliveira et al., 2014). Em contraste, estima-se que insetos polinizam a maioria das espécies vegetais utilizadas na agricultura, sendo que um terço de todo alimento consumido no mundo é polinizado somente por abelhas (Dixon, 2009). Além disso, muitas espécies têm sido utilizadas como bioindicadores de qualidade ambiental, uma vez que a sua presença/ausência, distribuição e densidade, definem a qualidade do ecossistema, especialmente em relação aos contaminantes do ar, solo e água (Kevan, 1999).

Outro exemplo da relação entre insetos e humanos é o fato de que os insetos são vetores de doenças que matam milhões de pessoas todos os anos e deixam outras dezenas de milhões adoecidas. Estima-se que a dengue, doença transmitida por mosquitos do gênero Aedes, afeta entre 50 e 100 milhões de pessoas a cada ano e é considerada endêmica em mais de 100 países (W.H.O., 2009). A malária, transmitida por mosquitos do gênero Anopheles, atinge cerca de $6 \%$ da população mundial e estima-se que existam mais de 200 milhões de casos por ano e cerca de 7 milhões de mortes causadas pela doença na última década (W.H.O., 2012).

Devido à falta de vacinas e medicamentos específicos e eficazes para o tratamento de várias doenças transmitidas por insetos, é comum combater o problema pela raiz, por meio da pulverização de inseticidas para controlar insetos vetores de tais doenças. Na agricultura, o uso de pesticidas e herbicidas também é uma prática amplamente utilizada no controle de pragas. No entanto, mais de $98 \%$ do inseticida e $95 \%$ do herbicida pulverizados chegam a um destino diferente de sua espécie alvo, incluindo espécies não-alvo, ar, água e solo, reduzindo a biodiversidade, contribuindo para o declínio dos polinizadores e colocando em risco espécies ameaçadas (Miller e Spoolman, 2011).

Por esses e outros motivos, diversos pesquisadores desenvolveram um arsenal de métodos químicos, biológicos, mecânicos e educacionais de controle de insetos (Ishaaya et al., 2012). Porém, para que sejam utilizados de maneira eficaz, tais métodos requerem o conhecimento da distribuição espaço-temporal dos insetos. Sem tal conhecimento, o emprego dessas técnicas torna-se custoso e ineficiente, além de agravar os problemas citados anteriormente.

Atualmente, estudar a distribuição espaço-temporal de insetos é uma tarefa custosa e demorada. Em linhas gerais, contagens de insetos são realizadas por meio de armadilhas, geralmente adesivas, que são recolhidas periodicamente e analisadas por especialistas que identificam e contam manualmente as espécies de insetos coletadas. Além de ser uma abordagem cara em termos de material e tempo dos especialistas, possui um atraso entre os instantes em que a armadilha é instalada e em que é analisada. Mesmo que esse intervalo 
seja de apenas uma semana, o que pode representar mais de meia vida de um inseto adulto, tal atraso pode ser suficiente para que a doença tenha contaminado um grande número de pessoas no momento em que os dados estejam disponíveis aos especialistas (Patnaik et al., 2007). Existe, portanto, uma necessidade de sensores automáticos e precisos, capazes de detectar, classificar e contar insetos de diferentes espécies em tempo real.

Por esse motivo, pesquisadores propuseram maneiras de estudar o comportamento de insetos de maneira automática, geralmente por sinais de áudio. A próxima seção apresenta alguns dos principais trabalhos inseridos nesse contexto.

\subsection{Identificação Automática de Insetos}

A identificação automática de insetos não é uma ideia recente. Em 1945, Kahn et al. (1945) utilizaram um microfone, acrescido de um amplificador de sinais, um filtro passafaixa e um gravador, para registrar e estudar os sons emitidos por mosquitos transmissores de doença, muitas vezes inaudíveis ao ser humano. Foram coletados sons de 4 espécies de mosquito: Anopheles quadrimaculatus, Aedes aegypti, Aedes albopictus e Culex pipiens. Para realizar a coleta foi necessário utilizar um ambiente a prova de ruídos externos e sob condições ideais de temperatura e umidade. Nesse estudo, foram identificados variados sons, que poderiam representar diferentes comportamentos dos insetos. Além disso, os pesquisadores ressaltam que a altura do som (pitch) pode ser uma forma simples de distinguir os machos e fêmeas de cada espécie, uma vez que os sons emitidos por mosquitos machos são mais altos que aqueles emitidos por mosquitos fêmeas, ou seja, possuem uma frequência maior.

Posteriormente, Kahn e Jr (1949) sugeriram que a evolução dos dispositivos eletrônicos de gravação seria tão rápida nos próximos anos, que estudar o comportamento de insetos por meio do som que produzem seria, em pouco tempo, uma tarefa simples e a observação de fenômenos relacionados aos insetos seriam precisas e rápidas. Entretanto, houve pouco avanço em relação à identificação automática de insetos por meio de dispositivos acústicos.

Até os dias de hoje, pesquisadores buscam identificar espécies e comportamentos de insetos por meio da utilização de microfones. As motivações dessas pesquisas costumam se basear na aplicação de novas técnicas de aprendizado de máquina e extração de atributos. Por exemplo, Potamitis et al. (2007) utilizaram uma rede neural probabilística e um modelo de mistura de gaussianas a partir de atributos utilizados no domínio de reconhecimento de locutor para classificar grilos e cigarras a partir de gravações realizadas em laboratório. Em um trabalho mais recente, Le-Qing (2011) também utilizou atributos aplicados na tarefa de reconhecimento de locutor e uma rede neural probabilística para 
classificar diferentes comportamentos de insetos, como vibração de asas, movimento e alimentação de insetos no solo e contatos com madeira e outros materiais, por meio de gravações de áudio com duração entre 3 e 60 segundos.

Esse tipo de abordagem, que utiliza gravação de áudio de insetos, é utilizada em diversos outros trabalhos. Ganchev et al. (2007), por exemplo, analisaram diferentes técnicas de reconhecimento de locutor aplicadas à classificação de 313 espécies de grilos, gafanhotos e cigarras. Nesse trabalho, os pesquisadores utilizaram coeficientes cepstrais (em escala linear) para gerar classificadores baseados em rede neural probabilística, modelo de mistura de gaussianas e modelos ocultos de Markov. Também baseado em trabalhos de reconhecimento de locutor, Chaves et al. (2012) utilizaram MFCC e modelos ocultos de Markov para classificar 26 espécies de gafanhoto.

Todos esses trabalhos utilizaram gravações de insetos realizadas em um ambiente ideal para a gravação. Além disso, as espécies analisadas, em sua maioria, produzem sons bastante evidentes, como o "canto" de grilos e cigarras. Porém, a utilização de microfones para capturar a presença de outros insetos em campo não é trivial. Por exemplo, os sons produzidos por mosquitos possuem uma intensidade baixa. Além disso, microfones são muito sensíveis a interferências externas, como o sons produzidos por carros que transitam próximo ao local de coleta. Dessa maneira, alguns pesquisadores acabam por dedicar esforços para o desenvolvimento de técnicas para melhorar a qualidade o som capturado ou, algumas vezes, desenvolver novos materiais para melhorar a qualidade da captura (Mankin et al., 1996).

Seguindo por outra linha de trabalho, Moore et al. (1986) apresentaram um sensor óptico baseado no fotosensor proposto por Unwin e Ellington (1979). Nesse trabalho, o sensor foi utilizado para registrar digitalmente a variação de luz causada pela passagem de insetos. Utilizando esse aparelho, foi realizada uma análise da frequência das batidas de asas de duas espécies do gênero Aedes, do sexo masculino e feminino. Os autores sugerem que é possível classificar essas espécies utilizando um sistema de reconhecimento de padrões. Para demonstrar isso, Moore (1991) utilizou dados coletados em laboratório de duas espécies do gênero Aedes, separadas por sexo, para treinar uma rede neural artificial, que obteve uma acurácia de $92 \%$ na classificação de insetos em nível de espécie e sexo.

Posteriormente, Moore (1998) propôs um sistema de coleta, ilustrado na Figura 3.1. Basicamente, foi utilizado o sensor óptico proposto anteriormente ligado a um computador com recursos multimídia, equipado com softwares para processar o sinal obtido. Acima do sensor, foi disposta uma jarra plástica transparente, onde foram colocados insetos alados. A fonte de luz utilizada no sistema é uma lâmpada halógena, alocada acima da jarra transparente. Novamente utilizando uma rede neural artificial, Moore e Miller (2002) utilizaram dados coletados em laboratório a fim de demonstrar a viabilidade do sistema 
proposto. Com a melhor configuração encontrada para a rede, a acurácia média entre as cinco espécies analisadas foi de $69 \%$. Os autores relatam que há dois principais motivos para o resultado pouco satisfatório: vários dos sinais não foram gravados durante o voo do inseto, mas em momentos em que ele andava pela câmara de teste (jarra plástica disposta abaixo da fonte de luz) enquanto batia suas asas, e a orientação do voo dos insetos causaram uma diferença significativa na reflexão da luz, o que pode indicar um problema com o sensor proposto.

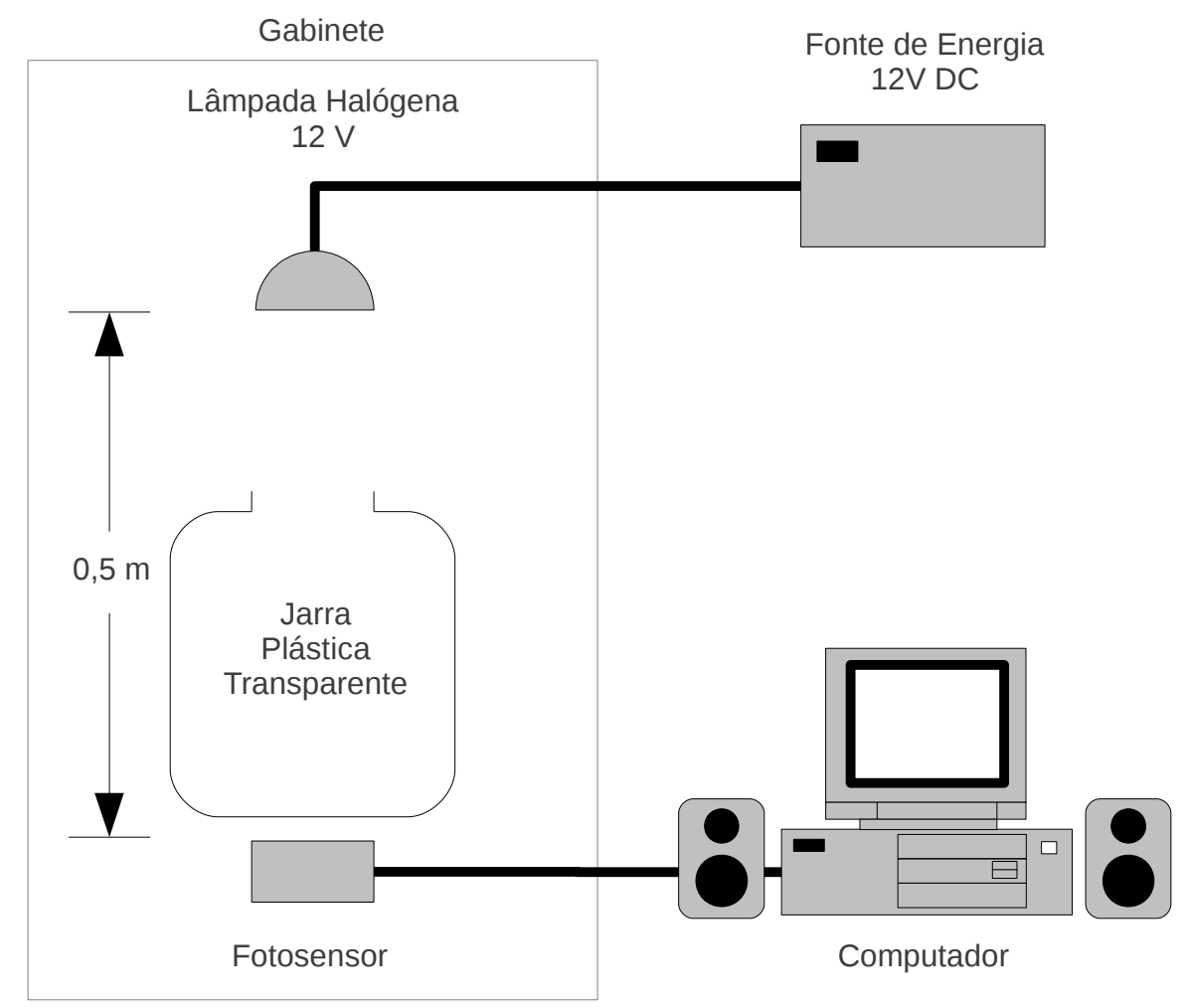

Figura 3.1: Sistema de captura de informações de insetos proposto por Moore (1998)

A principal contribuição desse sensor é o fato de, por ser óptico, não sofrer com interferências externas. Porém, dois fatores são impeditivos para seu uso em campo. O primeiro deles é a necessidade do uso de um computador, equipamento de alto valor comercial, o que pode estimular a prática de roubo. Isso impede sua utilização sem supervisão constante, além de diminuir o poder de disseminação do equipamento. Outro problema é a utilização de uma lâmpada como fonte de luz. Além dos problemas referentes a diferenças no sinal causadas pela orientação de voo, citados pelo próprio autor, o alcance dessa fonte de luz é pequeno, fazendo com que cada sensor cubra apenas uma pequena área.

Na próxima seção, é descrito um sensor óptico de baixo custo, que utiliza uma fonte de luz laser e um arranjo de fototransistores como principais componentes. 


\subsubsection{Descrição do Sensor}

Um sensor para capturar informações de insetos à distância está sendo desenvolvido com o objetivo de ser utilizado como ferramenta para auxiliar no controle ambiental de mosquitos vetores de doenças e pragas agrícolas. Um dos objetivos do desenvolvimento do sensor é sua ampla utilização, principalmente em países afetados por doenças como dengue e malária. Sendo assim, é necessário que o sensor tenha um baixo custo, facilitando sua ampla utilização e desestimulando a prática de roubo. É requerido que o sensor, quando produzido em escala, possua uma custo menor do que US $\$ 10$.

Os principais elementos desse sensor são um feixe de luz laser e um arranjo de fototransistores, como mostrado na Figura 3.2. Quando um inseto cruza esse feixe, ocorre uma variação na luz emitida, gerada pela oclusão parcial da luz ocasionada por seus movimentos, principalmente as batidas de suas asas. Essa variação é armazenada como uma série temporal e deve ser utilizada para contar e classificar os insetos que cruzam o sensor. O objetivo do projeto é construir um sistema que utilize tais séries temporais como entrada e forneça contagens dos insetos separadas por espécie e, possivelmente, sexo, uma vez que somente as fêmeas de mosquitos são vetores de doenças.

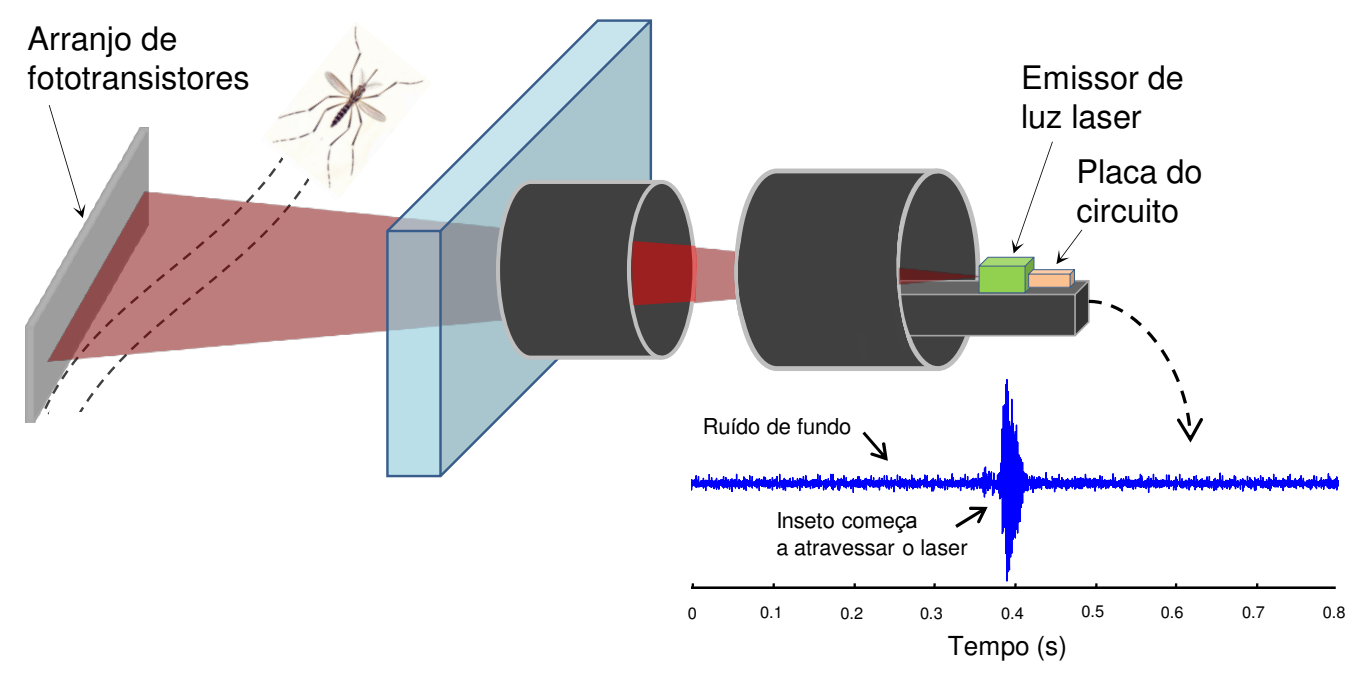

Figura 3.2: Projeto lógico do sensor em desenvolvimento

O sensor utiliza um circuito especialmente projetado para filtrar e amplificar os sinais capturados pelos fototransistores, atualmente gravados como arquivos de áudio. Dessa maneira, é possível utilizar o termo áudio para descrever os sinais capturados pelo sensor, ainda que os dados sejam obtidos opticamente. A distinção não é relevante, uma vez que os sinais soam exatamente como o som dos insetos capturados por microfones, com duas vantagens importantes: a primeira é que a luz laser pode trafegar grandes distâncias sem perda significativa de intensidade e, portanto, o sensor pode cobrir uma área de pelo 
menos algumas dezenas de metros quadrados; a segunda é que o sensor não sofre qualquer interferência externa, como o canto de pássaros e o trânsito de carros e aviões próximo ao local de coleta.

A primeira etapa para o funcionamento do sensor é a fase de coleta e pré-processamento dos dados capturados, apresentada na próxima seção.

\subsubsection{Coleta e Pré-Processamento de Dados}

A coleta foi realizada em laboratório, em condições de temperatura e umidade controladas. As temperaturas durante as coletas variaram de $21^{\circ} \mathrm{C}$ a $23^{\circ} \mathrm{C}$ e a umidade entre $50 \%$ e $70 \%$. Os sinais foram coletados a uma taxa de amostragem de $44100 \mathrm{~Hz}$, sendo posteriormente amostrados para $16000 \mathrm{~Hz}$, a fim de reduzir os requisitos de armazenamento e processamento dos dados. Essa taxa de amostragem é suficiente para caracterizar os sinais de insetos, uma vez que é capaz de representar frequências de até $8000 \mathrm{~Hz}$, sendo que os insetos normalmente apresentam sinais na faixa de $100 \mathrm{~Hz}$ a $1000 \mathrm{~Hz}$.

Os dados coletados pelo sensor são constituídos, em geral, de ruído de fundo com "bips" ocasionais, resultado dos breves cruzamentos do inseto com o laser. Na Figura 3.3, é exibido um exemplo do dado coletado pelo sensor, obtido pela passagem de um mosquito da espécie Aedes aegypti. Note que o sinal gerado pelo inseto possui uma amplitude significativamente maior que a amplitude do ruído de fundo. Dessa maneira, é uma tarefa relativamente simples contar o número de insetos que cruzam o laser, mas classificar os sinais em espécies é uma tarefa bem mais complexa.

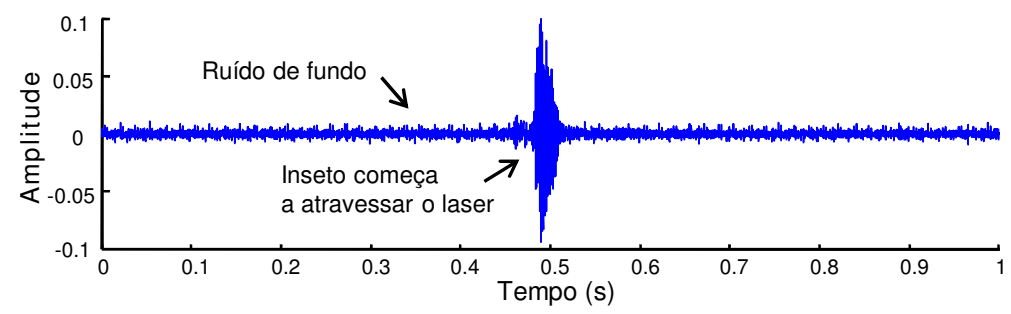

Figura 3.3: Exemplo de sinal gravado pelo sensor, espécie Aedes aegypti

Apesar dos sinais coletados pelo sensor possuírem uma boa relação sinal-ruído, o ruído de fundo é suficiente para contribuir negativamente em várias fases da análise. Primeiro, a presença de ruído pode dificultar a correta identificação da localização dos cruzamentos dos insetos com o sensor. Além disso, ruídos podem prejudicar a análise por similaridade ou, até mesmo, a extração de atributos. Por isso, é aplicado um filtro baseado em subtração espectral, responsável por suprimir certas componentes frequência relacionadas ao ruído (Boll, 1979). Para isso, é utilizada uma janela no início do sinal, constituída apenas por ruído de fundo, como referência. 
Após a aplicação desse filtro, os sinais gerados pelos insetos são segmentados, utilizando um detector de passagem. O detector utiliza uma janela deslizante sobre os dados e calcula as magnitudes das componentes do sinal dentro da janela. Então, é utilizada a magnitude máxima dentro dessa faixa de frequências como um valor de confiança para o detector. Dessa maneira, quanto maior for a magnitude, maior a confiança de que o sinal não é um ruído de fundo. Todos os sinais com magnitude acima de um limiar especificado pelo usuário são considerados um evento gerado por um inseto. A alta razão sinal-ruído dos dados coletados pelo sensor permite ao usuário especificar valores baixos para o limiar, de modo a garantir a identificação de sinais curtos ou de baixa amplitude, sem o risco de falsos positivos. Na Figura 3.4, é ilustrado o funcionamento do detector.

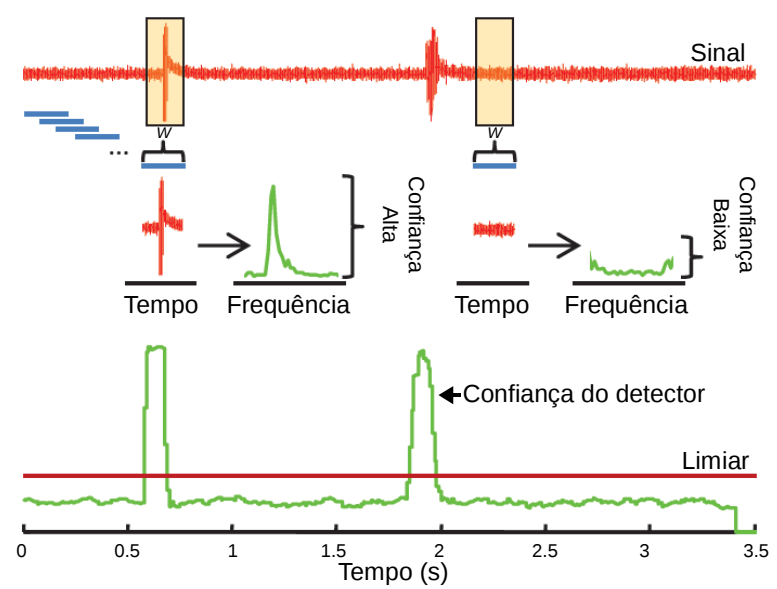

Figura 3.4: Esquema do detector de batidas de asas

O passo final de pré-processamento consiste em extrair segmentos com eventos individuais utilizando o detector. Cada segmento é, então, armazenado como um arquivo de áudio. Os segmentos extraídos são automaticamente rotulados, uma vez que os sinais são coletados separadamente por espécie. A partir dessa coleção de arquivos de áudio, é necessário analisar os sinais, a fim de criar classificadores capazes de identificar as espécies que os geraram.

\subsubsection{Armadilha Inteligente}

Diversas espécies de insetos podem ser prejudiciais à produção de alimentos. Por exemplo, algumas espécies carregam micro-organismos que podem causar doenças em frutas, como o cancro cítrico. Além disso, há espécies que se alimentam de folhas e frutos, prejudicando o desenvolvimento de algumas espécies de frutos e vegetais. Como citado anteriormente, esse problema é atacado em sua raiz, por meio da utilização de herbicidas 
e/ou pesticidas. Entretanto, grande parte do uso desses métodos é desperdiçado, atingindo destinos que não as espécies alvo (Miller e Spoolman, 2011). Esses destinos incluem água, solo, terra e espécies que podem ser benéficas, como abelhas.

O sensor descrito anteriormente é útil, principalmente, em duas tarefas: estimativa da população de insetos em um determinado ambiente e auxílio ao controle de espécies maléficas ao bem-estar do ser humano. No primeiro caso, a aplicação do sensor é direta. No segundo, o sensor deve ser parte complementar de uma ferramenta com devido fim.

Por exemplo, o sensor pode ser acoplado em armadilhas comerciais, utilizadas para capturar insetos em plantações. Na Figura 3.5, é exibida uma armadilha utilizada em lavouras para capturar insetos, fabricada e comercializada pela empresa ISCA Technologies, parceira do projeto desde sua concepção. Essa armadilha é projetada de modo que atraia, principalmente, determinadas espécies de insetos. Por exemplo, o tamanho da entrada da armadilha pode ser adequada para entrar insetos pequenos, mas pequena o suficiente para que não capture mariposas ou outros insetos de maior porte. Além disso, ela é cilíndrica e da altura de uma pessoa de média estatura, de modo que alguns insetos podem confundí-la com um ser humano. Entretanto, essas estratégias não impedem a captura de insetos benéficos, como abelhas, agentes polinizadores, ou joaninhas, que se alimentam de insetos nocivos a lavouras.

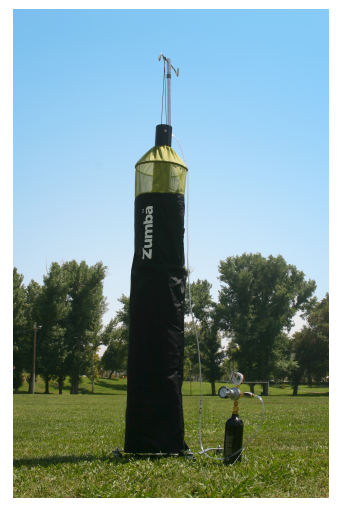

Figura 3.5: Armadilha comercial utilizada para capturar insetos em lavouras

Nessa armadilha, o sensor pode ser adaptado, de forma que apenas insetos de interesse sejam capturados. A armadilha inteligente consiste basicamente de dois atuadores, o sensor óptico e um ventilador. Os atuadores são portas responsáveis por capturar ou liberar insetos e o ventilador é responsável por direcionar o inseto para a saída ou para um papel adesivo, que irá retê-lo. O projeto geral da armadilha com o sensor adaptado é exibido na Figura 3.6.

Os insetos são atraídos à porta da armadilha graças a um atrativo liberado pela armadilha. Por exemplo, o gás carbônico é conhecido por atrair diversas espécies de mos- 


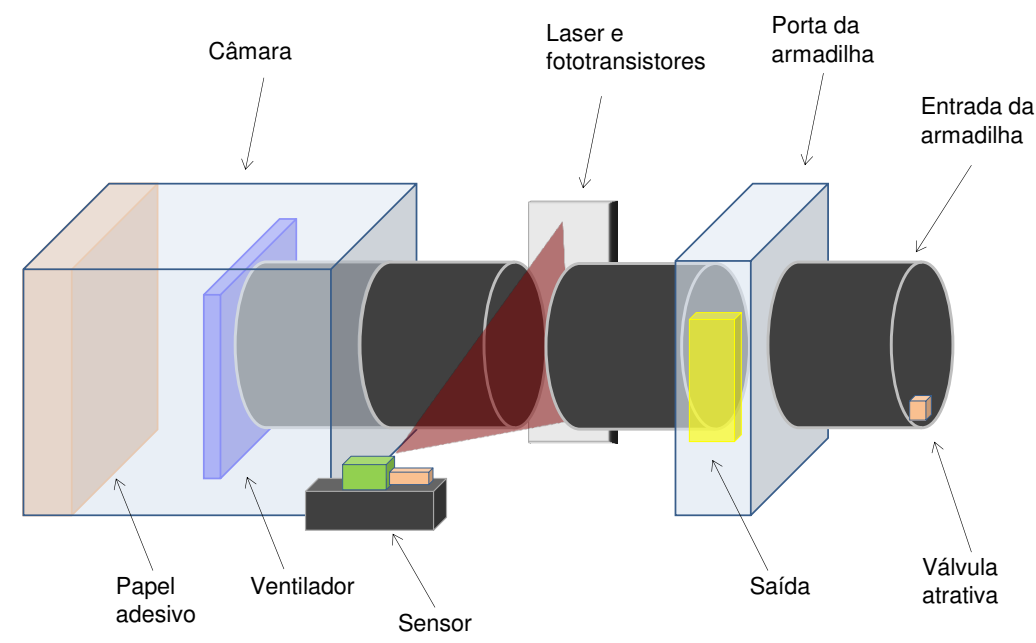

Figura 3.6: Projeto lógico da armadilha inteligente

quitos (Kline et al., 1990), uma vez que é o gás resultante da respiração de seres vivos. Quando um inseto voa em frente à entrada da armadilha, ele é direcionado pelo fluxo de ar causado pelo ventilador. Assim, o inseto passa pelo sensor, momento em que é tomada a decisão de captura ou não. Se o inseto não deve ser capturado, a porta de saída é aberta e o ventilador é revertido. Se o inseto deve ser capturado, ele é direcionado para o papel adesivo, que pode ser utilizado para estimar a densidade populacional dos insetos capturados.

Na Figura 3.7, é exibida uma foto do sensor adaptado à armadilha comercial apresentada na Figura 3.5.

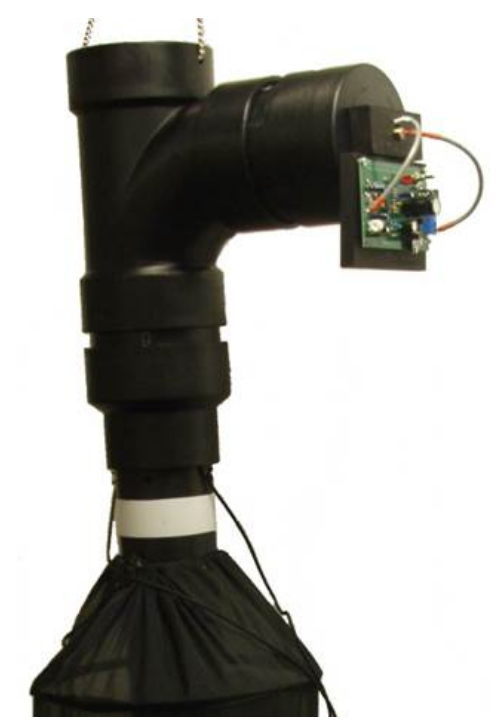

Figura 3.7: Sensor adaptado à armadilha comercial para capturar insetos em lavouras 


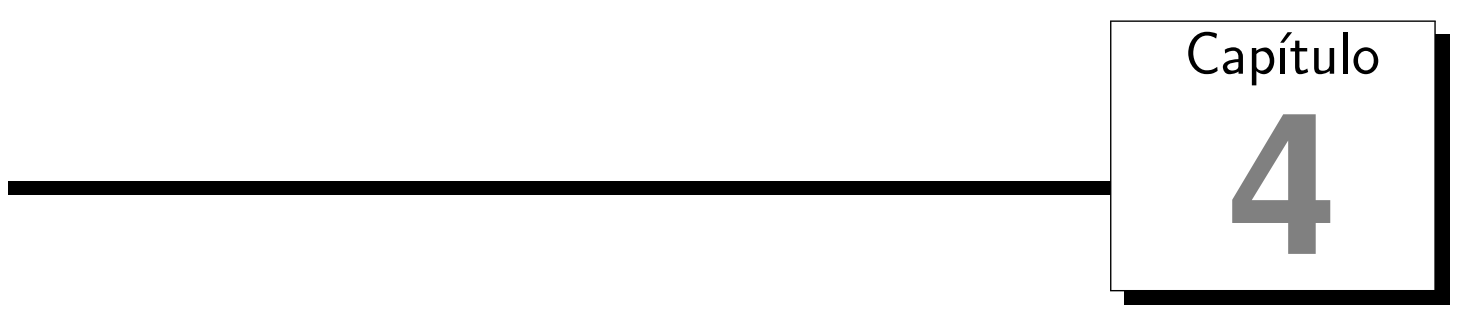

\section{Classificação de Insetos por Similaridade}

Há duas principais abordagens para realizar a classificação de séries temporais: por similaridade e por extração de atributos. Neste capítulo, é abordada a classificação por similaridade aplicada ao contexto de classificação de insetos por sinais coletados por sensores ópticos. Apesar de simples e intuitiva, a classificação por similaridade consegue alcançar ótimos resultados em diversos domínios de aplicação. A principal questão relacionada a essa abordagem é a escolha da representação da série temporal e da medida de distância a ser utilizada.

O restante deste capítulo está organizado da seguinte maneira: na Seção 4.1, são apresentados resultados da similaridade no domínio temporal; na Seção 4.2, são apresentados os resultados da aplicação de diferentes medidas de distância em diferentes representações do sinal. Os resultados apontam que a representação espectral contém informações mais relevantes para a tarefa de classificação por similaridade do que as representações temporal e cepstral; finalmente, o capítulo é concluído com considerações finais, apresentadas na Seção 4.3.

\subsection{Similaridade na Representação Temporal}

Os primeiros experimentos executados neste trabalho tiveram por objetivo verificar desempenho da classificação dos sinais coletados pelo sensor utilizando a estratégia de 
similaridade entre os sinais. Os resultados obtidos originaram um trabalho apresentado em congresso científico (Silva et al., 2011).

Os dados utilizados nesta etapa foram coletados durante 15 dias de três espécies de insetos: Bombus impatiens, espécie de abelhas, benéfica ao ser humano; Aedes aegypti, vetor da dengue e da febre amarela; e Culex quinquefasciatus, vetor de diversas doenças graves como encefalites (em especial St. Louis e Venezuelana), filariose bancroftiana e febre do Nilo Ocidental.

Como os eventos gerados pelos insetos possuem durações diferentes, foi decidido extrair segmentos com duração de um segundo. Tais segmentos são longos o suficiente para armazenar a maioria dos eventos, que tipicamente duram um ou dois décimos de segundo. Note que os eventos podem ocorrer com qualquer intervalo de tempo entre eles, de forma que não é possível garantir que cada segmento de um segundo possui somente um único evento. Entretanto, pode-se garantir que cada segmento possui ao menos um evento.

A detecção e pré-processamento dos dados resultou em 5982 séries temporais, sendo que cada uma dessas séries possui duração de um segundo, ou 16000 observações. Uma maneira simples de interpretar esses dados é pensá-los como uma tabela atributo-valor com 5982 exemplos e 16000 "atributos", além do atributo classe. As limitações dessa representação para este problema são bastante evidentes. Por exemplo, apesar das séries temporais representarem sinais de áudio de um segundo, a duração das passagens de insetos é variável, tendo duração típica de um a dois décimos de segundo (vide Figura 3.3). Por outro lado, tal representação permite a utilização de um grande número de algoritmos de classificação disponíveis na literatura.

Uma descrição resumida dos dados utilizados nesta fase do trabalho é exibida na Tabela 4.1.

Tabela 4.1: Descrição resumida do conjunto de dados com três espécies de insetos

\begin{tabular}{lrr}
\hline Classe & Exemplos & Distribuição (\%) \\
\hline Aedes Aegypti & 1231 & $20,58 \%$ \\
Bombus impatiens & 499 & $8,34 \%$ \\
Culex quinquefasciatus & 4252 & $71,08 \%$ \\
\hline Total & 5982 & $100,00 \%$ \\
\hline
\end{tabular}

Apesar dos primeiros experimentos possuírem foco na similaridade entre as séries temporais, também foi verificada a eficácia de outros métodos de classificação sem a extração de atributos, ou seja, utilizando as observações do sinal na representação temporal como atributos. Para a execução dos experimentos, foram utilizados quatro diferentes algoritmos de classificação: $k$-vizinhos mais próximos, com os parâmetros $k=5$ e votação ponderada pelo inverso da distância (Batista e Silva, 2009); naïve Bayes; J48 (implementação 
do algoritmo de árvore de decisão C4.5); e máquina de suporte vetorial (treinada pelo algoritmo de otimização sequencial SMO). Todos os experimentos foram feitos utilizando o método de validação cruzada em 10-folds. As acurácias obtidas nesse procedimento são exibidas na Tabela 4.2 .

Tabela 4.2: Descrição resumida dos resultados da classificação utilizando apenas as observações no domínio temporal, no conjunto de dados com três espécies de insetos

\begin{tabular}{lc}
\hline Algoritmo & Acurácia \\
\hline$k$-vizinhos mais próximos & $68,34 \%$ \\
J48 & $66,50 \%$ \\
Naïve Bayes & $40,17 \%$ \\
Máquina de suporte vetorial & $67,34 \%$ \\
\hline
\end{tabular}

Nesses experimentos, o classificador que obteve o melhor desempenho foi o $k$-vizinhos mais próximos, com acurácia de 68,34\%, inferior à porcentagem de exemplos da classe majoritária, 71,08\% (vide Tabela 4.1). Isso significa que esse método possui desempenho inferior ao classificador trivial, que classifica todos os exemplos como pertencentes à classe majoritária.

Uma possível crítica a esses experimentos é que os segmentos interessantes dos sinais a serem classificados - passagens dos insetos - são muito mais curtos do que as séries temporais utilizadas como exemplos. Uma parte significativa das observações é meramente ruído de fundo, uma característica que pode dificultar, por exemplo, a interpretação de distâncias calculadas pelo classificador $k$-vizinhos mais próximos. Entretanto, é importante ressaltar que o problema de separar sinal e ruído de fundo não é trivial. A duração dos sinais, como observado anteriormente, é variável. Comumente, os sinais possuem entre 1 e 3 décimos de segundo. Em casos especiais, alguns sinais têm duração próxima a um segundo, como no caso das abelhas que ocasionalmente pairavam em frente ao laser. Isso impossibilita a transformação dos sinais em uma tabela atributo-valor cujos exemplos possuam o mesmo número de atributos, exigência para a utilização de grande parte dos algoritmos de aprendizado de máquina.

Para eliminar a possibilidade de que os resultados modestos apresentados pelos classificadores tenham como origem a curta duração média das passagens em comparação com a duração total da série temporal, decidiu-se extrair segmentos mais curtos, com duração de 3 décimos de segundo. Novamente, os dados foram transformados em uma tabela atributo-valor. Foi utilizado como classificador o algoritmo $k$-vizinhos mais próximos, dado que ele obteve a melhor acurácia nos experimentos anteriores. A acurácia obtida neste novo experimento foi de 70,49\%, ou seja, ainda inferior à acurácia do classificador trivial. 
Os resultados iniciais evidenciam que a classificação dos sinais coletados pelo sensor utilizando a representação temporal como dados de entrada para algoritmos de aprendizado, baseados ou não em similaridade, não é uma abordagem muito eficaz. O desempenho pouco satisfatório da classificação por similaridade, nesse domínio, pode estar relacionado a vários fatores. Alguns exemplos são a influência do ruído de fundo e do alinhamento das observações.

Entretanto, é possível que as informações contidas em outras representações do sinal, como o espectro de frequências, sejam potencialmente úteis para distinguir as espécies de insetos no contexto deste trabalho. Na próxima seção, são descritos os resultados obtidos pela classificação por similaridade nas representações espectral e cepstral, que confirmam tal suposição.

\subsection{Similaridade em Diferentes Representações de Séries Temporais}

Na seção anterior, foi evidenciado o fato da classificação por similaridade na representação temporal não obter bons resultados no contexto da classificação de insetos por meio do sensor apresentado. Para verificar se informações contidas em outras representações de séries temporais podem, de fato, contribuir na classificação dos sinais, foi realizada uma simples análise das frequências fundamentais dos sinais utilizados nos experimentos da Seção 4.1, coletados de três espécies de insetos: Aedes aegypti, Bombus impatiens e Culex quinquefasciatus. O método utilizado para isso foi a obtenção dessa medida no domínio cepstral (vide Seção 2.2.2).

Nos sinais coletados pelo sensor, a frequência fundamental do sinal define a frequência da batida de asas dos insetos. A frequência de batida de asas é um importante atributo para classificar insetos, pois é intimamente relacionada ao seu tamanho. No caso de espécies dimórficas, esse atributo pode também ajudar a separar machos e fêmeas, sendo que as fêmeas tendem a ser maiores que os machos e, portanto, apresentar frequências de batida de asas mais baixas (Byrne et al., 1988).

Ao gerar um histograma das frequências de batida de asas dos insetos analisados, exibido na Figura 4.1, é possível verificar que as classes se assemelham a uma distribuição gaussiana com uma longa cauda esquerda. Também pode-se notar que que as frequências da espécie Bombus impatiens (abelhas) são linearmente separáveis das espécies de mosquitos. Analisando somente os mosquitos, Aedes aegypti possui uma frequência de batida de asas mais alta que o Culex quinquefasciatus. Entretanto, existe uma sobreposição nas frequências de batida de asas dessas duas espécies. A Tabela 4.3 provê estatísticas sobre as frequências de batida de asas obtidas. 


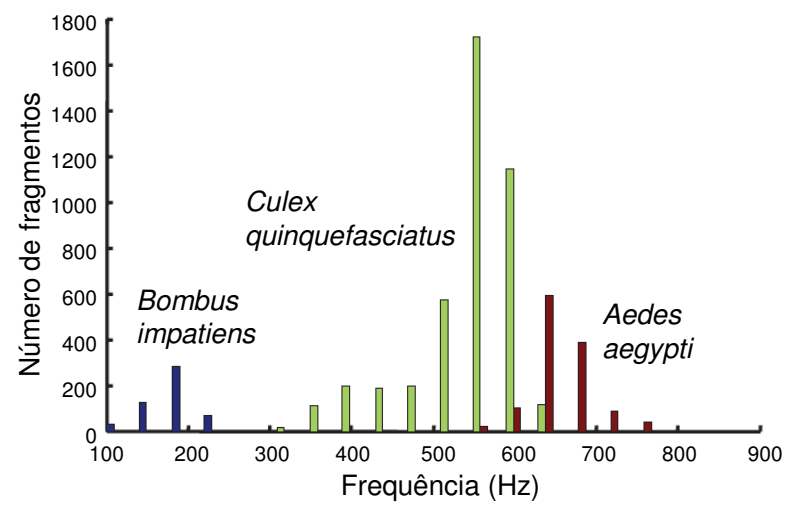

Figura 4.1: Histograma da frequência da batida de asas das espécies Bombus impatiens, Aedes aegypti e Culex quinquefasciatus (Batista et al., 2011a)

Tabela 4.3: Histograma da frequência da batida de asas de três espécies de insetos (Batista et al., 2011a)

\begin{tabular}{llll}
\hline Classe & Exemplos & Média $\mathbf{( H z )}$ & Desvio Padrão $\mathbf{( H z )}$ \\
\hline Aedes aegypti & 1231 & 644,76 & 34,86 \\
Bombus impatiens & 499 & 173,76 & 26,42 \\
Culex quinquefasciatus & 4252 & 528,12 & 62,67 \\
\hline
\end{tabular}

Com essa simples análise, é possível verificar que o domínio espectral contém informações relevantes para a classificação de insetos. Dessa maneira, é intuitivo pensar que a similaridade espectral, ou seja, a similaridade entre os espectros relativos aos sinais analisados, pode fornecer uma medida adequada para a comparação dos sinais capturados pelo sensor.

\subsubsection{Similaridade nas Representações Espectral e Cepstral}

A fim de verificar se diferentes representações do sinal são mais adequadas na classificação por similaridade, foram realizados experimentos com diferentes medidas de distância aplicadas nos domínios espectral e cepstral. Para isso, foi utilizado um conjunto de dados com cinco espécies, com cem exemplos cada, resumido na Tabela 4.4. Uma vez que esse conjunto de dados é relativamente pequeno, foi utilizada a técnica de validação leave-oneout, em que, para cada exemplo do conjunto de dados, são considerados todos os demais exemplos como conjunto de treinamento e apenas o exemplo analisado no momento como teste.

A classificação nesse conjunto de dados se caracteriza como uma tarefa mais difícil do que no caso do conjunto de dados com três classes. Primeiramente, pelo fato de haver mais classes no novo conjunto de dados. Além disso, as cinco espécies em análise 
Tabela 4.4: Descrição resumida do conjunto de dados com cinco espécies de insetos

\begin{tabular}{lrr}
\hline Classe & Exemplos & Distribuição (\%) \\
\hline Aedes aegypti & 100 & $20,00 \%$ \\
Drosophila melanogaster & 100 & $20,00 \%$ \\
Culex quinquefasciatus & 100 & $20,00 \%$ \\
Culex tarsalis - fêmea & 100 & $20,00 \%$ \\
Culex tarsalis - macho & 100 & $20,00 \%$ \\
\hline Total & 500 & $100,00 \%$ \\
\hline
\end{tabular}

possuem tamanho - e, portanto, frequência de batida de asas - mais próximos do que as espécies contidas no conjunto de dados anterior. Um exemplo disso são as duas classes que representam a mesma espécie de inseto, se diferenciando apenas pelo sexo.

Para fins de comparação, a classificação nesse conjunto de dados também foi realizada por meio da similaridade no domínio temporal. Para isso, foram utilizadas cinco diferentes medidas de distância: euclidiana, Manhattan, Chebyshev, cosseno e correlação. A decisão da classe a ser atribuída ao exemplo de teste foi baseada na regra do vizinho mais próximo. Na Tabela 4.5, são apresentados os resultados obtidos.

Tabela 4.5: Resultado da classificação por similaridade no domínio temporal utilizando o conjunto de dados com cinco espécies de insetos e as distâncias euclidiana, Manhattan, Chebyshev, cosseno e correlação

\begin{tabular}{lr}
\hline Medida de distância & Acurácia \\
\hline Euclidiana & $53,80 \%$ \\
Manhattan & $49,80 \%$ \\
Chebyshev & $43,00 \%$ \\
Cosseno & $64,00 \%$ \\
Correlação & $64,00 \%$ \\
\hline
\end{tabular}

Os resultados obtidos nesse experimento podem ser analisados sob dois pontos de vista distintos. Se comparados aos obtidos no conjunto de dados com três espécies, esses resultados parecem bastante promissores. Anteriormente, o erro da classificação era maior que o obtido pelo classificador trivial. Isso não acontece nos resultados obtidos no conjunto de dados com cinco classes, uma vez que a classe majoritária possui exatamente $20 \%$ dos exemplos do conjunto de dados. O melhor resultado obtido foi de $64 \%$.

Entretanto, se os resultados forem avaliados sob o ponto de vista da aplicação, eles foram abaixo do esperado. Para que o sensor seja utilizado na prática, uma acurácia de apenas $64 \%$ não é adequada. Por exemplo, no contexto do estudo da distribuição espaço-temporal de insetos, fazê-lo com um grau de confiança baseado nessa acurácia pode fornecer uma estimativa muito grosseira. Além disso, esse resultado pode ser ainda pior quando o método for aplicado a conjuntos de dados com maior número de classes. 
A principal hipótese assumida nesta seção é que as informações de frequência dos sinais coletados pelo sensor fornecem informações mais valiosas do que as evidentes no domínio temporal. Essa suposição foi parcialmente comprovada pela análise das frequências de batida de asas, apresentada na Figura 4.1. A fim de validar a hipótese, foi verificada a eficácia da classificação por similaridade no espectro de frequências dos sinais. Para isso, foram utilizadas as mesmas medidas de distância aplicadas à análise por similaridade no domínio de frequências. Os resultados desse experimento são exibidos na Tabela 4.6.

Tabela 4.6: Resultado da classificação por similaridade no domínio de frequências utilizando o conjunto de dados com cinco espécies de insetos e as distâncias euclidiana, Manhattan, Chebyshev, cosseno e correlação

\begin{tabular}{lr}
\hline Medida de distância & Acurácia \\
\hline Euclidiana & $85,60 \%$ \\
Manhattan & $88,20 \%$ \\
Chebyshev & $79,80 \%$ \\
Cosseno & $87,00 \%$ \\
Correlação & $86,60 \%$ \\
\hline
\end{tabular}

Os experimentos com a similaridade na representação espectral foram bastante superiores aos obtidos no domínio temporal. Nas medidas de distância avaliadas até então, a diferença na acurácia entre os domínios temporal e espectral foi maior que $20 \%$ em todos os casos. Isso evidencia, ainda mais, o fato das componentes de frequência fornecerem informações mais relevantes sobre o sinal do que as observações no domínio temporal, no contexto da classificação por similaridade.

Para finalizar a verificação da qualidade das informações contidas em diferentes representações do sinal, o mesmo experimento foi realizado na representação cepstral. Ao aplicar as mesmas medidas de distância sobre o cepstro no conjunto de dados analisado, foram obtidos os resultados apresentados na Tabela 4.7 .

Tabela 4.7: Resultado da classificação por similaridade no domínio cepstral utilizando o conjunto de dados com cinco espécies de insetos e as distâncias euclidiana, Manhattan, Chebyshev, cosseno e correlação

\begin{tabular}{lr}
\hline Medida de distância & Acurácia \\
\hline Euclidiana & $81,40 \%$ \\
Manhattan & $56,00 \%$ \\
Chebyshev & $76,40 \%$ \\
Cosseno & $84,80 \%$ \\
Correlação & $84,20 \%$ \\
\hline
\end{tabular}

Segundo os resultados apresentados, a similaridade no domínio cepstral é claramente mais eficaz que a similaridade na representação temporal. O mesmo não acontece quando 
os resultados são comparados com os obtidos no domínio de frequências. A melhor acurácia atingida com as distâncias analisadas ao se utilizar o cepstro dos sinais é menor do que a acurácia alcançada pela utilização de quatro das cinco medidas de distância aplicadas à comparação entre espectros. Além disso, os resultados obtidos pela classificação por similaridade no cepstro foram mais sensíveis à escolha da medida de distância. Em outras palavras, o desempenho da classificação varia significativamente de acordo com a distância utilizada. Enquanto no domínio espectral a variação entre o melhor e o pior resultado obtido foi de apenas 8,40\%, no domínio de tempo foi de 21,00\% e no domínio cepstral foi de $28,80 \%$.

\subsubsection{Diferentes Medidas de Distância Aplicadas na Representação Espectral}

A fim de se assegurar os bons resultados e a estabilidade da classificação por similaridade no domínio de frequências, foi realizado um experimento semelhante ao anterior, mas com outras medidas de distância. As medidas utilizadas e a acurácia da classificação, alcançada por sua utilização, são apresentadas na Tabela 4.8 .

Tabela 4.8: Resultado da classificação por similaridade no domínio de frequências utilizando o conjunto de dados com cinco espécies de insetos e as distâncias de Canberra, Jaccard, Topsoe, Clark, média $L_{1} L_{\infty}, \chi^{2}$ quadrático, e $\chi^{2}$ aditivo simétrico

\begin{tabular}{lr}
\hline Medida de distância & Acurácia \\
\hline Canberra & $85,00 \%$ \\
Jaccard & $87,00 \%$ \\
Topsoe & $89,60 \%$ \\
Clark & $84,40 \%$ \\
Média $L_{1} L_{\infty}$ & $88,40 \%$ \\
$\chi^{2}$ Quadrático & $89,80 \%$ \\
$\chi^{2}$ Aditivo Simétrico & $90,60 \%$ \\
\hline
\end{tabular}

Ao utilizar diferentes medidas de distância, é possível melhorar o desempenho da classificação por similaridade no domínio de frequências. Mais especificamente, neste simples experimento, a utilização da medida $\chi^{2}$ aditivo simétrico proporcionou um resultado acima de $90 \%$ de acurácia.

Como foi mostrado anteriormente, a frequência fundamental dos sinais - no caso, a frequência da batida de asas - de cada espécie de inseto varia dentro de uma determinada faixa de valores. Intuitivamente, isso significa uma pequena variação da localização do maior pico no gráfico do espectro. Além da localização do maior pico de magnitude, há outras informações importantes no domínio de frequências, como a localização das harmônicas, que também podem sofrer essas pequenas variações. 
Para explorar esse fato, foi realizado um breve experimento com a medida de distância DTW. Com essa medida, é possível realizar o alinhamento não-linear das componentes de frequência, de modo que as amplitudes de diferentes valores de frequência podem ser combinadas no cálculo da distância. A utilização da DTW padrão pode causar casamentos de amplitudes em valores de frequência muito diferentes, o que pode acarretar em casamentos indesejados. Por isso, foi utilizada a banda de Sakoe-Chiba, com largura de cinco observações. Em outras palavras, um valor de amplitude na frequência $f$ é comparado apenas com valores no intervalo $[f-5, f+5]$ do espectro resultante do sinal a ser comparado. O desempenho obtido nesse experimento foi abaixo dos alcançados com outras medidas de distância, 88,60\% de acurácia.

\subsubsection{Filtro de Suavização Sobre Diferentes Representações}

Pequenas variações no sinal podem causar pequenas alterações nos seus respectivos espectro e cepstro. Isso pode resultar em diferenças de magnitude em alguns valores de frequência - ou de quefrência - que não deveriam ser significativos no cálculo da medida de distância. Por exemplo, há faixas de frequência que não são, de fato, relevantes ao sinal analisado. Ainda assim, é possível haver uma variação (pico ou vale) em uma frequência específica nessa faixa, que pode contribuir negativamente no cálculo da distância. A fim de minimizar esse problema, é possível aplicar um filtro de suavização na representação utilizada. Um exemplo da aplicação desse tipo de filtro é ilustrado na Figura 4.2.

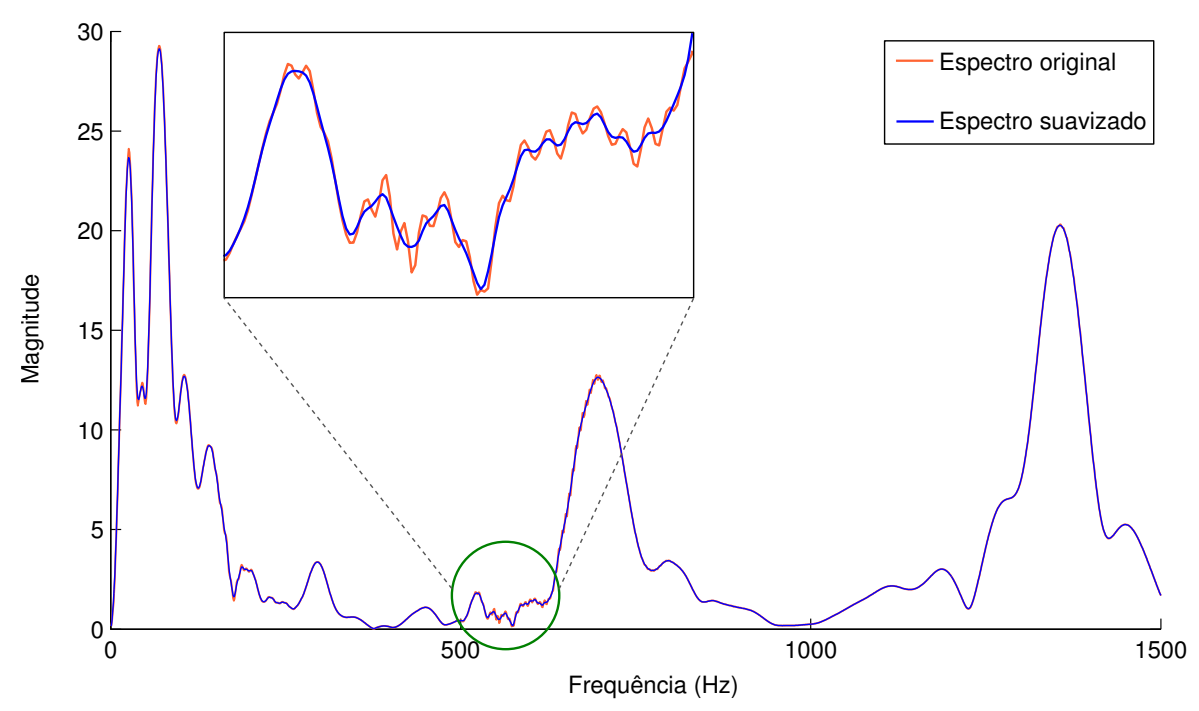

Figura 4.2: Exemplo de um espectro de frequências antes e após a aplicação de filtro de suavização (sobrepostos). Na área em destaque é possível perceber que a aplicação do filtro de suavização resulta em uma sequência de valores sem muita variação entre frequências vizinhas 
Na Tabela 4.9, são exibidos os resultados da classificação antes e após a aplicação da suavização no espectro, com a medida $\chi^{2}$ Aditivo Simétrico, e no cepstro, com a distância do cosseno. Essas medidas de distância foram escolhidas por terem apresentados os melhores resultados nos experimentos anteriores.

Tabela 4.9: Resultado da classificação por similaridade nos domínios espectral e cepstral após a aplicação de um filtro de suavização no conjunto de dados de cinco espécies de insetos

\begin{tabular}{lrr}
\hline Medida de distância & Acurácia sem suavização & Acurácia com suavização \\
\hline$\chi^{2}$ Aditivo Simétrico - Espectro & $90,60 \%$ & $91,60 \%$ \\
Cosseno - Cepstro & $84,80 \%$ & $85,00 \%$ \\
\hline
\end{tabular}

Esses resultados mostram que a suavização pode fornecer um ganho na acurácia. Isso é mais evidente no resultado alcançado pela suavização no espectro de frequências. No caso do cepstro, houve um aumento de 0,20\% de acurácia, o que equivale a apenas um exemplo do conjunto de dados.

\subsubsection{Similaridade Espectral Aplicada na Classificação de Nove Espécies de Insetos}

No decorrer do trabalho, foi criado um conjunto de dados mais complexo, com maior número de exemplos e de classes. Dessa vez, foi optado por não utilizar segmentos de duração fixa. Essa característica era importante para a fase de análise de similaridade no domínio temporal. Porém, foi comprovado que essa abordagem não é muito eficaz para o problema, sendo descartada nos experimentos seguintes. Assim, os segmentos que compõem esse conjunto de dados possuem duração variada, comumente com poucos décimos de segundo. Um exemplo de segmento contido nesse conjunto de dados é exibido na Figura 4.3.

Após as etapas de coleta e pré-processamento, formou-se um conjunto de dados com 18151 segmentos que representam passagens de insetos pelo sensor. O conjunto possui nove classes: Aedes aegypti (transmissor da dengue, entre outras doenças); Anopheles gambiae (um dos mosquitos responsáveis pela transmissão da malária); Apis mellifera (abelha produtora de mel); Cotinis mutabilis (besouro que se alimenta, principalmente, de pólen, néctar e pétalas); Culex quinquefasciatus (vetor de diversas doenças, entre elas a febre do Nilo Ocidental); Culex tarsalis (transmissor de doenças como a encefalite); Drosophila melanogaster (mosca da fruta, fonte de fármacos, mas conhecida pela inutilização de comida em grandes estoques); Musca domestica (esse tipo de mosca pode transmitir febre tifoide, amebíase, entre outros); e Psychodidae diptera (transmissora de algumas doenças, entre elas a leishmaniose). Devido ao fato de haver uma quantidade expressiva de 


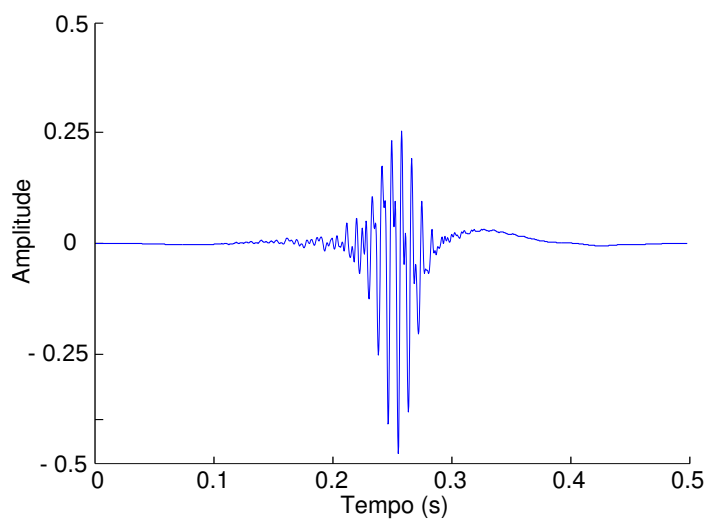

Figura 4.3: Exemplo de sinal segmentado relativo à passagem de um Aedes aegypti pelo sensor óptico

segmentos, o conjunto de dados foi dividido em partições padrão de treinamento e teste. Essa divisão foi realizada de modo estratificado, deixando $33 \%$ dos exemplos no conjunto de treinamento e o restante, no conjunto de teste. Esse conjunto de dados é resumido na Tabela 4.10.

Tabela 4.10: Descrição resumida do conjunto de dados com nove espécies de insetos

\begin{tabular}{lrr}
\hline Classe & Exemplos & Distribuição (\%) \\
\hline Aedes aegypti & 4756 & 26,25 \\
Anopheles gambiae & 1411 & 7,79 \\
Apis mellifera & 511 & 2,82 \\
Cotinis mutabilis & 172 & 0,95 \\
Culex quinquefasciatus & 3137 & 17,32 \\
Culex tarsalis & 5309 & 29,31 \\
Drosophila melanogaster & 777 & 4,29 \\
Musca domestica & 1343 & 7,41 \\
Psychodidae diptera & 699 & 3,86 \\
\hline Total & 18151 & $100,00 \%$ \\
\hline
\end{tabular}

Dados os experimentos no conjunto de dados com cinco classes, foi decidido utilizar apenas a estratégia de classificação por similaridade no domínio espectral. Para isso, foram aplicadas as mesmas medidas de distância utilizadas anteriormente, resultando nas taxas de acurácia exibidas na Tabela 4.11.

Conforme foi constatado em experimentos no conjunto de dados com cinco espécies, a utilização de um filtro de suavização sobre o espectro de frequências pode melhorar os resultados obtidos pela classificação por similaridade na representação espectral. Por esse motivo, a mesma abordagem foi utilizada sobre o conjunto de dados com nove espécies. Os resultados, apresentados na Tabela 4.12, evidenciam ainda mais o fato da suavização ser uma abordagem útil na classificação por similaridade no domínio de frequências. 
Tabela 4.11: Resultado da classificação por similaridade no domínio de frequências utilizando o conjunto de dados com nove espécies de insetos

\begin{tabular}{lr}
\hline Medida de distância & Acurácia \\
\hline Euclidiana & $76,14 \%$ \\
Manhattan & $80,09 \%$ \\
Chebyshev & $71,20 \%$ \\
Cosseno & $77,25 \%$ \\
Correlação & $76,60 \%$ \\
Canberra & $72,28 \%$ \\
Jaccard & $77,26 \%$ \\
Topsoe & $81,54 \%$ \\
Clark & $75,59 \%$ \\
Média $L_{1} L_{\infty}$ & $80,09 \%$ \\
$\chi^{2}$ Quadrático & $81,38 \%$ \\
$\chi^{2}$ Aditivo Simétrico & $81,01 \%$ \\
DTW (largura de banda $=5)$ & $81,04 \%$ \\
\hline
\end{tabular}

Tabela 4.12: Resultado da classificação por similaridade no domínio espectral após a aplicação de um filtro de suavização no conjunto de dados de nove espécies de insetos

\begin{tabular}{lr}
\hline Medida de distância & Acurácia com suavização \\
\hline Euclidiana & $76,49 \%$ \\
Manhattan & $80,29 \%$ \\
Chebyshev & $71,47 \%$ \\
Cosseno & $77,56 \%$ \\
Correlação & $76,82 \%$ \\
Canberra & $71,78 \%$ \\
Jaccard & $77,51 \%$ \\
Topsoe & $81,87 \%$ \\
Clark & $74,92 \%$ \\
Média $L_{1} L_{\infty}$ & $80,31 \%$ \\
$\chi^{2}$ Quadrático & $81,74 \%$ \\
$\chi^{2}$ Aditivo Simétrico & $81,49 \%$ \\
DTW (largura de banda $=5)$ & $81,00 \%$ \\
\hline
\end{tabular}

\subsection{Considerações Finais}

Neste capítulo, foi avaliada a classificação de insetos por sensores ópticos por meio da similaridade no domínio de tempo. Os primeiros experimentos mostraram que tal abordagem pode, de fato, ser mais adequada do que a simples aplicação de algoritmos de aprendizado de máquina utilizando as observações da série temporal como atributos de entrada. Entretanto, a similaridade no domínio temporal também não alcança resultados satisfatórios.

Consequentemente, foi avaliada a classificação por similaridade entre os sinais por meio do cálculo de distância em outras representações da série temporal. Os resultados nas representações espectral e cepstral foram superiores aos obtidos na representação temporal. 
Especificamente, os melhores resultados foram obtidos pela dissimilaridade no espectro de frequências. Finalmente, a aplicação de um filtro de suavização sobre o espectro pode suprimir pequenas distorções nas magnitudes das componentes de frequência. Entretanto, os resultados apresentados não confirmam que essa operação pode auxiliar na obtenção de um melhor desempenho na classificação por similaridade.

Há uma segunda abordagem de classificação de séries temporais, muito eficaz em diversas aplicações de análise de áudio: a classificação por extração de atributos. No próximo capítulo, serão apresentados resultados obtidos pela utilização de técnicas de extração de atributos em diferentes representações da série temporal. Além disso, será discutido como essas técnicas podem contribuir umas com as outras, no contexto de classificação de insetos por meio de sensores ópticos. 



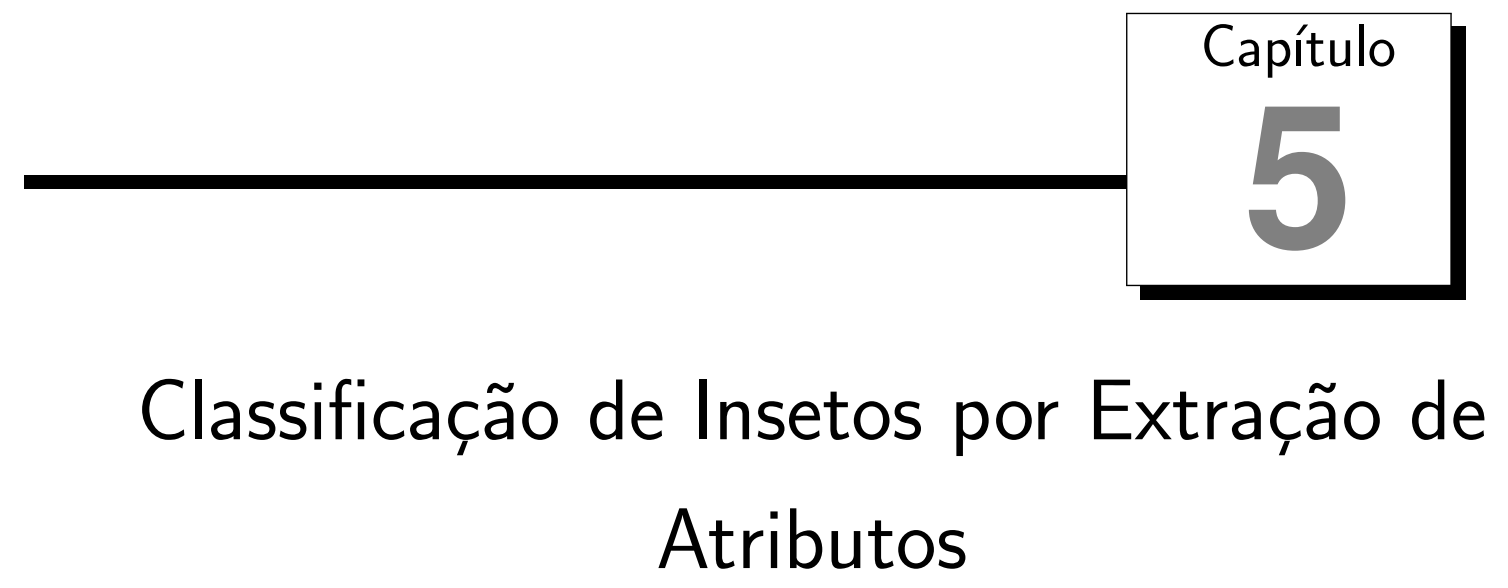

No Capítulo 4, foram apresentados os resultados da classificação de insetos por meio dos sinais coletados por sensores ópticos, utilizando a abordagem por similaridade em diferentes representações do sinal. A outra estratégia utilizada neste trabalho para o cumprimento da tarefa é a classificação por extração de atributos. Nessa abordagem, as diferentes representações dos sinais são utilizadas para identificar atributos, que são utilizados como entrada em algoritmos de aprendizado de máquina.

A fim de verificar a importância da extração de atributos na classificação de insetos, foram realizados experimentos comparativos entre a classificação por similaridade e a classificação por extração de atributos. Nessa etapa do trabalho, foram utilizados coeficientes mel-cepstrais como atributos para treinar diferentes classificadores. Os resultados mostraram que, com uma escolha adequada do algoritmo de classificação e seus parâmetros, a classificação por similaridade pode ser superada por uma diferença significativa (de Souza et al., 2013b). Os resultados obtidos são apresentados na Seção 5.1.

Posteriormente, foram utilizados atributos de diversas representações do sinal, mais especificamente, atributos temporais, espectrais, LPC, LSF e MFCC (Silva et al., 2013b). Além da escala mel, também foram utilizados coeficientes cepstrais nas escalas linear e logarítmica. Por fim, foram avaliados os resultados da combinação de diferentes classificadores e diferentes atributos. Os resultados são apresentados na Seção 5.2. 


\subsection{Estudo Comparativo Entre as Abordagens de Classificação por Similaridade e Extração de Atributos}

Apesar da estratégia de classificação de séries temporais por similaridade ter mostrado bons resultados, facilmente são encontrados na literatura bons resultados em tarefas de análise de séries temporais utilizando a abordagem de extração de atributos. Isso é mais evidente ao se tratar de séries temporais extensas e complexas, como sinais de áudio.

Nesta etapa do trabalho, foram realizados experimentos para verificar a qualidade dessa abordagem na classificação de insetos por meio de sinais capturados por sensores ópticos. Para isso, foram utilizados coeficientes mel-cepstrais. Esses atributos são muito utilizados na prática, comumente alcançando excelentes resultados. Como base para comparação, foi utilizado o resultado da classificação por similaridade no espectro dos sinais analisados.

\subsubsection{Baseline Baseado na Classificação por Similaridade no Domínio Espec- tral}

Nesta etapa do trabalho, foi utilizada uma versão preliminar do conjunto de dados de nove classes (vide Tabela 4.10). Porém, no momento em que esta fase do trabalho foi desenvolvida, parte do conjunto de dados não havia sido pré-processada (filtragem, detecção e segmentação do sinal). Por isso, essa versão possui apenas cinco espécies de inseto: Drosophila melanogaster, Musca domestica, Culex quinquefasciatus, Culex tarsalis e Aedes aegypti. Além disso, o número de exemplos de cada uma das espécies é menor do que o apresentado anteriormente. Desse modo, não é possível comparar diretamente os resultados obtidos nessa fase com os apresentados no Capítulo 4.

Para analisar o desempenho da classificação por extração de atributos, foi definido um baseline para os resultados. Tal base de referência foi definida como a acurácia da classificação por similaridade entre os espectros relativos aos sinais analisados. Para isso, foi utilizada a bem conhecida distância euclidiana, obtendo uma acurácia de 89,61\%. Dada a simplicidade desse método, é esperado que técnicas de classificação mais elaboradas obtenham melhores resultados.

\subsubsection{Extração de Atributos - Coeficientes Mel-Cepstrais}

Neste trabalho, foram utilizados coeficientes mel-cepstrais como atributos de entrada para a geração de modelos de classificação. Esses atributos são comumente utilizados com 
sucesso em diversas aplicações de análise de áudio, como o reconhecimento de fala e de locutor (Zhen et al., 2000).

A utilização de coeficientes mel-cepstrais está atrelada a um parâmetro de extrema importância, o número de coeficientes. Comumente, 13 coeficientes mel-cepstrais são aceitos como bom descritor para a classificação de sinais de áudio (Terasawa et al., 2005). Porém, métodos de classificação são muito sensíveis a uma escolha ruim do número de coeficientes, sendo que é mais adequado realizar o ajuste de valor desse parâmetro no conjunto de treinamento (Silva et al., 2013d). Desse modo, foi realizado um experimento com dois algoritmos de classificação, variando o número de coeficientes. O objetivo desse experimento foi encontrar um número de coeficientes mel-cepstrais que seja representativo para os dados avaliados.

Para isso, foram utilizados os algoritmos vizinho mais próximo (1-NN) e máquina de vetores de suporte (SVM, com kernel RBF, $c=1$ e $\gamma=0,01$ ). A escolha dos algoritmos deve-se a resultados satisfatórios obtidos em avaliações preliminares considerando valores padrão para os parâmetros. A quantidade de coeficientes foi variada de 3 a 69 (considerando-se somente valores ímpares). Os resultados obtidos nesse experimento podem ser vistos na Figura 5.1, em que o eixo horizontal denota o número de coeficientes utilizado e o eixo vertical corresponde à acurácia obtida para cada configuração.

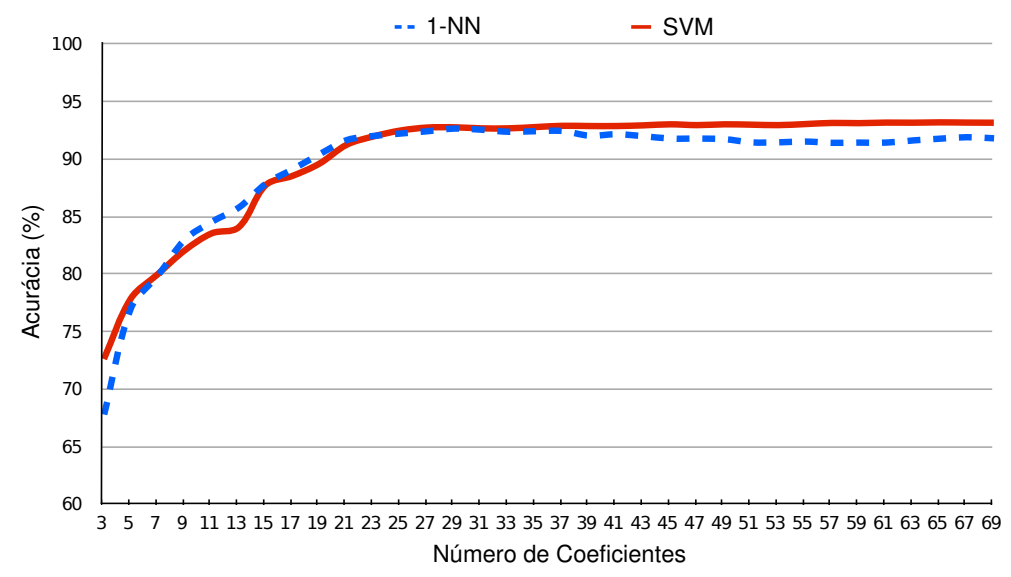

Figura 5.1: Resultados obtidos pelos algoritmos 1-NN e SVM, dada a variação no número de coeficientes mel-cepstrais

Nota-se que, para ambos os algoritmos, a curva que representa a acurácia mantém-se crescente para valores superiores a 13 (quantidade tipicamente utilizada) até se estabilizar, ao atingir aproximadamente 25 coeficientes. Embora não seja possível definir pontualmente o melhor número de coeficientes para ambos os algoritmos, é possível notar que as variações são pouco significativas a partir de 25 coeficientes. Além disso, a escolha por um número menor de coeficientes deve reduzir o tempo gasto na etapa de classifica- 
ção. Assim, os experimentos deste trabalho consideram um conjunto de 25 coeficientes mel-cepstrais para os algoritmos de aprendizado avaliados.

\subsubsection{Avaliação Experimental}

Utilizando os coeficientes mel-cepstrais, foram analisados os resultados da classificação por meio de diferentes técnicas de aprendizado de máquina. A maioria dos algoritmos de aprendizado possui parâmetros que podem influenciar significativamente seu desempenho. Por isso, foi realizado um experimento que consiste na busca por valores desses parâmetros que possam maximizar o desempenho dos algoritmos utilizados.

Uma vez que a partição destinada ao conjunto de teste é restrita à avaliação final dos classificadores, foi utilizada a validação cruzada em 10 folds no conjunto de treinamento, a fim de buscar os valores para os parâmetros. Para cada combinação possível de valores, a acurácia da classificação foi estimada nos conjuntos "internos" à validação cruzada. Então, as melhores combinações de valores de parâmetros foram tomadas como configuração final para cada algoritmo de aprendizado. Finalmente, foram utilizadas essas combinações para realizar o aprendizado com todo o conjunto de treino e avaliar o classificador resultante no conjunto de teste.

No caso da máquina de vetores de suporte (SVM), foram variados os parâmetros do algoritmo base e do kernel, utilizando a estratégia de busca em grade (Hsu et al., 2003). Dados os valores de mínimo, máximo e tamanho do passo, é avaliada a acurácia para cada combinação de valores de parâmetros. No entanto, essa busca é realizada em duas etapas. A primeira delas é uma busca grosseira, utilizando a validação cruzada com apenas dois folds. A segunda etapa refina essa busca nas regiões mais promissoras, ou seja, com melhor desempenho. Os parâmetros do classificador que obteve melhor acurácia na segunda etapa da busca são considerados a configuração final a ser utilizada na construção do modelo de classificação.

Os algoritmos utilizados nesta etapa, bem como os intervalos de variação de parâmetros são apresentados na Tabela 5.1. Foram utilizados, neste experimento, os algoritmos $k$-vizinhos mais próximos $(k-\mathrm{NN})$, floresta aleatória, árvore de classificação e regressão (CART), máquina de vetores de suporte (SVM), modelo de mistura de gaussianas (GMM), regressão logística e naüve Bayes.

Os valores de parâmetros encontrados nessa fase foram, então, utilizados para criar modelos de classificação para cada algoritmo descrito na Tabela 5.1, utilizando todo o conjunto de treinamento. Com isso, os dados do conjunto de teste foram utilizados para avaliar o desempenho dos classificadores. Os resultados dessa operação são exibidos na Tabela 5.2. 
Tabela 5.1: Algoritmos de classificação utilizados nos experimentos e parâmetros considerados para variação pelo método de busca em grade

\begin{tabular}{lll}
\hline Algoritmo & Parâmetros & Variação (início:passo:fim) \\
\hline$k$-NN & \# de vizinhos $(k)$ & $k=1: 2: 49$ \\
Floresta Aleatória & \# de árvores $(T)$ & $T=1: 10: 100$ \\
CART (com poda) & Min. instâncias por folha $(S L)$ & $S L=2: 2: 10$ \\
SVM (kernel Linear) & Regularização $(c)$ & $c=0,1: 0,5: 2,1$ \\
SVM (kernel Polinomial) & Regularização $(c) ;$ Grau $(d)$ & $c=0,1: 0,5: 2,1 ; d=1: 1: 10$ \\
SVM (kernel RBF) & Regularização $(c) ;$ Gama $(\gamma)$ & $c=0,1: 0,5: 2,1 ; \gamma=0,01: 0,01: 0,1$ \\
SVM (kernel Sigmoidal) & Regularização $(c) ;$ Gama $(\gamma)$ & $c=0,1: 0,5: 2,1 ; \gamma=0,01: 0,01: 0,1$ \\
GMM (cov. Diagonal) & \# de gaussianas $(G)$ & $G=1: 1: 10$ \\
GMM (cov. Completa) & \# de gaussianas $(G)$ & $G=1: 1: 10$ \\
Regressão Logística & - & - \\
Naive Bayes & - & - \\
\hline
\end{tabular}

Tabela 5.2: Resultados da classificação utilizando os parâmetros previamente encontrados. Os resultados destacados em negrito se referem aos que superaram o baseline

\begin{tabular}{lll}
\hline Algoritmo & Parâmetros encontrados & Acurácia \\
\hline$k$-Vizinhos Mais Próximos & $k=20$ & $\mathbf{9 2 , 1 4 \%}$ \\
Floresta Aleatória & $T=30$ & $88,37 \%$ \\
CART (com poda) & $S L=4$ & $81,18 \%$ \\
SVM (kernel Linear) & $c=0,5$ & $71,95 \%$ \\
SVM (kernel Polinomial) & $c=0,5 ; d=7$ & $\mathbf{9 0 , 7 4 \%}$ \\
SVM (kernel RBF) & $c=0,4 ; \gamma=0,01$ & $\mathbf{9 3 , 5 1 \%}$ \\
SVM (kernel Sigmoidal) & $c=0,5 ; \gamma=0,07$ & $71,77 \%$ \\
GMM (cov. Diagonal) & $G=7$ & $87,19 \%$ \\
GMM (cov. Completa) & $G=8$ & $88,01 \%$ \\
Regressão Logística & - & $80,62 \%$ \\
Naive Bayes & - & $87,44 \%$ \\
\hline Baseline & & $89,61 \%$ \\
\hline
\end{tabular}

\subsubsection{Análise dos Resultados}

Os resultados apresentados mostram que a classificação por extração de atributos pode ser promissora na identificação de insetos por sensores ópticos. Alguns dos cenários analisados obtiveram um desempenho melhor do que o baseline estabelecido pela classificação por similaridade. Porém, é possível notar importância da escolha adequada de algoritmos de aprendizado e seus respectivos parâmetros. Vários cenários obtiveram uma acurácia menor do que o simples classificador baseado na distância euclidiana.

Outro fator que pode influenciar negativamente na classificação por extração de atributos é, justamente, o atributo escolhido para descrever os sinais analisados. Além disso, algumas técnicas de extração de atributos possuem um parâmetro relacionado ao número de coeficientes a ser utilizado, como no caso dos MFCC. Os algoritmos de aprendizado de máquina são sensíveis a escolha desse parâmetro, como foi mostrado na Figura 5.1.

Por esses motivos, é necessário avaliar o desempenho de diferentes classificadores, bem como diferentes estratégias de extração de atributos. Na próxima seção, serão descritos os experimentos e resultados da classificação por extração de atributos em diferentes 
representações de séries temporais. Além disso, é avaliado o desempenho da combinação de diferentes classificadores e conjuntos de atributos.

\subsection{Extração de Atributos em Diferentes Representações de Séries Temporais}

Na seção anterior, foi descrito um trabalho que comprovou a eficácia da classificação por extração de atributos. Para isso, foram utilizados apenas coeficientes mel-cepstrais. Além disso, o número de coeficientes utilizados foi fixado após uma análise simples dos resultados obtidos por meio de sua variação em dois classificadores: SVM e 1-NN. A partir disso, é interessante investigar a classificação por meio de outros conjuntos de atributos, bem como a variação do parâmetro da fase de extração de atributos, para cada algoritmo de aprendizado.

Nesta seção, será apresentado um trabalho que utilizou atributos de diferentes representações de séries temporais na classificação de insetos por sensores ópticos. Além disso, vários experimentos foram realizados a fim de analisar a influência da combinação de diferentes algoritmos de aprendizado e diferentes conjuntos de atributos (Silva et al., 2013b). Para isso, foi utilizado o conjunto de dados com nove espécies de insetos, descrito na Tabela 4.10.

\subsubsection{Extração de Atributos}

Neste trabalho, foram utilizados os atributos temporais e espectrais apresentados na Seção 2.2. Para facilitar a leitura, neste capítulo serão utilizadas as denominações atributos temporais e atributos espectrais, referentes aos vetores de atributos extraídos na representação de tempo e de frequências, respectivamente. Na Tabela 5.3 são listados os atributos que compõem cada um desses vetores.

Além disso, também foram utilizados coeficientes mel-cepstrais (MFCC). Porém, os MFCC utilizam uma escala baseada em características da audição humana. A princípio, não há motivos para limitar a extração desses coeficientes apenas na escala mel, uma vez que não há evidência concreta de que a audição humana é adequada para identificar os sinais capturados pelo sensor. Por esse motivo, outras escalas foram utilizadas para a extração de coeficientes cepstrais. Mais especificamente, foram utilizados coeficientes cepstrais nas escalas linear (LFC) e log-linear (LLFC).

Por fim, foram utilizados coeficientes de predição linear (LPC), bem como sua variante Line Spectral Frequencies (LSF). Note que em todos esses casos, exceto nos atributos 
Tabela 5.3: Lista dos atributos que compõem os vetores de atributos temporais e espectrais

\begin{tabular}{|c|c|c|}
\hline Representação & Atributo & Método de Extração \\
\hline \multirow{12}{*}{ Temporal } & Magnitude média & Equação 2.6 \\
\hline & Root mean square & Equação 2.7 \\
\hline & Short-time energy & Equação 2.8 \\
\hline & Intervalo & Equação 2.9 \\
\hline & Centroide Temporal & Equação 2.10 \\
\hline & Zero-crossing rate & Equação 2.11 \\
\hline & Complexidade estimada & Equação 2.12 \\
\hline & Variância & Equação 2.13 \\
\hline & Desvio padrão & Equação 2.14 \\
\hline & Obliquidade & Equação 2.15 \\
\hline & Curtose & Equação 2.16 \\
\hline & Duração do sinal & Equação 2.5 \\
\hline \multirow{17}{*}{ Espectral } & Frequência fundamental & Estimada no domínio cepstral \\
\hline & Inarmonia & Equação 2.18 \\
\hline & Tristimulus 1 & Equação 2.19 \\
\hline & Tristimulus 2 & Equação 2.20 \\
\hline & Tristimulus 3 & Equação 2.21 \\
\hline & Irregularidade espectral & Equação 2.22 \\
\hline & Irregularidade espectral modificada & Equação 2.23 \\
\hline & Fluxo & Equação 2.24 \\
\hline & Centroide espectral & Equação 2.25 \\
\hline & Variância & Equação 2.13 , adaptada para espectro de frequência \\
\hline & Desvio padrão & Equação 2.14 , adaptada para espectro de frequência \\
\hline & Curtose & Equação 2.15 , adaptada para espectro de frequência \\
\hline & Obliquidade & Equação 2.16 , adaptada para espectro de frequência \\
\hline & Magnitude média & Equação 2.6, adaptada para espectro de frequência \\
\hline & Energia & Equação 2.8 , adaptada para espectro de frequência \\
\hline & Roll-off & Equação 2.26 \\
\hline & Achatamento & Equação 2.27 \\
\hline
\end{tabular}

temporais e espectrais, há um parâmetro relacionado ao número de coeficientes a ser utilizado. Em outras palavras, para os conjuntos de atributo MFCC, LFC, LLFC, LPC e LSF, existe um parâmetro adicional que também deve ser ajustado.

\subsubsection{Avaliação Experimental}

Utilizando os atributos descritos, foi realizada uma ampla avaliação experimental. Para isso, foram utilizados os algoritmos de aprendizado descritos na Tabela 5.4, juntamente aos valores de parâmetros que foram variados. Para escolher uma configuração adequada de parâmetros foi utilizado um procedimento similar ao descrito na Seção 5.1.3. Em outras palavras, foi utilizada a estratégia da variação de parâmetros em uma validação cruzada com 10 folds no conjunto de treinamento, exceto para o algoritmo máquina de vetores de suporte, em que foi utilizada a estratégia de busca em grade. Neste experimento, foram utilizados os algoritmos $k$-vizinhos mais próximos $(k-\mathrm{NN})$, floresta aleatória, árvore de decisão J48, máquina de vetores de suporte (SVM), modelo de mistura de gaussianas (GMM) e naïve Bayes.

Os resultados desse experimento são exibidos na Tabela 5.5. Devido ao grande número de variações de classificadores e conjuntos de atributos, alguns dos resultados foram 
Tabela 5.4: Algoritmos de aprendizado com seus respectivos intervalos de valores de parâmetros

\begin{tabular}{lll}
\hline Algoritmo & Parâmetros & Intervalo de valores (inicial:passo:final) \\
\hline$k$-NN & \# de vizinhos $(k)$ & $k=1: 2: 25$ \\
Floresta Aleatória & \# de árvores $(T)$ & $T=5: 2: 75$ \\
J48 & Fator de poda & $P=0.1: 0.1: 0.5$ \\
SVM - kernel polinomial & Regularização $(c)$; Grau $(d)$ & $c=10^{i}, i=-7: 1: 5 ; d=1: 1: 3$ \\
SVM - kernel RBF & Regularização $(c)$; Gama $(\gamma)$ & $c=10^{i}, i=-7: 1: 5 ; \gamma=10^{i}, i=-4: 1: 0$ \\
GMM (cov. Diagonal) & \# de gaussianas $(G)$ & $G=3: 2: 21$ \\
Naïve Bayes & - & - \\
\hline
\end{tabular}

omitidos. Por exemplo, os classificadores J48 e naïve Bayes obtiveram resultados muito inferiores a todos os outros. Além disso, a utilização do kernel polinomial obteve resultados inferiores à utilização do kernel RBF em todos os casos. Assim, foi decidido suprimir o resultado desses três classificadores.

Tabela 5.5: Resultados por classificador e conjunto de atributos, e os valores dos parâmetros ideais. O melhor resultado em cada conjunto de atributos está destacado em negrito

\begin{tabular}{|c|c|c|c|}
\hline $\begin{array}{l}\text { Conjunto de } \\
\text { Atributos }\end{array}$ & $\begin{array}{l}\text { Algoritmo de } \\
\text { Aprendizado }\end{array}$ & $\begin{array}{l}\text { Configuração de } \\
\text { Parâmetros }\end{array}$ & $\begin{array}{r}\text { Acurácia } \\
(\%) \\
\end{array}$ \\
\hline \multirow{4}{*}{ LFC } & $k-\mathrm{NN}$ & $\#$ de coeficientes $=75, k=7$ & 81,71 \\
\hline & Floresta Aleatória & $\#$ de coeficientes $=80, T=75$ & 83,49 \\
\hline & SVM RBF & $\#$ de coeficientes $=95, c=10, \gamma=1$ & 86,93 \\
\hline & GMM & $\#$ de coeficientes $=100, G=9$ & 83,17 \\
\hline \multirow{4}{*}{ LLFC } & $k$-NN & $\#$ de coeficientes $=15, k=7$ & 74,70 \\
\hline & Floresta Aleatória & $\#$ de coeficientes $=20, T=60$ & 76,30 \\
\hline & SVM RBF & $\#$ de coeficientes $=70, c=10000, \gamma=0,01$ & 79,05 \\
\hline & GMM & $\#$ de coeficientes $=20, G=17$ & 74,03 \\
\hline \multirow{4}{*}{ MFCC } & $k$-NN & $\#$ de coeficientes $=30, k=5$ & 83,61 \\
\hline & Floresta Aleatória & $\#$ de coeficientes $=35, T=75$ & 85,39 \\
\hline & SVM RBF & $\#$ de coeficientes $=40, c=10, \gamma=1$ & 87,33 \\
\hline & GMM & $\#$ de coeficientes $=45, G=13$ & 82,42 \\
\hline \multirow{4}{*}{ LPC } & $k$-NN & $\#$ de coeficientes $=45, k=21$ & 56,18 \\
\hline & Floresta Aleatória & $\#$ de coeficientes $=65, T=75$ & 60,90 \\
\hline & SVM RBF & $\#$ de coeficientes $=45, c=100000, \gamma=0,1$ & 66,85 \\
\hline & GMM & $\#$ de coeficientes $=40, G=19$ & 54,15 \\
\hline \multirow{4}{*}{ LSF } & $k-\mathrm{NN}$ & $\#$ de coeficientes $=95, k=5$ & 80,23 \\
\hline & Floresta Aleatória & $\#$ de coeficientes $=95, T=75$ & 84,25 \\
\hline & SVM RBF & \# de coeficientes $=100, c=10, \gamma=1$ & 84,97 \\
\hline & GMM & \# de coeficientes $=75, G=17$ & 75,28 \\
\hline \multirow{4}{*}{ Temporal } & $k$-NN & $k=11$ & 50,91 \\
\hline & Floresta Aleatória & $G=75$ & 60,13 \\
\hline & SVM RBF & $c=100000, \gamma=0,1$ & 60,62 \\
\hline & GMM & $G=19$ & 42,76 \\
\hline \multirow{4}{*}{ Espectrais } & $k-\mathrm{NN}$ & $k=5$ & 70,51 \\
\hline & Floresta Aleatória & $T=50$ & 79,38 \\
\hline & SVM RBF & $c=100000, \gamma=0,1$ & 76,24 \\
\hline & GMM & $G=21$ & 63,73 \\
\hline
\end{tabular}

Os melhores resultados foram obtidos com a utilização de MFCC, com LFC e LSF alcançando resultados próximos. Os conjuntos de atributos espectrais e LLFC obtiveram resultados um pouco inferiores a esses. Por outro lado, os resultados obtidos com o 
conjunto de atributos temporais e LPC foram substancialmente menores que as outras características.

Especificamente, o melhor desempenho foi obtido pelo uso do algoritmo SVM com kernel RBF aplicado sobre um conjunto de MFCC, com acurácia de 87,33\%. O melhor resultado obtido na classificação por similaridade havia sido $81,87 \%$ de acurácia.

\subsubsection{Combinação de Atributos e de Algoritmos de Aprendizado}

Esta etapa experimental tem por objetivo investigar combinações entre as saídas de diferentes classificadores. Diferentes algoritmos e características podem cometer erros em diferentes exemplos. Então, é possível construir combinações de classificadores para explorar essa diversidade. Para combinar as saídas, foram utilizadas três estratégias:

- Votação simples: cada classificador deposita um voto para a classe predita por ele e a resposta final é dada pela classe com o maior número de votos. Em caso de empate, a classe com maior probabilidade a priori é escolhida;

- Soma de scores: cada classificador contribui com votos de diferentes valores para cada classe, dados pelos valores de pontuação (scores) estimados pelo modelo de classificação;

- Multiplicação de scores: semelhante à soma de scores, porém multiplica os valores obtidos ao invés de somá-los.

Uma possível vantagem das duas últimas estratégias, em relação à votação simples, é considerar o fato de que os classificadores podem atribuir valores de pontuação diferentes, de acordo com a probabilidade de cada exemplo pertencer a cada classe. Por exemplo, exemplos que estão próximos à fronteira de decisão entre as classes $a$ e $b$ de um classificador recebem valores de pontuação aproximadamente iguais para essas duas classes. Nesse caso, se um classificador fornecer a classe inadequada ao exemplo, o peso dessa decisão não será tão grande na decisão final da combinação.

Na Tabela 5.6, são apresentados os resultados da combinação de diferentes algoritmos de aprendizado, aplicados ao mesmo conjunto de dados. São exibidos dois resultados para cada conjunto de atributos: o primeiro obtido pela combinação de todos os classificadores e o segundo obtido pela combinação das saídas dos três melhores classificadores que utilizaram tais atributos, segundo resultados apresentados na Tabela 5.5.

Dados os resultados, é claro o fato de que a combinação de diferentes classificadores aplicados sobre o mesmo conjunto de dados não melhora os resultados obtidos de modo sistemático. Os valores de acurácia obtidos pela combinação foram melhores do que os 
Tabela 5.6: Resultados obtidos pela combinação da saída de diferentes classificadores treinados com o mesmo conjunto de atributos. Os resultados destacados representam um ganho de acurácia sobre o melhor classificador individual que utiliza o conjunto de atributos analisado

\begin{tabular}{|c|c|c|c|c|c|}
\hline \multirow{2}{*}{$\begin{array}{l}\text { Conjunto de } \\
\text { Atributos }\end{array}$} & \multirow{2}{*}{$\begin{array}{l}\text { Acurácia } \\
\text { Individual (\%) }\end{array}$} & \multirow{2}{*}{$\begin{array}{l}\text { Algoritmos } \\
\text { Combinados }\end{array}$} & \multicolumn{3}{|c|}{ Acurácia (\%) } \\
\hline & & & Soma & Produto & Votação \\
\hline \multirow{2}{*}{ LFC } & \multirow{2}{*}{86,93} & SVM RBF, $k$-NN, GMM, Floresta Aleatória & 84,86 & 84,70 & 86,07 \\
\hline & & SVM RBF, GMM, Floresta Aleatória & 83,58 & 83,94 & 86,29 \\
\hline \multirow{2}{*}{ LLFC } & \multirow{2}{*}{79,05} & SVM RBF, $k$-NN, GMM, Floresta Aleatória & 77,94 & 77,75 & 79,12 \\
\hline & & SVM RBF, GMM, Floresta Aleatória & 77,48 & 77,88 & 78,68 \\
\hline \multirow{2}{*}{ MFCC } & \multirow{2}{*}{87,33} & SVM RBF, $k$-NN, GMM, Floresta Aleatória & 85,48 & 85,22 & 86,69 \\
\hline & & SVM RBF, $k$-NN, Floresta Aleatória & 85,30 & 85,80 & 86,59 \\
\hline \multirow{2}{*}{$\mathrm{LSF}$} & \multirow{2}{*}{84,97} & SVM RBF, $k$-NN, GMM, Floresta Aleatória & 81,72 & 80,49 & 84,64 \\
\hline & & SVM RBF, $k$-NN, Floresta Aleatória & 83,78 & 84,15 & 84,84 \\
\hline \multirow{2}{*}{ Espectrais } & \multirow{2}{*}{79,38} & SVM RBF, $k$-NN, GMM, Floresta Aleatória & 73,82 & 72,55 & 77,02 \\
\hline & & SVM RBF, GMM, Floresta Aleatória & 77,22 & 77,51 & 78,41 \\
\hline
\end{tabular}

obtidos pelo classificador base em apenas um $(3,33 \%)$ dos casos analisados. Mesmo nesse caso, o ganho não é significativo.

Também foi avaliada a hipótese de que a combinação de diferentes representações podem prover diversidade suficiente para melhorar os resultados da classificação. Para isso, foram conduzidos experimentos com diferentes combinações de conjuntos de atributos utilizando um único algoritmo de classificação.

Primeiramente, foi verificado se diferentes escalas de frequência utilizadas para extrair coeficientes cepstrais podem ser complementares. Assim, foram criadas combinações de LFC, LLFC e MFCC. Também foram utilizados os atributos espectrais e LSF, em combinação com MFCC, uma vez que alcançaram alguns dos melhores resultados no primeiro experimento, e LFC, que obteve resultados competitivos em comparação ao MFCC. Além disso, também foi avaliada a combinação de todos esses conjuntos de atributos (LFC, LLFC, MFCC, LSF e espectral). Os resultados são exibidos na Tabela 5.7.

A combinação de diferentes conjuntos de atributos alcançou melhores resultados em termos de acurácia. No total, $31(64,58 \%)$ dos casos analisados demonstraram melhoria. Vale a pena notar que a combinação de todos os conjuntos de atributos - com exceção dos atributos temporais e dos LPC - aumenta a acurácia dos classificadores simples em todos os casos.

Esse resultado pode levar o leitor ao questionamento sobre a contribuição real de cada atributo na combinação de classificadores. Até aqui, foram analisadas apenas combinações da saída de classificadores treinados com tipos de atributos diferentes entre eles. Para saber a real contribuição entre os diferentes tipos de atributos, foi construído um conjunto de dados com todos os atributos, com o maior número de coeficientes utilizados anteriormente. Em outras palavras, foi construído um conjunto de dados com 529 atributos, sendo eles: 100 LFC, 100 LLFC, 100 MFCC, 100 LSF, 100 LPC, 12 atributos 
Tabela 5.7: Resultados obtidos pela combinação da saída de classificadores treinados com diferentes conjuntos de atributos. Os resultados destacados representam um ganho de acurácia sobre o melhor classificador individual que utiliza o algoritmo de aprendizado analisado

\begin{tabular}{|c|c|c|c|c|c|}
\hline \multirow{2}{*}{$\begin{array}{l}\text { Algoritmo de } \\
\text { Aprendizado }\end{array}$} & \multirow{2}{*}{$\begin{array}{l}\text { Acurácia } \\
\text { Individual (\%) }\end{array}$} & \multirow{2}{*}{$\begin{array}{l}\text { Conjuntos de } \\
\text { Atributos }\end{array}$} & \multicolumn{3}{|c|}{ Acurácia (\%) } \\
\hline & & & Soma & Produto & Votação \\
\hline \multirow{4}{*}{ SVM RBF } & \multirow{4}{*}{87,33} & LFC, LLFC, MFCC & 87,46 & 87,27 & 87,91 \\
\hline & & LFC, LSF, Espectrais & 86,83 & 86,44 & 87,09 \\
\hline & & MFCC, LSF, Espectrais & 86,85 & 86,35 & 87,14 \\
\hline & & LFC, LLFC, MFCC, LSF, Espectrais & 88,70 & 88,47 & 88,44 \\
\hline \multirow{4}{*}{$k-\mathrm{NN}$} & \multirow{4}{*}{83,61} & LFC, LLFC, MFCC & 85,48 & 85,57 & 84,57 \\
\hline & & LFC, LSF, Espectrais & 83,94 & 83,56 & 82,46 \\
\hline & & MFCC, LSF, Espectrais & 84,82 & 84,45 & 83,05 \\
\hline & & LFC, LLFC, MFCC, LSF, Espectrais & 86,15 & 86,00 & 85,18 \\
\hline \multirow{4}{*}{ GMM } & \multirow{4}{*}{83,17} & LFC, LLFC, MFCC & 85,50 & 86,35 & 84,72 \\
\hline & & LFC, LSF, Espectrais & 83,17 & 84,16 & 81,49 \\
\hline & & MFCC, LSF, Espectrais & 82,86 & 82,68 & 81,18 \\
\hline & & LFC, LLFC, MFCC, LSF, Espectrais & 86,20 & 86,01 & 85,50 \\
\hline \multirow{4}{*}{ Floresta Aleatória } & \multirow{4}{*}{85,39} & LFC, LLFC, MFCC & 86,69 & 86,93 & 84,82 \\
\hline & & LFC, LSF, Espectrais & 86,50 & 86,36 & 84,76 \\
\hline & & MFCC, LSF, Espectrais & 86,99 & 86,89 & 85,44 \\
\hline & & LFC, LLFC, MFCC, LSF, Espectrais & 87,83 & 87,97 & 86,14 \\
\hline
\end{tabular}

temporais e 17 atributos espectrais. Esse número de coeficientes (100) é um número alto, considerando-se que raramente são encontrados trabalhos em que o número de coeficientes utilizados se aproxima de uma centena.

Devido à alta dimensionalidade desse conjunto de dados, foram aplicadas técnicas de seleção de atributos sobre ele. Especificamente, foram utilizados os algoritmos correlationbased feature selection (CFS) (Hall, 1999) e relief (Kononenko, 1994). No caso do relief, o algoritmo apenas cria um ranking dos atributos de acordo com seu bom desempenho na tarefa de classificação. É necessário, então, escolher quantos atributos serão utilizados e selecioná-los de acordo com a ordem estabelecida pelo algoritmo. Foram utilizados 27, 53, 106 e 159 atributos $(5 \%, 10 \%, 20 \%$ e 30\% do total). O algoritmo CFS não possui esse parâmetro, sendo que esse algoritmo selecionou, automaticamente, 74 atributos. Na Tabela 5.8, são exibidos os atributos que foram selecionados nesta fase.

É interessante notar que os coeficientes mel-cepstrais sempre são selecionados em grandes quantidades. Em todos os casos, CFS e variações do relief, o conjuto de atributos com maior número de coeficientes selecionados foi sempre o MFCC. Isso comprova ainda mais sua qualidade na aplicação.

Os coeficientes cepstrais tomados em escala linear e as LSF também foram tomados em grande número pelos algoritmos de seleção. O mesmo aconteceu para os atributos espectrais. Por outro lado, os coeficientes de predição linear e os atributos temporais tiveram grande parte de seus atributos descartados.

Os algoritmos de aprendizado utilizados nesta etapa foram o $k$-NN, a floresta aleatória e o SVM com kernel RBF. Essa escolha foi feita pelo fato desses algoritmos terem 
Tabela 5.8: Atributos selecionados pelos algoritmos CFS e relief

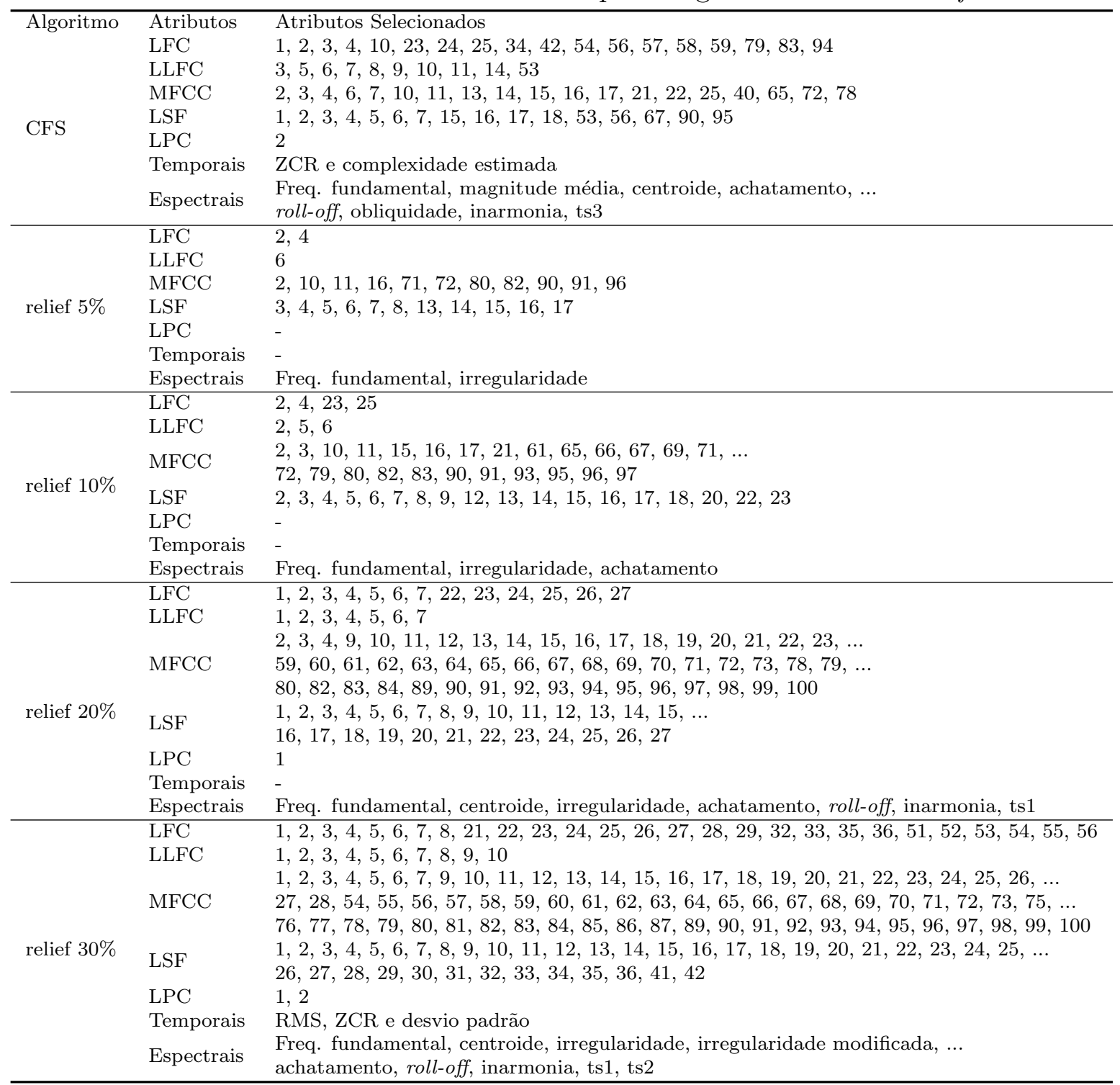

apresentado os melhores resultados nos experimentos anteriores. Os resultados obtidos são apresentados na Tabela 5.9.

Ao analisar os resultados, é interessante notar que a utilização de todos os conjuntos de atributos não melhora sistematicamente o desempenho dos classificadores. Em um dos classificadores analisados, essa estratégia obteve um desempenho inferior ao classificador treinado com apenas um conjunto de atributos. O mesmo não acontece quando é utilizada alguma estratégia de seleção de atributos. No caso do algoritmo CFS, sua aplicação melhorou o desempenho do classificador em todos os casos. O mesmo foi verificado para o algoritmo relief, quando são selecionadas quantidades adequadas de atributos. Nesse caso, $20 \%$ (106) e 30\% (159) do número total de atributos. 
Tabela 5.9: Resultado da classificação com todos os conjuntos de atributos e técnicas de seleção de atributos. Os valores destacados são relativos àqueles com melhor desempenho do que o classificador base, considerando o melhor conjunto de atributos para ele

\begin{tabular}{|c|c|c|c|c|c|c|c|}
\hline $\begin{array}{l}\text { Algoritmo de } \\
\text { Aprendizado }\end{array}$ & $\begin{array}{l}\text { Acurácia } \\
\text { Individual (\%) }\end{array}$ & $\begin{array}{r}\text { Todos os } \\
\text { Atributos }\end{array}$ & CFS & relief $5 \%$ & relief $10 \%$ & relief $20 \%$ & relief $30 \%$ \\
\hline$k-\mathrm{NN}$ & 83,61 & 83,51 & 86,19 & 83,07 & 82,76 & 83,85 & 85,23 \\
\hline Floresta Aleatória & 85,39 & 86,98 & 88,37 & 85,63 & 86,16 & 86,86 & 87,54 \\
\hline SVM RBF & 87,33 & 89,14 & 88,78 & 85,88 & 86,96 & 87,38 & 89,55 \\
\hline
\end{tabular}

\subsubsection{Classificação por Extração de Atributos Considerando Classes Binárias}

Até esta etapa, foram avaliados apenas classificadores em um ambiente multiclasse. Embora essa configuração forneça uma avaliação global dos classificadores, nem todas as classes são igualmente importantes para a maioria das aplicações. Por exemplo, uma armadilha inteligente geralmente é utilizada para capturar uma única espécie de interesse, tal como um vetor de doença ou uma praga agrícola. Todas as outras espécies podem ser consideradas como pertencentes à classe negativa, sendo libertadas para o meio ambiente. Assim, muitas aplicações práticas requerem um classificador binário. Por esse motivo, também foi analisado o desempenho dos classificadores que consideram mosquitos vetores de doenças (Aedes aegypti, Anopheles gambiae, Culex quinquefasciatus e Culex tarsalis) como exemplos da classe positiva e as demais espécies (Apis mellifera, Cotinis mutabilis, Drosophila melanogaster, Musca domestica e Psychodidae diptera) como exemplos da classe negativa.

Ao dividir o conjunto de dados em tal configuração, é causado um claro desbalanceamento das classes. No conjunto de dados completo (treinamento e teste) o número de exemplos gerados por mosquitos vetores de doença é 14613, em comparação com apenas 3502 exemplos de outras espécies. Assim, neste experimento, não se avaliou apenas a acurácia, mas também a área sob a curva ROC (AUC), medida mais recomendada para a avaliação da classificação quando há o problema de desbalanceamento de classes (Batista et al., 2004).

Nessa etapa, foram utilizados 40 MFCC para treinar o algoritmo SVM-RBF, uma vez que foi a configuração com melhor resultado dentre os classificadores simples. Também foi avaliada a classificação utilizando-se a melhor configuração de combinação de classificadores: três escalas para a obtenção de coeficientes cepstrais, LSF e atributos espectrais, combinados pela soma da saída dos modelos obtidos pelo algoritmo SVM-RBF. No primeiro caso, foi obtida uma acurácia de 97,82\% e uma AUC de 0,966. No caso da combinação de classificadores, foi alcançada uma acurácia de 98\% e uma AUC de 0,968. O ganho de acurácia é devido, principalmente, ao fato de que os erros nos classificadores 
multiclasse estavam concentrados entre as espécies com características semelhantes, como diferentes espécies de mosquito.

\subsubsection{Análise dos Resultados}

Os experimentos e resultados apresentados nesta seção mostram que, de fato, com a estratégia de classificação por extração de atributos, é possível alcançar bons resultados na classificação de insetos por meio de sensores ópticos. Especificamente, os coeficientes mel-cepstrais formam o conjunto de atributos que obteve melhor resultado. Também foi mostrado que a combinação de diferentes atributos pode prover uma melhoria na qualidade da classificação. Por fim, foi verificado que essa estratégia também pode fornecer bons resultados em cenários em que são consideradas classes binárias, mesmo que desbalanceadas.

Uma possível crítica a esses resultados pode ser feita em relação ao custo computacional das técnicas utilizadas. Entretanto, o principal objetivo deste trabalho é identificar atributos e classificadores que possam fornecer bons resultados para a aplicação requerida. Além disso, uma análise de uso de memória e processamento seria impossível de ser realizada, uma vez que os experimentos apresentados utilizaram diferentes ferramentas para sua execução.

O que deve ser levado em consideração neste momento é o fato de que a combinação de diferentes conjuntos de atributos pode ser inviável, uma vez que deve ser realizada a fase de extração de atributos a cada passagem de inseto detectada pelo sensor. Isso é ainda mais evidente quando são utilizados todos os conjuntos de atributos analisados. Idealmente, o software embarcado no sensor deve extrair apenas um tipo de atributo, tornando essa fase menos custosa. Portanto, apesar dos resultados relativos à combinação de atributos se mostrarem melhores, as restrições de memória e processamento deverão ser levadas em conta quando as técnicas analisadas forem embarcadas no sensor.

Os resultados apresentados neste capítulo servirão de base para outro trabalho, com foco na criação de classificadores que podem ser melhor adaptados ao sensor óptico para a classificação de insetos (Lemes, 2013).

Por fim, esses resultados também serão base para a análise de dados em fluxo nãoestacionário. Analisar os sinais sob esse ponto de vista é importante principalmente devido a alterações ambientais, que também podem causar variações nos movimentos dos insetos e, consequentemente, nos dados capturados pelo sensor. No decorrer deste trabalho, foi realizada uma cooperação que gerou resultados iniciais na classificação de insetos em fluxo de dados. Esses resultados são brevemente apresentados na próxima seção. 


\subsection{Classificação de Insetos em Fluxo de Dados}

Na maioria das aplicações que envolvem sensores inteligentes, não é possível assumir que os dados são gerados por um processo estocástico estacionário. No caso do sensor para classificação automática de insetos, tal suposição está relacionada à existência de variações nas condições ambientais, que podem interferir no metabolismo dos insetos. Por exemplo, as variações climáticas sugestionam o comportamento dos insetos, uma vez que seu metabolismo é influenciado pela temperatura (Taylor, 1963), pressão do ar (Chadwick e Williams, 1949) e umidade (Mellanby, 1936). Assim, um sensor inteligente tem de se adaptar a essas variações, uma ideia conhecida na literatura como mudança de conceito (ou, em inglês, concept drift) (Widmer e Kubat, 1996).

Essas considerações não são escopo principal deste trabalho, mas sim de um trabalho em desenvolvimento (de Souza, 2011). Entretanto, neste trabalho foram realizados primeiros esforços na terafa de classificação de insetos considerando fluxo de dados. Nesta seção, serão apresentados os resultados iniciais (de Souza et al., 2013a).

Os dados utilizados nestes experimentos é o mesmo subconjunto dos dados com nove classes que foi utilizado na Seção 5.1, melhor descrito na Seção 5.1.1. Com esse conjunto de dados, foi decidido utilizar dois algoritmos de aprendizado: vizinho mais próximo (1-NN), naturalmente incremental, e modelo de mistura de gaussianas (GMM), que naturalmente gera probabilidades de pertinência a cada classe. O conjunto de atributos utilizado neste trabalho é composto por 50 coeficientes mel-cepstrais.

\subsubsection{Estratégias de Aprendizado em Fluxo de Dados}

De modo geral, são utilizadas duas estratégias para lidar com mudanças de conceito em fluxo de dados (Sebastião e Gama, 2009): detectar a mudança e, então, adaptar o modelo de classificação ou adaptá-lo em intervalos regulares de tempo, independentemente da detecção de mudanças.

Neste trabalho preliminar, foi considerada apenas a segunda estratégia. Essa abordagem assume que as informações obtidas a partir dos dados mais recentes são mais relevantes. Para isso, utiliza-se técnicas de janelamento que mantêm apenas os dados mais recentes ou atribui pesos aos exemplos de acordo com sua idade, sendo que dados antigos possuem peso menor. Neste trabalho, foram utilizados cinco tipos de janelas:

- Janela fixa no início do fluxo de dados: O conjunto de treinamento é composto por uma porcentagem dos dados, no início do fluxo, e não é atualizado em nenhum momento. Com isso, é possível verificar se os dados no início do fluxo são suficientes para construir um classificador que não precisa se adaptar ao longo do tempo; 
- Janela de referência atualizada com os rótulos preditos: O conjunto de treinamento é inicialmente composto por uma porcentagem dos dados. Mas, quando um novo exemplo é apresentado ao classificador, ele é agregado ao conjunto de dados de treinamento com sua classe predita. Assim, esse conjunto de dados aumenta de tamanho gradualmente. É necessário notar que, caso o exemplo seja classificado incorretamente, essa estratégia insere ruídos no conjunto de dados;

- Janela de referência atualizada com os rótulos corretos: Similar à estratégia anterior, mas o novo exemplo é agregado ao conjunto de dados com seu rótulo correto. Note que essa abordagem é impossível na prática, por isso é utilizada apenas como referencial;

- Janela deslizante atualizada com os rótulos preditos: Essa estratégia utiliza janelas deslizantes de tamanho fixo como conjunto de treinamento. Inicialmente, o conjunto de dados é composto por uma janela com os dados do início do fluxo. A cada exemplo que é apresentado ao classificador, o exemplo mais antigo é descartado e o mais novo é agregado ao conjunto de dados. Desse modo, é possível observar se os dados mais recentes são mais representativos que dados antigos;

- Janela deslizante atualizada com os rótulos corretos: Similar à estratégia anterior, mas o novo exemplo é agregado ao conjunto de dados com seu rótulo correto.

A configuração de janela fixa no início do fluxo simula a utilização de um modelo estático aplicado em um cenário de fluxo de dados. O resultado obtido por essa configuração pode ser considerado como uma referência inferior para as outras definições, no sentido de que as outras configurações são capazes de adaptar-se a dados recentes e devem, portanto, ser capazes de superar esse cenário. As configurações que atualizam o conjunto de dados com os rótulos preditos são as mais próximas ao que é requerido na aplicação prática do sensor. As configurações que atualizam os dados com as classes corretas representam o melhor caso das duas configurações anteriores, e podem ser utilizadas como referência superior para elas.

\subsubsection{Resultados e Discussões}

Foram realizados experimentos com quatro diferentes tamanhos de janela: 5\%, 10\%, $15 \%$ e $20 \%$ do número total de exemplos. Uma vez que os resultados são muito semelhantes, somente serão apresentados os resultados obtidos por um valor intermediário, de 15\% do tamanho do fluxo. 
Os resultados obtidos com as cinco estratégias de janelamento e o algoritmo do vizinho mais próximo são apresentados graficamente na Figura 5.2. Nesse gráfico, o eixo horizontal representa a ordem temporal dos exemplos no fluxo e o eixo vertical representa a acurácia prequential (Gama et al., 2013) ao longo do tempo. Acurácia prequential é a acurácia obtida pelo subconjunto cumulativo de todas as classificações realizadas a cada momento.

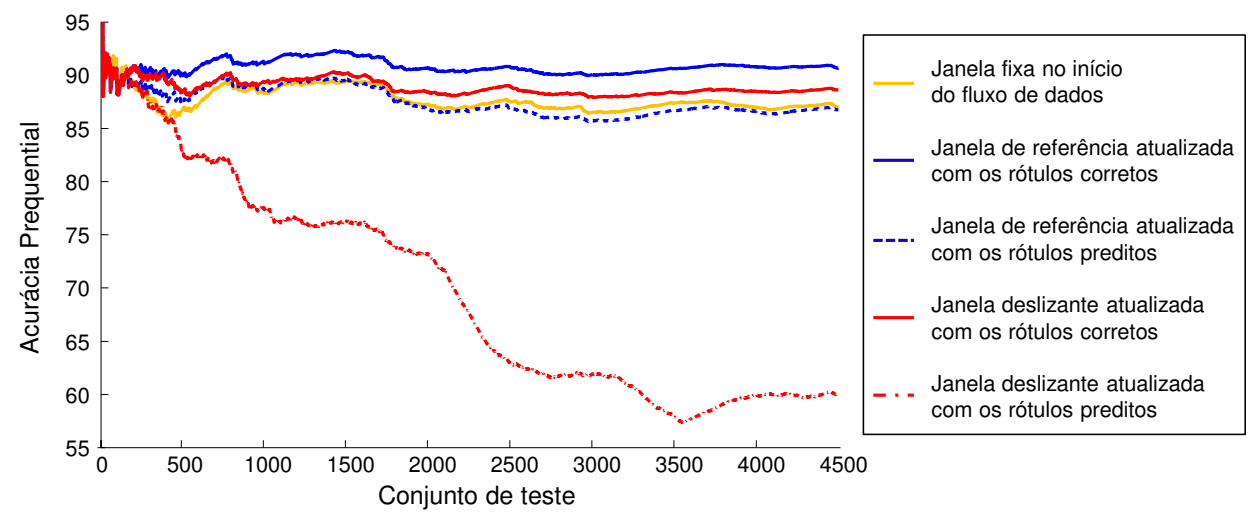

Figura 5.2: Desempenho do algoritmo 1-NN na classificação de insetos em fluxo de dados

O melhor resultado foi obtido pela estratégia de janela de referência que não descarta dados antigos. Uma possível explicação para isso é a ocorrência de mudanças recorrentes. Um exemplo disso é o ritmo circadiano (Taylor e Jones, 1969). Vários insetos possuem maior atividade dentro de determinados períodos do dia. Por exemplo, mosquitos da espécie Culex quinquefasciatus possuem maior atividade entre o anoitecer e o amanhecer do dia seguinte. Assim, o descarte de exemplos antigos causa perda de informação que será necessária em um tempo futuro.

Além disso, é possível verificar que as únicas configurações que conseguem superar os resultados obtidos ao fixar uma janela no início do fluxo foram as estratégias que atualizam o classificador utilizando os rótulos corretos dos novos exemplos. Isso deve ocorrer, principalmente, pela inserção de ruídos no conjunto de dados. Esse fato é ainda mais evidente ao se analisar o resultado obtido pela estratégia de janela deslizante, que descarta os dados mais antigos. A partir de um determinado momento, só há dados com rótulos preditos, alguns deles incorretamente. Esse erro se acumula conforme surgem novos dados, com maior probabilidade de erro, dado que o conjunto de dados possui cada vez mais exemplos erroneamente rotulados.

Uma maneira de se contornar esse problema, é utilizando um classificador probabilístico, de modo que só são incluídos no conjunto de dados aqueles exemplos que possuírem uma alta probabilidade de pertencerem à classe ao qual foram associados. Para isso, foram utilizados modelos de mistura de gaussianas. Os exemplos classificados só foram agrega- 
dos ao conjunto de dados quando sua probabilidade foi maior que $95 \%$. Os resultados dessa operação são exibidos na Figura 5.3.

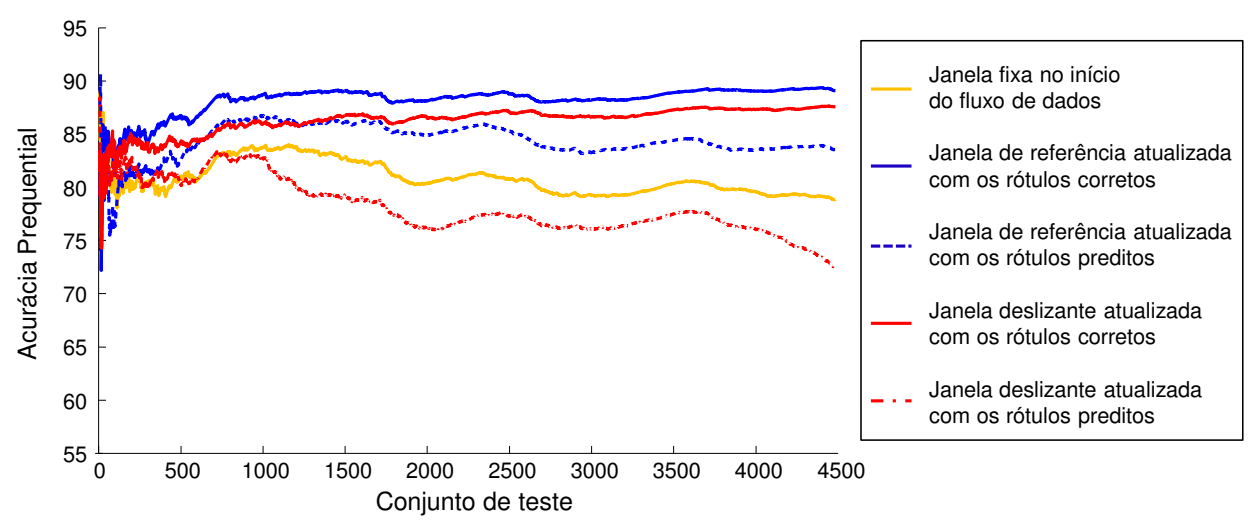

Figura 5.3: Desempenho do algoritmo GMM na classificação de insetos em fluxo de dados

Novamente, o classificador que utiliza janela deslizante, atualizado com o rótulo predito, obteve resultado pior do que o que utiliza janela fixa no início do fluxo. Entretanto, é claro que sua acurácia prequential é muito mais estável do que a que foi obtida pelo algorimo do vizinho mais próximo. Mesmo que o desempenho geral do GMM tenha sido inferior, algoritmos probabilísticos são interessantes, pois permitem explorar diferentes estratégias de inserção e descarte de exemplos no cenário de classificação em fluxo de dados.

\subsubsection{Análise dos Resultados}

Nesta seção, foi apresentada a avaliação de diferentes estratégias de aprendizado em fluxo de dados utilizando dois algoritmos de classificação. Os resultados mostram que o algoritmo do vizinho mais próximo obteve os melhores resultados globais. No entanto, o modelo de mistura de gaussianas obteve melhorias significativas de desempenho para os classificadores atualizados com rótulos preditos.

É interessante notar que o método que utiliza um conjunto de exemplos fixo no início do fluxo obteve resultados competitivos com as demais técnicas. Entretanto, esses resultados tendem a ser bastante otimistas. Os dados utilizados nesses experimentos foram coletados em ambiente controlado. Por isso, provavelmente são muito mais estáveis do que dados coletados em campo. Dessa maneira, uma das atividades futuras deste trabalho é a análise de dados coletados em diferentes condições ambientais. Para isso, poderão ser realizadas coletas de dados em ambientes com temperatura e umidade controladas, mas que passam por grandes variações em determinados momentos. 


\subsection{Considerações Finais}

Neste capítulo, foram apresentados os resultados da classificação de insetos, utilizando sinais capturados por sensores ópticos, por meio da extração de atributos. Foi demonstrado que é possível obter bons resultados utilizando essa estratégia. Os resultados obtidos nestes experimentos foram superiores aos alcançados pela estratégia de classificação por similaridade. Mais especificamente, o conjunto de atributos que obteve melhor desempenho foi aquele composto por coeficientes mel-cepstrais. 



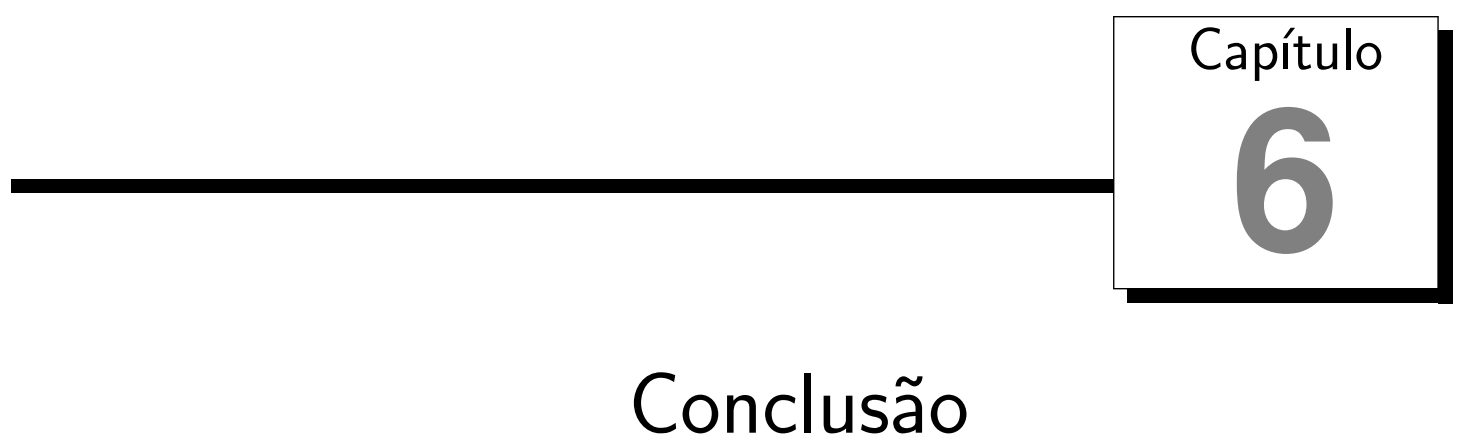

O sensor apresentado neste trabalho é de grande interesse em diferentes aplicações. Dois exemplos são a estimativa da distribuição espaço-temporal de insetos em determinados ambientes e parte integrante de uma armadilha inteligente, que pode ser utilizada para capturar mosquitos vetores de doenças ou insetos considerados pragas agrícolas.

Para seu pleno funcionamento, é necessário investigar técnicas de classificação de séries temporais que possam ser aplicadas aos sinais obtidos pelo sensor. Para isso, foram utilizadas duas abordagens: a classificação por similaridade e a classificação por extração de atributos. Ambas estratégias foram aplicadas com a utilização de diferentes representações de séries temporais.

A classificação por similaridade apresentou bons resultados, quando há uma escolha adequada da representação e da medida de distância a ser utilizada. Especificamente, os resultados obtidos pela similaridade no espectro de frequência foram superiores aos obtidos nas representações temporal e cepstral.

Além disso, foi demonstrado que a utilização de diferentes medidas de distância fornece resultados relativamente diferentes. Foram aplicadas doze medidas de distância à tarefa de classificação por similaridade no domínio de frequências. Com isso, os resultados variaram de $72,28 \%$ a $81,54 \%$ de acurácia, uma diferença de quase $10 \%$. Por fim, foi demonstrado que a utilização de um filtro de suavização pode melhorar a acurácia da classificação. Entretanto, a diferença entre o classificador por similaridade, utilizando a mesma medida de distância, antes e após a aplicação do filtro, não foi maior que 0,5\% de acurácia em nenhum dos casos analisados. 
A segunda abordagem utilizada foi a extração de atributos. Foram utilizados atributos das representações temporal, espectral e cepstral, além de coeficientes de predição linear e sua variante LSF. Esses atributos foram utilizados como entrada em diversos algoritmos de aprendizado de máquina, de diferentes paradigmas. Foi demonstrado que, em diversas configurações de atributos e classificadores, a abordagem por extração de atributos é mais eficaz que a classificação por similaridade. Mais especificamente, um classificador baseado em máquina de vetores de suporte com kernel RBF, treinada com coeficientes mel-cepstrais, obteve 87,33\% de acurácia. Isso representa uma melhora de quase $7 \%$ em relação ao classificador por similaridade.

Também foram avaliadas diferentes maneiras de combinar algoritmos de classificação e de extração de atributos. Foi comprovado que a combinação da saída de diferentes classificadores, treinados com o mesmo vetor de atributos, não fornece melhora no desempenho da classificação. Porém, ao combinar diferentes vetores de atributos como entrada para o mesmo algoritmo de aprendizado, os resultados são positivos. No caso em que a combinação é feita pela saída de diferentes classificadores, a melhor acurácia foi de 88,70\%. No caso dos atributos serem utilizados em um só conjunto de dados, e amostrados de acordo com a saída de técnicas de seleção de atributos, a acurácia alcançou 89,55\%. Entretanto, esse ganho de acurácia pode não ser suficiente para justificar o custo adicional da extração de atributos em diferentes representações. Essa análise faz parte das atividades futuras deste trabalho.

Além da aplicação principal, a classificação de insetos por meio de sensores ópticos, houve contribuições significativas em outras aplicações. Essas contribuições também são relacionadas à análise de séries temporais e sinais de áudio por similaridade e por extração de atributos.

Foi proposta uma medida de dissimilaridade baseada em uma representação do padrão de recorrência e uma medida de distância entre imagens, baseada em compressão de vídeo. Essa medida foi utilizada na classificação de séries temporais de diferentes domínios, incluindo medicina, biologia, processamento de sinais e movimentos humanos. Sua utilização se mostrou competitiva com outras medidas de distância, consideradas estado-da-arte na classificação de séries temporais. Além disso, foi mostrado que é possível saber com antecedência se a medida proposta pode ou não superar as técnicas adversárias.

Essa medida de distância também foi utilizada em uma aplicação específica: a recuperação de informação de música por conteúdo. Para isso, foram utilizados atributos cromáticos para representar a variação de acordes musicais no tempo. Essa variação constitui uma série temporal multivariada correspondente à música analisada. A utilização da medida proposta se mostrou superior a métodos semelhantes, encontrados na literatura. 
Em relação à extração de atributos, foi realizado um estudo que mostrou que as LSF podem ser excelentes descritores da fala, mais especificamente no domínio do reconhecimento de dígitos falados. Nessa aplicação, são comumente utilizados coeficientes melcepstrais. Entretanto, foi demostrado que as LSF podem obter resultados superiores aos MFCC.

Além disso, foi também evidenciada a importância da correta escolha do número de coeficientes a ser utilizado como descritor da fala. É comum encontrar trabalhos que assumem a quantidade de treze coeficientes mel-cepstrais como uma boa configuração de atributos. Este trabalho contribuiu parcialmente para essa suposição, sendo que esse número de coeficientes encontrou-se em um intervalo de valores em que o desempenho da classificação utilizando MFCC mostrou-se estável. Entretanto, a classificação utilizando esses atributos é muito mais sensível a uma má escolha do número de coeficientes do que se forem utilizadas as LSF.

\subsection{Perspectivas Futuras}

Os resultados deste trabalho servirão como base para diferentes atividades futuras. Em relação ao sensor óptico para a identificação automática de insetos, há diversos rumos de trabalho a serem tomados. Os principais deles são a criação de classificadores que podem ser melhor adaptados a restrições de memória e processamento e a análise de fluxo de dados não-estacionários. Especificamente, pretense-se criar algoritmos de classificação anytime, classe de algoritmos que fornece uma resposta válida independentemente do tempo disponível para a execução. É esperado que, quanto maior o tempo disponível para a resposta, maior a qualidade da solução apresentada. Além disso, a análise dos sinais como fluxo de dados é uma importante tarefa para que o sensor seja utilizado na prática. Uma dificuldade relacionada a essa tarefa, é que não se pode assumir que os rótulos corretos serão apresentados ao classificador depois de um curto período de tempo, suposição assumida por grande parte dos trabalhos nesse domínio de aplicação. 



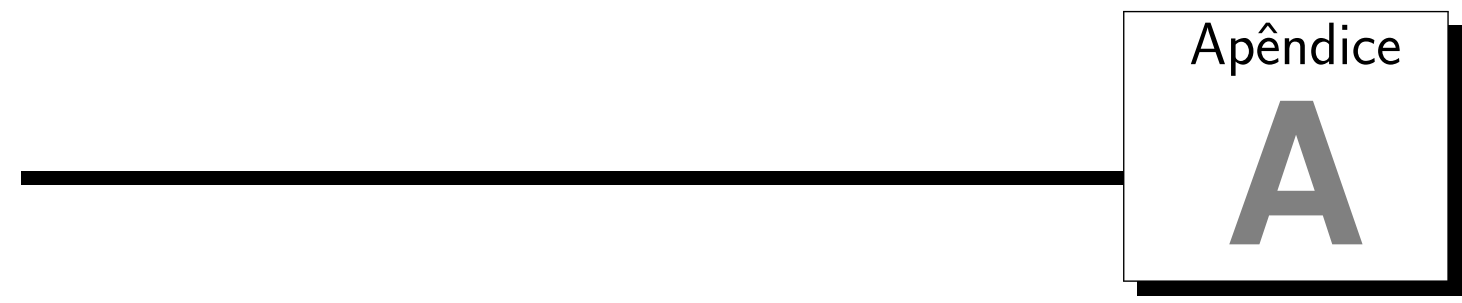

\section{Outras Contribuições}

Durante o desenvolvimento deste trabalho, a análise de séries temporais e sinais de áudio foi extrapolada em relação à análise dos sinais coletados pelo sensor para classificação de insetos. Foram realizadas contribuições em diferentes tipos de sinais. Tais diferenças se dão tanto em termos da produção do sinal quanto em termos de duração e complexidade. Por complexidade, entenda o nível da variação estrutural do sinal. Por exemplo, um sinal relativo a uma música erudita provavelmente possui muitas variações em sua forma ao longo do tempo. Por isso, pode ser considerado um sinal de alta complexidade. Um sinal obtido pela gravação de uma única nota musical emitida por um violino, por exemplo, possui apenas uma perturbação no sinal, sendo, portanto, um sinal de baixa complexidade.

O sinais de insetos coletados pelo sensor óptico são extremamente curtos e sem grandes variações estruturais durante sua produção. Dessa maneira, não é necessária uma estratégia de janelamento para analisá-los. Em outros tipos de sinais, entretanto, isso é necessário. Por exemplo, na análise de fala, os sinais variam de acordo com o fonema produzido a cada momento. Nesse caso, o espaço de características do sinal deve evidenciar as transições entre os fonemas. Por isso, diferentes estratégias de extração de atributos devem ser adotadas de acordo com a complexidade e duração do sinal.

Além disso, a análise de diferentes tipos de produção de áudio pode exigir diferentes vetores de características para alcançar bons resultados. Por exemplo, na análise de sinais musicais, é comum a utilização de atributos cromáticos. Essa representação é específica 
para música, uma vez que separa as componentes de frequência do sinal nos intervalos correspondentes às doze notas (tons e semitons) musicais.

Como primeira aplicação, foi estudada a classificação de dígitos falados. Nesse estudo, foi descoberto que o vetor de atributos LSF pode superar o comumente utilizado MFCC. Também foram evidenciados os efeitos da variação do número de atributos extraídos do sinal, uma vez que comumente são utilizados 13 MFCC para tarefas de análise de fala. Os experimentos e resultados dessa etapa são descritos na Seção A.1.

Posteriormente, foi proposta uma maneira de realizar a tarefa de classificação de séries temporais, que se mostrou bastante eficiente no cumprimento da tarefa. Uma abordagem semelhante foi utilizada para recuperar informação por sinais de música baseado em sua estrutura. Essa abordagem, bem como os resultados obtidos por ela são exibidos na Seção A.2.

\section{A.1 Reconhecimento de Dígitos Falados}

Nas últimas décadas, a tarefa de reconhecimento de voz e locutor tem atraído um grande interesse da indústria e da academia, principalmente devido ao grande número de aplicações que envolvem esse tipo de tecnologia. Alguns exemplos são a autenticação biométrica, em que a voz do usuário é utilizada para permitir ou negar o acesso a um sistema, e a acessibilidade, em que um usuário é capaz de controlar equipamentos ou navegar na internet utilizando apenas a fala, facilitando a execução dessas tarefas por pessoas com deficiências físicas.

Uma importante aplicação do reconhecimento de fala, especialmente útil para provedores de serviços de telefonia, é o reconhecimento de dígitos falados isoladamente. Alguns exemplos de tais serviços são a discagem telefônica por voz, a reserva de passagens aéreas, operações bancárias, cotações de preços, etc. Ao utilizar esse tipo de interação, as empresas podem tornar seus serviços mais amigáveis quando comparados com, por exemplo, a digitação de números no teclado do telefone. Isso é ainda mais evidente quando o procedimento é feito através de dispositivos móveis com tela sensível ao toque, em que não há um teclado fisicamente separado para discagem.

O reconhecimento de dígitos falados pode parecer uma tarefa fácil quando comparado com o reconhecimento de fala em geral. No entanto, é desafiador devido a duas razões principais (Kopparapu e Rao, 2004):

1. Dígitos falados são de curta duração, tipicamente alguns segundos de fala;

2. Alguns dígitos são acusticamente muito semelhantes entre si. 
Devido à relevância da tarefa de reconhecimento de dígitos falados, vários trabalhos têm sido publicados sobre esse tema para diversos idiomas, como japonês (Kondo et al., 1994), inglês (Abushariah et al., 2010), árabe (Alotaibi, 2003; Hu et al., 2011), hindu (Panwar et al., 2011), bengali (Ghanty et al., 2010) e urdu (Azam et al., 2007). Geralmente, esses trabalhos possuem uma estrutura comum, na qual são utilizados MFCC como principais atributos, em conjunto com um algoritmo de aprendizado de máquina.

Nesta seção, serão apresentados os resultados de dois trabalhos publicados durante este trabalho de Mestrado (Silva et al., 2012, 2013d), que estão diretamente relacionados à tarefa de reconhecimento de dígitos falados. Na Seção A.1.1, são apresentados os resultados obtidos pelo uso de LSF no reconhecimento de dígitos falados em português. Na seção seguinte, A.1.2, são apresentados experimentos que estendem os experimentos realizados na Seção A.1.1.

\section{A.1.1 Reconhecimento de Dígitos Falados em Português Utilizando LSF}

Ao buscar na literatura por trabalhos que propõem abordagens e/ou avaliam técnicas aplicadas à tarefa de reconhecimento de dígitos falados em português, é possível verificar uma enorme lacuna de pesquisa nessa língua. Pelo melhor de nosso conhecimento, antes dos trabalhos gerados durante o desenvolvimento deste trabalho, só era possível encontrar dois trabalhos nessa área específica. Rodrigues e Trancoso (1999) utilizaram MFCC e modelos ocultos de Markov para realizar essa tarefa e, mais recentemente, Bresolin et al. (2008) compararam atributos baseados em transformada de wavelet com a utilização de MFCC, mostrando que esses atributos podem obter resultados ligeiramente melhores, caso sejam encontrados os melhores parâmetros a serem utilizados na extração de atributos wavelet.

Devido a essa lacuna, foi realizado um estudo sobre o desempenho de diferentes conjuntos de atributos no reconhecimento de dígitos falados em português (Silva et al., 2012). Como citado e evidenciado anteriormente, essa fase é de extrema importância, uma vez que algoritmos de aprendizado de máquina são altamente sensíveis à qualidade dos dados de entrada. Além dos MFCC, comumente utilizados na tarefa de reconhecimento de dígitos falados, foi avaliada a utilização de coeficientes LSF. Os resultados evidenciam que as LSF são capazes de prover melhores resultados que os MFCC nessa tarefa.

Neste trabalho, foi utilizado o conjunto de dados criado por Bresolin et al. (2008). Utilizar dados públicos restringe qualquer viés que poderia surgir, caso seja decidido criar o próprio conjunto de dados. Além disso, utilizar dados públicos possibilita a comparação com os resultados da literatura e facilita a reprodutibilidade dos resultados (Keogh e 
Kasetty, 2003). Em contrapartida, isso pode implicar em algumas limitações na análise experimental, conforme será discutido na Seção A.1.2.

Para a fase de extração de atributos, foi decidido utilizar uma técnica semelhante à utilizada por Bresolin et al. (2008). Para isso, foi aplicada a estratégia de janelamento com tamanho dinâmico. A importância dessa técnica se dá por dois motivos: primeiro, o janelamento permite extrair atributos localmente em segmentos do sinal, caracterizandoo no tempo; segundo, o janelamento dinâmico permite ajustar o tamanho da janela de modo que os vetores de atributos possuam o mesmo comprimento, independentemente da duração do sinal.

O segundo motivo está relacionado ao fato de algoritmos tradicionais de aprendizado de máquina não lidarem com exemplos com diferentes quantidades de atributos. Geralmente, o reconhecimento de voz envolve a classificação de sinais com durações diferentes. Essa variabilidade ocorre não só inter-classe, porque as palavras têm diferentes comprimentos, mas também intra-classes, pois os diferentes locutores geralmente têm ritmos diferentes de fala. Dados com comprimento variável são um problema para vários algoritmos de aprendizado de máquina, que esperam uma tabela atributo-valor de tamanho fixo como entrada. O janelamento dinâmico pode ser uma importante ferramenta para superar essa limitação.

Tal técnica é uma estratégia simples para quebrar um sinal de duração arbitrária em um conjunto de vetores de atributos. Cada vetor é uma coleção de atributos extraídos dos vários segmentos do sinal original, obtidos por uma janela deslizante de largura $w_{s}$. O valor de $w_{s}$ é dependente da duração do sinal $(s)$ e o número de janelas que serão utilizadas $(N)$. Além disso, cada janela possui uma sobreposição com a anterior, como pode ser visto na Figura A.1. Tal sobreposição deve ser grande o suficiente para que nenhuma informação seja perdida nas transições do sinal. Comumente, é utilizado uma sobreposição de $50 \%$.

Nos experimentos realizados, foram utilizadas janelas de largura $w_{s}$ de acordo com a Equação A.1, em que o é a taxa de sobreposição, com valor no intervalo entre 0 e 1, e $e$ é a largura da janela, desconsiderando a sobreposição entre as janelas consecutivas. O valor de $e$ pode ser obtido pela Equação A.2, em que $l_{s}$ é o comprimento do sinal e $N$ é o número de janelas a serem utilizadas.

$$
\begin{gathered}
w_{s}=\left\lceil\frac{e}{1-o}\right\rceil \\
e=\left\lceil\frac{l_{s}}{N}\right\rceil
\end{gathered}
$$




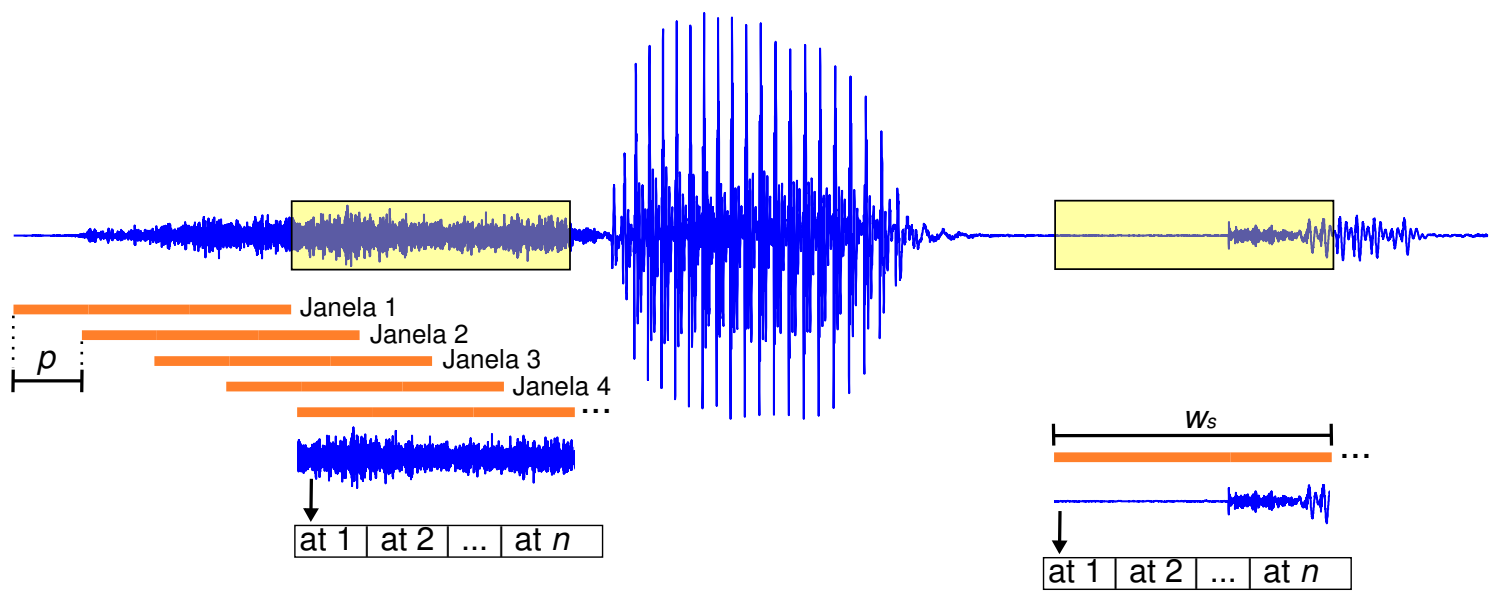

Figura A.1: No janelamento dinâmico, a extração de atributos utiliza uma janela deslizante de largura $w_{s}$, proporcional a um número de janelas pré-determinado $(N)$, com tamanho de passo $p$ e, consequentemente, sobreposição de largura $w_{s}-p$ entre janelas consecutivas. Então, um vetor de atributos $n$-dimensional é extraído de cada janela. Ao fim desse processo, o resultado é um vetor de $n \times N$ atributos que descrevem o sinal

Obviamente, o janelamento dinâmico deve ser utilizado com um pouco de precaução. A existência de sinais consideravelmente diferentes em duração fará com que os tamanhos de janela, bem como do tamanho dos passos, tenham uma grande variabilidade. Passos muito grandes podem causar perda de informação sobre a evolução do sinal no tempo. Além disso, em algumas aplicações, sinais de tamanhos muito diferentes podem de fato significar que um sinal possui um número de variações no tempo muito diferente do outro. Portanto, isso deve ser levado em consideração na escolha da estratégia de janelamento.

O conjunto de dados utilizado neste trabalho é composto de dígitos falados em português, coletados durante um período de três meses, de 82 homens com idade entre 18 e 42 anos de idade. A taxa de amostragem da gravação é de $22.050 \mathrm{~Hz}$. Ao todo, o conjunto de dados possui 216 sequências de 10 dígitos $(0-9)$ cada, totalizando 10 classes e 2.160 exemplos. Dessa maneira, o conjunto de dados possui as classes perfeitamente balanceadas.

Cada gravação de áudio é relacionada a um único locutor que fala todos os dígitos de 0 a 9, em ordem numérica. Entretanto, os sinais não são segmentados em cada dígito, sendo que cada arquivo possui a frase que compreende a fala de todos os dez dígitos. É, portanto, necessário que cada arquivo de áudio seja segmentado em dez fragmentos, cada um contendo um dígito.

Uma vez que a relação sinal-ruído é alta, é possível utilizar um simples detector baseado em amplitude. Primeiramente, o sinal é normalizado, dividindo-se seus valores pelo valor absoluto mais alto observado. Então, as amplitudes relativas estarão no intervalo entre -1 
e 1. Após isso, a amplitude média dentro de uma janela deslizante é calculada e utilizada como grau de confiança estimada. Quanto maior for a amplitude calculada, maior será a confiança de que a janela contém parte de um sinal de fala. Finalmente, é possível definir um limiar de aceitação, de modo que as porções acima do limiar são indicativos de um dígito falado. Os segmentos acima do limiar são armazenados em arquivos separados. Esse método de detecção é ilustrado na Figura A.2. Dado que os arquivos de áudio possuem os dígitos falados em ordem numérica, a tarefa de fornecer os rótulos corretos para cada fragmento é trivial.
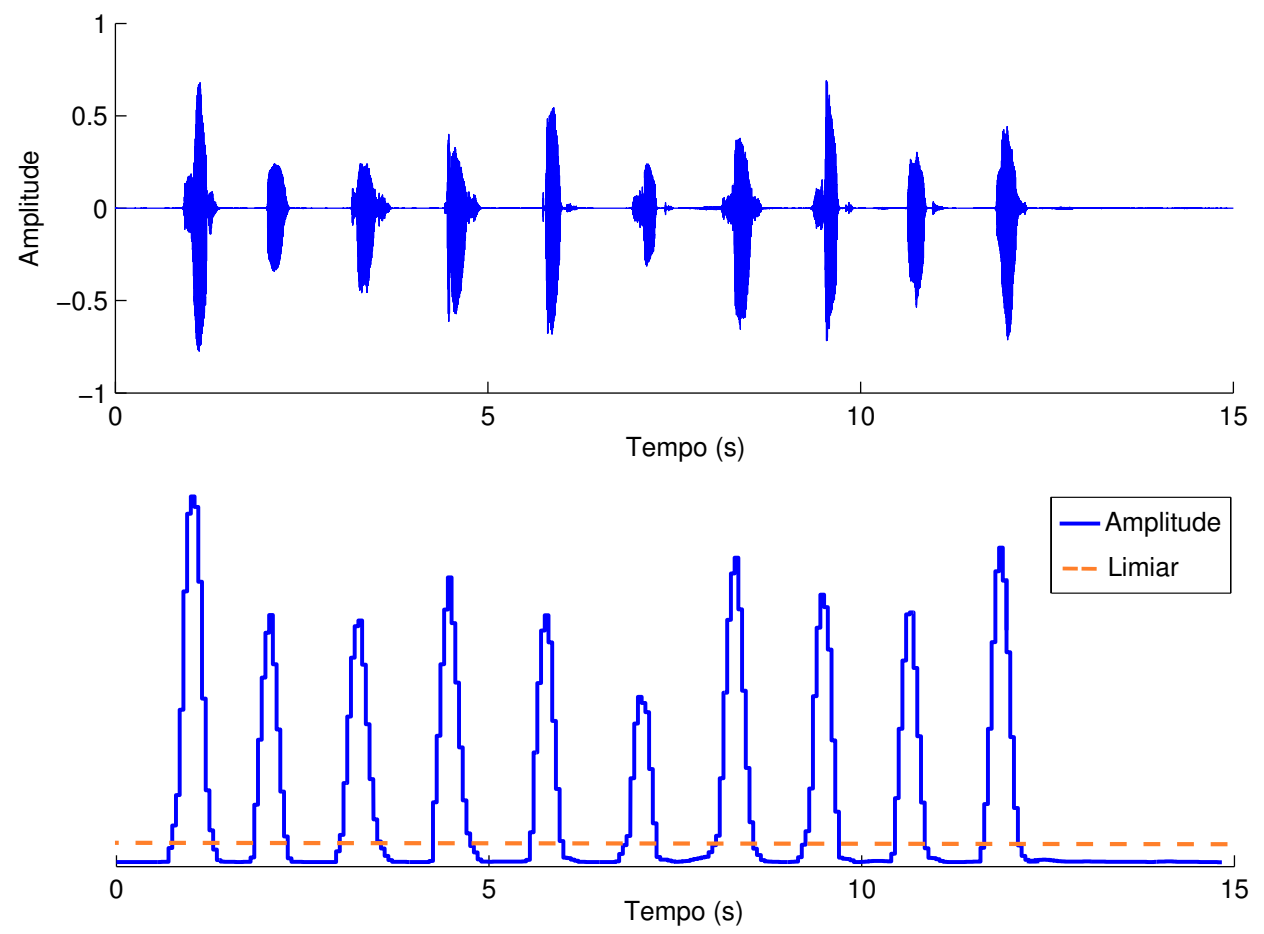

Figura A.2: Esquema de segmentação por amplitude. Utilizando uma janela deslizante, é calculada a média das amplitudes do sinal original (topo) de modo a formar um vetor que define um nível de confiança para a existência de um sinal interessante na janela (parte inferior). Finalmente, é definido um limiar de aceitação

Na fase experimental, foram comparados 13 MFCC contra 24 e 48 LSF. Esses números de coeficientes foram escolhidos pois 13 MFCC e 12 coeficientes de predição linear são comumente considerados adequados para descrever sinais de áudio (Terasawa et al., 2005; Orság, 2010). Além disso, é comum a utilização de um múltiplo do número de coeficientes de predição linear como o número de coeficientes LSF a serem utilizados.

Ambos conjuntos de atributos foram testados em doze diferentes cenários. Cada cenário é diferente de acordo com as configurações do algoritmo de classificação utilizado. Os algoritmos utilizados e suas respectivas configurações são apresentados na Tabela A.1. 
Tabela A.1: Descrição dos cenários de classificação

\begin{tabular}{l|l}
\hline Cenário & Indutor/parâmetros \\
\hline \hline 1-NN & Vizinho Mais Próximo \\
5-NN & 5-Vizinhos Mais Próximos ponderado pelo inverso da distância \\
7-NN & 7-Vizinhos Mais Próximos ponderado pelo inverso da distância \\
9-NN & 9-Vizinhos Mais Próximos ponderado pelo inverso da distância \\
SVM-Poly1 & Máquina de Vetores de Suporte com kernel polinomial de grau 1 \\
SVM-Poly2 & Máquina de Vetores de Suporte com kernel polinomial de grau 2 \\
SVM-Poly3 & Máquina de Vetores de Suporte com kernel polinomial de grau 3 \\
SVM-RBF0,01 & Máquina de Vetores de Suporte com kernel RBF com $\gamma=0,01$ \\
SVM-RBF0,05 & Máquina de Vetores de Suporte com kernel RBF com $\gamma=0,05$ \\
SVM-RBF0,1 & Máquina de Vetores de Suporte com kernel RBF com $\gamma=0,1$ \\
NB & Nä̈ve Bayes \\
RF & Floresta Aleatória com 15 árvores \\
\hline
\end{tabular}

Na fase de extração de atributos, foi utilizada a estratégia de janelamento dinâmico. Foi estabelecido o número de 25 janelas com uma sobreposição de $75 \%$ entre janelas consecutivas. Portanto, cada método de extração de atributos gerou um conjunto de dados cujos exemplos consistem de $25 \times n$ atributos, sendo $n$ o número de atributos extraídos por segmento. Em outras palavras, cada sinal foi transformado em um exemplo com 325, 600 e 1.200 atributos para os 13 MFCC, 24 LSF e 48 LSF, respectivamente.

A estratégia utilizada para a divisão do conjunto de dados em partições de treinamento e teste foi a validação cruzada com dez folds. Para reduzir a chance de resultados por acaso, esse processo foi repetido dez vezes, ordenando-se aleatoriamente os exemplos entre duas execuções consecutivas. Em outras palavras, foi utilizada a estratégia $10 \times 10$-fold cross-validation.

Os resultados da classificação são resumidos na Tabela A.2. Os valores apresentados são relativos à média e desvio padrão da acurácia obtida na validação cruzada. Cada linha representa o resultado de um indutor aplicado sobre o conjunto de dados produzido a partir das características extraídas pelo método apresentado na coluna. O melhor resultado da classificação para cada algoritmo é realçado na tabela.

Cada execução da validação cruzada em dez folds gera uma matriz de confusão, onde é possível avaliar valores de acurácia e tipos de erros cometidos pelo classificador. Um exemplo de tais matrizes de confusão pode ser visto na Tabela A.3. Nessa matriz em particular, são mostrados os resultados de uma das dez execuções do classificador SVM-Poly2 sobre o conjunto de dados gerados com a extração de 48 LSF, escolhida aleatoriamente. Nela, é possível observar que os erros são bem localizados. Os erros entre os dígitos 2 e 8, por exemplo, ocorre em 5 ocasiões, num total de 15 erros cometidos. Como a matriz original é muito esparsa, os valores zero foram omitidos para melhorar a apresentação da tabela. 
Tabela A.2: Acurácia e desvio padrão médios para os três métodos de extração de atributos analisados nos 12 cenários

\begin{tabular}{l|l|l|l}
\hline Cenário & 13 MFCC & 24 LSF & 48 LSF \\
\hline \hline 1-NN & $86,33(2,15)$ & $92,92(1,51)$ & $\mathbf{9 3 , 0 3 ( 1 , 6 4 )}$ \\
5-NN & $89,52(1,88)$ & $95,57(1,19)$ & $\mathbf{9 5 , 6 6}(\mathbf{1 , 2 7})$ \\
7-NN & $89,61(1,85)$ & $95,82(1,32)$ & $\mathbf{9 5 , 9 8}(\mathbf{1 , 3 7})$ \\
9-NN & $90,20(1,82)$ & $\mathbf{9 6 , 1 3}(\mathbf{1}, \mathbf{2 6})$ & $95,67(1,24)$ \\
SVM-Poly1 & $97,96(0,86)$ & $98,85(0,69)$ & $\mathbf{9 9 , 3 0 ( 0 , 5 7 )}$ \\
SVM-Poly2 & $97,88(0,93)$ & $98,77(0,70)$ & $\mathbf{9 9 , 3 1 ( 0 , 5 7 )}$ \\
SVM-Poly3 & $97,91(0,90)$ & $98,75(0,72)$ & $\mathbf{9 9 , 1 7}(\mathbf{0 , 6 3})$ \\
SVM-RBF0,01 & $93,62(1,71)$ & $97,93(0,95)$ & $\mathbf{9 8 , 6 4}(\mathbf{0 , 8 3})$ \\
SVM-RBF0,05 & $96,88(1,17)$ & $98,54(0,83)$ & $\mathbf{9 8 , 7 0 ( 0 , 7 7 )}$ \\
SVM-RBF0,1 & $97,19(1,04)$ & $\mathbf{9 8 , 3 2}(\mathbf{0 , 8 8})$ & $98,02(0,90)$ \\
NB & $90,63(1,66)$ & $\mathbf{9 4 , 8 6}(\mathbf{1 , 4 6 )}$ & $94,72(1,35)$ \\
RF & $91,83(1,90)$ & $\mathbf{9 6 , 3 6}(\mathbf{1 , 2 3})$ & $95,89(1,37)$ \\
\hline
\end{tabular}

Tabela A.3: Matriz de confusão de uma execução do algoritmo SVM-Poly2 no conjunto de dados de dígitos, com o conjunto de atributos 48-LSF

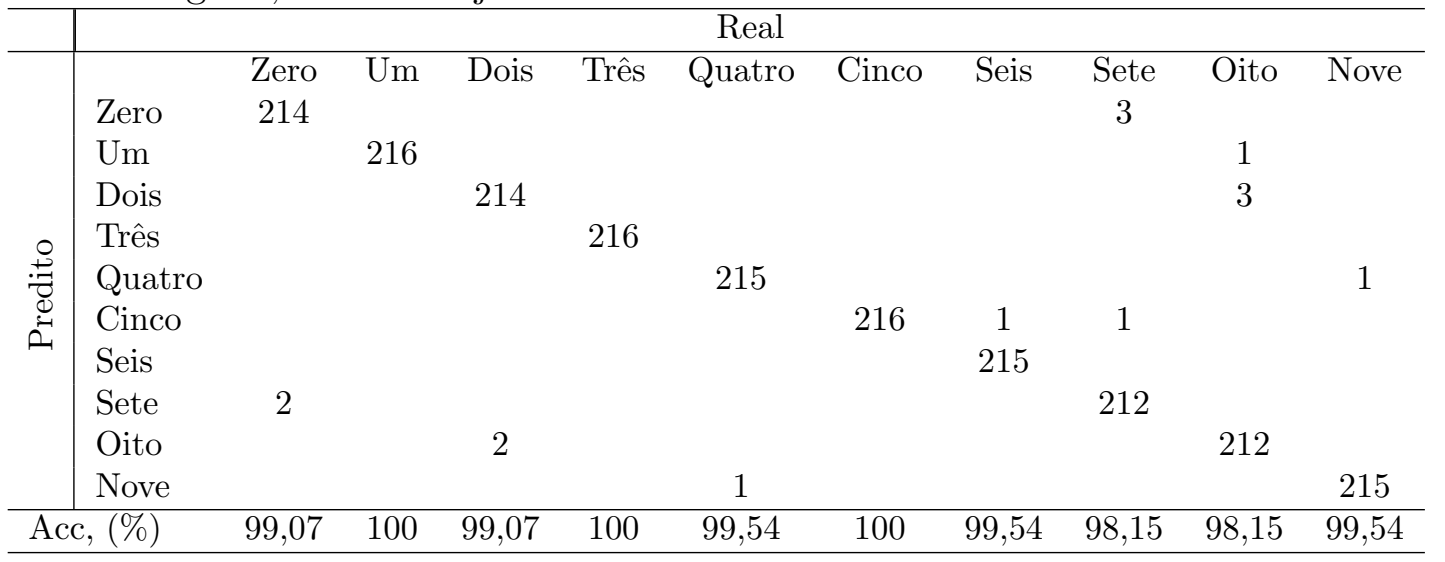

Os resultados desses experimentos mostraram que coeficientes LSF podem superar as estratégias que consideram os comumente utilizados 13 MFCC. Mais especificamente, nesse conjunto de dados, o uso de LSF obteve resultados melhores do que o MFCC em todos os cenários. De modo a assegurar maior confiança aos resultados, foi realizado o teste estatístico de Wilcoxon (Demšar, 2006). Esse teste é recomendado para comparar populações pareadas. O teste indicou que 24 e 48 LSF de fato obtiveram melhor desempenho que o método de comparação (MFCC) com um grau de confiança de 95\%.

Porém, algumas perguntas ainda ficaram em aberto nesse estudo. Por exemplo, foram utilizados apenas um número fixo de atributos, determinado a priori, na fase de extração Mas, quanto a variação do número de atributos extraídos pode influenciar na classificação de dígitos falados isoladamente? Os resultados são iguais em outras línguas ou apenas em português? A taxa de amostragem dos dados pode influenciar na qualidade da classificação? Além disso, houve uma deficiência devida ao fato do conjunto de dados possuir 
apenas vozes de homens adultos. O estudo apresentado foi complementado de maneira a superar essas limitações. Os novos experimentos e resultados são apresentados na seção a seguir.

\section{A.1.2 Estudo Comparativo Entre a Utilização de MFCC e LSF no Reconhe- cimento de Dígitos Falados em Português e Inglês}

O trabalho descrito na seção anterior apresentou o uso de LSF na classificação de dígitos falados em português. Entretanto, houve limitações experimentais que levantaram diversas questões interessantes. A fim de respondê-las, foi conduzido um novo trabalho (Silva et al., 2013d), conforme será descrito nesta seção.

Nesse trabalho, o estudo anterior foi estendido em termos da metodologia e análise dos dados nos seguintes aspectos:

- Foi utilizado um novo conjunto de dados de dígitos falados em português e inglês. Com isso, foi possível avaliar a influência da língua nos resultados da classificação, bem como o potencial de extrapolar as técnicas para outros idiomas;

- Foi avaliado um conjunto mais amplo de situações experimentais com diferentes números de coeficientes MFCC e LSF. Assim, proporcionou-se um entendimento mais profundo da influência de tais parâmetros no desempenho da classificação;

- Foi variada a taxa de amostragem de áudio para simular a faixa de resposta de frequência de redes telefônicas públicas. Dessa maneira, é possível avaliar a robustez dos métodos em canais de baixa qualidade, como linhas telefônicas padrão.

Para isso, foi construído um conjunto de dados com a intenção de superar algumas das limitações dos dados anteriores. Mais especificamente, esse conjunto de dados possui as seguintes características:

- 33 locutores, de 20 a 50 anos de idade de ambos os sexos (72,73\% são vozes masculinas e 27, $27 \%$ são do sexo feminino). O conjunto de dados anterior tinha apenas locutores homens;

- Os voluntários falam os dígitos em uma ordem aleatória. No conjunto de dados anterior, todos os locutores disseram os dígitos em ordem crescente, o que causou uma mudança de entonação clara nos últimos dígitos;

- A divisão dos dados em partições de treinamento e teste é absoluta. Isso faz com que a comparação com outros métodos seja mais simples e evita que o mesmo locutor 
apareça no treinamento e no teste ao mesmo tempo. O conjunto de dados anterior não tinha divisão definitiva de partições de treinamento e teste;

- Os dígitos são falados em duas línguas: português e inglês. O conjunto de dados anterior continha apenas dígitos falados em português;

- O novo conjunto de dados é segmentado. Embora o locutor diga todos os 10 dígitos em uma sequência predefinida, tais sequências já foram divididas em 10 segmentos, cada um contendo um dígito distinto. O conjunto de dados anterior não era originalmente segmentado. Como há o interesse apenas na análise do desempenho de extração de características e métodos de classificação, fornecer os dados segmentados isola a influência do algoritmo de segmentação sobre os resultados.

O conjunto de dados foi separado entre as diferentes línguas e, para cada uma, foi realizada a separação em treinamento e teste. O conjunto de treinamento é composto por dois terços do conjunto de dados e o restante é utilizado como conjunto de teste. Esta divisão é aleatória. No entanto, se um locutor está presente entre os exemplos de teste, ele/ela não aparece nos exemplos de treinamento e vice-versa. Portanto, o desempenho de classificação é independente de locutor e mais consistente com aplicações do mundo real.

Ao todo, $87.88 \%$ dos voluntários são falantes nativos da língua portuguesa. O restante é nativo da língua espanhola. Portanto, apesar das gravações serem efetuadas também na língua inglessa, não há nenhum locutor nativo nesse idioma.

Além disso, o ruído de fundo não foi controlado. Apesar de todos os arquivos de áudio terem sido gravados em espaços fechados, tais salas são sensíveis ao ruído externo e, por vezes, havia aparelhos de ar condicionado ou computadores ligados próximo ao local da gravação. Alguns arquivos podem ter ruído de chuva ou pessoas falando nos ambientes ao redor.

Todas essas características não são comumente vistas em outros conjuntos de dados. Isso adiciona maiores desafios à tarefa de reconhecimento.

Uma vez que os sinais podem possuir tais ruídos de fundo, foi utilizado um filtro baseado em subtração espectral (Boll, 1979) a fim de reduzí-los. Após isso, o conjunto de dados foi segmentado utilizando a estratégia de detecção por amplitude, conforme descrito na Seção A.1.1.

Para extrair os vetores de características, novamente foi utilizada a estratégia de janelamento com tamanho dinâmico. Dessa vez, o número de cenários de classificação foi aumentado para dezesseis, variando o algoritmo de classificação e seus parâmetros internos. Os algoritmos utilizados para a classificação e as suas relativas configurações são apresentados na Tabela A.4. 
Tabela A.4: Descrição dos cenários de classificação

\begin{tabular}{l|l}
\hline Cenário & Indutor/parâmetros \\
\hline \hline 1-NN & Vizinho Mais Próximo \\
$5-\mathrm{NN}$ & 5-Vizinhos Mais Próximos ponderado pelo inverso da distância \\
$7-\mathrm{NN}$ & 7-Vizinhos Mais Próximos ponderado pelo inverso da distância \\
$9-\mathrm{NN}$ & 9-Vizinhos Mais Próximos ponderado pelo inverso da distância \\
$11-N N$ & 11-Vizinhos Mais Próximos ponderado pelo inverso da distância \\
SVM-Poly1 & Máquina de Vetores de Suporte com kernel polinomial de grau 1 \\
SVM-Poly2 & Máquina de Vetores de Suporte com kernel polinomial de grau 2 \\
SVM-Poly3 & Máquina de Vetores de Suporte com kernel polinomial de grau 3 \\
SVM-RBF0,01 & Máquina de Vetores de Suporte com kernel RBF com $\gamma=0,01$ \\
SVM-RBF0,05 & Máquina de Vetores de Suporte com kernel RBF com $\gamma=0,05$ \\
SVM-RBF0,1 & Máquina de Vetores de Suporte com kernel RBF com $\gamma=0,1$ \\
NB & Naïve Bayes \\
$10 R F$ & Floresta Aleatória com 10 árvores \\
$15 R F$ & Floresta Aleatória com 15 árvores \\
$20 R F$ & Floresta Aleatória com 20 árvores \\
\hline
\end{tabular}

Um problema inerente no uso de coeficientes MFCC (e de outros vetores de características) é a escolha do número de coeficientes a serem utilizados. Comumente, 13 MFCC são utilizados nas aplicações de reconhecimento de voz e locutor. A fim de verificar se este número de fato fornece a melhor acurácia da classificação utilizando MFCC e também para estimar um bom número de coeficientes LSF, foi realizado um experimento com uma grande variação no número de atributos extraídos. Para cada cenário de classificação, que executa a validação cruzada 10 vezes ao longo do conjunto de treinamento, foi variado o número de coeficientes de 7 a 59, em passos de 2 . Uma vez estimado o melhor número de atributos nos dados de treinamento, foi avaliado o desempenho da classificação no conjunto de teste. Esta abordagem de estimativa de parâmetros em dados de treinamento é a metodologia correta para avaliar o desempenho de classificadores. Há trabalhos que evidenciam que o desempenho de classificadores que selecionam o melhor conjunto de parâmetros baseado nos erros medidos no conjunto de teste tendem a mostrar resultados muito otimistas (Salzberg, 1997).

As vozes que compõem o conjunto de dados foram gravadas com amostragem de $44100 \mathrm{~Hz}$. No entanto, diversas aplicações de reconhecimento de dígitos falados devem trabalhar com taxas de amostragem restritas. Um exemplo é a faixa de resposta de frequência de redes de telefonia pública, que está comumente próxima a $3400 \mathrm{~Hz}$. A fim de analisar a robustez dos métodos em ambientes onde os dados são coletados em taxas de amostragem mais baixas, também foram realizados experimentos com os dados reamostrados a $20 \%$ da taxa original. Isso significa que a taxa de amostragem de áudio foi reduzida para $8820 \mathrm{~Hz}$, permitindo uma faixa de frequência entre 0 e $4410 \mathrm{~Hz}$, similar aos encontrados em redes de telefonia e outras aplicações. 
Na Figura A.3 são apresentados os resultados da classificação em todos os cenários. Esses resultados apresentam a acurácia obtida para cada classificador após a busca pelo melhor número de MFCC e LSF utilizando a validação cruzada no conjunto de treinamento. Resumindo os resultados como o número de vitórias e derrotas, MFCC obteve os melhores resultados globais para a língua inglesa (12 vitórias e 4 derrotas) e LSF ganhou para o português (também 12 vitórias e 4 derrotas). No entanto, LSF obteve a maior acurácia para ambas as línguas, com o algoritmo SVM com kernel polinomial de grau 3. Os melhores classificadores obtiveram 87,27\% e 89,09\% de acurácia para inglês e português, respectivamente.

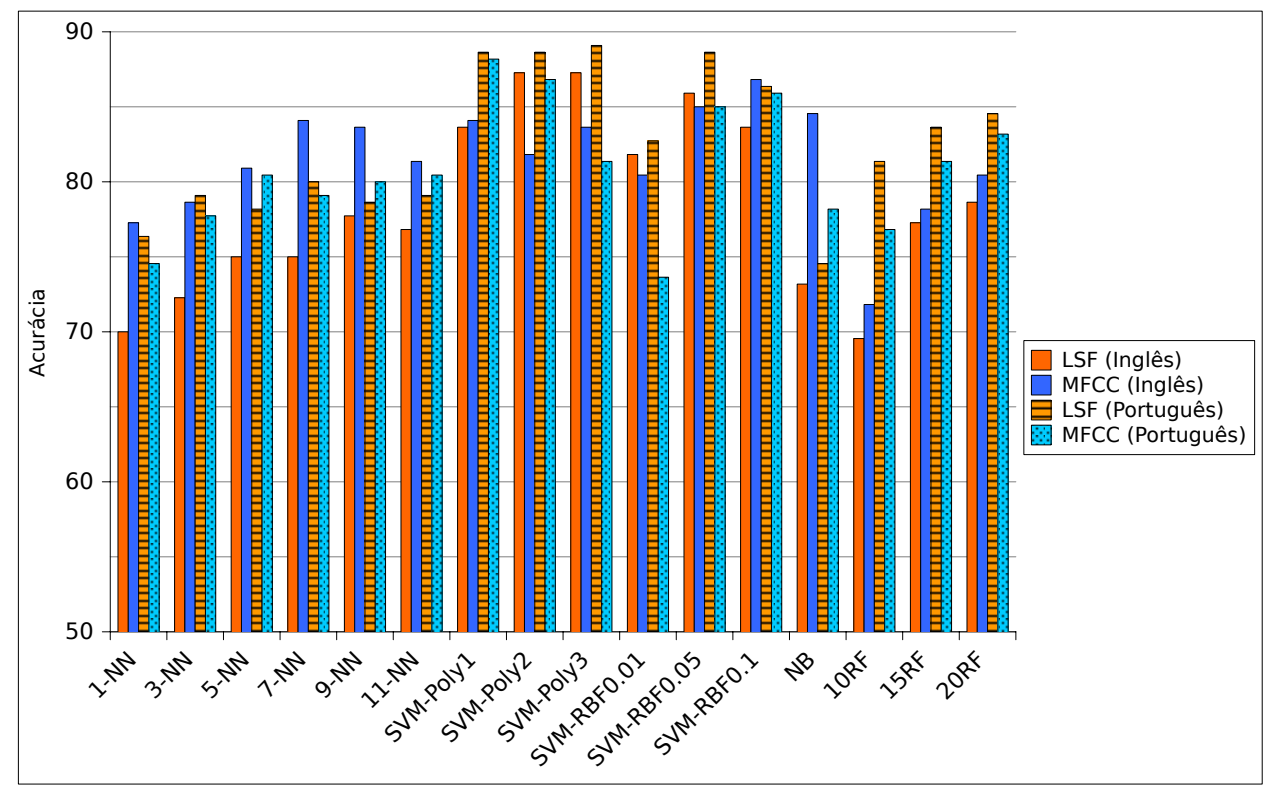

Figura A.3: Resultado do reconhecimento de dígitos falados em português e inglês, gravados com taxa de amostragem de $44100 \mathrm{~Hz}$

Para avaliar a suscetibilidade dos métodos de extração de atributos à uma escolha inapropriada do número de coeficientes, foi avaliada a variação da acurácia em relação à variação do número de atributos extraídos por segmento do sinal. A fim de facilitar a visualização do resultado, foi escolhido mostrar os resultados apenas de um algoritmo por paradigma de aprendizado: baseado em distância (KNN); estatístico (SVM); probabilístico (NB); e árvores de decisão (RF). Para cada paradigma, foram analisados os classificadores com maior acurácia (vide Figura A.3). Com isso, a Figura A.4 mostra graficamente os resultados de LSF e MFCC para essa análise. Note que os resultados são similares nas duas línguas abordadas.

Os resultados mostram que LSF é menos dependente da escolha de um determinado número de coeficientes do que MFCC. O desempenho das LSF permanece relativamente 

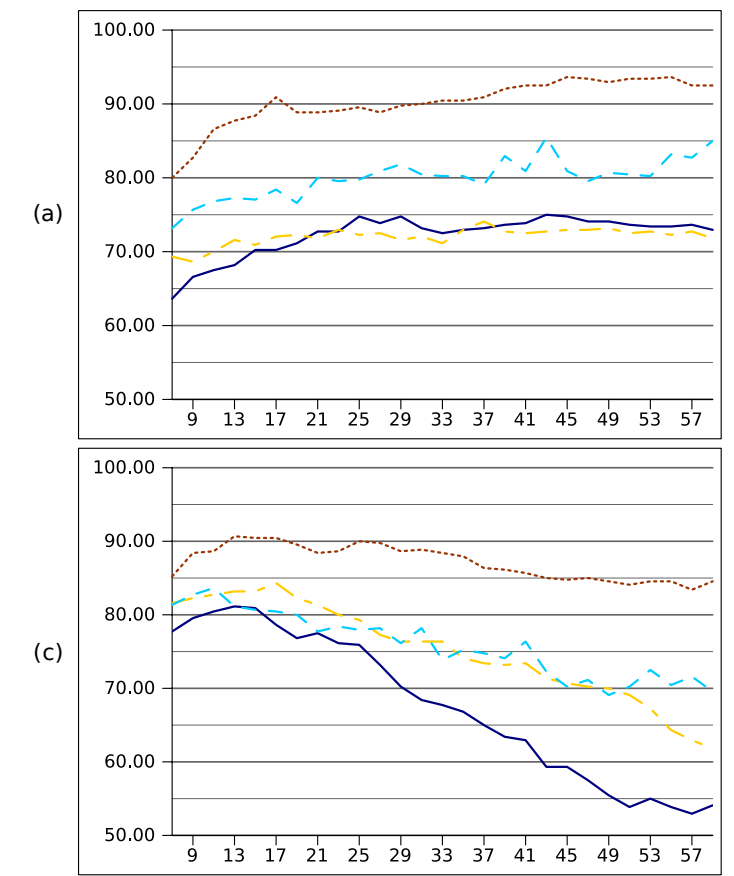

(b)
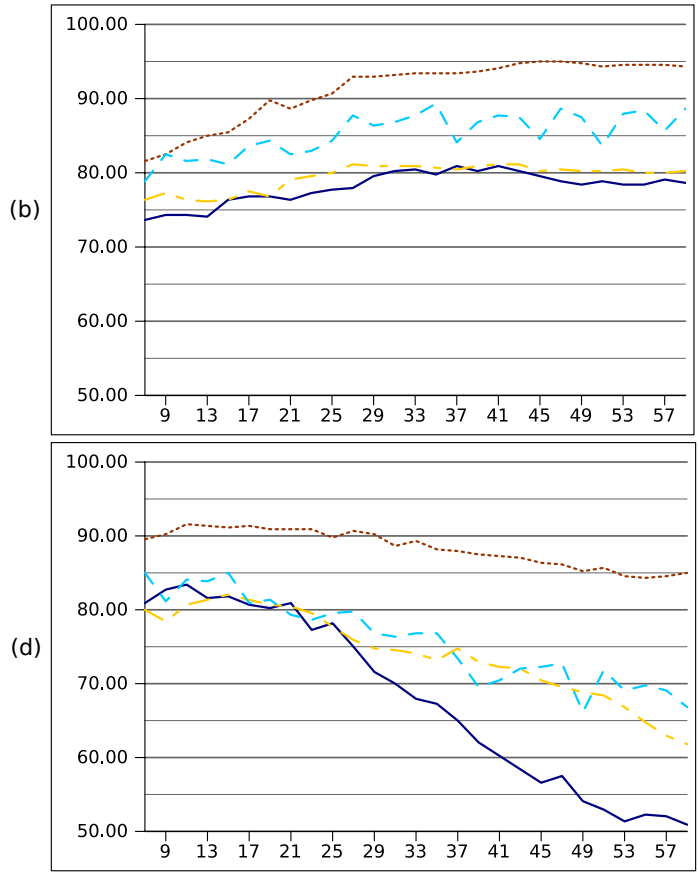

KNN

$---\mathrm{NB} \quad----\mathrm{RF}$

Figura A.4: Acurácia obtida por diferentes classificadores conforme variação do número de atributos extraídos: (a) LSF extraídos do conjunto de dígitos falados em português; (b) LSF extraídos do conjunto de dígitos falados em inglês; (c) MFCC extraídos do conjunto de dígitos falados em português; (d) MFCC extraídos do conjunto de dígitos falados em inglês

constante para todos os classificadores em uma ampla gama de coeficientes, com uma ligeira tendência a aumentar o desempenho conforme o número de coeficientes aumenta. O desempenho do MFCC é mais dependente do número correto de coeficientes, tendo uma tendência a cair consideravelmente à medida que o número de coeficientes aumenta. Em todas as configurações, o uso de mais do que 25 coeficientes pode ser considerado inadequado. Em contraste, a configuração ótima para o MFCC está num intervalo estreito entre 11 e 23 para todos os classificadores, restringindo o espaço de busca.

A fase experimental é concluída com a avaliação da classificação sobre o mesmo conjunto de dados, mas com taxa de amostragem reduzida a $8820 \mathrm{~Hz}$. Novamente, foi utilizada a estratégia de validação cruzada no conjunto de treinamento, para estimar o melhor número de atributos em cada configuração antes de rotular os conjuntos de teste. Os resultados, para as duas línguas, são apresentados na Figura A.5.

É interessante notar que, em termos de acurácia, os resultados não se alteraram significativamente em comparação com aqueles obtidos ao se utilizar os sinais de maior qualidade. Os melhores resultados de classificação para dígitos pronunciados em ambas as línguas foram atingidos por SVM com kernel RBF e 0,1 como valor do parâmetro $\gamma$. No 


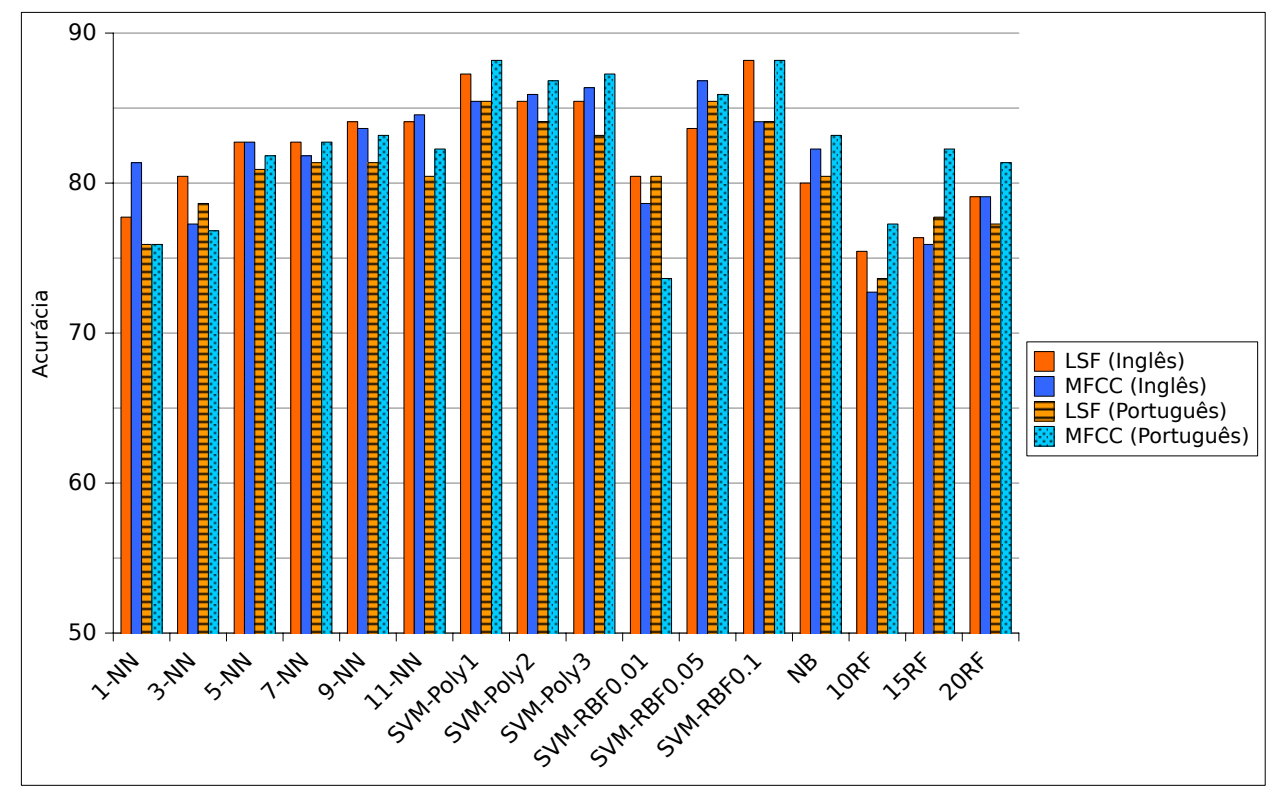

Figura A.5: Resultado do reconhecimento de dígitos falados em português e inglês, reamostrados a uma taxa de $8820 \mathrm{~Hz}$

entanto, nesse caso, os coeficientes LSF proporcionaram o melhor espaço de atributos para o inglês com acurácia de 88,18\% e MFCC foram os melhores atributos para o português, também com $88,18 \%$.

Na Tabela A.5, são mostrados os resultados dos classificadores com maior acurácia, separados por classe. Para cada dígito e cada tipo de atributo, são também apresentados os erros mais frequentes. Os resultados são separados por língua e taxa de amostragem.

Tabela A.5: Resultados obtidos pelos melhores classificadores para os diferentes tipos de atributos e taxas de amostragem no reconhecimento de dígitos em português e inglês

\begin{tabular}{|c|c|c|c|c|c|c|c|c|}
\hline Dígito & \multicolumn{2}{|c|}{$\begin{array}{c}\text { Inglês } \\
\text { 44100HZ } \\
\text { 55LSF } \\
\text { SVM-Poly3 } \\
\text { Erro } \\
\text { Acurácia } \quad \text { mais } \\
\\
\text { comum }\end{array}$} & \multicolumn{2}{|c|}{$\begin{array}{c}\text { Português } \\
\text { 44100HZ } \\
\text { 41LSF } \\
\text { SVM-Poly3 }\end{array}$} & \multicolumn{2}{|c|}{$\begin{array}{l}\text { Inglês } \\
8820 \mathrm{HZ} \\
21 \mathrm{LSF}\end{array}$} & $\begin{array}{r}\text { Port } \\
882 \\
13 \mathrm{M} \\
\text { SVM- } \\
\text { Acurácia }\end{array}$ & $\begin{array}{l}\text { uês } \\
\mathrm{HZ} \\
\mathrm{CC} \\
\text { 3F0.1 } \\
\text { Erro } \\
\text { mais } \\
\text { comum }\end{array}$ \\
\hline 0 & 95,45 & 9 & 90,90 & 5 e 7 & 81,82 & 2 & 86,36 & 1,2 e 7 \\
\hline 1 & 95,45 & 9 & 86,36 & 8 & 90,90 & 4 e 9 & 100,00 & - \\
\hline 2 & 72,73 & 3 & 90,90 & 3 e 9 & 86,36 & 0 & 77,27 & 8 \\
\hline 3 & 90,90 & 2 e 8 & 95,45 & 2 & 77,27 & 8 & 86,36 & 2 \\
\hline 4 & 77,27 & 2 & 86,36 & 9 & 95,45 & 9 & 90,90 & 9 \\
\hline 5 & 81,82 & 9 & 95,45 & 1 & 81,82 & 9 & 95,45 & 1 \\
\hline 6 & 100,00 & - & 86,36 & 7 & 81,82 & 3 & 77,27 & 0 e 3 \\
\hline 7 & 86,36 & 0 & 95,45 & 0 & 100,00 & - & 81,82 & 6 \\
\hline 8 & 86,36 & 3 & 86,36 & 1 & 95,45 & 3 & 100,00 & - \\
\hline 9 & 86,36 & 1 & 77,27 & 4 & 90,90 & 1 e 5 & 86,36 & 1,4 e 8 \\
\hline
\end{tabular}

Pelos resultados apresentados, nota-se que as técnicas utilizadas obtiveram desempenho semelhante para ambos idiomas analisados. As evidências empíricas sugerem, por- 
tanto, que a mesma metodologia pode ser utilizada de maneira eficaz no reconhecimento de dígitos em outras línguas. Entretanto, essa suposição ainda requer validação experimental.

Também foram apresentadas evidências que a escolha adequada do número de coeficientes pode ser tão importante quanto a escolha do classificador correto. Os resultados apresentados contribuem apenas parcialmente para o conhecimento geral do uso de 13 MFCC, como é frequentemente utilizado na literatura.

Finalmente, os resultados não foram significativamente alterados pela utilização de uma taxa de amostragem reduzida. Portanto, é possível concluir que as técnicas avaliadas são adequadas para serem utilizadas em aplicações que requerem canais de baixa qualidade.

\section{A.2 Análise de Séries Temporais e Sinais Musicais por Distância Baseada em Compressão de Vídeos}

O núcleo de muitas aplicações de análise de séries temporais é uma medida de distância/similaridade. Na tarefa de classificação, há trabalhos que evidenciam que o simples algoritmo do vizinho mais próximo é muito difícil de ser batido em diversos domínios. Porém, também foi mostrado que, em alguns casos, as principais características das séries temporais não são evidentes em sua representação primitiva. Por isso, muitos trabalhos utilizam uma tranformação dos dados, de modo a evidenciar características importantes.

Durante o desenvolvimento deste trabalho, esses dois conceitos foram unidos para criar um novo método de classificação de séries temporais. Esse método consiste na mudança de representação e na aplicação de uma medida de distância para comparar séries temporais. Basicamente, cada série é transformada em uma representação de autosimilaridade entre suas subsequências. Após isso, é utilizada uma medida de distância baseada em compressão de vídeo para estimar a dissimilaridade entre as séries na nova representação.

Esse método foi aplicado à classificação de séries temporais em diversos contextos (Silva et al., 2013a), mostrando-se superior a métodos estado-da-arte em vários deles. Após isso, essa abordagem foi avaliada em uma aplicação específica, a recuperação de informação de música por conteúdo (Silva et al., 2013c). Essa tarefa se diferencia da classificação de séries temporais pois requer passos adicionais de extração de atributos, além de não haver interesse apenas no objeto mais similar, mas sim na construção de um ranking baseado em similaridade. 
Nesta seção, serão apresentados os trabalhos resultantes dessa proposta. Na seção A.2.1, além da explicação detalhada do método proposto e suas partes, há a descrição dos resultados obtidos na classificação de séries temporais em diversos conjuntos de dados, obtidos em aplicações como economia, medicina, biologia e movimentos humanos. A seguir, na Seção A.2.2, serão apresentados os resultados da aplicação da medida de distância proposta na tarefa de recuperação de música por conteúdo.

\section{A.2.1 Classificação de Séries Temporais pela Medida de Distância RPCD}

Nos últimos anos, a comunidade de mineração de dados tem testemunhado um grande aumento de interesse na análise de séries temporais. Tal interesse é justificado pelo grande número de aplicações que envolvem esse tipo de dados. Praticamente todos os dados coletados por processos biológicos, movimentos e sensores são suscetíveis a variações no tempo. O estudo de como essas variações ocorrem é essencial para o entendimento de tais processos.

Dentre todas as tarefas de análise de séries temporais, provavelmente a mais proeminente é a classificação. Como descrito na Seção 2.1, a classificação por similaridade tem conseguido excelentes resultados em muitas aplicações. O principal problema associado a esse procedimento é a escolha da medida de distância a ser utilizada. Comumente são utilizadas medidas de distância para comparar as observações da série no domínio temporal. Entretanto, certas características da série temporal não são evidentes nesse domínio.

Silva et al. (2013a) propuseram um procedimento para comparar séries temporais de acordo com seu padrão de recorrência. Para isso, foi utilizada uma representação chamada gráficos de recorrência (em inglês, recurrence plots - RP) (Eckmann et al., 1987). Essa representação é utilizada, para realizar uma avaliação qualitativa da série temporal em sistemas dinâmicos, explicitando padrões e mudanças estruturais ocultos nos dados. Mais especificamente, RP consistem em uma ferramenta para categorizar como a similaridade entre subsequências varia no tempo.

Nesse trabalho, foi assumida a hipótese inicial que esse tipo de informação pode ser útil na classificação de séries temporais em uma ampla gama de domínios. A ideia intuitiva por trás dessa hipótese é que padrões de recorrência são regularidades frequentemente associadas a comportamentos interessantes. Um comportamento recorrente indica a presença de um mecanismo interno responsável por gerar tais padrões. Esse tipo de mecanismo é oposto à geração aleatória de dados, em que uma série temporal não terá tal tipo de padrão. A representação explícita de tais regularidades pode revelar os mecanismos que geraram os dados e, portanto, são um recurso potencialmente útil para a classificação de séries temporais. 
Os RP são representações (originalmente) binárias, em que cada ponto do gráfico revela se um estado - ou subsequência da série temporal - é recorrente ou não. Geralmente, na análise de séries temporais por meio da utilização dessa representação, são extraídos atributos que representam, entre outas coisas, a quantidade de repetições ocorridas, a duração das repetições e o grau de aleatoriedade da série analisada. Essa abordagem não leva em conta, por exemplo, a localização das recorrências. Neste trabalho, foi proposta a comparação direta das imagens formadas pelos RP, por meio da medida de distância Campana-Keogh (CK-1) (Campana e Keogh, 2010). Além disso, a etapa de binarização do gráfico não foi realizada. Dessa maneira, foi considerada a proximidade das subsequências, em vez de definir uma região de adjacência para cada uma delas.

Nesta seção, serão descritos os conceitos básicos dos gráficos de recorrência, bem como a medida de distância utilizada. Além disso, serão apresentados experimentos e resultados, que demonstram a eficácia do método proposto.

\section{Gráficos de Recorrência}

A relevância de comportamentos recorrentes, como a sazonalidade, em processos naturais tem sido estudada há décadas (Monk e Compton, 1939). No entanto, a visualização desses comportamentos é muito difícil no domínio do tempo. Para superar essa limitação, Eckmann et al. (1987) criaram uma representação chamada gráficos de recorrência. Essa ferramenta permite a investigação de trajetórias $m$-dimensionais em um espaço bidimensional. Tal representação é capaz de revelar em que pontos essas trajetórias retornam a um estado anteriormente visitado.

Formalmente, um RP pode ser definido de acordo com a Equação A.3, em que $N$ é a quantidade de estados, $\vec{x}_{i}$ e $\vec{x}_{j}$ são as subsequências observadas nas posições $i$ e $j$, respectivamente, $\|\cdot\|$ é a norma (por exemplo, norma euclidiana) entre as observações, $\epsilon$ é um limiar para a proximidade e $\theta$ a função de Heaviside, definida pela Equação A.4.

$$
\begin{gathered}
R_{i, j}=\theta\left(\epsilon-\left\|\vec{x}_{i}-\vec{x}_{j}\right\|\right), \vec{x} . \in \Re^{m}, i, j=1 . . N \\
\theta(z)=\left\{\begin{array}{l}
0, \text { se } z<0 \\
1, \text { caso contrário }
\end{array}\right.
\end{gathered}
$$

Na Equação A.3 é expresso que, caso a trajetória $m$-dimensional da série temporal no tempo $j$ seja próxima - em termos de uma vizinhança pré-definida - da subsequência observada no momento $i$, haverá um valor 0 na posição $(i, j)$ da chamada matriz de recorrência. Caso contrário, o valor será 1. Na representação gráfica, uma imagem de 
$N \times N$ pixels é definida de modo que os pixels que correspondem a posições da matriz com valores 0 são geralmente pretos e os de valor 1 são brancos. Na Figura A.6, são exibidos exemplos de gráficos de recorrência em diferentes graus de aleatoriedade.
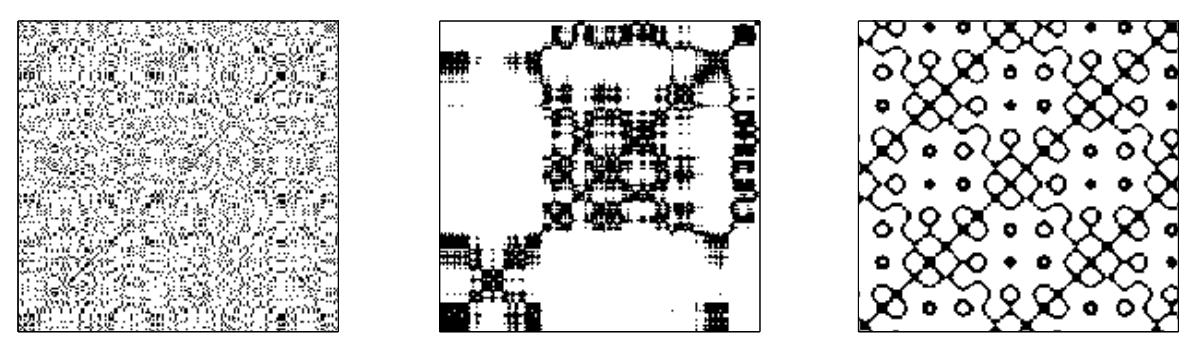

Figura A.6: Alguns exemplos de gráficos de recorrência: ruído totalmente aleatório (esquerda); caminhada aleatória (meio); composição de senos e cossenos (direita)

Apesar de sua simplicidade, esse método requer a especificação de um parâmetro de limiar de proximidade, que define o tamanho de uma vizinhança em que duas subsequências são consideradas semelhantes. No entanto, a determinação de um valor adequado para esse parâmetro não é intuitiva. Na prática, esse problema costuma ser contornado pelo uso de algumas heurísticas. Por exemplo, um limiar de $10 \%$ da maior distância observada ou um valor que resulta em uma determinada porcentagem de pontos pretos. No entanto, essas são heurísticas locais, ou seja, que utilizam a informação de um único gráfico de recorrência para definir o valor do limiar. Portanto, é difícil generalizar um limiar que seja consistente com vários gráficos de recorrência.

A fim de eliminar o parâmetro de proximidade, é possível fazer uso da informação de cor. O gráfico de recorrência, nesse caso, deixa de ser uma ferramenta para analisar as recorrências considerando vizinhanças e passa a ser uma ferramenta para analisar o quão perto cada par de subsequências está no espaço de trajetórias (Iwanski e Bradley, 1998). Para isso, a imagem é gerada com tons de cinza ou outros mapas de cor, de modo que as distâncias são representados pelas cores. Assim, a imagem é uma representação direta da matriz de distância. Essa representação pode ser encontrada com os nomes gráficos de recorrência unthresholded, gráficos de distância ou matrizes de auto-similaridade. Na Figura A.7, é exibido um exemplo de gráficos de recorrência com e sem a utilização do limiar de proximidade para uma mesma série temporal.

A definição de RP dada na Equação A.3 possui um segundo parâmetro, $m$, que define a dimensão da trajetória. Esse parâmetro também é conhecido como dimensão embarcada. Nos experimentos executados neste trabalho, foi escolhida a utilização de $m=1$ para todos os conjuntos de dados. Isso significa que, ao invés de considerar $m$ pontos consecutivos da série para analisar a trajetória, foram consideradas apenas subsequências unitárias. Foi escolhido fixar $m=1$ uma vez que a estrutura dos gráficos de recorrência 


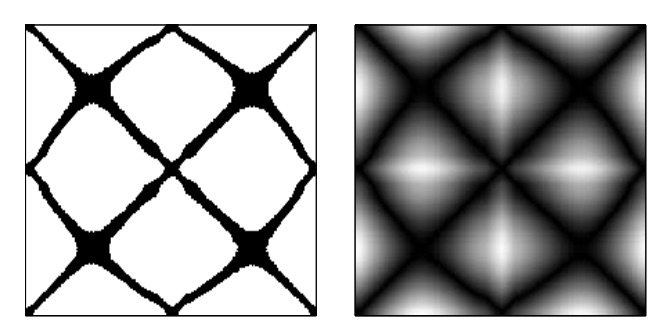

Figura A.7: Exemplo de gráficos de recorrência com (esquerda) e sem (direita) a utilização do limiar de proximidade, ambos gerados a partir de uma mesma série temporal

parece mudar muito pouco à medida que se varia tal parâmetro. Essa opinião também é suportada pela literatura sobre gráficos de recorrência. Por exemplo, em um estudo compreensível em relação a esse parâmetro, Iwanski e Bradley (1998) afirmam que "ao examinar vários gráficos de recorrência de um conjunto de dados particular, notamos que suas aparências pareciam permanecer inalteradas qualitativamente com a mudança da dimensão embarcada".

Apesar disso, vale notar que essa abordagem - apesar de simplificar o método - pode não fornecer os melhores resultados para a classificação. Ajustar esse parâmetro nos conjuntos de treinamento seria uma abordagem mais adequada. Portanto, os resultados obtidos são relativamente pessimistas ao se comparar com as demais abordagens, como a classificação utilizando distância euclidiana ou DTW no domínio temporal.

\section{Medidas de Distância Baseadas em Compressão}

Campana-Keogh (CK-1) é uma distância proposta para estimar a dissimilaridade entre duas imagens (Campana e Keogh, 2010), incialmente apresentada como medida de distância entre texturas. A principal base teórica para a medida CK-1 é o conceito de complexidade de Kolmogorov. A complexidade de Kolmogorov $K(x)$ de uma string $x$ é definida como o tamanho do programa mais curto capaz de produzir $x$ em um computador universal, tal como uma máquina de Turing (Li e Vitanyi, 1997). Intuitivamente, $K(x)$ é a quantidade mínima de informação necessária para gerar uma string $x$ com um programa.

Para que se possa definir uma distância de acordo com a complexidade de Kolmogorov, é necessária a noção de complexidade condicional. Li et al. (2001) definem uma distância entre duas strings $x$ e $y$ de acordo com a Equação A.5, em que $K(x \mid y)$ é definido como o tamanho do menor programa que computa $x$, dado $y$ como entrada auxiliar. $K(x y)$ é definido como a complexidade de Kolmogorov da concatenação das sequências $x$ e $y$. 


$$
d_{k}(x, y)=\frac{K(x \mid y)+K(y \mid x)}{K(x y)}
$$

Apesar da complexidade condicional de Kolmogorov dar origem a uma medida de distância ótima, no sentido de que ela engloba outras medidas, tal distância é incomputável no caso geral. Por isso, vários pesquisadores têm proposto aproximações para essa distância utilizando algoritmos de compressão (Li et al., 2004; Keogh et al., 2007b) e muitos outros têm avaliado essas aproximações em diversos domínios (Krasnogor e Pelta, 2004; Bratko et al., 2006).

Dado um algoritmo de compressão, define-se $C(x)$ como o tamanho da compressão de $x$ e $C(x \mid y)$ como o tamanho da compressão de $x$ após "treinar" o compressor com $y$. A parcela $C(x y)$ é definida como o tamanho da compressão das strings $x$ e $y$ concatenadas. É possível calcular uma aproximação da complexidade de Kolmogorov, definida na Equação A.5, utilizando uma medida de distância por compressão definida na Equação A.6.

$$
d_{c}(x, y)=\frac{C(x \mid y)+C(y \mid x)}{C(x y)}
$$

Quanto melhor for o algoritmo de compressão, melhor é a aproximação de $d_{c}$ em relação a $d_{k}$ (Keogh et al., 2007b).

Uma das distâncias que fazem uso de uma aproximação por compressão da complexidade de Kolmogorov mais conhecidas é a distância de compressão normalizada (em inglês, Normalized Compression Distance - NCD) (Li et al., 2004). Ela é definida de acordo com a Equação A.7.

$$
d_{n c d}(x, y)=\frac{C(x y)-\min \{C(x), C(y)\}}{\max \{C(x), C(y)\}}
$$

A NCD tem sido aplicada com sucesso para medir a similaridade entre duas sequências em uma série de domínios de aplicação. Por exemplo, Li et al. (2004) utilizam NCD para construir uma árvore de filogenia baseada em genomas mitocondriais e, também, uma árvore de idiomas para mais de 50 línguas euro-asiáticas.

Embora a NCD seja adequada para comparar sequências de objetos discretos, o seu uso para a comparação de imagens exige a linearização da imagem, o que acarreta em perda de informação espacial. A medida CK-1 estende a aplicabilidade das distâncias baseadas em compressão para a utilização em imagens, aplicando compressão de vídeo. Dadas duas imagens $x$ e $y$, a medida CK-1 é definida pela Equação A.8, em que $C(a \mid b)$ é o tamanho de um vídeo MPEG-1 sintético composto por dois quadros $b \in\{x, y\}$ e $a \in\{x, y\}$, nessa ordem. 


$$
d_{c k-1}(x, y)=\frac{C(x \mid y)+C(y \mid x)}{C(x \mid x)+C(y \mid y)}-1
$$

A maioria dos algoritmos de codificação de vídeo, assim como MPEG-1, comprimem vídeos encontrando padrões recorrentes dentro de um quadro (compressão intra-quadro) e/ou entre quadros (compressão inter-quadros). Quando $x$ e $y$ são duas imagens semelhantes, o passo de compressão intra-quadro deve ser capaz de explorar esse fato para produzir um arquivo menor, o que pode ser interpretado como uma semelhança significativa. Como o vídeo digital é uma aplicação comercial importante, muitos esforços foram realizados a fim de se conseguir altas taxas de compressão em codificação de vídeo, tornando-se uma boa aproximação da complexidade condicional de Kolmogorov. Além disso, não é necessário realizar nenhuma a modificação interna no algoritmo, uma vez que a única informação utilizada na medida é o tamanho dos arquivos comprimidos.

\section{Trabalhos Relacionados}

Gráficos de recorrência foram introduzidos por Eckmann et al. (1987) e são, até os dias de hoje, frequentemente utilizados em pesquisas e aplicações de séries temporais. Alguns exemplos são a análise do comportamento de insetos sociais (Neves et al., 2012), a previsão estrutural de proteínas (Shao e Chen, 2012), a análise do mercado de ações (Bastos e Caiado, 2011) e análise de gestos comunicativos multimodais (Delaherche et al., 2012). Um campo de estudo em que o uso de gráficos de recorrência é relativamente comum é a análise de sinais biológicos. Alguns exemplos são a análise de eletrocardiogramas (Subha et al., 2010), eletroencefalogramas (Carrubba et al., 2012) e eletromiografia (González-Izal et al., 2012; Ouyang et al., 2012), bem como a detecção de doença arterial coronariana (Dua et al., 2012).

Em geral, a classificação utilizando gráficos de recorrência é feita por extração de características locais dos gráficos, que tentam quantificar as estruturas de pequena escala. Vários pesquisadores têm proposto medidas baseadas na densidade de pontos de recorrência e em estruturas de linhas diagonais e verticais no gráfico. Muitas dessas medidas são detalhadas em Marwan et al. (2007).

Em nossa proposta, foi utilizada uma abordagem ortogonal, de modo que não foram extraídos atributos locais. Em vez disso, os gráficos de recorrência foram diretamente comparados utilizando-se uma medida de distância baseada em compressão. Essa abordagem é simples e tem a vantagem adicional de ser independente de conjunto de atributos e de domínio, além de ser livre de parâmetros.

Bello (2011) apresentou o trabalho com a ideia mais semelhante à proposta neste trabalho. O autor utilizou gráficos de recorrência - aplicando um limiar de proximidade - 
construídos a partir de vetores de atributos cromáticos (representação da sequência de acordes de uma música) como representação estrutural em música. A medida NCD foi utilizada para medir a distância entre os gráficos. No entanto, como observado anteriormente, NCD utiliza algoritmos de compressão padrão que são bem adaptados para a compressão de sequências discretas, tais como strings. Esses algoritmos procuram subsequências exatamente recorrentes e as substituem por símbolos ou (curtas) subsequências chave a fim de obter a compressão. No entanto, subsequências exatamente recorrentes são raras em dados com valores reais, tais como as informações de cor das imagens, tornando esses algoritmos uma aproximação inadequada à complexidade de Kolmogorov no contexto de imagens. Além disso, os algoritmos de compressão padrão trabalham com sequências e não são capazes de fazer uso da informação espacial de imagens.

Em contraste, a CK-1 é uma distância mais adequada entre matrizes de valor real que representam as imagens dos gráficos de recorrência. Essa medida de distância tem se mostrado muito eficaz em várias tarefas. Por exemplo, foi utilizada com sucesso para classificar mariposas (Batista et al., 2010), para identificar sons gerados por insetos utilizando-se espectrogramas (Hao et al., 2012) e para analisar imagens digitalizadas de letras estilizadas que iniciam capítulos de textos históricos (Hu et al., 2012).

\section{Método Proposto}

Neste trabalho, foi avaliada a hipótese de que as informações de recorrência podem ajudar na classificação de séries temporais numa grande variedade de domínios de aplicação. Essa hipótese foi levantada ao observar que séries temporais de diferentes classes frequentemente apresentam gráficos de recorrência que podem ser facilmente separados, simplesmente pela visualização das imagens. Na Figura A.8, são exibidos gráficos de recorrência de diferentes conjuntos de dados (linhas) e diferentes classes (colunas).

Em contraste, as séries temporais de uma mesma classe frequentemente apresentam gráficos de recorrência com forte semelhança aparente.

Essas observações podem ser ilustradas com um simples experimento. Nesse experimento, foi escolhida uma amostra aleatória de seis folhas do conjunto de dados Swedish Leaf, que foram incorretamente classificadas pelo algoritmo do vizinho mais próximo com distância euclidiana, mas corretamente classificados por meio do cálculo de distância de seus gráficos de recorrência. Com esses exemplos, foi realizado um agrupamento hierárquico, cujo resultado pode ser observado na Figura A.9.

Note que, na Figura A.9, apesar de todas as séries temporais possuírem um formato parecido com a letra "w", os gráficos de recorrência para objetos de diferentes classes podem ser facilmente diferenciados visualmente. Além disso, os gráficos de recorrência 


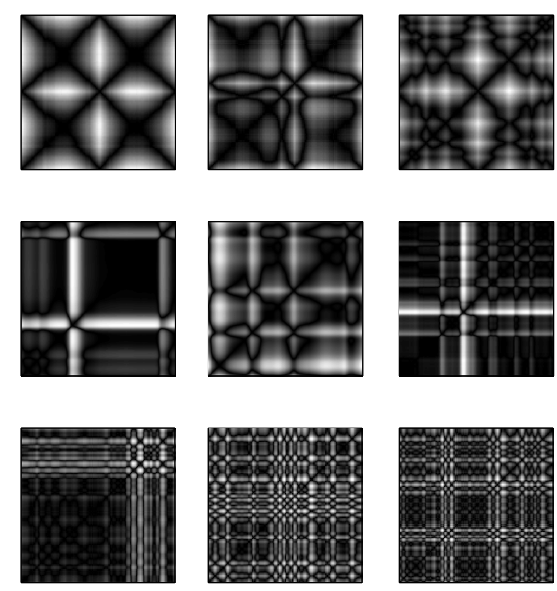

Figura A.8: Gráficos de recorrência de três conjuntos de dados (cada conjunto em uma linha) e, para cada conjuntos de dados, três diferentes classes (cada classe em uma coluna)

para os objetos da mesma classe compartilham fortes semelhanças. É possível verificar que os resultados obtidos com a distância euclidiana (Figura A.9 - esquerda) não são intuitivos, associando objetos de diferentes classes. Em contraste, os resultados obtidos com o agrupamento por similaridade utilizando-se gráficos de recorrência e a medida CK-1 combinam perfeitamente as classes analisadas (Figura A.9 - direita).

A abordagem para a classificação de séries temporais utilizando gráficos de recorrência é simples e sem parâmetro. No Algoritmo 1, é apresentado o algoritmo geral de classificação baseado na bem conhecida regra do vizinho mais próximo, assim como o procedimento de cálculo da acurácia.

Na Figura A.10, esse algoritmo é ilustrado de modo intuitivo. O método proposto recebeu o nome de distância de compressão de padrões de recorrência (em inglês, Recurrence Patterns Compression Distance - RPCD).

\section{Avaliação Experimental}

Foi realizada uma avaliação experimental ampla, utilizando uma grande variedade de conjuntos de dados temporais. No total, a avaliação incluiu 38 conjuntos de dados de diferentes domínios, como medicina, entomologia, engenharia, astronomia, processamento de sinais, entre outros. Mais especificamente, todos os conjuntos de dados utilizados nos experimentos podem ser encontrados no repositório de dados para classificação e agrupamento de séries temporais da $\mathrm{UCR}^{1}$. Esses conjuntos de dados possuem partições padrão de treinamento e teste, facilitando a realização dos experimentos e a comparação de resultados.

\footnotetext{
${ }^{1}$ http://www.cs.ucr.edu/ ${ }^{\sim}$ eamonn/time_series_data/
} 


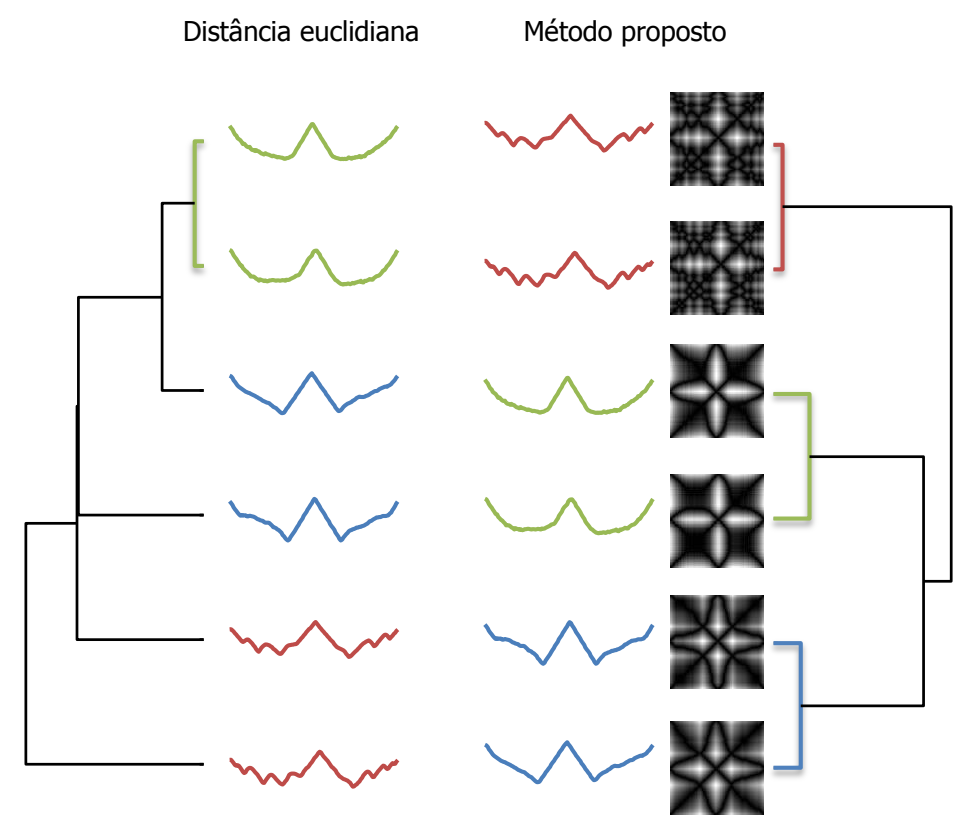

Figura A.9: Dendrogramas obtidos pelo agrupamento de seis séries temporais de três classes classes diferentes, utilizando-se distância euclidiana (esquerda) e distância baseada nos gráficos de recorrência (direita)

O uso de conjuntos de dados de benchmark facilita a reprodução de resultados e a comparação direta com outros métodos propostos na literatura. O repositório de séries temporais da UCR contém 43 conjuntos de dados, mas 5 deles são sintéticos, de modo que foram gerados por algum procedimento pré-definido. Foi decidido excluir todos os conjuntos de dados sintéticos nestes experimentos, uma vez que normalmente são gerados para um propósito ou algoritmo específico. Assim, foi utilizado um total de 38 conjuntos de dados.

A seção experimental está organizada da seguinte maneira: primeiramente, a RPCD é comparada com a distância euclidiana e a DTW no domínio temporal. É mostrado que o método proposto apresenta resultados competitivos. Mais importante, por meio de gráficos Texas sharpshooter, é mostrado que é possível prever com antecedência quando a RPCD irá superar as medidas de distância estado-da-arte. Posteriormente, é mostrado que a medida CK-1 é, de fato, uma distância adequada para comparar gráficos de recorrência. Isso é feito por meio da comparação da CK-1 com distância euclidiana e NCD na tarefa de classificar séries temporais com tal representação.

Os resultados da primeira etapa, ou seja, da comparação da RPCD contra distância euclidiana e DTW são mostrados na Tabela A.6.

Para facilitar a visualização dos resultados, as taxas de acurácia apresentadas na Tabela A.6 são representadas graficamente na Figura A.11. Nesses gráficos, cada conjunto 


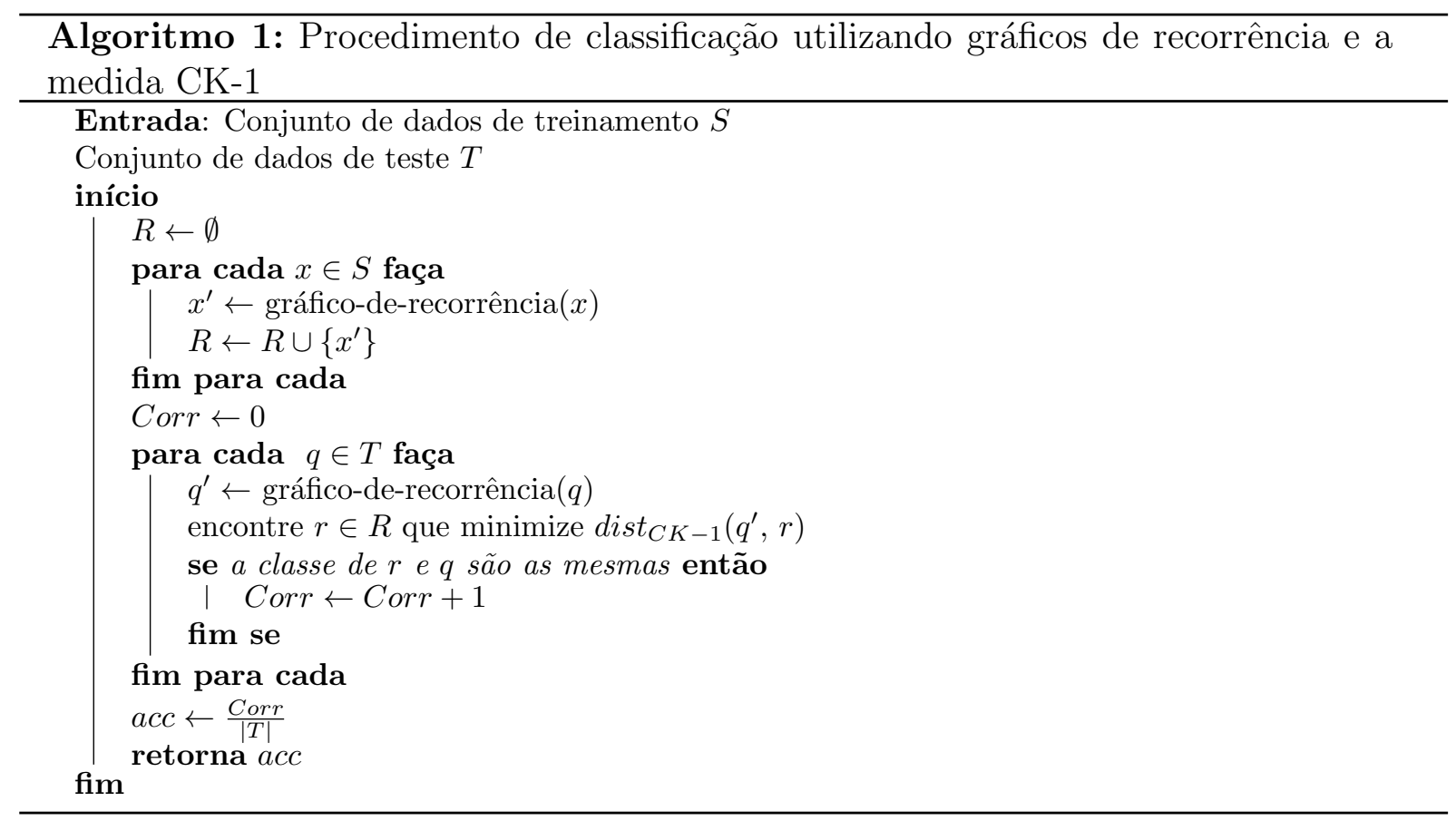

de dados é representado por um ponto, em que a coordenada y expressa a acurácia obtida pela RPCD e a coordenada $x$ indica a acurácia obtida pelo método competidor. Assim, pontos acima da diagonal principal referem-se a conjuntos de dados em que a RPCD obteve melhor resultado.

A RPCD é muito competitiva com a distância euclidiana e a DTW. Dentre os 38 conjuntos de dados utilizados nos experimentos, a RPCD foi superior à distância euclidiana em 28 deles (73,68\%), e superior à DTW em 20 (52,63\%).

É interessante olhar para os dados de diferentes domínios de aplicação e analisar quando a RPCD pode ou não ajudar no cumprimento da tarefa. Por exemplo, o repositório da UCR possui conjuntos de dados gerados a partir do contorno de imagens. Esse é um truque de representação em que as formas de objetos (como folhas e rostos) são convertidos em "série temporal", medindo-se a distância entre o ponto central do objeto e pontos consecutivos de seu contorno (Keogh et al., 2009). Na Figura A.12 esse procedimento é ilustrado. À medida que se caminha ao redor do objeto, obtém-se uma sequência de distâncias. Outro tipo de série temporal encontrado nesse repositório é referente a séries geradas pela observação de movimentos humanos. Tais movimentos são transformados em séries temporais, comumente pelo uso de acelerômetros ou por rastreamento de vídeo.

Observando os resultados de séries temporais geradas a partir de formas, é possível notar que a RPCD superou a distância euclidiana e a DTW em todos os oito conjuntos de dados nessa categoria. Possivelmente, a RPCD obteve bons resultados nesse tipo de 


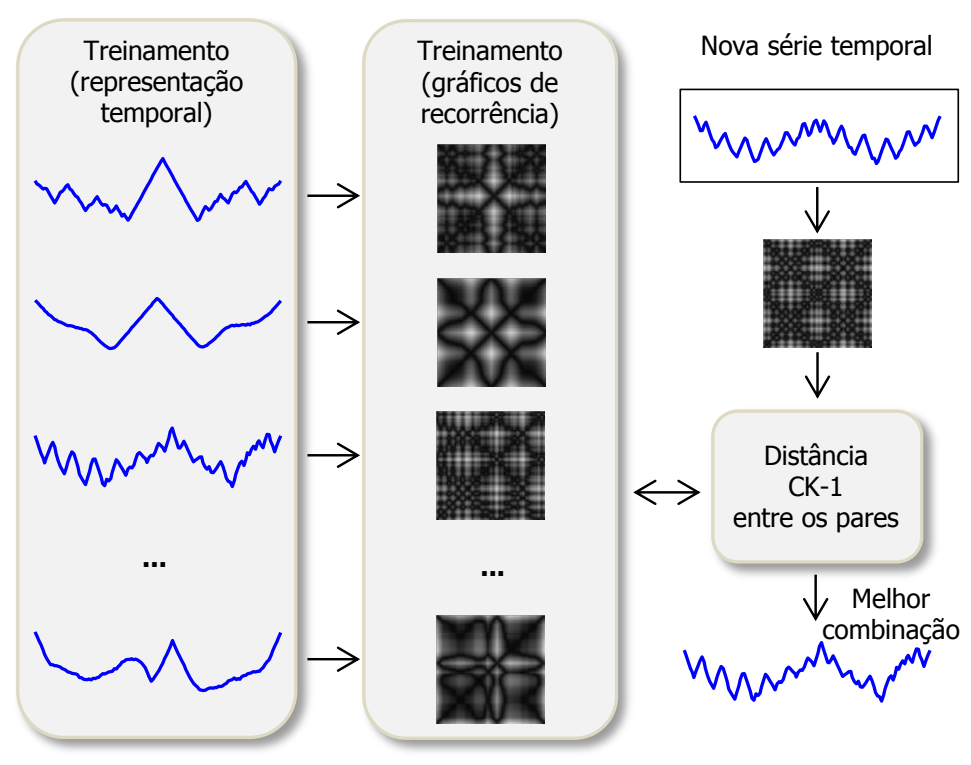

Figura A.10: Procedimento para calcular a medida de distância Recurrence Patterns Compression Distance

dados pois as formas frequentemente resultam em séries temporais estacionárias que são caracterizadas por padrões de repetição. Esses padrões podem ser facilmente observados no formato de folhas, que são frequentemente citadas como exemplos de fractais naturais. Fractais têm a propriedade de auto-similaridade, que é caracterizada por um padrão repetitivo que ocorre em diferentes escalas. Outros objetos que não possuem o comportamento fractal, como contornos faciais, podem apresentar outras propriedades que também provocam padrões de repetição, como simetrias e concavidades.

Como um exemplo contrastante, a RPCD não consegue obter bons resultados para séries temporais de movimentos humanos. Dos oito conjuntos de dados nessa categoria, a DTW supera a RPCD em sete deles. Note que séries temporais de movimentos nãorepetitivos também podem conter alguns padrões recorrentes. No entanto, geralmente são altamente não-estacionárias, resultando no fato de que uma determinada trajetória nunca visite um estado visitado anteriormente. Em contraste, a DTW é muito eficaz para este tipo de dados, uma vez que pode lidar muito bem com as diferenças de movimentos desalinhados no tempo.

Foi realizado um teste estatístico para detectar diferenças significativas entre os métodos de classificação analisados. Para isso, utilizou-se o teste de Friedman com pós-teste de Bonferroni-Dunn (Demšar, 2006) com 95\% para o nível de confiança. O teste de Friedman rejeitou a hipótese nula de que todos os métodos têm desempenho similar. Dessa maneira, foi realizado o pós-teste de Bonferroni-Dunn, utilizando o método com RPCD como controle. O pós-teste indicou uma diferença significativa entre a RPCD e a dis- 
Tabela A.6: Acurácia para cada medida de distância. Os símbolos $\boldsymbol{\nabla}, \boldsymbol{\Delta}$ e $\bullet$ representam dados obtidos por contorno de figuras, por movimentos humanos e pelos demais tipos de produção de dados, respectivamente

\begin{tabular}{|c|c|c|c|c|}
\hline Conjunto de dados & Euclidiana & DTW & RPCD & Tipo \\
\hline 50words & 63,10 & 69,00 & 77,36 & $\bullet$ \\
\hline Adiac & 61,10 & 60,40 & 61,64 & $\nabla$ \\
\hline Beef & 53,30 & 50,00 & 63,33 & $\bullet$ \\
\hline ChlorineConcentration & 65,00 & 64,80 & 51,09 & $\bullet$ \\
\hline CinC ECG torso & 89,70 & 65,10 & $\mathbf{9 7 , 9 0}$ & $\bullet$ \\
\hline Coffee & 75,00 & 82,10 & 100,00 & $\bullet$ \\
\hline Cricket X & 57,40 & 77,70 & 70,77 & $\boldsymbol{\Delta}$ \\
\hline Cricket Y & 64,40 & 79,20 & 73,85 & $\boldsymbol{\Delta}$ \\
\hline Cricket Z & 62,00 & 79,20 & 70,77 & $\boldsymbol{\Delta}$ \\
\hline DiatomSizeReduction & 93,50 & 96,70 & 96,41 & $\bullet$ \\
\hline ECG200 & 88,00 & 77,00 & 86,00 & $\bullet$ \\
\hline ECGFiveDays & 79,70 & 76,80 & 86,41 & $\bullet$ \\
\hline FaceAll & 71,40 & 80,80 & 80,95 & $\nabla$ \\
\hline FaceFour & 78,40 & 83,00 & 94,32 & $\nabla$ \\
\hline FacesUCR & 76,90 & 90,49 & 94,15 & $\nabla$ \\
\hline Fish & 78,30 & 83,30 & 87,43 & $\nabla$ \\
\hline Gun Point & 91,30 & 90,70 & 100,00 & $\boldsymbol{\Delta}$ \\
\hline Haptics & 37,00 & 37,70 & 38,64 & $\bullet$ \\
\hline InlineSkate & 34,20 & 38,40 & 32,00 & $\boldsymbol{\Delta}$ \\
\hline ItalyPowerDemand & 95,50 & 95,00 & 84,26 & $\bullet$ \\
\hline Lighting2 & 75,40 & 86,90 & 75,41 & $\bullet$ \\
\hline Lighting7 & 57,50 & 72,60 & 64,38 & $\bullet$ \\
\hline MedicalImages & 68,40 & 73,70 & 71,05 & $\bullet$ \\
\hline Motes & 87,90 & 83,50 & 79,71 & $\bullet$ \\
\hline OliveOil & 86,70 & 86,70 & 83,33 & $\bullet$ \\
\hline OSULeaf & 51,70 & 59,10 & 64,46 & $\boldsymbol{\nabla}$ \\
\hline SonyAIBORobotSurface & 69,50 & 72,50 & 79,70 & $\bullet$ \\
\hline SonyAIBORobotSurfaceII & 85,90 & 83,10 & 84,26 & $\bullet$ \\
\hline StarLightCurves & 84,90 & 90,70 & 88,17 & $\bullet$ \\
\hline SwedishLeaf & 78,70 & 79,00 & 90,24 & $\boldsymbol{\nabla}$ \\
\hline Symbols & 90,00 & 95,00 & 90,45 & $\bullet$ \\
\hline TwoLeadECG & 74,70 & 90,40 & 87,36 & $\bullet$ \\
\hline uWaveGestureLibrary X & 73,90 & 72,70 & 59,30 & $\boldsymbol{\Delta}$ \\
\hline uWaveGestureLibrary Y & 66,20 & 63,40 & 62,12 & $\boldsymbol{\Delta}$ \\
\hline uWaveGestureLibrary Z & 65,00 & 65,80 & 61,67 & $\Delta$ \\
\hline Wafer & 99,50 & 98,00 & 99,66 & $\bullet$ \\
\hline WordsSynonyms & 61,80 & 64,90 & 72,41 & $\bullet$ \\
\hline Yoga & 83,00 & 83,60 & 86,60 & $\nabla$ \\
\hline Vitórias & $8 / 38$ & $13 / 38$ & $18 / 38$ & \\
\hline
\end{tabular}

tância euclidiana, mas não houve diferença significativa entre RPCD e DTW. Na figura Figura A.13, é representada graficamente a comparação entre o classificador vizinho mais próximo com o uso de RPCD e o mesmo classificador baseado nas medidas DTW e distância euclidiana.

Devemos interpretar os resultados do teste estatístico com uma certa cautela. Primeiro, porque a avaliação realizada é puramente quantitativa, com conjuntos de dados de diferentes domínios de aplicação. Porém, é muito difícil, se não impossível, propor uma representação ou algoritmo de classificação de séries temporais que é o melhor para todos os domínios de aplicação. No entanto, a utilização da RPCD superou estatisticamente a 

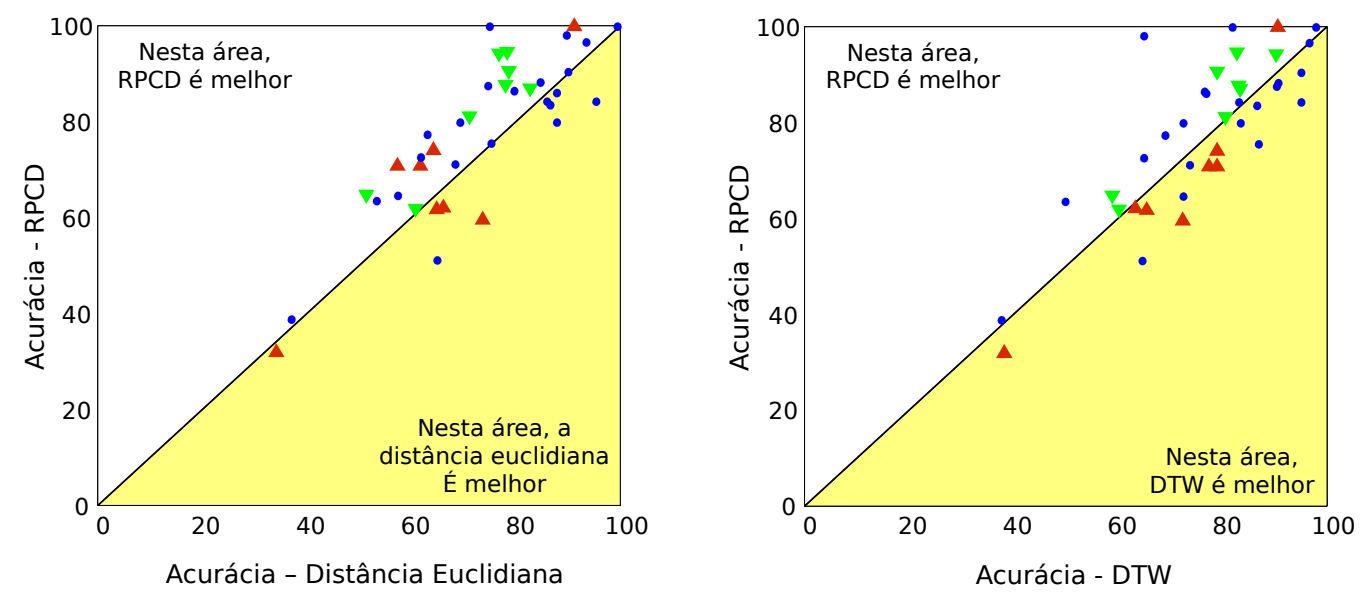

Figura A.11: Representação gráfica dos resultados obtidos pela RPCD contra as distâncias euclidiana e DTW. Cada ponto representa um conjunto de dados diferente. Os pontos acima da diagonal principal representam os conjuntos de dados em que a RPCD superou distância euclidiana (esquerda) ou DTW (direita). Os símbolos $\boldsymbol{\nabla}, \boldsymbol{\Delta}$ e $\bullet$ representam dados obtidos de contorno de figuras, de movimentos humanos e os dos demais tipos de produção de dados, respectivamente

distância euclidiana e teve um desempenho similar à DTW, que é considerada uma função de distância estado-da-arte para a classificação de séries temporais (Ding et al., 2008).

Tão importante quanto ter um bom desempenho médio em vários conjuntos de dados é fornecer uma melhora significativa na acurácia da classificação de determinados problemas relevantes. Note que a RPCD melhorou consideravelmente o desempenho da classificação, em comparação às distâncias utilizadas para comparação, em diversos conjuntos de dados, tais como Coffee, ECGFivedays, FaceFour, SwedishLeaf e outros. Obviamente, esses conjuntos de dados em que a RPCD pode melhorar significativamente o desempenho de classificação possuem algum tipo de correspondência entre as características dos dados e o viés da representação.

No entanto, o método proposto é inútil, caso não seja possível identificar quando ele irá fornecer resultados mais precisos. Na próxima seção, é mostrado como isso pode ser feito por meio de uma representação simples, utilizando gráficos. Esses gráficos indicam que é possível identificar com segurança os problemas em que é adequada a utilização de RPCD com base na análise de desempenho utilizando apenas dados de treinamento.

\section{A Falácia do Atirador Texano}

Como demonstrado na seção anterior, a RPCD é capaz de superar a distância euclidiana e a DTW em $73.68 \%$ e $52.63 \%$ dos conjuntos de dados analisados, respectivamente. 

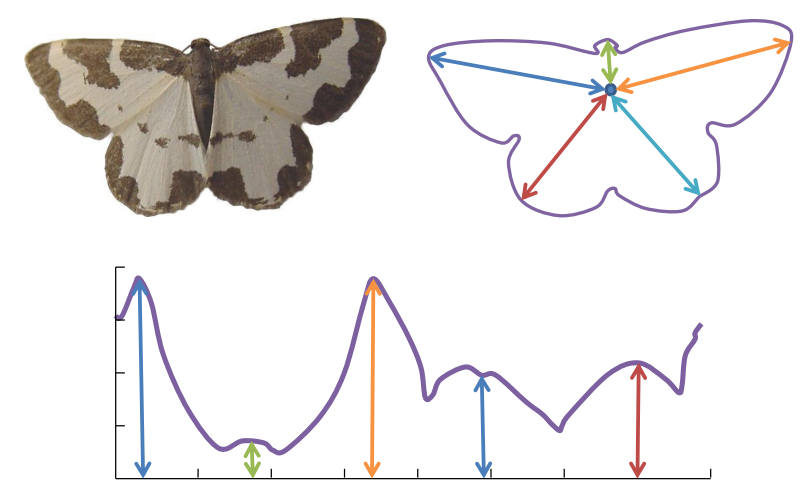

Figura A.12: Exemplo do truque de representação que transforma objetos em séries temporais (Batista et al., 2010)

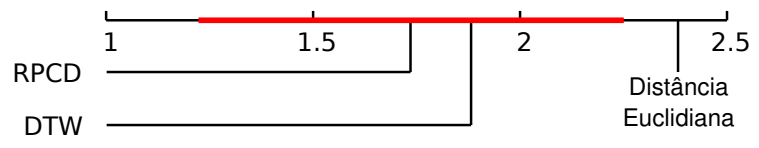

Figura A.13: Representação gráfica do pós-teste de Bonferroni-Dunn. O intervalo marcado representa o intervalo de rankings sem diferença estatística em relação à $\mathrm{RPCD}$, utilizada como controle

Apesar da RPCD não obter as melhores taxas de acurácia em todos os conjuntos de dados, é possível identificar quando sua utilização superar os métodos concorrentes.

Muitos trabalhos na literatura de classificação de séries temporais afirmam que seu método ou sua medida de distância proposta é útil, uma vez que superou o estado-da-arte em alguns conjuntos de dados. No entanto, como observado por Batista et al. (2011b), é inútil ter um algoritmo que pode ser melhor em apenas alguns problemas, a menos que seja possível saber com antecedência quais os problemas que serão mais adequados para sua utilização.

Uma maneira simples de mostrar que é possível prever quando o método proposto vai obter resultado superior aos demais métodos é utilizar gráficos do tipo Texas sharpshooter (Batista et al., 2011b). A falácia do atirador texano provém de uma anedota sobre um texano que dispara sua arma na lateral de um celeiro e, então, pinta um alvo em torno do lugar onde a maioria dos buracos de bala estão agrupados (Thompson, 2009). Isso é, em essência, o mesmo que avaliar um método que funciona bem em alguns problemas e dizer a posteriori que o método é eficaz para os problemas em que teve bom desempenho. Uma maneira de saber em quais problemas o novo método irá, de fato, ter um bom desempenho é estimando a eficácia dos métodos concorrentes olhando apenas para os dados de treinamento. Essa informação é utilizada para escolher qual algoritmo irá classificar os objetos ainda não rotulados. 
A fim de fazer isso, pode-se calcular o ganho de acurácia, definido pela Equação A.9.

$$
\text { ganho }=\frac{\text { acurácia }(\text { método proposto })}{\text { acurácia }(\text { método de comparação })}
$$

Valores de ganho superiores a 1 indicam que espera-se que o método proposto irá superar o concorrente em um determinado conjunto de dados. Valores de ganho inferiores a 1 indicam o oposto.

Define-se ganho esperado como o ganho calculado sobre o conjunto de treinamento e ganho real como o ganho sobre o conjunto de teste. Uma vez que o repositório da UCR fornece conjuntos de dados com partições padronizadas de treinamento e teste, foram utilizadas essas partições de dados para calcular os valores de ganho. Para calcular o ganho no do conjunto de treinamento (ganho esperado) foi utilizada a estratégia de validação cruzada leave-one-out, já que os conjuntos de treinamento frequentemente possuem poucos exemplos. Também foi calculado o ganho no conjunto de teste (ganho real), utilizando-se os valores de acurácia apresentados na Tabela A.6. Os valores de ganhos esperado e real são exibidos na Tabela A.7.

Na Figura A.14, são exibidos os gráficos de valores de ganho esperado versus ganho real. Os gráficos mostram os resultados da comparação da RPCD contra a distância euclidiana (esquerda) e contra a DTW (direita). Os gráficos são divididos em quatro regiões:

Verdadeiro positivo (VP) Nessa região, acredita-se de antemão que a RPCD melhoraria a acurácia, e a suposição está correta;

Verdadeiro negativo (VN) Nessa região, afirma-se corretamente que o uso de RPCD não é adequado para o caso, pois irá causar perda de acurácia;

Falso negativo (FN) Nessa região, é estabelecido com antecedência que a RPCD irá causar uma perda de acurácia, porém sua utilização iria, na verdade, causar um ganho no desempenho. Essa situação causa a perda da oportunidade de se utilizar o método proposto, mas isso não é pior do que nem mesmo tentá-lo;

Falso positivo (FP) Essa região é o único caso ruim para o método proposto. A análise de ganho aponta que a RPCD irá resultar em ganho de acurácia, porém essa suposição está errada.

A maioria dos pontos na Figura A.14 estão nas regiões VN e VP. Isso significa que podemos prever com bastante confiança se o uso da RPCD vai fornecer um ganho de acurácia em comparação a outros métodos de classificação. Especificamente, 31 pontos 
Tabela A.7: Ganhos esperados e reais entre RPCD e outras distâncias

\begin{tabular}{|c|c|c|c|c|}
\hline & \multicolumn{2}{|c|}{ Euclidiana } & \multicolumn{2}{|c|}{ DTW } \\
\hline & Esperado & Real & Esperado & Real \\
\hline 50words & 1,140 & 1,226 & 1,048 & 1,121 \\
\hline Adiac & 1,025 & 1,009 & 1,115 & 1,021 \\
\hline Beef & 0,867 & 1,188 & 1,300 & 1,267 \\
\hline ChlorineConcentration & 0,797 & 0,786 & 0,840 & 0,788 \\
\hline CinC ECG torso & 1,118 & 1,091 & 1,357 & 1,504 \\
\hline Coffee & 1,273 & 1,333 & 1,273 & 1,218 \\
\hline Cricket X & 1,249 & 1,233 & 0,949 & 0,911 \\
\hline Cricket Y & 1,138 & 1,147 & 0,886 & 0,932 \\
\hline Cricket Z & 1,263 & 1,141 & 0,960 & 0,894 \\
\hline DiatomSizeReduction & 1,000 & 1,031 & 1,000 & 0,997 \\
\hline ECG200 & 0,988 & 0,977 & 1,063 & 1,117 \\
\hline ECGFiveDays & 0,895 & 1,084 & 1,000 & 1,125 \\
\hline FaceAll & 1,105 & 1,134 & 1,020 & 1,002 \\
\hline FaceFour & 1,250 & 1,203 & 1,000 & 1,136 \\
\hline FacesUCR & 1,245 & 1,224 & 0,984 & 1,040 \\
\hline Fish & 1,113 & 1,117 & 1,138 & 1,050 \\
\hline Gun Point & 1,042 & 1,095 & 1,250 & 1,103 \\
\hline Haptics & 0,975 & 1,044 & 1,258 & 1,025 \\
\hline InlineSkate & 1,000 & 0,936 & 0,714 & 0,833 \\
\hline ItalyPowerDemand & 0,922 & 0,882 & 0,922 & 0,887 \\
\hline Lighting2 & 1,093 & 1,000 & 0,959 & 0,868 \\
\hline Lighting7 & 1,044 & 1,120 & 0,979 & 0,887 \\
\hline MedicalImages & 0,993 & 1,039 & 0,954 & 0,964 \\
\hline Motes & 0,867 & 0,907 & 0,867 & 0,955 \\
\hline OliveOil & 1,000 & 0,961 & 1,040 & 0,961 \\
\hline OSULeaf & 1,169 & 1,247 & 1,014 & 1,091 \\
\hline SonyAIBORobotSurface & 0,947 & 1,147 & 1,002 & 1,099 \\
\hline SonyAIBORobotSurfaceII & 1,057 & 0,981 & 1,057 & 1,014 \\
\hline StarLightCurves & 1,036 & 1,039 & 1,001 & 0,972 \\
\hline SwedishLeaf & 1,197 & 1,147 & 1,182 & 1,142 \\
\hline Symbols & 1,048 & 1,005 & 0,917 & 0,952 \\
\hline TwoLeadECG & 1,222 & 1,169 & 1,048 & 0,966 \\
\hline uWaveGestureLibrary X & 0,787 & 0,802 & 0,879 & 0,816 \\
\hline uWaveGestureLibrary Y & 0,905 & 0,938 & 0,884 & 0,980 \\
\hline uWaveGestureLibrary Z & 0,919 & 0,949 & 0,882 & 0,937 \\
\hline Wafer & 1,002 & 1,002 & 1,004 & 1,017 \\
\hline WordsSynonyms & 1,191 & 1,172 & 1,051 & 1,116 \\
\hline Yoga & 1,095 & 1,043 & 1,045 & 1,036 \\
\hline
\end{tabular}

(81, 58\%) estão nessas regiões, ao se comparar com a distância euclidiana; contra DTW, 34 pontos $(89,47 \%)$.

Há apenas 6 pontos na área de $\mathrm{FN}$ dos dois gráficos (5 para euclidiana e 1 para DTW). Esses pontos indicam um diagnóstico incorreto, ou seja, previu-se uma perda de desempenho com o uso da RPCD, quando, na verdade, haveria um melhor desempenho na classificação. No entanto, pode-se entender essa situação como uma oportunidade perdida, já que rejeitar o uso de RPCD é o mesmo que nem mesmo ter tentado utilizá-lo.

O pior caso, como citado anteriormente, é a área FP. Entretanto, contando ambos os gráficos, há apenas 5 pontos nessa área. Todos eles estão próximos a regiões de fronteira, indicando uma diferença que pode facilmente ter ocorrido devido ao acaso. 

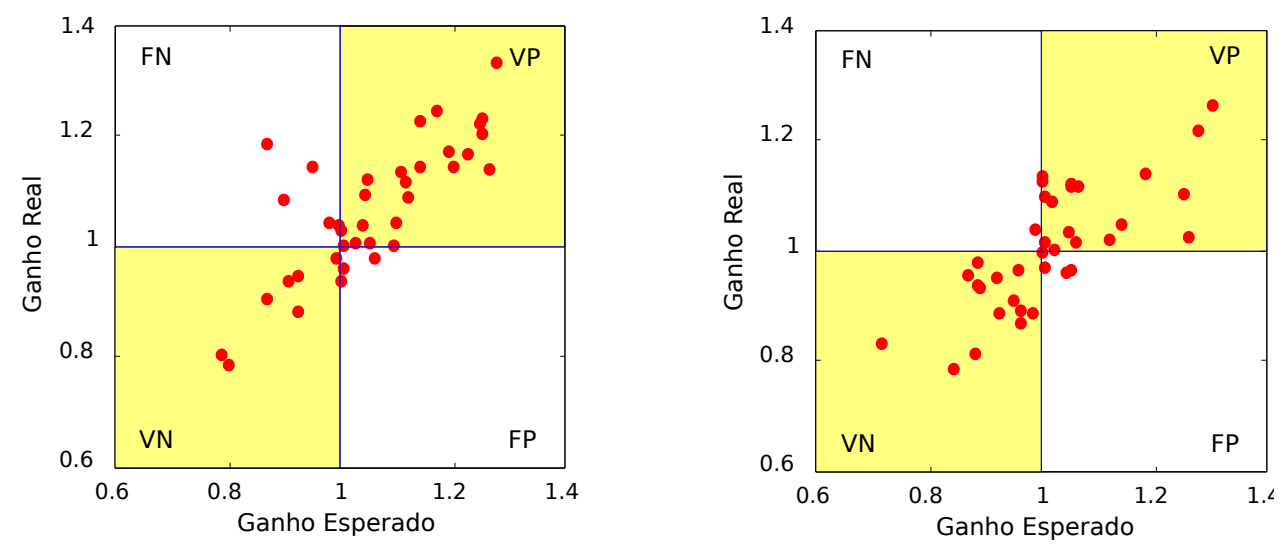

Figura A.14: Gráfico Texas sharpshooter da RPCD versus a distância euclidiana (esquerda) e a DTW (direita)

\section{Medidas de Distância Entre Gráficos de Recorrência}

Até este ponto, foi mostrado que a RPCD pode ser uma boa medida de distância para a classificação de séries temporais. No entanto, é interessante analisar o real motivo de seu bom desempenho. Em particular, foi assumida a hipótese que a medida CK-1 é adequada para comparar gráficos de recorrência, uma vez que ela leva em consideração a informação espacial das imagens. Nesta seção, serão mostrados resultados que mostram que a CK-1 pode realmente superar outras medidas de distância entre gráficos de recorrência para a classificação de séries temporais. Para isso, foi realizado um experimento utilizando o algoritmo do vizinho mais próximo, com CK-1, distância euclidiana e distância de compressão normalizada. A NCD foi calculada utilizando-se a implementação CompLearn $N C D^{2}$. Os resultados são apresentados na Tabela A.8.

Os resultados exibidos na Tabela A.8, são graficamente apresentados na Figura A.15. Nesses gráficos, cada conjunto de dados é representado por um ponto. A coordenada y indica a acurácia obtida pela utilização da medida CK-1 para se comparar os gráficos de recorrência. A coordenada $x$ representa a acurácia obtida pela comparação utilizando-se NCD ou distância euclidiana. Os resultados acima da diagonal principal são relativos aos conjuntos de dados em que a dissimiaridade pela medida CK-1 é superior ao método adversário.

A partir dos resultados apresentados, é evidente que a CK-1 supera a distância euclidiana e a NCD na comparação de gráficos de recorrência para a classificação de séries temporais. Em particular, a RPCD superou a NCD em todos, exceto dois, conjuntos de dados. Em muitos deles por uma margem grande. No entanto, foi realizado um teste de hipóteses, a fim de verificar se o desempenho dos métodos de comparação são estatisti-

\footnotetext{
${ }^{2}$ http://complearn.org/ncd.html
} 
Tabela A.8: Taxas de acurácia do classificador do vizinho mais próximo com distância euclidiana, NCD e CK-1 (RPCD) entre gráficos de recorrência

\begin{tabular}{|c|c|c|c|}
\hline Conjunto de dados & Euclidiana & NCD & RPCD \\
\hline 50words & 63,08 & 5,93 & 77,36 \\
\hline Adiac & 62,92 & 54,22 & 61,64 \\
\hline Beef & 66,67 & 23,33 & 63,33 \\
\hline ChlorineConcentration & 63,70 & 62,32 & 51,09 \\
\hline CinC ECG torso & 97,25 & 51,52 & 97,90 \\
\hline Coffee & 100,00 & 53,57 & 100,00 \\
\hline Cricket X & 53,85 & 12,31 & 70,77 \\
\hline Cricket $\mathrm{Y}$ & 54,87 & 8,21 & 73,85 \\
\hline Cricket Z & 56,15 & 12,05 & 70,77 \\
\hline DiatomSizeReduction & 96,08 & 69,28 & 96,41 \\
\hline ECG200 & 87,00 & 71,00 & 86,00 \\
\hline ECGFiveDays & 80,49 & 76,07 & 86,41 \\
\hline FaceAll & 74,38 & 2,01 & 80,95 \\
\hline FaceFour & 79,55 & 25,00 & 94,32 \\
\hline FacesUCR & 75,46 & 17,71 & 94,15 \\
\hline Fish & 78,29 & 37,14 & 87,43 \\
\hline Gun Point & 89,33 & 94,00 & 100,00 \\
\hline Haptics & 39,61 & 23,38 & 38,64 \\
\hline InlineSkate & 33,09 & 22,18 & 32,00 \\
\hline ItalyPowerDemand & 96,21 & 61,61 & 84,26 \\
\hline Lighting2 & 73,77 & 52,46 & 75,41 \\
\hline Lighting7 & 54,79 & 21,92 & 64,38 \\
\hline MedicalImages & 69,08 & 57,89 & 71,05 \\
\hline Motes & 79,87 & 62,78 & 79,71 \\
\hline OliveOil & 86,67 & 26,67 & 83,33 \\
\hline OSULeaf & 52,89 & 48,35 & 64,46 \\
\hline SonyAIBORobotSurface & 76,71 & 57,07 & 79,70 \\
\hline SonyAIBORobotSurfaceII & 85,10 & 62,96 & 84,26 \\
\hline StarLightCurves & 88,96 & 75,11 & 88,17 \\
\hline SwedishLeaf & 82,40 & 44,16 & 90,24 \\
\hline Symbols & 87,74 & 49,85 & 90,45 \\
\hline TwoLeadECG & 75,68 & 94,38 & 87,36 \\
\hline uWaveGestureLibrary X & 56,39 & 30,82 & 59,30 \\
\hline uWaveGestureLibrary Y & 59,55 & 24,96 & 62,12 \\
\hline uWaveGestureLibrary Z & 58,24 & 30,63 & 61,67 \\
\hline Wafer & 99,58 & 99,53 & 99,66 \\
\hline WordsSynonyms & 61,29 & 15,05 & 72,41 \\
\hline Yoga & 82,37 & 66,90 & 86,60 \\
\hline Vitórias & $12 / 38$ & $1 / 38$ & $26 / 38$ \\
\hline
\end{tabular}

camente diferentes. Uma vez que o desempenho utilizando-se NCD foi muito ruim neste experimento, a medida foi excluída do teste de hipóteses. Utilizou-se o teste de Friedman com o pós-teste de Bonferroni-Dunn com 95\% de nível de confiança. O teste rejeitou a hipótese nula de que a CK-1 e a distância euclidiana possuem desempenhos semelhantes na tarefa analisada. Na Figura A.16, a comparação entre o classificador vizinho mais próximo com o uso da CK-1 e a distância euclidiana é representada graficamente.

\section{Conclusões}

A abordagem apresentada é simples e livre de parâmetros. Mesmo assim, é capaz de prover excelentes resultados na classificação de séries temporais. 

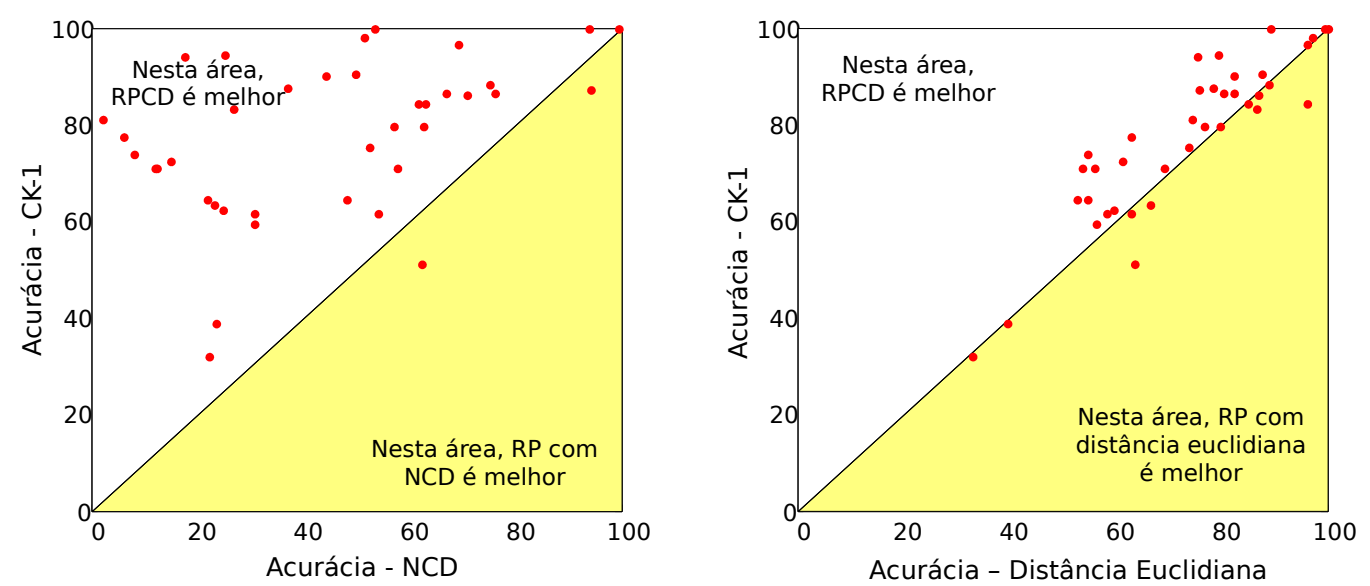

Figura A.15: Representação gráfica dos resultados obtidos por CK-1, distância euclidiana e NCD sobre RP. Cada ponto representa um conjunto de dados diferente. Os pontos acima da diagonal representam os conjuntos de dados em que os RP foram comparados com CK-1 obtiveram melhores resultados em relação ao uso da NCD (esquerda) e da distância euclidiana (direita)

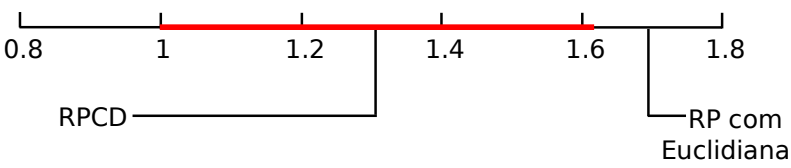

Figura A.16: Representação gráfica do pós-teste de Bonferroni-Dunn. O intervalo marcado representa o intervalo de rankings sem diferença estatística em relação ao RPCD, utilizado como controle

Para garantir a eficácia do método proposto, foram realizados experimentos em um grande número de conjuntos de dados. Os resultados mostraram que o algoritmo proposto supera a distância euclidiana em $73,68 \%$ e a DTW em 52,63\% dos conjuntos de dados analisados. Em alguns conjuntos de dados, a RPCD supera as distâncias concorrentes por uma larga margem. Também foi mostrado, com o gráfico Texas sharpshooter, que é possível prever de antemão em quais conjuntos de dados a RPCD irá superar as outras distâncias. Por fim, foi mostrado que, de fato, a medida CK-1 é bastante adequada para o cumprimento da tarefa.

Na próxima seção, será apresentada uma dessas aplicações, a recuperação de informação por conteúdo.

\section{A.2.2 Recuperação de Música por Conteúdo pela Medida de Distância RPCD}

No contexto de organização e recuperação em coleções de música, a noção de similaridade entre gravações de música é de grande importância em muitas aplicações, tais 
como sumarização (Cooper e Foote, 2002) ou recuperação de covers (Ellis e Poliner, 2004). Comumente, a similaridade entre duas gravações é medida pela comparação da suas respectivas séries temporais.

Sinais de áudio de música são altamente estruturados e comumente apresentam segmentos recorrentes. Um exemplo disso é a chamada sonata na forma ABA (exposição desenvolvimento - recapitulação) na música clássica. Desde sua introdução, matrizes de auto-similaridade tornaram-se representações comuns para visualizar a estrutura temporal de um sinal de áudio em termos de auto-similaridade e recorrências (Foote, 1999). Tais representações bidimensionais são obtidas pelo cálculo da similaridade par a par de atributos de áudio (como coeficientes mel-cepstrais (Logan e Salomon, 2001) ou vetores cromáticos (Bartsch e Wakefield, 2005)) e permitem colocar em evidência padrões que não são claramente revelados diretamente no domínio temporal. Por exemplo, padrões repetidos no áudio, como refrões, são representados por linhas diagonais na matriz resultante.

Entre as diversas aplicações baseadas em tarefas de recuperação, existe, neste trabalho, o interesse na seguinte tarefa: dada uma peça musical de consulta, recuperar automaticamente todas as performances (várias interpretações da música de consulta) de uma determinada coleção. O foco do trabalho foi a música clássica.

Duas interpretações da mesma peça possuem um conteúdo musical semelhante, mas podem ser diferentes em muitos aspectos. Além de articulação, fraseado e ornamentação, o andamento global pode ser diferente de uma performance a outra. Variações de andamento locais como ritardando também podem existir. Além disso, outros fatores, como as condições de gravação, o volume ou a instrumentação podem resultar em disparidades entre as duas interpretações.

Apesar dessas variações, alguns trabalhos têm mostrado que é possível medir com precisão a similaridade estrutural entre duas gravações calculando a similaridade entre seus pares de matrizes de auto-similaridade, sem extrair explicitamente a estrutura do áudio. Essa abordagem é utilizada por Izumitani e Kashino (2008) no problema de detecção de música cover. Martin et al. (2009) utilizaram essa abordagem para construir um sistema de recuperação que procura em um banco de dados a peça musical que melhor corresponde a uma consulta em representação simbólica. Em particular, há dois trabalhos de maior correlação com este (Bello, 2011; Grosche et al., 2012). Neles, os autores mostram que é possível relacionar, de maneira robusta, diferentes interpretações da mesma obra musical, utilizando medidas de distância diretamente aplicadas sobre pares de representações estruturais.

No trabalho que será apresentado nesta seção, foi utilizada a medida RPCD na tarefa de recuperação de música por conteúdo, baseada em sua estrutura. Foi mostrado que a 
utilização dessa medida de distância supera os resultados dos trabalhos anteriores, que utilizaram uma abordagem semelhante, mas outras medidas de distância.

\section{Recuperação de Informação Musical Baseada em Estrutura}

A tarefa realizada nesta etapa é diferente da classificação de séries temporais por dois motivos principais: existe a necessidade de uma fase de extração de atributos, que utiliza estratégia de janelamento sobre os sinais analisados, e, nesse caso, não há o interesse apenas no exemplo de treinamento mais similar, mas sim em um ranking por similaridade.

Nesta seção, será utilizado o termo matriz de auto-similaridade no lugar de gráficos de recorrência, uma vez que esse termo é comumente utilizado no domínio de análise de sinais de música. Considere também que, nesse caso, a distância do cosseno foi utilizada como a norma entre as subsequências. Além disso, esse termo determina, implicitamente, que não é utilizado o limiar de proximidade na obtenção da representação gráfica.

O primeiro passo a ser realizado consiste em extrair um conjunto de atributos que forneça informações relevantes sobre a estrutura musical. Entre as várias características que os seres humanos utilizam para determinar a estrutura de uma peça musical, a progressão harmônica é, provavelmente, a mais importante (Bruderer et al., 2009). Desde sua introdução, os pitch class profiles (Fujishima, 1999) ou atributos cromáticos (em inglês, chroma features) (Wakefield, 1999) tornaram-se características comuns para descrever o conteúdo harmônico de uma música. Os atributos cromáticos são, em essência, vetores 12-dimensionais que representam a energia espectral das classes de altura da escala cromática. Em outras palavras, em cada janela, é calculada a energia do espectro nas faixas de frequência relativas aos 12 tons e semitons da escala de notas musicais. Esses atributos têm sido utilizados com sucesso em várias tarefas de análise de sinais musicais, principalmente em trabalhos anteriores sobre recuperação baseadas em conteúdo (Bello, 2011; Grosche et al., 2012).

Seguindo essa abordagem, foram extraídas sequências de atributos cromáticos, bem como duas variações: o Chroma Energy Normalized Statistics (CENS) e o Chroma DCTReduced log Pitch (CRP). Os atributos CENS envolvem uma etapa adicional de suavização e downsampling temporal, levando a uma maior robustez em relação a pequenas variações locais de tempo. Os atributos CRP aumentam o grau de invariância ao timbre. Maiores detalhes sobre ambas as representações podem ser vistos no trabalho de Müller e Ewert (2011). Para calcular tais vetores de atributos, foi utilizada a ferramenta Matlab chroma toolbox ${ }^{3}$. Todos os vetores foram normalizados para que tenham norma unitária.

\footnotetext{
${ }^{3}$ http://www.mpi-inf.mpg.de/resources/MIR/cromatoolbox/
} 
Uma vez que diferentes gravações possuem uma natural diferença em sua duração, os vetores de atributos extraídos do sinal possuem tamanhos diferentes. Esses vetores são, então, redimensionados. Isso irá garantir que todas as matrizes de auto-similaridade tenham o mesmo tamanho, restrição imposta pela medida CK-1. Os vetores são, finalmente, utilizados para construir as matrizes de auto-similaridade, conforme descrito na Seção A.2.1.

O objetivo principal da tarefa de recuperação de informação, nesse caso, é construir um ranking de similaridade a partir de uma consulta. Idealmente, se há $n$ gravações da mesma peça musical que a consulta, esses exemplos devem ocorrer nas primeiras $n$ posições do ranking. Neste trabalho, foi considerado o seguinte cenário: dada uma gravação de consulta e uma coleção de gravações de música com várias performances da mesma peça que a consulta, junto com gravações de composições diferentes, deve-se recuperar todas as apresentações da peça musical consultada. Para este fim, define-se os passos de treinamento e recuperação pelos Algoritmo 2 e 3, respectivamente.
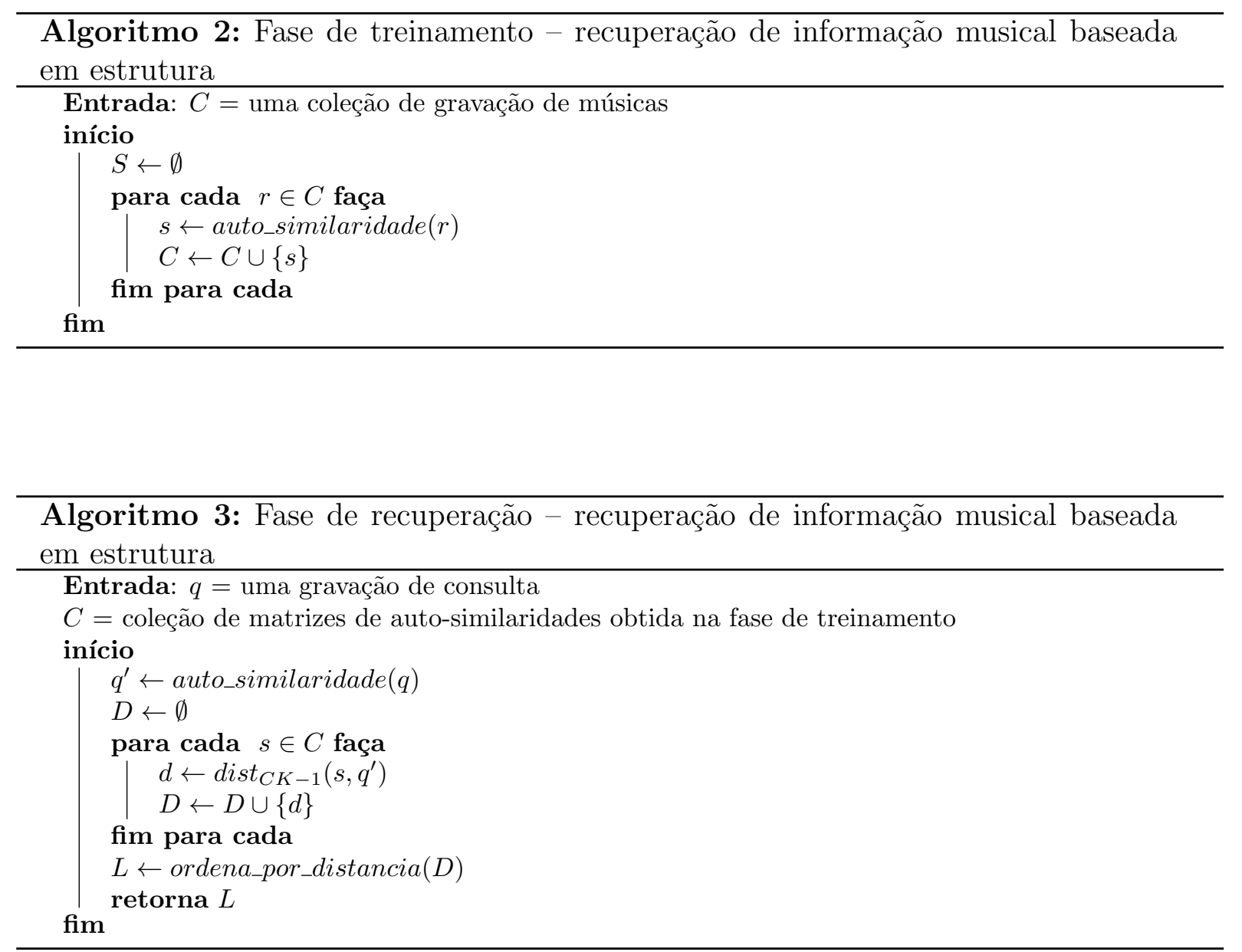


\section{Trabalhos Relacionados}

Bello (2011) provavelmente foi o primeiro a realizar a tarefa de recuperação de música por informação baseando-se diretamente na similaridade da estrutura de diferentes performances. A abordagem proposta pelo autor utiliza gráficos de recorrência binários como representação da estrutura da música e NCD como medida de similaridade entre dois gráficos. O trabalho faz uma avaliação em larga escala da abordagem proposta, incluindo experimentos realizados para encontrar a melhor configuração de parâmetros para a obtenção dos gráficos de recorrência, além de uma comparação de diferentes variações de atributos cromáticos. Apoiado por tal avaliação experimental, o autor fornece evidências da eficácia da abordagem proposta.

Posteriormente, um método similar foi proposto por Grosche et al. (2012), utilizando a distância euclidiana. Devido à simplicidade de tal distância, o método proposto resultou em uma abordagem mais eficiente em termos de tempo de execução. No entanto, pequenas variações temporais podem causar alterações nos padrões de recorrência e a distância euclidiana é muito sensível a esse tipo de mudança. Para superar essa limitação, os autores utilizaram uma técnica para desfocar o gráfico resultante. Os resultados, obtidos em um conjunto de dados um pouco diferente do utilizado por Bello (2011) (com um número menor de gravações), mostraram que esse método também é eficaz na recuperação de música baseada em sua estrutura.

\section{Avaliação Experimental}

Foi realizada uma ampla avaliação experimental para avaliar a eficácia do método proposto. A fim de comparar o novo método de forma justa a trabalhos anteriores, foram utilizados os mesmos conjuntos de dados e a mesma variação de parâmetros da extração de atributos utilizada por Bello (2011). Além disso, foram realizados experimentos com uma técnica semelhante à apresentada por Grosche et al. (2012), aplicando métodos de desfoque sobre gráficos de recorrência.

Desse modo, foram utilizados dois conjuntos de dados de música clássica:

- O primeiro conjunto de dados, nomeado neste trabalho como 123tracks, é composto por 123 gravações de 19 diferentes obras dos períodos clássico e romântico. Dentre essas gravações, 56 são executadas no piano e as demais 67 são movimentos sinfônicos. Ao todo, há 59 pianistas/orquestras diferentes; 
- O segundo conjunto de dados, referido por Mazurkas, consiste de 2919 gravações ${ }^{4}$ de 49 mazurkas de Chopin para piano. Essas gravações foram realizadas por 135 pianistas diferentes.

Como citado anteriormente, a medida CK-1 é livre de parâmetro, bem como o procedimento para gerar as matrizes de auto-similaridade. No entanto, a CK-1 tem uma pequena ressalva: a medida requer que todas as imagens tenham a mesma dimensão. Uma vez que a dimensão das matrizes de auto-similaridade são proporcionais às durações das gravações, que são variáveis, é necessário redimensionar as sequências de atributos para uma dimensão $d$ fixa, antes de calcular a matriz. Nos experimentos realizados neste trabalho, foi utilizado o processo de reamostragem, resultando em cinco dimensões de atributos diferentes, $d \in\{300 ; 500 ; 700 ; 900 ; 1100\}$.

Para cada variação de atributos cromáticos (Croma, CENS e CRP), foram utilizados sete diferentes tamanhos de janela, resultando em sete diferentes taxas de amostragem de atributos: $f \in\{0,333 ; 0,5 ; 1 ; 1,25 ; 2,5 ; 5 ; 10\}$ atributos/segundo.

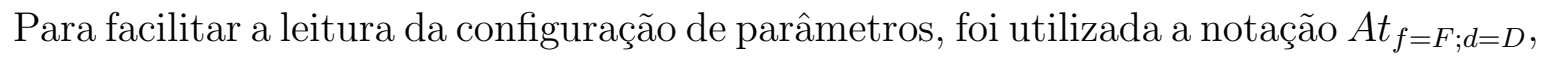
em que $A t \in\{C r o m a ; C E N S ; C R P\}$ e $F$ e $D$ são valores para a frequência de extração atributos (ou taxa de amostragem) $(f)$ e dimensão dos vetores de atributos $(d)$, respectivamente.

Todos os experimentos foram avaliados utilizando a medida mean average precision (MAP). Considere uma coleção $C$ que consiste de $M$ itens, e um subconjunto $Q \subset C$ contendo $n$ diferente performances da mesma peça musical. Dada a consulta $q_{i} \in Q$, constrói-se uma lista ranqueada pela distância calculada entre todas as peças da coleção e a consulta $q_{i}$. A precisão média (AP) é definida pela Equação A.10, em que $P(r)$ é a precisão na posição $r$ do ranking. A precisão, por sua vez, é definida pela equação A.11, em que $\Omega(r)$ é 0 caso o trabalho na posição $r$ seja relevante ou 1, caso contrário. Nesse caso, um trabalho é considerado relevante se ele corresponde a uma gravação da mesma peça musical da consulta.

$$
\begin{gathered}
A P\left(q_{i}\right)=\frac{1}{n} \sum_{r=1}^{M} P(r) \Omega(r) \\
P(r)=\frac{1}{r} \sum_{i=1}^{r} \Omega(i)
\end{gathered}
$$

\footnotetext{
${ }^{4}$ Este é o número de gravações apresentadas na descrição oficial do conjunto de dados. No entanto, há peças que não estão disponíveis, sendo que foi encontrado um total de 2914 gravações. Essa condição também se aplica a trabalhos anteriores. Consequentemente, não afeta a comparação de resultados.
} 
Finalmente, a medida MAP é definida pela média de todas as AP calculadas para o conjunto.

\section{Resultados no Conjunto de Dados 123tracks}

Os resultados dos experimentos realizados foram divididos de acordo com o conjunto de dados analisado, a fim de facilitar sua apresentação e comparação com trabalhos anteriores. O primeiro conjunto de dados analisado foi o 123tracks. Nas Tabelas A.9, A.10 e A.11, são exibidos os resultados obtidos pelo método proposto, com as diferentes variações de parâmetro para a obtenção dos atributos e dimensão utilizada. Os resultados são referentes aos obtidos pelo uso de atributos cromáticos, CENS e CRP, respectivamente. Foram aplicados o teste pareado de Friedman e o pós-teste de Dunnet para comparar se houve diferenças estatísticas entre os resultados. As células em amarelo representam resultados estatisticamente equivalentes ao melhor resultado da tabela.

Tabela A.9: Resultados (MAP) obtidos com atributos cromáticos no conjunto 123tracks. As células em amarelo representam resultados sem diferença estatística em relação ao obtido pela configuração Croma $_{f=2.5 ; d=300}$

\begin{tabular}{r|rrrrr}
\hline Taxa de & \multicolumn{5}{|c}{ Dimensão dos vetores de atributos (d) } \\
amostragem (f) & 300 & 500 & 700 & 900 & 1100 \\
\hline 10 & 0,914 & 0,915 & 0,904 & 0,900 & 0,897 \\
5 & 0,918 & 0,910 & 0,902 & 0,894 & 0,896 \\
2,5 & $\mathbf{0 , 9 3 0}$ & 0,922 & 0,898 & 0,890 & 0,885 \\
1,25 & 0,927 & 0,923 & 0,903 & 0,893 & 0,887 \\
1 & 0,929 & 0,928 & 0,913 & 0,903 & 0,889 \\
0,5 & 0,930 & 0,928 & 0,917 & 0,907 & 0,890 \\
0,33 & 0,930 & 0,927 & 0,918 & 0,907 & 0,888 \\
\hline
\end{tabular}

Tabela A.10: Resultados (MAP) obtidos com atributos CENS no conjunto 123tracks. As células em amarelo representam resultados sem diferença estatística em relação ao obtido pela configuração $C E N S_{f=0.5 ; d=300}$

\begin{tabular}{r|rrrrr}
\hline Taxa de & \multicolumn{6}{|c}{ Dimensão dos vetores de atributos (d) } \\
amostragem (f) & 300 & 500 & 700 & 900 & 1100 \\
\hline 10 & 0,926 & 0,920 & 0,914 & 0,911 & 0,908 \\
5 & 0,943 & 0,929 & 0,923 & 0,917 & 0,915 \\
2,5 & 0,946 & 0,945 & 0,941 & 0,935 & 0,930 \\
1,25 & 0,943 & 0,943 & 0,937 & 0,933 & 0,930 \\
1 & 0,944 & 0,944 & 0,941 & 0,938 & 0,936 \\
0,5 & $\mathbf{0 , 9 4 6}$ & 0,944 & 0,940 & 0,940 & 0,942 \\
0,33 & 0,942 & 0,940 & 0,934 & 0,932 & 0,932 \\
\hline
\end{tabular}

Uma vez que as configurações de parâmetros utilizadas neste experimento são as mesmas que as utilizadas por Bello (2011), os resultados podem ser diretamente comparados. 
Tabela A.11: Resultados (MAP) obtidos com atributos CRP no conjunto 123tracks. As células em amarelo representam resultados sem diferença estatística em relação ao obtido pela configuração $C R P_{f=1.25 ; d=500}$

\begin{tabular}{r|rrrrr}
\hline Taxa de & \multicolumn{5}{|c}{ Dimensão dos vetores de atributos (d) } \\
amostragem (f) & 300 & 500 & 700 & 900 & 1100 \\
\hline 10 & 0,930 & 0,936 & 0,937 & 0,932 & 0,935 \\
5 & 0,933 & 0,933 & 0,937 & 0,934 & 0,935 \\
2,5 & 0,933 & 0,940 & 0,936 & 0,935 & 0,934 \\
1,25 & 0,935 & $\mathbf{0 , 9 4 1}$ & 0,935 & 0,936 & 0,936 \\
1 & 0,933 & 0,936 & 0,932 & 0,934 & 0,937 \\
0,5 & 0,930 & 0,937 & 0,929 & 0,933 & 0,932 \\
0,33 & 0,929 & 0,937 & 0,929 & 0,932 & 0,931 \\
\hline
\end{tabular}

Os resultados obtidos com o método proposto superou os resultados de Bello (2011) em todas as configurações de parâmetros. Por exemplo, o melhor resultado obtido com a medida CK-1 é de $0,946\left(C E N S_{f=0.5 ; d=300}\right)$. O melhor resultado obtido pelo método adversário, ao fixar os parâmetros diretamente relacionados aos gráficos de recorrência, foi de $0,863\left(C R P_{f=10 ; d=700}\right)$, uma diferença significativa de quase $9 \%$. Além disso, a medida CK-1 e as matrizes de auto-similaridade não têm parâmetros internos a serem ajustados. Por outro lado, os gráficos de recorrência utilizados por Bello (2011) possuem três parâmetros que precisam ser definidos. De acordo com o autor, após uma pesquisa computacionalmente intensiva no espaço de parâmetros - variando o limiar de proximidade, o tempo de atraso e a dimensão embarcada -, o melhor resultado obtido foi de 0,921 . O tempo de atraso $(\tau)$ é relativo à distância entre observações consecutivas das subsequências analisadas, quando a dimensão embarcada é maior que 1 . Se $\tau=1$, a subsequência é formada por observações/janelas consecutivas do sinal. Caso contrário, as observações tomadas para montar as subsequências a serem comparadas possuem uma distância de $\tau$ observações entre elas. Note que o resultado obtido ainda é superado pelo método proposto, sem parâmetros.

Embora a diferença de desempenho seja muito pequena, a fim de providenciar uma diferença estatisticamente significativa, com alta confiança, existem outros aspectos que devem ser considerados. O método proposto neste trabalho é muito mais simples de ser utilizado e ter seus resultados replicados pela comunidade de pesquisa, devido à não necessidade de ajustar parâmetros internos. Outra questão relevante é que o método proposto é robusto em relação a mudanças de parâmetros externos. Uma má escolha dos parâmetros na etapa de extração de atributos não afeta significativamente o desempenho. Por exemplo, o pior resultado obtido pelo método proposto foi 0,885 , utilizando Croma $_{f=2,5 ; d=1100}$, enquanto o pior resultado obtido por Bello (2011) foi de 0,225. Tal invariabilidade para a definição do parâmetro é verificada pela ausência de diferenças estatisticamente significa- 
tivas entre o melhor e grande parte dos demais resultados, quando os parâmetros externos são variados. Também foi obtido um excelente desempenho médio, de 0,926 sobre todos os valores de parâmetros.

\section{Comparação com Outras Medidas de Distância}

Na Seção A.2.1, foi demonstrado que a medida CK-1 é, de fato, bastante adequada para estimar a distância entre gráficos de recorrência. A comparação realizada entre a CK-1, a NCD e a distância euclidiana mostrou que os melhores resultados são comumente obtidos pela medida baseada em compressão de vídeo. Para verificar se o mesmo acontece nesta aplicação específica, foram analisados os resultados obtidos pelas duas outras medidas de distância, utilizando-se as melhores configurações de parâmetros obtidas anteriormente. Além disso, também foi verificado o resultado da aplicação da NCD e da distância euclidiana na configuração $C R P_{f=10 ; d=700}$, que obteve melhor resultado no trabalho de Bello (2011). Diferente do que foi feito em seu trabalho, neste experimento utilizamos a versão dos gráficos de recorrência sem a aplicação do limiar de proximidade. Os resultados são apresentados na Tabela A.12.

Tabela A.12: Resultados obtidos pela aplicação da NCD e da distância euclidiana sobre matrizes de auto-similaridade em algumas configurações de parâmetros da extração de atributos

\begin{tabular}{r|rr}
\hline Configuração & NCD & Euclidiana \\
\hline Croma $_{f=2.5 ; d=300}$ & 0.322 & 0.279 \\
$C E N S_{f=0.5 ; d=300}$ & 0.382 & 0.313 \\
$C R P_{f=1.25 ; d=500}$ & 0.276 & 0.257 \\
$C R P_{f=10 ; d=700}$ & 0.271 & 0.262 \\
\hline
\end{tabular}

Com esse simples experimento, é possível notar que a distância euclidiana e a NCD não são adequadas para comparar matrizes de auto-similaridade de música diretamente. No entanto, Grosche et al. (2012) mostraram que a distância euclidiana pode ser efetivamente utilizada na tarefa de recuperação de música por estrutura, desde que haja um préprocessamento adequado nas matrizes de auto-similaridade. Neste trabalho, também foi utilizada essa ideia, aplicando-se a medida CK-1 com técnicas semelhantes para a construção das matrizes.

Como o código utilizado por Grosche et al. (2012) não é público, foram simulados experimentos com técnicas semelhantes, aplicando-se os passos de binarização (aplicação do limiar) e desfoque. Em outras palavras, não foi aplicada nenhuma técnica de realce, como feito por Grosche et al. (2012), antes de aplicar o limiar de proximidade. O objetivo não foi comparar diretamente os resultados, mesmo porque o conjunto de dados utilizado 
no trabalho também não é acessível - é uma versão reduzida do conjunto Mazurkas. No entanto, pode-se comparar o uso das medidas CK-1 e euclidiana quando algumas operações de pré-processamento são aplicadas sobre as matrizes de auto-similaridade.

Na etapa de binarização, foi utilizada a estratégia de considerar que $k \%$ dos pontos do gráfico de recorrência correspondem a estados recorrentes. Assim, $k \%$ dos pontos, com os menores valores de distância, são transformados em pixels pretos (0) no RP resultante. Os demais pontos são transformados em pixels brancos (1). Para avaliar diferentes cenários, foram utilizados três diferentes valores para o limiar: $k \in\{10,25,50\}$. Além disso, foi utilizado um filtro de média bidimensional circular (Pillbox) para desfocar a imagem, utilizando cinco dimensões diferentes: $l \in\{1,5,10,20,30\}$. Na Figura A.17, são exibidas diferentes representações da mesma gravação do Prelúdio Op.28 No.4 de Chopin: o gráfico (a) representa a matriz de auto-similaridade; o gráfico (b) representa o gráfico de recorrência com $25 \%$ dos pontos mais próximos; nos gráficos (c) e (d) são apresentados o resultado da aplicação de um filtro de desfoque sobre o RP do gráfico (b), com diferentes dimensões.

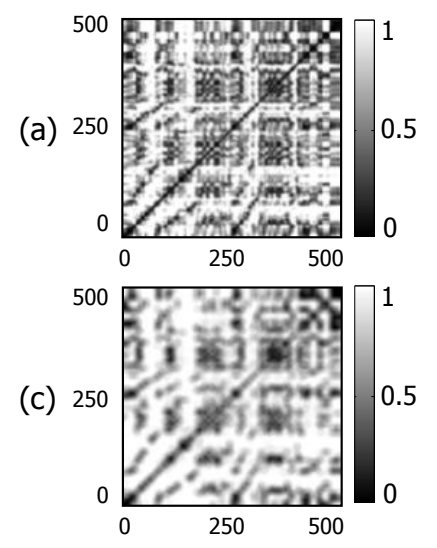

(b)

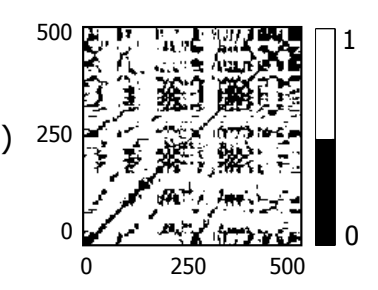

(d) 250

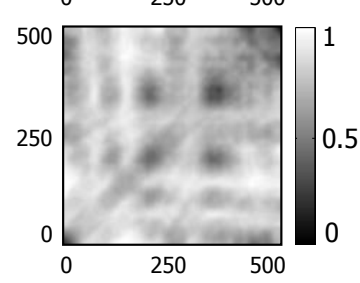

Figura A.17: Quatro diferentes representações da mesma gravação de uma peça de Chopin: (a) matriz de auto-similaridade; (b) gráfico de recorrência (com limiar de proximidade); (c) RP após aplicação de filtro de desfoque de dimensão $l=10$; (d) RP após aplicação de filtro de desfoque de dimensão $l=30$

Resumidamente, os resultados obtidos utilizando a distância euclidiana neste contexto foram melhores que a maioria dos alcançados por Bello (2011). Entretanto, a utilização da medida CK-1 superou os resultados obtidos pela distância euclidiana, ao se preprocessar os gráficos de recorrência, em todos os cenários. Os melhores resultados obtidos para cada distância e cada conjunto de atributos é apresentado na Tabela A.13. Tais resultados evidenciam, novamente a adequabilidade da medida CK-1 no contexto em que está sendo aplicada. 
Tabela A.13: Resultados obtidos após a aplicação da binarização e do filtro de desfoque nos gráficos de recorrência. O valor $k$ é a porcentagem de pontos pretos no gráfico e $l$ é a dimensão do filtro de desfoque. O símbolo * indica que a utilização da medida CK-1 supera, com diferença estatisticamente significativa, o resultado obtido pelo uso da distância euclidiana com a mesma configuração de parâmetros

\begin{tabular}{lccl|r}
\hline & $k(\%)$ & $l$ & Distância & MAP \\
\hline & \multirow{2}{*}{50} & 1 & CK-1 & $0.941 *$ \\
Croma $_{f=2.5 ; d=300}$ & & & Euclidiana & 0.816 \\
& \multirow{2}{*}{10} & 20 & CK-1 & 0.905 \\
& & & Euclidiana & 0.872 \\
\hline \multirow{2}{*}{25} & \multirow{2}{*}{5} & CK-1 & $0.924 *$ \\
& & & Euclidiana & 0.829 \\
& \multirow{2}{*}{25} & \multirow{2}{*}{1} & CK-1 & 0.919 \\
& & & Euclidiana & 0.910 \\
\hline & \multirow{2}{*}{25} & \multirow{2}{*}{30} & CK-1 & $0.958 *$ \\
& & & Euclidiana & 0.893 \\
& & & CK-1 & 0.953 \\
& \multirow{2}{*}{10} & \multirow{2}{*}{30} & Euclidiana & 0.941 \\
\hline
\end{tabular}

\section{Resultados no Conjunto de Dados Mazurkas}

Na última etapa deste trabalho, foram realizados experimentos sobre o conjunto de dados Mazurcas, a fim de validar os resultados obtidos nos experimentos anteriores. A princípio, foi optado utilizar a configuração $C E N S_{f=0,5 ; d=300}$, uma vez que ela obteve o melhor desempenho no conjunto de dados 123tracks. No entanto, o método proposto alcançou um valor de 0,611, o que pode ser considerado insatisfatório. Uma análise mais detalhada das matrizes de auto-similaridade mostrou que, em muitos casos, as matrizes não foram capazes de representar claramente a estrutura da gravação. Isso deveu-se ao fato da distância de cosseno, utilizada para extrair as matrizes, resultar em distâncias bastante pequenas em muitos casos. Assim, a figura gerada por tais distâncias contém cores muito escuras quando aplicada a uma escala de cores entre 0 e 1.

Depois de analisar as gravações, pode-se concluir que as distâncias com valores pequenos poderiam estar diretamente relacionadas com a frequência em que os atributos foram extraídos. Taxas de amostragem muito baixas correspondem a uma janela de análise muito grande, resultando na mistura de diversos segmentos estruturalmente distintos de música. Uma vez que muitas peças desse conjunto de dados possuem curta duração e inúmeras variações estruturais de curta duração, sua estrutura só pode ser analisada com precisão ao se utilizar uma frequência de extração de atributos maior do que a utilizada anteriormente. Para provar esse fato, foi realizado o mesmo experimento utilizando-se a configuração $C E N S_{f=1 ; d=300}$, alcançando 0,760 , similar ao melhor resultado alcançado 
por Bello (2011), 0,767. Na Figura A.18, é mostrado um exemplo da diferença entre as matrizes de auto-similaridade obtidas por diferentes taxas de extração de características.
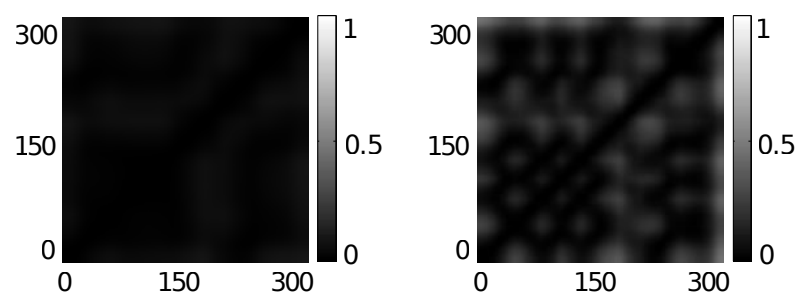

Figura A.18: Matrizes de auto-similaridade de uma mesma peça musical, extraídas com diferentes taxas amostragem: $0.5 \mathrm{f} / \mathrm{s}$ (esquerda) e $1 \mathrm{f} / \mathrm{s}$ (direita)

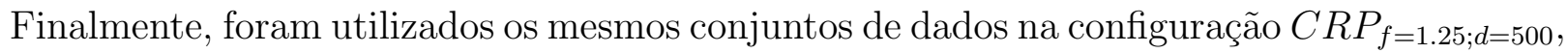
depois da aplicação de um limiar de proximidade (de modo que $k=25$ ) e um filtro de desfoque $(l=30)$. Essa configuração foi escolhida por ter obtido melhor desempenho no conjunto de dados 123tracks. Novamente, a utlização da medida CK-1 mostrou-se bastante eficaz para o cumprimento da tarefa. Ao aplicá-la no conjunto de dados $M a-$ zurkas, oteve-se um resultado de 0,795. Esse aumento no desempenho também pode ter relação com o fato de, nesse caso, a taxa de amostragem ser maior do que as utilizadas anteriormente. A aplicação da distância euclidiana nas mesmas condições resultou em $M A P=0,652$. Esses resultados foram submetidos ao teste de hipótese, que apontou diferença estatística entre eles.

\section{Perspectivas Futuras}

Como trabalho futuro, será avaliada a robustez da RPCD para diferentes características das séries temporais, como a não-estacionaridade, bem como sua invariância a rotação, complexidade, oclusão, fase, escala, entre outros. Também será avaliado o desempenho da RPCD em outras tarefas de análise de séries temporais, como agrupamento e descoberta de motifs. Por fim, serão estudadas maneiras para melhorar a eficiência dessas tarefas utilizando a medida proposta. 



\section{Referências Bibliográficas}

Abushariah, A., Gunawan, T., Khalifa, O., e Abushariah, M. (2010). English digits speech recognition system based on hidden markov models. Em International Conference on Computer and Communication Engineering, páginas 1-5. Citado na página 83.

Agostini, G., Longari, M., e Pollastri, E. (2003). Musical instrument timbres classification with spectral features. EURASIP Journal on Advances in Signal Processing, 2003(1):514. Citado na página 29.

Alotaibi, Y. (2003). High performance arabic digits recognizer using neural networks. Em International Joint Conference on Neural Networks, páginas 670 - 674. Citado na página 83.

Altaf, M. U. B. e Juang, B.-H. (2011). Audio signal classification with temporal envelopes. Em IEEE International Conference on Acoustics, Speech and Signal Processing, páginas 469-472. Citado na página 16.

Assmann, P. F., Nearey, T. M., e Bharadwaj, S. (2008). Analysis of a vowel database. Canadian Acoustics, 36(3):148-149. Citado na página 29.

Azam, S., Mansoor, Z., Mughal, M., e Mohsin, S. (2007). Urdu spoken digits recognition using classified MFCC and backpropgation neural network. Em Computer Graphics, Imaging and Visualisation, páginas 414-418. Citado na página 83.

Bartsch, M. e Wakefield, G. (2005). Audio thumbnailing of popular music using chromabased representations. IEEE Transactions on Multimedia, 7(1):96-104. Citado na página 115. 
Bastos, J. A. e Caiado, J. (2011). Recurrence quantification analysis of global stock markets. Physica A: Statistical Mechanics and its Applications, 390(7):1315-1325. Citado na página 101.

Batista, G. E. A. P. A., Campana, B. J. L., e Keogh, E. J. (2010). Classification of live moths combining texture, color and shape primitives. Em International Conference on Machine Learning and Applications, páginas 903-906. Citado nas páginas 102 e 109.

Batista, G. E. A. P. A., Keogh, E. J., Mafra-Neto, A., e Rowton, E. (2011a). SIGKDD demo: sensors and software to allow computational entomology, an emerging application of data mining. Em ACM International Conference on Knowledge Discovery and Data Mining, páginas 761-764. ACM. Citado na página 47.

Batista, G. E. A. P. A., Prati, R. C., e Monard, M. C. (2004). A study of the behavior of several methods for balancing machine learning training data. SIGKDD Exploration Newsletter, 6(1):20-29. Citado na página 69.

Batista, G. E. A. P. A. e Silva, D. F. (2009). How k-nearest neighbor parameters affect its performance. Em Argentine Symposium on Artificial Intelligence, páginas 95-106. Citado na página 44.

Batista, G. E. A. P. A., Silva, D. F., e Prati, R. C. (2012). An experimental design to evaluate class imbalance treatment methods. Em International Conference on Machine Learning and Applications, volume 2, páginas 95-101. IEEE. Citado na página 5.

Batista, G. E. A. P. A., Wang, X., e Keogh, E. J. (2011b). A complexity-invariant distance measure for time series. Em SIAM International Conference on Data Mining, páginas 699-710. Citado na página 109.

Bello, J. P. (2011). Measuring structural similarity in music. IEEE Transactions on Audio, Speech \& Language Processing, 19(7):2013-2025. Citado nas páginas 101, 115, $116,118,120,121,122,123$, e 125.

Benesty, J., Chen, J., e Huang, Y. (2008). Linear prediction. Em Benesty, J., Sondhi, M. M., e Huang, Y., editores, Springer Handbook of Speech Processing, páginas 121-134. Springer. Citado na página 27.

Beyer, K., Goldstein, J., Ramakrishnan, R., e Shaft, U. (1999). When is nearest neighbor meaningful? Em International Conference on Database Theory, páginas 217-235. Citado na página 19. 
Bogert, B., Healy, M., e Tukey, J. (1963). The quefrency alanysis of time series for echoes: Cepstrum, pseudo-autocovariance, cross-cepstrum and saphe cracking. Em Symposium on Time Series Analysis, páginas 209-243. Citado na página 18.

Boll, S. (1979). Suppression of acoustic noise in speech using spectral subtraction. IEEE Transactions on Acoustics, Speech and Signal Processing, 27(2):113-120. Citado nas páginas 39 e 90.

Borges, L. d. A. (2011). Extração de parâmetros característicos para detecção acústica de vazamento de água. Tese de Doutorado, Universidade de São Paulo. Citado na página 14.

Bratko, A., Cormack, G., Filipic, B., Lynam, T., e Zupan, B. (2006). Spam filtering using statistical data compression models. Journal of Machine Learning Research, 7:26732698. Citado na página 100.

Bresolin, A. A., Neto, A. D. D., e Alsina, P. J. (2008). Digit recognition using wavelet and SVM in brazilian portuguese. Em IEEE International Conference on Acoustics, Speech and Signal Processing, páginas 1545-1548. Citado nas páginas 83 e 84.

Bruderer, M. J., McKinney, M. F., e Kohlrausch, A. (2009). The perception of structural boundaries in melody lines of western popular music. Musicae Scientiae, 13(2):273-313. Citado na página 116.

Byrne, D. N., Buchmann, S. L., e Spangler, H. G. (1988). Relationship between wing loading, wingbeat frequency and body mass in homopterous insects. Journal of Experimental Biology, 135(1):9-23. Citado na página 46.

Caetano, M. e Rodet, X. (2011). Improved estimation of the amplitude envelope of time-domain signals using true envelope cepstral smoothing. Em IEEE International Conference on Acoustics, Speech and Signal Processing, páginas 4244 -4247. Citado na página 16.

Callou, D. M. I. e Leite, Y. (2003). Iniciação à Fonética e à Fonologia. Jorge Zahar Editores, 10 edição. Citado na página 29.

Campana, B. J. L. e Keogh, E. J. (2010). A compression based distance measure for texture. Em SIAM International Conference on Data Mining, páginas 850-861. Citado nas páginas 97 e 99. 
Carrubba, S., Minagar, A., Chesson Jr, A., Frilot, C., e Marino, A. (2012). Increased determinism in brain electrical activity occurs in association with multiple sclerosis. Neurological Research, 34(3):286-290. Citado na página 101.

Cha, S.-H. (2007). Comprehensive survey on distance/similarity measures between probability density functions. International Journal of Mathematical Models and Methods in Applied Sciences, 1(4):300-307. Citado na página 9.

Chadwick, L. E. e Williams, C. M. (1949). The effects of atmospheric pressure and composition on the flight of drosophila. The Biological Bulletin, 97(2):115-137. Citado na página 71.

Chaves, V., Travieso, C., Camacho, A., e Alonso, J. (2012). Katydids acoustic classification on verification approach based on mfcc and hmm. Em IEEE International Conference on Intelligent Engineering Systems, páginas 561-566. Citado na página 36.

Chesmore, D. (2004). Automated bioacoustic identification of species. Anais Da Academia Brasileira De Ciencias, 76(2):436-440. Citado na página 30.

Clemins, P. J., Johnson, M. T., Leong, K. M., e Savage, A. (2005). Automatic classification and speaker identification of african elephant (loxodonta africana) vocalizations. Journal of the Acoustical Society of America, 117(2):956-63. Citado na página 31.

Cooley, J. W. e Tukey, J. W. (1965). An algorithm for the machine calculation of complex Fourier series. Mathematics of Computation, 19(90):297-301. Citado na página 18.

Cooper, M. e Foote, J. (2002). Automatic music summarization via similarity analysis. Em International Society for Music Information Retrieval Conference, páginas 81-85. Citado na página 115.

Corcoran, A. J. (2007). Automated acoustic identification of nine bat species of the Eastern United States. Dissertação de Mestrado, Humboldt State University. Citado na página 31.

Costa, Y. M., Oliveira, L., Koerich, A. L., Gouyon, F., e Martins, J. (2012). Music genre classification using LBP textural features. Signal Processing, 92(11):2723-2737. Citado na página 14.

de Souza, V. M. A. (2011). Classificação de fluxo de dados não estacionários com aplicação em sensores identificadores de insetos. Projeto Fapesp - Processo 2011/17698-5. Citado na página 71 . 
de Souza, V. M. A., Silva, D. F., e Batista, G. E. A. P. A. (2013a). Classification of data streams applied to insect recognition: Initial results. Em Brazilian Conference on Intelligent Systems, páginas 76-81. Citado na página 71.

de Souza, V. M. A., Silva, D. F., Garcia, P. R., e Batista, G. E. A. P. A. (2013b). Avaliação de classificadores para o reconhecimento automático de insetos. Em Encontro Nacional de Inteligência Artificial e Computacional, páginas 1-12. Citado nas páginas 4 e 57.

Delaherche, E., Chetouani, M., Mahdhaoui, A., Saint-Georges, C., Viaux, S., e Cohen, D. (2012). Interpersonal synchrony: A survey of evaluation methods across disciplines. IEEE Transactions on Affective Computing, 3(3):349-365. C Citado na página 101.

Demšar, J. (2006). Statistical comparisons of classifiers over multiple data sets. Journal of Machine Learning Research, 7:1-30. Citado nas páginas 88 e 106.

Deng, J., Simmermacher, C., e Cranefield, S. (2008). A study on feature analysis for musical instrument classification. IEEE Transactions on Systems, Man, and Cybernetics, Part B: Cybernetics, 38(2):429-438. Citado na página 28.

Ding, H., Trajcevski, G., Scheuermann, P., Wang, X., e Keogh, E. J. (2008). Querying and mining of time series data: experimental comparison of representations and distance measures. Very Large Databases Endowment, 1(2):1542-1552. Citado nas páginas 8, 11 , e 108.

Dixon, K. W. (2009). Pollination and Restoration. Science, 325(5940):571-573. Citado na página 34 .

dos Santos, J. (2006). Percepção de fala: análise das vogais do português brasileiro em tempo comprimido. Dissertação de Mestrado, Universidade de São Paulo. Citado na página 2.

Dua, S., Du, X., Sree, S. V., e V. I., T. A. (2012). Novel classification of coronary artery disease using heart rate variability analysis. Journal of Mechanics in Medicine and Biology, 12(4):1-19. Citado na página 101.

Eckmann, J. P., Kamphorst, O. S., e Ruelle, D. (1987). Recurrence plots of dynamical systems. Europhysics Letters, 4(9):973-977. Citado nas páginas 96, 97, e 101.

Ellis, D. e Poliner, G. (2004). Identifying cover songs with chroma features and dynamic programming beat tracking. Em IEEE International Conference on Acoustics, Speech and Signal Processing, páginas IV-1429-IV-1432. Citado na página 115. 
Eronen, A. e Klapuri, A. (2000). Musical instrument recognition using cepstral coefficients and temporal features. Em IEEE International Conference on Acoustics, Speech, and Signal Processing, páginas II753-II756 vol.2. Citado na página 29.

Foote, J. (1999). Visualizing music and audio using self-similarity. Em ACM Multimedia, páginas 77-80. Citado na página 115.

Fujishima, T. (1999). Real-time chord recognition of musical sound: a system using common lisp music. Em International Computer Music Association Conference, páginas 464-467. Citado na página 116.

Gama, J., Sebastião, R., e Rodrigues, P. (2013). On evaluating stream learning algorithms. Machine Learning, 90:317-346. Citado na página 73.

Ganchev, T., Potamitis, I., e Fakotakis, N. (2007). Acoustic monitoring of singing insects. Em IEEE International Conference on Acoustics, Speech and Signal Processing, volume 4, páginas 721-724. Citado na página 36.

Geurts, P. (2001). Pattern extraction for time series classification. Em Raedt, L. D. e Siebes, A., editores, European Conference on Principles of Data Mining and Knowledge Discovery, volume 2168 of Lecture Notes in Computer Science, páginas 115-127. Springer. Citado na página 19.

Ghanty, S., Shaikh, S., e Chaki, N. (2010). On recognition of spoken Bengali numerals. Em International Conference on Computer Information Systems and Industrial Management Applications, páginas 54-59. Citado na página 83.

Ghoraani, B. e Krishnan, S. (2011). Time-frequency matrix feature extraction and classification of environmental audio signals. IEEE Transactions on Audio, Speech, and Language Processing, 19(7):2197-2209. Citado na página 14.

Giusti, R. e Batista, G. E. A. P. A. (2013). An empirical comparison of dissimilarity measures for time series classification. Em Brazilian Conference on Intelligent Systems, páginas 82-88. Citado nas páginas 9 e 11.

González-Izal, M., Malanda, A., Gorostiaga, E., e Izquierdo, M. (2012). Electromyographic models to assess muscle fatigue. Journal of Electromyography and Kinesiology, 22(4):501-512. Citado na página 101.

Grey, J. M. (1975). An exploration of musical timbre. Center for Computer Research in Music and Acoustics Report, 64:467-472. Citado na página 29. 
Grey, J. M. (1977). Multidimensional perceptual scaling of musical timbres. The Journal of the Acoustical Society of America, 61(5):1270-1277. Citado na página 29.

Grosche, P., Serrà, J., Muller, M., e Arcos, J. (2012). Structure-based audio fingerprinting for music retrieval. Em International Society for Music Information Retrieval Conference, páginas 55-60. Citado nas páginas 115, 116, 118, e 122.

Hall, M. A. (1999). Correlation-based feature selection for machine learning. Tese de Doutorado, The University of Waikato. Citado na página 67.

Hao, Y., Campana, B. J. L., e Keogh, E. J. (2012). Monitoring and mining insect sounds in visual space. Em SIAM Conference on Data Mining, páginas 792-803. Citado na página 102.

Hillenbrand, J., Getty, L. A., Clark, M. J., e Wheeler, K. (1995). Acoustic characteristics of american english vowels. The Journal of the Acoustical Society of America, 97:30993111. Citado na página 30.

Hsu, C. W., Chang, C. C., e Lin, C. J. (2003). A practical guide to support vector classification. Relatório técnico, Department of Computer Science, National Taiwan University. Citado na página 60.

Hu, B., Rakthanmanon, T., Campana, B. J. L., Mueen, A., e Keogh, E. J. (2012). Image mining of historical manuscripts to establish provenance. Em SIAM Conference on Data Mining, páginas 804-815. Citado na página 102.

Hu, X., Zhan, L., Xue, Y., Zhou, W., e Zhang, L. (2011). Spoken arabic digits recognition based on wavelet neural networks. Em IEEE International Conference on Systems, Man, and Cybernetics, páginas 1481-1485. Citado na página 83.

Ishaaya, I., Palli, S. R., e Horowitz, A. R. (2012). Advanced technologies for managing insect pests. Springer. Citado na página 34.

Itakura, F. (1975a). Line spectrum representation of linear predictor coefficients of speech signals. The Journal of the Acoustical Society of America, 57:S35. Citado na página 27.

Itakura, F. (1975b). Minimum prediction residual principle applied to speech recognition. IEEE Transactions on Acoustics, Speech and Signal Processing, 23(1):67-72. Citado na página 12. 
Iwanski, J. S. e Bradley, E. (1998). Recurrence plots of experimental data: To embed or not to embed? Chaos: An Interdisciplinary Journal of Nonlinear Science, 8(4):861-871. Citado nas páginas 98 e 99.

Izumitani, T. e Kashino, K. (2008). A robust musical audio search method based on diagonal dynamic programming matching of self-similarity matrices. Em International Society for Music Information Retrieval Conference, páginas 609-613. Citado na página 115 .

Kahn, M. C., Celestin, W., e Jr, W. O. (1945). Recording of sounds produced by certain disease-carrying mosquitoes. Science, 101(2622):335-336. Citado na página 35.

Kahn, M. C. e Jr, W. O. (1949). The identification of certain west african mosquitoes by sound. The American Journal of Tropical Medicine and Hygiene, 29(5):827-836. Citado na página 35.

Keogh, E. J. e Kasetty, S. (2003). On the need for time series data mining benchmarks: a survey and empirical demonstration. Data Mining and Knowledge Discovery, 7(4):349371. Citado na página 83.

Keogh, E. J., Lin, J., Lee, S.-H., e Van Herle, H. (2007a). Finding the most unusual time series subsequence: algorithms and applications. Knowledge and Information Systems, 11(1):1-27. Citado na página 8.

Keogh, E. J., Lonardi, S., Ratanamahatana, C. A., Wei, L., Lee, S., e Handley, J. (2007b). Compression-based data mining of sequential data. Data Minining and Knowledge Discovery, 14(1):99-129. Citado na página 100.

Keogh, E. J. e Ratanamahatana, C. A. (2005). Exact indexing of dynamic time warping. Knowledge and Information Systems, 7(3):358-386. Citado na página 9.

Keogh, E. J., Wei, L., Xi, X., Vlachos, M., Lee, S.-H., e Protopapas, P. (2009). Supporting exact indexing of arbitrarily rotated shapes and periodic time series under euclidean and warping distance measures. Very Large Databases Journal, 18(3):611-630. Citado na página 105.

Kevan, P. (1999). Pollinators as bioindicators of the state of the environment: species, activity and diversity. Agriculture, Ecosystems \& Environment, 74(1-3):373-393. Citado na página 34.

Kirchgässner, G. e Wolters, J. (2007). Introduction to Modern Time Series Analysis. Springer-Verlag Berlin Heidelberg. Citado na página 8. 
Kline, D., Takken, W., Wood, J., e Carlson, D. (1990). Field studies on the potential of butanone, carbon dioxide, honey extract, l-octen-3-ol, l-lactic acid and phenols as attractants for mosquitoes. Medical and veterinary entomology, 4(4):383-391. Citado na página 42 .

Kondo, K., Kamata, H., e Ishida, Y. (1994). Speaker-independent spoken digits recognition using lvq. Em IEEE World Congress on Computational Intelligence, volume 7, páginas 4448-4451. Citado na página 83.

Kononenko, I. (1994). Estimating attributes: analysis and extensions of relief. Em European Conference on Machine Learning, páginas 171-182. Citado na página 67.

Kopparapu, S. e Rao, P. (2004). Enhancing spoken connected-digit recognition accuracy by error correction codes: A novel scheme. Sadhana, 29(5):559-571. Citado na página 82.

Krasnogor, N. e Pelta, D. A. (2004). Measuring the similarity of protein structures by means of the universal similarity metric. Bioinformatics, 20:1015-1021. Citado na página 100.

Krimphoff, J., McAdams, S., e Winsberg, S. (1994). Caractérisation du timbre des sons complexes. ii. analyses acoustiques et quantification psychophysique. Le Journal de Physique IV, 4(C5):C5-625. Citado na página 24.

Last, M., Klein, Y., e Kandel, A. (2001). Knowledge discovery in time series databases. IEEE Transactions on Systems, Man, and Cybernetics, 31(1):160-169. Citado nas páginas 1 e 8.

Le-Qing, Z. (2011). Insect Sound Recognition Based on MFCC and PNN. International Conference on Multimedia and Signal Processing, 2:42-46. Citado na página 35.

Lemes, C. I. (2013). Algoritmos anytime para classificação de fluxos de dados com aplicação em classificação de insetos. Projeto Fapesp - Processo 2013/16081-0. Citado na página 70.

Li, M., Badger, J. H., Chen, X., Kwong, S., Kearney, P., e Zhang, H. (2001). An information-based sequence distance and its application to whole mitochondrial genome phylogeny. Bioinformatics, 17(2):149-154. Citado na página 99.

Li, M., Chen, X., Li, X., Ma, B., e Vitanyi, P. (2004). The similarity metric. IEEE Transactions on Information Theory, 50(12):3250-3264. Citado na página 100. 
Li, M. e Vitanyi, P. (1997). An introduction to Kolmogorov complexity and its applications. Springer Verlag, segunda edição. Citado na página 99.

Lindblom, B. E. e Studdert-Kennedy, M. (1967). On the role of formant transitions in vowel recognition. The Journal of the Acoustical Society of America, 42:830-843. Citado na página 30.

Liu, C. e Fu, Q.-J. (2007). Estimation of vowel recognition with cochlear implant simulations. IEEE Transactions on Biomedical Engineering, 54(1):74-81. Citado na página 30 .

Logan, B. e Salomon, A. (2001). A music similarity function based on signal analysis. Em IEEE International Conference on Multimedia and Expo. Citado na página 115.

Lopes, M., Gioppo, L., Higushi, T., Kaestner, C., Silla, C., e Koerich, A. (2011). Automatic bird species identification for large number of species. Em IEEE International Symposium on Multimedia, páginas 117-122. Citado na página 30.

Mankin, R. W., Shuman, D., e Coffelt, J. A. (1996). Noise shielding of acoustic devices for insect detection. Journal of Economic Entomology, 89(5):1301-1308. Citado na página 36.

Martin, B., Robine, M., e Hanna, P. (2009). Musical structure retrieval by aligning selfsimilarity matrices. Em International Society for Music Information Retrieval Conference. Citado na página 115.

Marwan, N., Romano, M. C., Thiel, M., e Kurths, J. (2007). Recurrence plots for the analysis of complex systems. Physics Reports, 438(5-6):237 - 329. Citado na página 101.

McAdams, S., Beauchamp, J. W., e Meneguzzi, S. (1999). Discrimination of musical instrument sounds resynthesized with simplified spectrotemporal parameters. The Journal of the Acoustical Society of America, 105:882-897. Citado na página 24.

Mellanby, K. (1936). Humidity and insect metabolism. Nature, 138:124-125. Citado na página 71.

Miller, G. T. e Spoolman, S. E. (2011). Food, soil, and pest management. Em Sustaining the Earth, capítulo 8, páginas 131-154. Cengage Learning. Citado nas páginas 34 e 41.

Monk, A. T. e Compton, A. H. (1939). Recurrence phenomena in cosmic ray intensity. Reviews of Modern Physics, 11(3-4):173-179. Citado na página 97. 
Moore, A. (1991). Artificial neural network trained to identify mosquitoes in flight. Journal of Insect Behavior, 4:391-396. Citado na página 36.

Moore, A. (1998). Development of a data acquisition system for long-term outdoor recording of insect flight activity using a photosensor. Em Conference on Aerobiology and Biometeorology. American Meteorological Society. Citado nas páginas 36 e 37.

Moore, A., Miller, J. R., Tabashnik, B. E., e Gage, S. H. (1986). Automated identification of flying insects by analysis of wingbeat frequencies. Journal of Economic Entomology, 79(6):1703-1706. Citado na página 36.

Moore, A. e Miller, R. H. (2002). Automated identification of optically-sensed aphid (homoptera: Aphidae) wingbeat waveforms. Annals of the Entomological Society, 95(1):18. Citado na página 36.

Mueen, A. (2013). Enumeration of time series motifs of all lengths. Em IEEE International Conference on Data Mining, páginas 547-556. Citado na página 8.

Müller, M. e Ewert, S. (2011). Chroma Toolbox: MATLAB implementations for extracting variants of chroma-based audio features. Em International Society for Music Information Retrieval Conference. Citado na página 116.

Neves, F. M., Pie, M. R., e Viana, R. L. (2012). Self-organization in the movement activity of social insects (hymenoptera: Formicidae). Em AIP Conference Proceedings, páginas 658-661. Citado na página 101.

Nielsen, A., Sigurdsson, S., Hansen, L., e Arenas-Garcia, J. (2007). On the relevance of spectral features for instrument classification. Em IEEE International Conference on Acoustics, Speech and Signal Processing, páginas II-485-II-488. Citado na página 29.

Noll, A. M. (1967). Cepstrum pitch determination. Journal of the Acoustical Society of America, 41(2):293-309. Citado na página 26.

Oliveira, C., Auad, A., Mendes, S., e Frizzas, M. (2014). Crop losses and the economic impact of insect pests on brazilian agriculture. Crop Protection, 56:50-54. Citado na página 34 .

Oppenheim, A., Schafer, R., Buck, J., et al. (1989). Discrete-time signal processing, volume 2. Prentice Hall. Citado na página 27.

Orság, F. (2010). Speaker dependent coefficients for speaker recognition. International Journal of Security and Its Applications, 4(1):31-48. Citado na página 86. 
Ouyang, G., Ju, Z., e Liu, H. (2012). Surface EMG signals determinism analysis based on recurrence plot for hand grasps. Em International Joint Conference on Neural Networks, páginas 1-6. Citado na página 101.

Paliwal, K. (1989). A study of line spectrum pair frequencies for vowel recognition. Speech Communication, 8(1):27 - 33. Citado na página 30.

Paliwal, K. e Kleijn, W. (1995). Quantization of LPC parameters. Speech Coding and Synthesis, páginas 433-466. Citado na página 28.

Panwar, M., Sharma, R., Khan, I., e Farooq, O. (2011). Design of wavelet based features for recognition of hindi digits. Em International Conference on Multimedia, Signal Processing and Communication Technologies, páginas 232-235. Citado na página 83.

Papa, J., Marana, A., Spadotto, A., Guido, R., e Falcão, A. (2010). Robust and fast vowel recognition using optimum-path forest. Em IEEE International Conference on Acoustics Speech and Signal Processing, páginas 2190-2193. Citado na página 30.

Park, T. H. (2004). Towards Automatic Musical Instrument Timbre Recognition. Tese de Doutorado, Princeton University. Citado nas páginas 14, 15, 23, 24, e 29.

Parsons, S. e Jones, G. (2000). Acoustic identification of twelve species of echolocating bat by discriminant function analysis and artificial neural networks. Journal of Experimental Biology, 203(17):2641-2656. Citado na página 31.

Patnaik, J. L., Juliusson, L., e Vogt, R. L. (2007). Environmental predictors of human west nile virus infections, colorado. Emerging Infectious Diseases, 13(11):1788-1790. Citado na página 35.

Plomp, R. (1970). Timbre as a multidimensional attribute of complex tones. Em International Symposium on Frequency Analysis and Periodicity Detection in Hearing. Citado na página 29.

Poli, G. D. e Prandoni, P. (1997). Sonological models for timbre characterization. Journal of New Music Research, 26(2):170-197. Citado na página 29.

Pollard, H. e Jansson, E. (1982). A tristimulus method for the specification of musical timbre. Acta Acustica united with Acustica, 51(3):162-171. Citado na página 23.

Potamitis, I., Ganchev, T., e Fakotakis, N. (2007). Automatic acoustic identification of crickets and cicadas. Em International Symposium on Signal Processing and Its Applications, páginas 1-4. Citado na página 35 . 
Prati, R. C., Silva, D. F., e Batista, G. E. A. P. A. (2014). Class imbalance revisited: a new experimental setup to assess the performance of treatment methods. Submetido ao Journal of Knowledge and Information Systems, páginas 1-20. Citado na página 5.

Ratanamahatana, C. A. e Keogh, E. J. (2004). Making time-series classification more accurate using learned constraints. Em SIAM International Conference on Data Mining, páginas 11-22. Citado na página 9.

Ratanamahatana, C. A., Lin, J., Gunopulos, D., Keogh, E., Vlachos, M., e Das, G. (2010). Mining time series data. Em Data Mining and Knowledge Discovery Handbook, páginas 1049-1077. Springer. Citado na página 1.

Riede, K. (1998). Acoustic monitoring of orthoptera and its potential for conservation. Journal of Insect Conservation, 2(3-4):217-223. Citado na página 14.

Rodrigues, F. e Trancoso, I. (1999). Digit recognition using the SPEECHDAT corpus. Em Conference on Telecommunications, páginas 1-4. Citado na página 83.

Sakoe, H. e Chiba, S. (1978). Dynamic programming algorithm optimization for spoken word recognition. IEEE Transactions on Acoustics, Speech and Signal Processing, 26(1):43-49. Citado na página 12.

Salzberg, S. L. (1997). On comparing classifiers: Pitfalls to avoid and a recommended approach. Data Mining and Knowledge Discovery, 1(3):317-328. Citado na página 91.

Sebastião, R. e Gama, J. (2009). A study on change detection methods. Em Portuguese Conference on Artificial Intelligence, páginas 353-364. Citado na página 71.

Shao, G. e Chen, Y. (2012). Prediction protein structural classes with a hybrid feature. Em IEEE Symposium on Electrical Electronics Engineering, páginas 202-205. Citado na página 101.

Shirazi, J. e Ghaemmaghami, S. (2008). Audio classification based on sinusoidal model: A new feature. Em IEEE Region 10 Conference, páginas 1-5. Citado na página 14.

Silva, D. F., Batista, G. E. A. P. A., Keogh, E. J., e Mafra-Neto, A. (2011). Resultados preliminares na classificação de insetos utilizando sensores ópticos. Em Encontro Nacional de Inteligência Artificial, páginas 1-12. Citado nas páginas 4 e 44.

Silva, D. F., de Souza, V. M. A., e Batista, G. E. A. P. A. (2013a). Time series classification using compression distance of recurrence plots. Em IEEE International Conference on Data Mining, páginas 687-696. Citado nas páginas 5, 95, e 96. 
Silva, D. F., de Souza, V. M. A., e Batista, G. E. A. P. A. (2014). Exploring low cost laser sensors to identify flying insect species. Submetido ao Journal of Intelligent and Robotic Systems, páginas 1-20. Citado na página 4.

Silva, D. F., de Souza, V. M. A., Batista, G. E. A. P. A., e Giusti, R. (2012). Spoken digit recognition in portuguese using line spectral frequencies. Em Pavon, J., Duque-Mendez, N., e Fuentes-Fernandez, R., editores, Advances in Artificial Intelligence - IBERAMIA 2012, volume 7637 of Lecture Notes in Computer Science, páginas 241-250. Springer Berlin Heidelberg. Citado nas páginas 4 e 83.

Silva, D. F., de Souza, V. M. A., Batista, G. E. A. P. A., Keogh, E. J., e Ellis, D. P. W. (2013b). Applying machine learning and audio analysis techniques to insect recognition in intelligent traps. Em International Conference on Machine Learning and Applications, páginas 99-104. Citado nas páginas 4, 57, e 62.

Silva, D. F., Papadopoulos, H., Batista, G. E. A. P. A., e Ellis, D. P. W. (2013c). A video compression-based approach to measure music structural similarity. Em International Society for Music Information Retrieval Conference, páginas 95-100. Citado nas páginas 5 e 95 .

Silva, D. F., Souza, V. M. A. d., e Batista, G. E. A. P. A. (2013d). A comparative study between MFCC and LSF coefficients in automatic recognition of isolated digits pronounced in Portuguese and English. Acta Scientiarum. Technology, 35(4):621-628. Citado nas páginas 5, 59, 83, e 89 .

Singer, A. C., Nelson, J. K., e Kozat, S. S. (2009). Signal processing for underwater acoustic communications. IEEE Communications Magazine, 47(1):90-96. Citado na página 14 .

Soltis, J., Leighty, K. A., Wesolek, C. M., e Savage, A. (2009). The expression of affect in african elephant (loxodonta africana) rumble vocalizations. Journal of Comparative Psychology, 123(2):222-225. Citado na página 31.

Song, Y., Wang, W.-H., e Guo, F.-J. (2009). Feature extraction and classification for audio information in news video. Em International Conference on Wavelet Analysis and Pattern Recognition, páginas 43 -46. Citado na página 14.

Stevens, S. S., Volkmann, J., e Newman, E. B. (1937). A scale for the measurement of the psychological magnitude pitch. Journal of the Acoustical Society of America, 8(3):185-190. Citado na página 26. 
Subha, D. P., Joseph, P. K., Acharya U, R., e Lim, C. M. M. (2010). EEG signal analysis: a survey. Journal of Medical Systems, 34(2):195-212. Citado na página 101.

Swanepoel, R., Oosthuizen, D. J., e Hanekom, J. J. (2012). The relative importance of spectral cues for vowel recognition in severe noise. The Journal of the Acoustical Society of America, 132:2652-2662. Citado na página 30.

Taylor, B. e Jones, M. D. R. (1969). The circadian rhythm of flight activity in the mosquito Aedes aegypti (L.): the phase-setting effects of light-on and light-off. Journal of Experimental Biology, 51(1):59-70. Citado na página 73.

Taylor, L. R. (1963). Analysis of the effect of temperature on insects in flight. Journal of Animal Ecology, 32(1):99-117. Citado na página 71.

Terasawa, H., Slaney, M., e Berger, J. (2005). The thirteen colors of timbre. Em IEEE Workshop on Applications of Signal Processing to Audio and Acoustics, páginas 323326. Citado nas páginas 26, 29, 59, e 86.

Thasleema, T. M., Kabeer, V., e Narayanan, N. K. (2007). Malayalam vowel recognition based on linear predictive coding parameters and k-nn algorithm. Em International Conference on Conference on Computational Intelligence and Multimedia Applications, páginas 361-365. Citado na página 30.

Thompson, W. C. (2009). Painting the target around the matching profile: the Texas sharpshooter fallacy in forensic DNA interpretation. Law, Probability and Risk, 8(3):257-276. Citado na página 109.

Unwin, D. M. e Ellington, C. P. (1979). An optical tachometer for measurement of the wing-beat frequency of free-flying insects. Journal of Experimental Biology, 82(1):377378. Citado na página 36.

Vreysen, M. e Robinson, A. (2011). Ionising radiation and area-wide management of insect pests to promote sustainable agriculture. a review. Agronomy for Sustainable Development, 31:233-250. Citado na página 34.

Wakefield, G. H. (1999). Mathematical representation of joint time-chroma distribution. Em International Symposium on Optical Science, Engineering, and Instrumentation, páginas 637-645. Citado na página 116.

Wang, W., Yu, X., Wang, Y. H., e Swaminathan, R. (2012). Audio fingerprint based on spectral flux for audio retrieval. Em International Conference on Audio, Language and Image Processing, páginas 1104-1107. IEEE. Citado na página 24. 
Wang, X., Mueen, A., Ding, H., Trajcevski, G., Scheuermann, P., e Keogh, E. J. (2013). Experimental comparison of representation methods and distance measures for time series data. Data Mining and Knowledge Discovery, 26(2):275-309. Citado nas páginas 8 e 11 .

W.H.O. (2009). Dengue: guidelines for diagnosis, treatment, prevention and control. Relatório técnico, World Health Organization. Citado na página 34.

W.H.O. (2012). The world malaria report. Relatório técnico, World Health Organization. Citado na página 34.

Wicaksana, H., Hartono, S., e Wei, F. S. (2006). Recognition of musical instruments. Em IEEE Asia Pacific Conference on Circuits and Systems, páginas 327-330. Citado na página 29.

Widmer, G. e Kubat, M. (1996). Learning in the presence of concept drift and hidden contexts. Machine learning, 23(1):69-101. Citado na página 71.

Yang, Q. e Wu, X. (2006). 10 challenging problems in data mining research. International Journal of Information Technology and Decision Making, 5(4):597-604. Citado na página 1.

Yazama, Y., Mitsukura, Y., Fukumi, M., e Akamatsu, N. (2004). Vowel recognition method by using features included in amplitude for mobile device. Em IEEE International Workshop on Robot and Human Interactive Communication, páginas 613-618. Citado na página 30.

Zhen, B., Wu, X., Liu, Z., e Chi, H. (2000). On the importance of components of the MFCC in speech and speaker recognition. Em Annual Conference of the International Speech Communication Association, páginas 487-490. ISCA. Citado nas páginas 14, 26 , e 59 . 